\title{
TITLE: FINAL REPORT OF THE MEXICO CITY 1991 LIDAR MEASUREMENTS CAMPAIGN
}

AUTHOR(S): C. R.,Quick, Jr., CLS-4

F. L. ARchuleta, CLS-4

D. E. Hof, CLS-4

W. E. Eichinger, $P-3$

D. B. Holtkamp, P-3

L. L. Tellier, $\mathrm{P}-3$

J. J. Tiee, CLS-4

R. R. Karl, CLS -4

submitteo to: To interested Parties

\section{DISCLAIMER}

This report was prepared as an account of work sponsored by an agency of the United States Government. Neither the United States Government nor any agency thereof, nor any of their employees, makes any warranty, express or implied, or assumes any legal liability or responsibility for the accuracy, completeness, or usefulness of any information, apparatus, product, or process disclosed, or represents that its use would not infringe privately owned rights. Reference herein to any specific commercial product, process, or service by trade name, trademark, manufacturer, or otherwise does not necessarily constitute or imply its endorsement, recommanufacturer, or otherwise does not necessarily constitute or imply its endorsement, recomand opinions of authors expressed herein do not necessarily state or reflect those of the United States Government or any agency thereof.

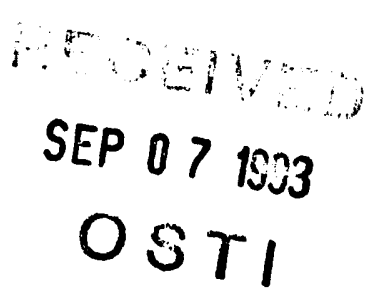

By acceptance of this arficle. the publisher recognizes that the US Government retains a nonexclusive. royalty-free license to publish or reproduce the published torm of inis contribution or to allow others to do so. for US Government purposes.

The Los Alamos National Laboratory requests that the publisher identily inis article as work performed under the auspices of the U S Departmeni of Energy
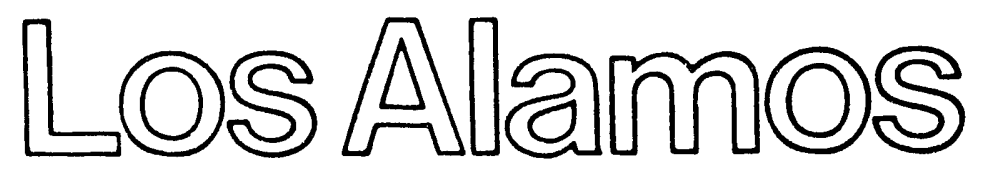

Los Alamos National Laboratory
Los Alamos,New Mexico 87545

$d^{2}$ 


\section{Final Report of the Mexico City 1991 Lidar Measurements Campaign**}

C. R. Quick, Jr., F. L. Archuleta, D. E. Hof R. R. Karl, Jr., J. J. Tiee Los Alamos National Laboratory Chemistry and Laser Sciences Division Los Alamos, New Mexico 87545

W. E. Eichinger, D. B. Holtkamp, L. L. Tellier Los Alamos National Laboratory Physics Division Los Alamos, Nev' Mexico 87545

** Work carried out under the auspices of the US Department of Energy in support of the Mexico City Air Quality Research Initiative, which is a joint project between the Los Alamos National Laboratory and the Mexican Petroleum Institute (IMP). 


\section{Foreword}

The authorship shown in this project report reflects the Los Alamos National Laboratory lidar personnel that contributed significantly to the development, preparation, and execution of the 1991 Mexico City lidar measurements campaign. The data presented here was processed, analyzed and interpreted by the principal author (C. R. Quick, Jr.). The views and opinions expressed here, are not necessarily those of other Los Alamos lidar personnel. Any errors or omissions are the responsibility of the primary author. Any questions regarding the data and its interpretation should be addressed to the primary author. 


\section{Index}

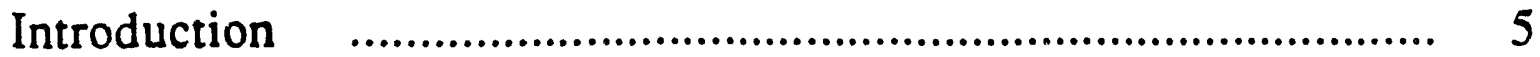

Lidar Technique $\quad$...................................................................... 7

Lidar System Description ...................................................... 7

Measurement Locations $\quad$.......................................................... 8

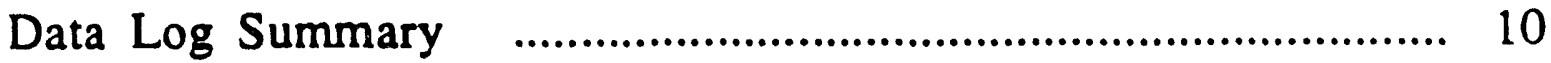

Data Analysis Strategy

Lidar Data Plot Generation Procedures ........................................ 11

Lidar Data Examples ............................................................. 13

Data Compilations …............................................................... 15

Interpretation of Lidar Data f............................................... 15

Height of the Mixing-Layer as Derived From Lidar Data

Time Sequences of Lidar Return Signals ........................................ 26

Atmospheric Extinction Derived From Lidar Data ......................... 27

Comparison of Lidar Data to NCAR Measurements ........................ 29

Comparison of Lidar Data to Rawinsonde Results ........................... 33

References $\quad$............................................................................ 36

Acknowledgements $\quad$............................................................... 37

Appendix A : Data Logs

Appendix B : APD Sensitivity vs Bias Voltage

Appendix C : Atmospheric Extinction Effects, Systematic and Random Noise in the Data

Appendix D : NCAR ASAS Aerosol Probe Data

Appendix E : NCAR Meteorological and Air Pollutant Ascent Data

Appendix F : Mexico City Airport Rawinsonde Data 


\section{List of Figures}

1. Lidar technique schematic

2. Photograph of elastic lidar truck (courtesy of J. Tejeda)

3. Photograph of vel tical scan over Mexico City (courtesy of J. Tejeda)

4. Mexico City map showing all lidar sites

5. City map of thermo-electric site location

6. City map of CINVESTAV site, looking south

7. City map of CINVESTAV site, looking north

8. City map of the UNAM botanical gardens site, looking north

9. Example of raw lidar data at one angle

10. Example of vertical scan at thermo-electric site

11. Example of vertical scan at CINVESTAV site showing mixing layer height

12. Example of vertical scan at CINVESTAV site showing entrainment

13. Example of horizontal scan over industrial area from CINVESTAV site

14. Example of vertical scan at UNAM site.

15. Vertical scan example showing mixing height, entrainment estimates

16. Time sequence of lidar signals for February 22

17. Time sequence of lidar signals for February 26

18. $0^{\circ}$ elevation trace for atmospheric extinction analysis

19. Least Squares Fit of Fig. 18 data

20. February 26 extinction vs time plot

21. February $26-28$ extinction vs time plot

22. NCAR ASAS aerosol probe \& lidar vs altitude, February 22

23. Lidar 2-D vertical scan close in time of NCAR flight, $22 \mathrm{feb} 40.2 \mathrm{~d}$

24. NCAR potential temperature vs altitude, February 22

25. NCAR ozone \& lidar vs altitude, February 22

26. NCAR ASAS aerosol probe \& lidar vs altitude, February 26

27. Lidar 2-D vertical scan close in time to NCAR flight, 26feb21.2d

28. NCAR potential temperature vs altitude, February 26

29. NCAR ozone \& lidar vs altitude, February 26

30. Rawinsonde potential temperature $\& z$ lidar $10^{\circ}$ elev. data vs altitude, February 17,

31. Lidar 2-D vertical scan close in time of rawinsonde ascent, 17 feb91.2d 
32. Rawinsonde pot. temperature \& lidar $30^{\circ} \mathrm{elev}$. data vs altitude, February 17,

33. Rawinsonde pot. temperature \& lidar $10^{\circ}$ elev. data vs altitude, February 22,

34. Lidar $2-\mathrm{D}$ vertical scan close in time to rawinsonde ascent, $22 \mathrm{feb} 46.2 \mathrm{~d}$

35. Rawinsonde potential temperature \& lidar $10^{\circ}$ elev. data vs altitude, February 26,

36. Rawinsonde potential temperature $\&$ lidar $30^{\circ}$ elev. data vs altitude, February 26

37. Lidar $2-\mathrm{D}$ vertical scan close in time to rawinsonde ascent, $26 \mathrm{feb} 22.2 \mathrm{~d}$ 


\section{Introduction}

Over the last two decades, Mexico City, like many large industrial and populous urban areas, has developed a serious air pollution problem, especially during the winter months when there are frequent temperature inversions and weak winds. The deterioration in air quality is the result of several factors. The basin within which Mexico City lies is Mexico's center of political, administrative and economic activity, generating $34 \%$ of the gross domestic product and $42 \%$ of the industrial revenue, and supporting a population which is rapidly approaching the 20 million mark. The basin is surrounded by mountains on three sides which inhibit rapid dispersal of pollutants. Emissions from the transportation fleet (more than 3 million vehicles) are one of the primary pollution sources, and are mostly uncontrolled. Catalytic converters are just now being introduced into the fleet.

The Mexico City Air Quality Research Initiative is an international collaborative project between the Los Alamos National Laboratory and the Mexican Petroleum Institute dedicated to the investigation of the air quality problem in Mexico City. The main objective of the project is to identify and assess the cost and benefits of major options being proposed to improve the air quality. The project is organized into three main activity areas:

Task 1 : Modeling and simulation

Task 2 : Characterization and Measurements

Task 3 : Strategic Evaluation

Task 1 is concerned with the development and adaptation of computer codes that will model the basic meteorology of the Mexico City basin (3-dimensional, time-dependent calculations of the wind and temperature fields), the pollutant transport and dispersion over and beyond the urban terrain, and the photochemistry. Ultimately, the models will be used to make predictions of the effect that various mitigation strategies would have on the spatial and temporal variations of selected air quality 
parameters, such as ozone, carbon monoxide, nitrogen oxides, and visibility levels.

Task 2 is charged with characterizing the meteorology and ambient air quality with appropriate measurement and data gathering efforts. The data obtained will be used to validate the performance of the atmospheric models being developed.

Task 3 will provide socioeconomic analyses of proposed air quality improvement strategies using the atmospheric model predictions of the effect on the selected air quality parameters.

In February of 1991, a major measurements campaign was carried out in an attempt to gather sufficient information to allow a basic understanding of the meteorological processes that dominate the behavior of the atmosphere above the valley in which Mexico City is located. The campaign involved approximately 100 investigators from Mexico and the US. In addition to standard EPA ground based instrumentation designed to measure the concentration of major pollutants, numerous advanced measurement techniques were utilized, including a fully instrumented aircraft laboratory, a real-time infrared vehicle emission monitor, a mobile lidar system for aerosol characterization, a mobile lidar for $\mathrm{SO}_{2}$ measurements, tethersonde instrumentation, time lapse photography, satellite imagery, rawinsonde monitoring, solar radiation monitors, particle-induced $x$-ray elemental analysis of aerosol particles, a cloud ceilometer, and GC/MS analysis of hydrocarbon samples.

The focus of this report is on the data obtained with the Los Alamos lidar system designed to examine the spatial and temporal distribution of aerosol particles present during high air pollution periods. The main objectives of the lidar measurements were to characterize the mixing-layer, its height, texture and breakup, the manner in which plumes are transported and dispersed, and to obtain information regarding the atmospheric opacity.

A mobile lidar system designed to characterize the spatial and temporal variation of the concentration of atmospheric aerosol particles over kilometer scale distances was deployed at three different locations within the Mexico City basin over a period of two weeks in February of 1991. The vertical distribution of aerosols was examined many times an hour over a period of several days at each location. The vertical scans 
showed complicated atmospheric layering as well as systematic temporal variations. Occasional horizontal scans were also taken, revealing the location of major aerosol sources such as glass manufacturing, steel making operations, and major highways, as well as minor sources such as roads, buming refuse and restaurant activity. A few three-dimensional volume scans of the atmospheric aerosol were also carried out.

\section{Lidar Technique}

In the lidar experimental technique shown schematically in Fig. 1, a laser is used to generate a pulse of light that is launched into the atmosphere in a predetermined direction. As the pulse of light propagates through the air, it is scattered in all directions, primarily by aerosol particles within its path. A small fraction of this scattered light travels back towards the laser source where it is collected with a large telescope and measured with a photodetector. The photodetector signal is proportional to the volume backscattering coefficient of the aerosol particles. In general, the volume backscattering coefficient is a function of the aerosol particle chemical composition, size, and shape. The time it takes the backscattered photons to arrive back at the light source determines the distance to the aerosol scatterers. By making angular scans (vertical and horizontal) of the laser/telescope direction, the spatial variation of aerosol concentration can be mapped out (in 1-, 2- or 3dimensions) over kilometer distances, with a few meters resolution, in a few minutes.

\section{Lidar System Description}

A photograph of the mobile lidar system used in Mexico City is shown in Fig. 2. Briefly, a Nd:YAG laser operating at $1.06 \mu \mathrm{m}, 10$ pulsesper-second, $1 \mathrm{mrad}$ divergence is located within the vehicle (step-van). The energy-per-pulse was adjusted to be $30-50 \mathrm{~mJ}$ so as to minimize the nominal optical hazard distance (less than $2 \mathrm{~km}$ ). The laser beam is made parallel, with a Coude' system, to the optical axis of a 16" diameter, f/8 
telescope that is mounted on top of the step-van. The laser/telescope assembly is moved under computer (ALR $486 \mathrm{PC)}$ ) control in discrete angular steps to execute vertical (see Fig. 3), horizontal, or combination scans of the atmosphere. Laser photons scattered backwards towards the lidar by the atmospheric aerosol particles are collected by the telescope and focused onto a silicon avalanche photodiode (APD) mounted on the back of the telescope. A 3-nm bandpass filter was used to block out solar background. The APD/filter combination allowed night and day operation. A light-funnel assembly, consisting of a tapered cone, was used to increase the telescope field-of-view to approximately $3 \mathrm{mrad}$. Signals from the APD (10-MHz frequency response) were transmitted through a fiber optic cable/receiver system to a CAMAC-based digital transient waveform recorder (LeCroy TR8818, 8 bit) sampling at 100-MHz. A PC computer running a turbo-Pascal data acquisition program was used to store, display and analyze the digitized data waveforms. Typically 10 laser shots $(1 \mathrm{sec})$ were averaged together at each scan angle and stored to disk $(0.5 \mathrm{sec})$. Several types of scans were taken: vertical, horizontal, 3-dimensional, and time-domain. For vertical scans, the laser/telescope elevation angle was increased while holding the azimuth angle constant. For horizontal scans, the azimuth angle was varied while holding the elevation angle constant. The laser beam/telescope are defined as having an $A z=90^{\circ}$ when they are aimed directly away from the back end of and parallel to the length of the truck. $A z=0^{\prime}\left(180^{\circ}\right)$ corresponds to the left (right) hand side of the truck looking from in front towards the back. For 3-dimensional scans both the elevation and azimuth angles were varied according to a predetermined pattern. For time-domain scans, both elevation and azimuth angles are held constant, and the computer stores the average result of a selected number of shots, repeating this procedure a predetermined number of times, one right after the other. The usual time required to complete a vertical or horizontal scan varied from 1-5 minutes depending on the number of angles in the scan and the number of laser shots per angle.

\section{Measurement Locations}

The Los Alamos lidar was located at three different sites: 
1) Thermo-electric power plant (Feb. 16-18)

The power plant is located northeast of city center at about $98^{\circ} 58^{\prime}$ $18^{\prime \prime}$ longitude and $19^{\circ} 37^{\prime}$ latitude, at an elevation of approximately $2240-\mathrm{m}$ above sea level. The Los Alamos tethersonde was located within $100-\mathrm{m}$ of the lidar truck, approximately due west. The site was approximately 29 $\mathrm{km}$ from the airport. During the 16th \& 17 th, the lidar truck was aligned so that its $\mathrm{Az}=90^{\circ}$ corresponded to $276^{\circ}$ magnetic north or $284^{\circ}$ true north, and approximately directly over the tethersonde location. After $1: 15 \mathrm{pm}$ on the 17th, the lidar truck was tumed around, so that its $\mathrm{Az}=90^{\circ}$ corresponded to $92^{\circ}$ magnetic north or approximately $100^{\circ}$ true north. The $\mathrm{SO}_{2}$ lidar from the Institute for Electrical Investigations was co-located with the LANL lidar. Available power was such that either the $\mathrm{SO}_{2}$ lidar or the aerosol lidar could operate. Figs. $4 \& 5$ indicate the approximate position of the lidar truck on a city street map for the two predominant scan directions. The lidar $A z=90^{\circ}$ direction turned out to be very close to the direction in which several large cooling towers were present. The cooling towers produced, at periodic time intervals, large concentrations of water vapor aerosols which formed plumes that were often too thick to allow passage of the laser light when at low elevation angles.

2) CINVESTAV (Feb. 19-23)

The Centro de Investigacion y Estudios Avanzados (CINVESTAV) is located north of city center a: about $99^{\circ} 7^{\prime} 42^{\prime \prime}$ longitude and $19^{\circ} 30^{\prime} 35^{\prime \prime}$ latitude, at an elevation of approximately 2240 -m above sea level, about 1 $\mathrm{km}$ northeast of the Polytechnic Institute soccer stadium where the tethersonde was located. The site was approximately $13 \mathrm{~km}$ from the airport. For Feb. 19-22, the lidar truck was oriented such that its Az=900 pointed directly towards the tethersonde location, which corresponded to approzimately $211^{\circ}$ magnetic or $219^{\circ}$ true north. On Feb. 23, the lidar truck was turned around to face almost due north so that its $\mathrm{Az}=90^{\circ}$ corresponded to $349^{\circ}$ magnetic or $357^{\circ}$ true north. Figs. 6 \& 7 show the approximate lidar truck locations on a city street map. 
3) UNAM Botanical Gardens (Feb. 25 - Mar. 1)

The UNAM botanical gardens site is located southwest of city center at about $99^{\circ} 11^{\prime} 42^{\prime \prime}$ longitude and $19^{\circ} 18^{\prime} 56^{\prime \prime}$ latitude, at an elevation of approximately $2320-\mathrm{m}$ above sea level, or about $80-100 \mathrm{~m}$ above city center. The site was approximately $24 \mathrm{~km}$ from the airport. The lidar truck was oriented such that its $A z=90^{\circ}$ corresponded to approximately $32^{\circ}$ magnetic or $40^{\circ}$ true north. At this time the tethersonde was located at a site in Xochimilco, south of the city. Given the elevation at this site, lidar data taken at an elevation angle of $0^{\circ}$ actually monitors aerosol particles at a variety of altitudes on range and direction (up-slope, down-slope, etc.). Fig. 8 shows the approximate location of the lidar truck on a city map.

\section{Data Log Summary}

A log detailing the main parameters of all the stored data files is included as Appendix A. The data $\log$ indicates the date and time the data was taken, the scan type, the number of shots averaged, the azimuth angle with respect to the lidar truck, the azimuth angle with respect to true north, the elevation angle, the avalanche photodiode detector (APD) voltage, the amount of attenuation in the signal chain, and whether or not a $10 \mathrm{MHz}$ filter was being used. The APD voltage shown does not correspond exactly to the voltage on the APD detector itself because of the temperature compensation circuit employed which attempts to maintain a constant APD gain. True APD voltages are probably $30-40 \mathrm{~V}$ lower than indicated in the bias column. There are hard copies of most data files except for the timedomain scans and some of the 3-dimensional scans. The APD detectivity vs bias voltage is shown in Appendix B.

\section{Data Analysis Strategy}

Only a few of the days during which lidar data was gathered were examined in detail. The selection process was based primarily on two factors : good data overlap between all the instruments deployed in the 
campaign (NCAR aircraft, satellite, lidar, tethersonde, etc.) and air quality index (IMECA) levels for ozone, as measured by the SEDUE (Mexico's equivalent to U.S. EPA) ground-based grid monitors. February 17 was selected on the basis of it being a "normal" day, with a typical $\mathrm{O}_{3}$ concentration (IMECA max $_{\max }=147, \mathrm{NW}$ sector). February 22 was selected due to the fact that it was the highest ozone level observed during the twoweek measurements period (IMECA $A_{\max }=280, \mathrm{SW}$ sector). The February 26-28 period was selected because it exhibited a change in the typical spatial distribution pattern, evolving from high concentrations in the southwest on the $26^{\text {th }}$ to high concentrations in the northeast on the $28^{\text {th }}$.

\section{Lidar Data Plot Generation Procedures}

The limited amount of analysis time available combined with the sheer volume of lidar data obtained and the immediately available image processing technology dictated that the data be processed in a simple manner. The data display procedures followed occasionally led to unusual plots. Two of the more noticeable effects to be described in this section are connected with atmospheric extinction, which is normally not removed from the data, and the occasional presence of clouds in the atmosphere.

The data analysis procedures used to generate the 2-D color plots were as follows. As the 2-D raw data files (stored on optical disks) were read into the computer, the data analysis program calculated the zero-signal baseline associated with each angle trace by taking the average value of a pre-selected portion of the signal curve, typically the last few hundred range bins, where the aerosol return signal had fallen into the noise. This baseline value is subtracted from each data point in the corresponding trace to produce signals that start and end at 0 digitizer counts $(0 \mathrm{mV})$. Each data point was then inultiplied by the square of its corresponding range value (in meters) to remove the $1 / \mathrm{r}^{2}$ fall-off character of lidar retum signals (see section below). The resulting 2-D data file was then plotted in color where the amplitude of the range corrected signal assumed one of 16 possible colors. In other words, whatever the range of lidar retum signal, for plotting purposes the signal is broken down into 16 levels only. This 
has the effect of greatly reducing the spatial resolution of the plotted data, and can produce a staircase appearance in the plots as one color changes into another. To allow different regions within the scanned volume to be displayed with high contrast, the plotting program can adjust the "exposure" level so that a selected range of signal level uses the entire range of available colors. Normally, the portion of the signal that is greater than the maximum value selected is set to the lowest possible value in the color scale (the color scheme rolls over). In the 2-D plots contained within this report, these over-exposed regions show up as white areas.

The radial features which originate at zero range and continue for several hundred meters (up to $1 \mathrm{~km}$ depending on APD detector bias voltage) represent the riging part of the lidar return signal and is due to an instrumental artifact related to the manner in which the laser beam enters the field-of-view of the telescope. It is normally not used in analysis.

Plots were also made of selected individual data traces that make up the complete 2-D scans. In these plots, the lidar return signal at a particular elevation angle is extracted from the 2-D files and plotted separately. Normally the data shown represents the average of a given number of laser shots (usually 10 or 50 ), and the individual traces are subjected to a 10 range bin average smoothing routine. The data is corrected for $1 / \mathrm{r}^{2}$ fall off but not for atmospheric extinction. The rising part of the signal does not indicate a low concentration of aerosols but rather reflects the previously discussed laser/telescope field-of-view overlap. Although the rising part is not normally used in data analysis, it can reveal the presence of sharp, well defined atmospheric layers.

The fact that atmospheric extinction has not been removed from the data leads to several systematic effects in the plots. Extinction will cause the range corrected lidar return signal to diminish with range and so, in general, there will tend to be a bias in the color plot in which the near regions appear to contain a higher concentration of aerosols than the far regions. The effects of atmospheric extinction, random and systematic noise on the lidar data plots are discussed in more detail in Appendix C.

\section{Lidar Data Examples}

1) Individual angle data 
Fig. 9 shows an example of a lidar retum signal taken at a $30^{\circ}$ elevation angle at the UNAM site at approximately 7:55 am. This trace is one of many that make up the complete scan (vertical in this case). The data is the average of 50 laser shots, and the resulting data file was subjected to a 10 point smoothing routine. The rising part of the signal (up to about $400 \mathrm{~m}$ in this example) does not indicate a low concentration of aerosols but rather reflects an instrumental characteristic related to how the laser beam enters the field-of-view of the telescope. This particular example shows that there are two strong gradients in aerosol concentration: one at an altitude of about $450 \mathrm{~m}$, and a second transition at about $1.9 \mathrm{~km}$.

2) Vertical and horizontal scans

An example of a vertical scan taken at the thermo-electric power plant site is shown in Fig. 10. It is made up of an angular sequence of 96 traces. The color bar indicates approximately the relative concentration of aerosol particles (in arbitrary units). The scan shows the strong atmospheric stratification that is occurring at this particular time. Many layers or bands of aerosol particles are visible. The area within the first few hundred meters that shows as white is actually an "overexposed" area, where the signal levels exceed the range indicated in the color bar. Close examination of this area shows that there is a strong gradient in aerosol concentration occurring at an altitude of $200-300 \mathrm{~m}$, most likely due to a thermal inversion. The height of this low-lying layer will be the altitude to which air pollutants can disperse, until later in the moming when the thermal inversion dissipates.

The variation in mixing layer height and texture is illustrated in Fig. 11 and 12. Fig. 11 is an example of a vertical scan taken at about 7:21 am at the CINVESTAV site that shows the height of the mixing layer as being approximately $225 \mathrm{~m}$. By 10:47 am, Fig. 12 shows the mixing layer has become extremely convoluted, reaching altitudes as high as $900-1000 \mathrm{~m}$.

An example of a horizontal scan taken at the CINVESTAV site is shown in Fig. 13. Overiaying this scan on a city map showed that the bright plumes observed here (shown in white and red) are connected with activities at a glass manufacturing plant and a steel making operation. This 
scan illustrates the lidar system's ability to pinpoint, locate, and identify the sources of atmospheric aerosols.

Fig. 14 shows an example of a vertical scan taken at the UNAM botanical gardens site. Huge plumes are seen rising from the city at specific locations. At this time of day, aerosols released into the atmosphere can be lofted up towards the top of the mix-layer which is at about $2.5 \mathrm{~km}$. Note the structure in the elevated boundary layer compared to the relatively flat case in Fig. 10. The plume between 2 and $3 \mathrm{~km}$ away may be associated with a major highway in the area. Clean cool air from above can be seen mixing with the polluted air below. The aerosol pattems give the impression that wind circulation is occurring.

\section{Data Compilations}

To provide a readily available temporal record of the variation of lidar aerosol return signals, single angle data was extracted from each of the vertical scans. Typically, $10^{\circ}, 300^{\circ}$, and $50^{\circ}$ or $0^{\circ}, 10^{\circ}$, and $30^{\circ}$ data were extracted, corrected for $1 / \mathrm{r}^{2}$ fall-off, corrected for angle so as to show altitude above ground (except for $0^{\circ}$ data), and plotted out. The $10^{\circ}$ data is most useful for examining the behavior of aerosol layers close to the ground, especially in the early morning hours when thermal inversions often occur close to the ground. However, the $10^{\circ}$ data are also the most affected by atmospheric extinction effects, as the beam traverses a much larger distance to get to the same altiude compared to the $30^{\circ}$ or $50^{\circ}$ data. The $30^{\circ}$ and $50^{\circ}$ data are most useful to see the distribution of aerosols to the top of the planetary boundary layer (typically $2-3 \mathrm{~km}$ ). The $0^{0}$ data is most useful to obtain atmospheric extinction information. The plots of most of the data files taken the selected days are available in a separate binder. This data-compilation binder also includes a selected subset of the vertical scan color plots. The vertical scan plots are most useful to examine the height, structure and texture of the aerosol layers. Some of the effects of systematic and random noise on the data plots are discussed in appendix $\mathrm{C}$. 


\section{Interpretation of Lidar Data}

An approximate, simplified formula for the signal vs range observed by the $1.06 \mu \mathrm{m}$ elastic scattering system is:

$$
S(r)=C G(r) \beta(r) T(r) / r^{2}
$$

where

$$
\begin{array}{ll}
S(r)= & \text { signal level detected at a range } r \\
C= & \text { instrumental system constant } \\
G(r)= & \text { geometrical overlap factor } \\
\beta(r)= & \text { volume backscattering coefficient } \\
T(r)= & \text { round-trip atmospheric transmission at } 1.06 \mu \mathrm{m} .
\end{array}
$$

The instrumental system constant, $\mathbf{C}$, includes such factors as the telescope transmission efficiency, APD gain and efficiency, laser pulse energy and width, signal attenuation, filter transmission, etc. The geometrical overlap factor, $G(r)$, attempts to describe the manner in which the laser beam, with its associated divergence, gradually enters the telescope's field-of-view (FOV) with range. It is a measure of the fractional laser energy within the FOV and approaches a constant in the telescope's far field region (constant $=1$ if laser beam entirely within telescope FOV). The volume backscattering coefficient, $\beta(r)$, is proportional to the number of photons scattered backwards from the incident laser pulse by the aerosol particles located at range $r$. In general, $\beta(r)$ depends not only on the concentration of aerosol particles but on the chemical composition, shape, and size distribution. The atmospheric transmission factor, $T(r)$, reflects the round-trip atmospheric attenuation at $1.06 \mu \mathrm{m}$ of the outgoing laser beam as it propagates out to range $r$, and of the backscattered photons as they propagate from range $r$ back towards the telescope. $T(r)$ is usually represented in terms of Beer's law as :

$$
T(r)=\exp \left\{-2 \int_{0}^{r} \sigma\left(r^{\prime}\right) d r^{\prime}\right\}
$$


where $\sigma(r)$ is the extinction coefficient at range $r$. Finally, the $r^{2}$ term represents the decrease with range of the backscatter solid angle subtended by the telescope. The lidar data described in this report are presented as $r^{2} S(r)$, thus effectively removing the $r^{2}$ behavior.

The interpretation of data obtained with this particular lidar system configuration is complicated by two fundamental uncertainties :

1) changes in particle chemical composition, shape, and size distributions with range and/or altitude

2) uncertainty in the relationship between the volume backscattering coefficient and associated extinction coefficient, partly due to 1) above.

There are many reasons why changes in particle chemical composition, shape, and size distributions can occur : the laser beam passes through a plume associated with a particular type of aerosol source, the size of the aerosol particle changes with altitude as it picks up moisture from the atmosphere, etc. The current lidar data set cannot provide an independent measure of these effects.

$\beta(r)$ and $\sigma(r)$ are a manifestation of the same physical process (photon scattering) and are thus related to each other. The relationship is affected by such factors as the shape of the particle and the complex index of refraction. A common assumption conceming the relationship between $\beta(r)$ and $\sigma(r)$ used to interpret lidar data consists of letting $\beta(r)$ be directly proportional to $\sigma(r)$

Given the rather complicated nature of aerosol sources and structures in a highly polluted urban environment, the lack of accurate data concerning the instrumental constant, and the fundamental difficulties mentioned in 1) and 2) above, it has not been possible at the time of this writing to accurately and reliably remove the effects of atmospheric extinction from the bulk of the data, except in the selected cases described in the atmospheric extinction section later in this document.

Qualitatively, atmospheric attenuation in the lidar data presented here manifests itself in various ways. In the extracted single angle data files, extinction causes a systematic decrease in the observed rangecorrected signal return. However, it is sometimes rather difficult to decide whether a particular decrease in signal is due to atmospheric attenuation being high or is due simply to a decreasing concentration of aerosols with 
range. Given the range of visibility normally encountered during the measurements (extinction coefficients in the range of $0.1-0.5 \mathrm{~km}^{-1}$ ), it is fairly safe to assume that most of the time, the abrupt changes (sharp gradients within a few hundred meters) in signal indicate a rapid reduction of aerosol particle concentration, and are a good measure of the height of a layer.

A great deal of care must be taken when interpreting the extracted single angle data. Single line-of-sight data can be easily misleading due to the presence of highly localized aerosol structures such as plumes. For example, a scan at $10^{\circ}$ might exhibit an abrupt transition at a particular elevation which is not due to a large scale atmospheric layering phenomenon but rather to the laser beam exiting a fairly well defined plume. Interpretation of the single angle data shouid always be verified by comparison with the two-dimensional scans which can help distinguish between a localized feature and larger scale (several km's) phenomena.

Examples of some of the effects described above on the visual appearance of the data plots are presented and discussed in appendix C.

\section{Height of the Mixing-Layer as Derived From Lidar Data}

Of primary concern to the atrnospheric models attempting to describe the air pollution in an urban area is the height of the mixing-layer (ML): the height to which contaminants produced by activity on the surface can be dispersed via turbulent mixing. The height of the ML deduced from the lidar data will discussed in this section.

The use of lidars to determine the height of the mixing-layer has been demonstrated and discussed before by several investigators. ${ }^{1-9}$ Essentially, atmospheric conditions such as temperature inversions can greatly inhibit the upward movement of particles and other air pollutants, leading to a sharp gradient in their concentration vs altitude. In general, lidars are expected to give good measurements of the mixing height except in cases where there are not enough particles to give a good return, there is not enough optical contrast in the spatial distribution of particles, or there has not been enough time since the onset of a temperature inversion to allow the aerosols to accumulate or become stratified. Comparisons to 
sodar, microwave radar, meteorological tower and radiosonde (rawinsonde) instrumentation have been carried out.3,5,6.9 Lidar data has been shown to give good measurements of the ML height, although there can be significant, sometimes systematic differences with other instrumentation. The accuracy of the lidar measurements as compared to other instrumentation is often dependent on the definition of the mix-layer height used in the analysis. Different investigators have historically used somewhat varying definitions, probably influenced by the characteristics of the instrumentation being used at the time. For a discussion of the differences in mixing-layer height determination by a variety of instruments see Kaimal, et al. 6

Lidar data itself has been interpreted using a variety of definitions for the mixing height depending on the atmospheric conditions present during the measurement. In geographical areas with low aerosol concentrations, lidar return signals tend to show a peak at the base of the capping inversion. 6 In urban areas with high aerosol concentrations, the backscatter signal is expected to decrease suddenly above the mixing height, and the altitude at which the maximum negative gradient occurs has been taken as the inversion base. 6 Both of these definitions suffer from the fact that late in the morning, when turbulent convective cells or plumes begin to rise, the surface that describes the mixing height over a given geographical area (several $\mathrm{km}$ in dimension) becomes very irregular. Warm dirty air from below becomes entrained with cold clean air from above and thus, a single lidar return signal, obtained at a particular azimuth and elevation angle, will give an answer that can vary over a wide range depending on whether the laser beam happens to exit through the highest point of the convective plume or between plumes. More recently, Boers et al..$^{8}$ have determined mixing height from 2-dimensional lidar scans where the azimuth is held constant while the elevation angle is varied in small steps over a given range of angles as was done in the Mexico City field campaign. Boers, et al. 8 interpreted the lidar backscatter signals following the work of Deardorff et al.10, who define the mean mixing height as the level at which $50 \%$ of the horizontal area exhibits the signal level of the clear air region above. Excellent agreement was found between the lidar mean mixing height and the values obtained from balloon and kytoon temperature soundings (correlation coefficient of 0.99). An example of 
this technique as applied to the Mexico City data is shown in Fig. 15. The entrainment zone, defined as the difference between the height reached by only the most vigorous of convective cells and the height below which the mixed layer air covers $90-95 \%$ of the total possible area ${ }^{8}$, and the mean mixing height were visually estimated in this example. Even this last definition of mixing height can be very difficult to apply accurately to the lidar data obtained in Mexico City.

In general, the color 2-D elevation angle scans combined with the single angle extracted data plots will be used to make visual estimates of the mixing heights. In the early morning hours, when the atmosphere is highly stratified, the maximum gradient in the color plots will be used as the measure of mixing height. Later in the day, when the mixing-layer surface becomes convoluted, the mean mixing height definition described above will be the basis of the height estimate. Individual angle data can be very misleading, primarily because of its spatially localized nature which makes it difficult to distinguish true large-scale features from isolated events due to localized structures. It must be kept in mind that because of the limited field-of-view available at some of the sites, the lidar system cannot clearly see aerosol structures below heights of about $100 \mathrm{~m}$.

Estimates of the ML height as a function of time will be given in tabular form. Also included in the tables will be the height of a second atmospheric boundary level that is commonly observed in the lidar data at all the sites monitored. This second boundary level correlates well with upper level temperature inversions seen by the rawinsondes (see rawinsonde section below) and undergoes substantial diumal variations. It is also the height to which particles can rise after the low level inversion rises and dissipates.

Examination of a subset of the entire sequence of 2-D elevation angle scans together with the extracted angle data yields the following tables showing the lidar estimate of the mixing-layer height. For these tables, when two low lying features occur, both will be indicated. The height of the elevated boundary level (discussed above) is shown as well.

February 17 
On February 17, the lidar system was located at the thermo-electric power plant site, which in retrospect is not a good site for ML height measurements. The presence of nearby large cooling towers and stacks creates substantial difficulty in the interpretation of lidar data in terms of ML heights. Hot air plumes can easily be lofted above low lying thermal inversion layers. Some of the scans clearly show a plume rising to $800 \mathrm{~m}$ in the middle of the night, apparently feeding aerosols into several layers along the way (see $17 \mathrm{feb} 80.2 \mathrm{~d}$ in data compilation). It is often not clear whether a sharp decrease in signal is due to a large-scale ML phenomenon or due to a plume of finite extent that happens to be at a given altitude at the time of the scan (this is especially true when looking at the single angle extracted data plots). The 2-D elevation angle scans taken during the early morning hours of the 17th show a highly stratified atmosphere with a great many aerosol layers or bands. When the towers are running at a greatly reduced output, a group of two or more layers within the first $75-300 \mathrm{~m}$ of altitude can be seen. It is not clear whether it is only the lowest of the layers that is defining the height to which freshly generated particles and other pollutants can rise, or whether it is the topmost layer in the group that represents the true limit.

$\begin{array}{lcc}\text { Time of Day } & \begin{array}{c}\text { Estimate of } \\ \text { mixing-layer } \\ \text { height }(\mathrm{m})\end{array} & \begin{array}{c}\text { elevated boundary } \\ \text { level }(\mathrm{m})\end{array} \\ \text { 2:28 am } & 250 & 2400 \\ \text { 3:05 am } & 200 & 2000 \\ \text { 6:47 am } & 100,300 & 2000 \\ \text { 7:55 am } & 125,300 & 1950 \\ \text { 9:18 am } & 300 & 1700 \\ \text { 1:06 pm } & 1800 & 1800 \\ 8: 18 \mathrm{pm} & & 3100 \\ 10: 22 \mathrm{pm} & & 2800\end{array}$

No lidar data is available between 1 and $8 \mathrm{pm}$ due to a power failure at the thermoelectric plant. The temperature profiles measured by the 
tethersonde instrument indicated surface radiation inversions below $100 \mathrm{~m}$ in the early moming hours.

\section{February 22}

On Fe'Uruary 22 the lidar system was located at the CINVESTAV site. The early moming hours of February 22 are characterized by a very strong gradient in the vertical aerosol distribution. The decrease in aerosol return signal starts at altitudes as low as $100 \mathrm{~m}$, decreasing by an order of magnitude by an altitude of $250-300 \mathrm{~m}$. The 2-D scans show that there was a source of aerosols (unidentified) within $1 \mathrm{~km}$ of the lidar site (see $22 \mathrm{feb} 34.2 \mathrm{~d}$ in data compilation). Lidar data estimates of the ML height are as follows:

$\begin{array}{lcc}\text { Time of Day } & \begin{array}{c}\text { Estimate of } \\ \text { mixing-layer } \\ \text { height (m) }\end{array} & \begin{array}{c}\text { elevated boundary } \\ \text { level (m) }\end{array} \\ \text { 4:22 am } & 250 & 2500 \\ 6: 28 \mathrm{am} & 250 & 2200 \\ 7: 24 \mathrm{am} & 250 & 2200 \\ \text { 8:49 am } & 300 & 2200 \\ \text { 9:28 am } & 400 & 2200 \\ \text { 9:59 am } & 600 & 2200 \\ 10: 49 \mathrm{am} & 800 & 2300 \\ 11: 30 \mathrm{am} & 1150 & 2600 \\ 11: 57 \mathrm{am} & 1250 & 2700 \\ 12: 12 \mathrm{am} & 1350 & 2700 \\ 1: 33 \mathrm{pm} & 1800 & 2700 \\ \text { 3:14 pm } & 2700 & 2700 \\ \text { 4:44 pm } & & 3100 \\ 5: 17 \mathrm{pm} & & 3700 \\ 6: 23 \mathrm{pm} & & 3800 \\ 7: 56 \mathrm{pm} & & 3500 \\ 10: 30 \mathrm{pm} & 650 & 3300\end{array}$


The height of the ML is not shown past 3 pm because it has coalesced with the upper level inversion, becoming indistinguishable from it. Late in the evening there is evidence in the lidar data that a low lying inversion has re-formed (see $22 \mathrm{feb} 103.2 \mathrm{~d}$ in data compilation).

\section{February 26-28}

On February 26-28 the lidar system was located at the National Autonomous University of Mexico (UNAM) in the botanical gardens area. This particular site was located a 80-100 m elevation compared to downtown Mexico City, on the mountain slopes to the southwest. Most of the scans were in a downslope direction. The altitude specified in the data plots and the table that follows has not been corrected for local elevation.

February 26

Estimate of Time of Day mixing-layer height (m)

elevated boundary level (m)

$\begin{array}{lll}\text { 2:30 am } & \text { nwd } & 2100 \\ 4: 19 \mathrm{am} & \text { nwd } & 2100 \\ \text { 6:24 am } & 200 & 1950 \\ \text { 8:54 am } & 250 & 1850 \\ \text { 9:25 am } & 400 & 1750 \\ 10: 22 \mathrm{am} & 475 & 1800 \\ 11: 16 \mathrm{am} & 650 & 1950 \\ 12: 09 \mathrm{pm} & \text { nwd } & 2000 \\ 1: 02 \mathrm{pm} & 2400 & 2400 \\ 2: 02 \mathrm{pm} & & 2600 \\ 3: 22 \mathrm{pm} & & 3000 \\ 4: 54 \mathrm{pm} & & 2900 \\ 5: 22 \mathrm{pm} & & 2850\end{array}$


6:06 pm

2600

$7: 45 \mathrm{pm}$

2600

9:28 pm

2400

$10: 33 \mathrm{pm}$

200

2150

nwd = not well defined in the data

February 27

$\begin{array}{lcc}\text { Time of Day } & \begin{array}{c}\text { Estimate of } \\ \text { mixing-layer } \\ \text { height }(\mathrm{m})\end{array} & \begin{array}{c}\text { elevated boundary } \\ \text { level (m) }\end{array} \\ \text { 0:47 am } & 200 & \text { nwd } \\ \text { 3:01am } & 100 & \text { nwd } \\ \text { 5:20 am } & 100 & \text { nwd } \\ \text { 6:16 am } & 150 & \text { nwd } \\ \text { 8:18 am } & 300 & \text { nwd } \\ \text { 9:45 am } & 300 & \text { nwd } \\ \text { 10:32 am } & 500 & \text { nwd } \\ \text { 10:51 am } & 850 & \text { nwd } \\ \text { 11:32 am } & 1000 & 1800 \\ \text { 12:30 am } & 2500 & 2500 \\ \text { 7:29 pm } & 200 & 1600 \\ \text { 8:29 pm } & 200 & 1600\end{array}$

nwd = not well defined in the data

February 28 :

Estimate of

Time of Day mixing-layer height (m)

elevated boundary level (m) 


$\begin{array}{lll}0: 36 \mathrm{am} & 300 & 1600 \\ 2: 39 \mathrm{am} & 200 & 1500 \\ 4: 47 \mathrm{am} & 200 & 1600 \\ 5: 48 \mathrm{am} & 250 & 1700 \\ 6: 27 \mathrm{am} & 200 & 1600 \\ 7: 30 \mathrm{am} & 250 & 1200 \\ 8: 28 \mathrm{am} & 250 & 1100 \\ 11: 40 \mathrm{am} & 750 & \text { nwd } \\ 12: 15 \mathrm{am} & 1900 & 1900 \\ 1: 34 \mathrm{pm} & 3000 & 3000 \\ 5: 16 \mathrm{pm} & & 2800 \\ 6: 29 \mathrm{pm} & & 2100 \\ 11: 48 \mathrm{pm} & 450 & \text { nwd }\end{array}$

nwd $=$ not well defined in the data

\section{Conclusions on lidar mixing-layer height measurements}

The thermo-electric site was not an ideal site for mixing-layer height measurements. The environment was very complicated due to the local sources and the field-of-view prevented examination of possible inversions below $100 \mathrm{~m}$ in altitude. It is clear that there was substantial stratification of the atmosphere throughout the early morning hours.

The ML on February 22 exhibited a common pattern. In the early morning hours, particles are confined to within the first few hundred meters of elevation. As the sun rises and starts to warm the earth's surface, the ML height starts to rise, slowly at first. After approximately 10 am, the ML height increases rapidly so that by early afternoon (1-2 pm) it has reached elevations above $2 \mathrm{~km}$, and begins to merge with an upper level boundary layer.

The particular lidar system configuration used for these measurements has some difficulty determining accurately the height of the ML under very stratified atmospheric conditions where there is more than one sharp aerosol layer very close to the ground $(<100 \mathrm{~m}$ altitude). This situation is mostly due to the restricted field-of-view at the selected sites 
and the range-dependent laser/telescope overlap function. A more fundamental problem arises from trying to determine whether it is only the lowest of a group of layers that effectively confines new surface-generated particles and pollutants. In any case, the lidar instrument shows where the particles and stable pollutanis are currently concentrated.

The 2-D lidar scans graphically show the difficulties in trying to assign a single height to the mixing-layer. The convective turbulence cells that transport pollutants to higher elevation late in the moming, give rise to very complicated surfaces, such that the height measured at a given spatial location is subject to a lot of intrinsic variability.

There is some evidence in the scans suggesting that the low-lying ML is becoming re-established early in the evening as the earth's surface starts to cool.

The upper level boundary layer exhibits a temporal variation following what appears to be a diurnal cycle.

\section{Time Sequences of Lidar Return Signals}

An animated time sequence of 2-D vertical scans can show the temporal evolution of the atmospheric aerosol spatial distribution in great detail. However, this approach requires some type of viewing screen for presentation. A simpler way to visualize the basic changes and trends in aerosol levels that are taking place as a function of time, and more amenable to the printed page, is as follows. First, range corrected data at a particular elevation angle ( $30^{\circ}$ for example) are extracted from a sequence of 2-D files taken under approximately the same conditions (same azimuth angle and APD bias voltage), corrected for angle to indicate altitude instead of range, and corrected for electronic signal voltage sitipsisilation. The extracted files are cast into 3-D matrix form, where the coordinates specify the time, altitude, and signal level. Linear interpolation between points and a smoothing routine are used to generate visually smooth grid of equally spaced points which is plotted using a color scale to represent the signal amplitude. Thus, a particular color will indicate a constant signal amplitude level. 
Fig. 16 shows the result of following the procedure outlined above on a time sequence of scans taken on February 22 at the CINVESTAV site. In this case, the height of the mixing layer (ML) stays within the first few hundred meters until about 7 am. As the rising sun starts to warm the surface and convective cells start to move upwards, the height of the ML starts to increase, slowly at first. By 12 noon the ML has reached altitudes higher than $1 \mathrm{~km}$. In addition, the plot shows that even though the ML height increases with time and, therefore, there is a larger volume of air to disperse pollutants into, the concentration of aerosols at low altitude is also increasing with time. This is probably due to increased output from the aerosol emission sources in the area (vehicular and industrial) as the level of human activity picks up.

A second example of a temporal sequence of lidar return signals is shown in Fig. 17 for the data obtained February 26 at the UNAM botanical gardens site. Although this example follows the ML height pattern discussed in the example above, it differs in that there was a large concentration of particles aloft during the early morning hours which appears to have disappeared fairly quickly by sun-up. The temporal variation of the elevated boundary layer (described in previous sections) also shows up fairly well. This plot also suggests that the ML height starts to decrease at about 3 or $4 \mathrm{pm}$. By $9 \mathrm{pm}$ the concentration of particles has dropped considerably.

\section{Atmospheric Extinction Derived From Lidar Data}

When the atmosphere is homogeneous (i.e. no variation in the concentration or physical parameters of the aerosol particles with range) it is not necessary to know the particle size distribution or the details of its backscattering characteristics in order to extract extinction information from the lidar retum signals. When $\beta(r)$ is approximately constant with range $r$, then the signal is easily interpreted in terms of a simple exponential decay function (slope method of inversion) governed by the extinction coefficient, $\sigma(r)$, which now is also invariant with range. In the present lidar data set, the homogeneous atmosphere condition is most often observed in the horizontal dimension (constant altitude), as the vertical 
distribution of aerosols usually exhibits an altitude dependence. The first two sites where the lidar equipment was located (see above) did not allow lidar measurements to be made along strictly horizontal paths (typically 8$10^{\circ}$ minimum elevation angle, see data logs). However, the UNAM botanical gardens site (February 26-28) did provide unobstructed views of the atmosphere at $0^{\circ}$ elevation. Some care must be taken in examining the data from this site because the site itself was located partly up the moutain slopes to the southwest, at an altitude of $80-100 \mathrm{~m}$ above the valley floor, so that the data obtained at $0^{\circ}$ elevation angle does not maintain a constant altitude above the surface until after the laser beam leaves the slope area.

By extracting the $0^{\circ}$ elevation angle data from the vertical scans taken on February 26-28 and choosing only those cases where the horizontal homogeneity condition is approximately satisfied, atmospheric extinction information can be obtained. Frequently, large plumes and other aerosol structures precluded analysis of the data. Fig. 18 is an example of a "good" case for extinction analysis, showing the range corrected lidar retum signal for $0^{\circ}$ elevation extracted trom a vertical scan taken on February 26 at approximately 11:52 am. The atmospheric extinction coefficient $\sigma$ at $1.06 \mu \mathrm{m}$ was obtained by using a least-squares (LSQ) fitting procedure to the first $1 \mathrm{~km}$ of useable data. The LSQ fit for the data in Fig. 18 is shown in Fig. 19. Fig. 20 shows the result of repeating this analysis procedure for a time sequence of vertical scans take on February 26, which yields the temporal variation of the atmospheric extinction coefficient at $1.06 \mu \mathrm{m}$ near this particular lidar site, at an altitude of $80-100 \mathrm{~m}$, in a direction looking primarily towards the city (Az $=40^{\circ}$ true north). The observed $\sigma$ ranges from 0.1 to $0.4 \mathrm{~km}^{-1}$. Note the increase in $\sigma$ that occurs at about 7-8 am and again at about $8 \mathrm{pm}$. This may be correlated to the morning and evening rush hour traffic. Unfortunately, the necessary atmospheric conditions that would have allowed continuous monitoring of $\sigma$ during the next few days to verify this pattern were not established, and only additional fragments of extinction vs time were obtained. The values of $\sigma$ obtained from the data of February 26 ihrough 28 is shown in Fig. 21.

In general, aerosol extinction coefficients are a function of wavelength, so that the extinction and visibility information derived from the lidar data at $1.06 \mu \mathrm{m}$ need to be adjusted to get values that represent the 
situation for visible light. A given visibility at $1.06 \mu \mathrm{m}$ indicates a somewhat lesser visibility in the visible region. Accurate transformation of the $1.06 \mu \mathrm{m}$ data to the visible range of wavelengths requires detailed knowledge of the aerosol particle scattering properties (shape, composition and size distribution). However, if the size distribution of the optically significant particles follows, as is common, a simple power law (Junge model), the extinction coefficient would scale as :

$$
\sigma(\lambda)=\text { Constant } \cdot \lambda \cdot \xi
$$

where $\lambda$ is the wavelength, and $\xi$ is a parameter that has been found to be in the 0.5-2.0 range ${ }^{11}$. Thus for $\sigma$ in the range of $0.1-0.4 \mathrm{~km}^{-1}$ at $1.06 \mu \mathrm{m}$, the corresponding range in the visible $(0.55 \mu \mathrm{m})$ would be $0.14-0.4 \mathrm{~km}^{-1}$ to $0.56-1.6 \mathrm{~km}^{-1}$.

\section{Comparison of Lidar Data to NCAR Measurements}

A fully instrumented aircraft belonging to the National Center for Atmospheric Research (NCAR) (King Air, Al Schanot, project manager) executed a variety of flight patterns over the valley of Mexico to gather information about the major air pollutant species such as $\mathrm{O}_{3}, \mathrm{SO}_{2}, \mathrm{CO}$, $\mathrm{NO}_{\mathrm{x}}$, aerosol particles, etc., as well as major meteorological parameters such as temperature, relative humidity, wind direction and velocity, solar radiation, etc. Most relevant to the lidar instrument for the purpose of comparison is the aerosoi data that was obtained using an ASAS aerosol probe, which relies on an optical light scattering method to determine aerosol particle concentration and size distribution information. In particular, the NCAR aircraft measured the concentration of particles and pollutants as a function of altitude at a specific time of day. The data that will be shown here were obtained as the aircraft made its initial ascent after take-off from the airport. In the comparisons that follow, several factors should be kept in mind : 1) the aircraft is sampling different portions of the atmosphere than the lidar system, typically at least $10 \mathrm{~km}$ apart, 2) the lidar system collects aerosol backscattering data on a time scale of seconds per line-of-sight whereas the NCAR ascent data takes about 10 minutes as 
the aircraft climbs in altitude, and 3) the aircraft passes through an atmospheric layer over a limited region of space, thus sampling the height of the layer at that particular location.

In order to compare the NCAR ascent data to the two-dimensional scan lidar data, a very simple approach was taken to keep the computational data processing time to a reasonable level. Essentially, line-of-sight data at selected angles was extracted from 2-D scans taken at a time close to the NCAR ascent time, subjected to a ten range bin average, corrected for $1 / r^{2}$ fall-off and plotted in terms of altitude above ground level.

The NCAR ASAS probe data gives the concentration of aerosol particles (per $\mathrm{cm}^{3}$ ) with sizes in the $0.12-3.12 \mu \mathrm{m}$ diameter range in the following size-range bins :

Bin Number

$\begin{array}{cc}1 & 0.120-0.145 \\ 2 & 0.145-0.195 \\ 3 & 0.195-0.270 \\ 4 & 0.270-0.370 \\ 5 & 0.370-0.495 \\ 6 & 0.495-0.645 \\ 7 & 0.645-0.820 \\ 8 & 0.820-1.020 \\ 9 & 1.020-1.245 \\ 10 & 1.245-1.495 \\ 11 & 1.495-1.770 \\ 12 & 1.770-2.070 \\ 13 & 2.070-2.395 \\ 14 & 2.395-2.745 \\ 15 & 2.745-3.120\end{array}$

The total number of particles in the $0.12-3.12 \mu \mathrm{m}$ diameter range is heavily dominated by the small particles (bins $1,2,3$ ), with typical concentrations exceeding $10^{3} \mathrm{~cm}^{-3}$ per bin. The larger particle bins usually 
had readings on the order of $1 \mathrm{~cm}^{-3}$. Some of the particle size distribution data is shown in Appendix $D$.

The ASAS probe data tapes showed an entry for each particle size bin every second during the ascent, which normally took about 10 minutes. However, many of the entries were 0 . In order to produce a smooth plot of particle concentration vs altitude, 20 seconds of data were averaged and plotted at the average altitude during the time segment. This produced plots with data points every $150-200 \mathrm{~m}$ of altitude.

In general, aerosol light scattering cross-sections decrease rapidly as the particle diameter becomes smaller than the wavelength of light being used. Thus, given the $1.06 \mu \mathrm{m}$ laser wavelength used in the present lidar system, only the particle concentration data for particles with diameters greater than $0.2 \mu \mathrm{m}$ (bins 3-15) was used for comparison to the lidar data. It should be kept in mind that the observed lidar signal is the result of a complicated superposition of backscattering efficiencies from a wide range of particle sizes and compositions.

\section{NCAR Ascent of February 22, 1991.}

Fig. 22 shows the NCAR aerosol data (solid line) obtained during the ascent portion of the flight on the morning of February 22 in the vicinity of the airport. Superimposed on the same plot is the range corrected lidar return signal (dotted line, scaled and shifted for comparison purposes) obtained at an elevation angle of $30^{\circ}$ during a 2-D scan taken at the CINVESTAV site (approximately $13 \mathrm{~km}$ from the airport) at a slightly earlier time. Recall that the rising part of the lidar signal is an instrumental artifact. The two instruments show reasonable agreement. Both show the same general features : a fairly sharp decrease in particle concentration at an altitude of about $400-500 \mathrm{~m}$, and a second transition region at an elevation of $2200-2300 \mathrm{~m}$. The 2-D scan from which the single lidar trace was taken is shown in Fig. 23 and it shows that the ML is starting to exhibit a fair amount of variability at this point in time. Thus, the agreement between the aircraft data (which samples one portion of the ML boundary) and the one angle lidar data cannot be expected to be better than the variability in the ML height. 
The NCAR potential temperature data is plotted in Fig. 24. It indicates a temperature inversion at about $400-500 \mathrm{~m}$, and thus the lidar data is accurately reflecting the inversion height in this instance.

A comparison between the NCAR ozone vs altitude profile and the lidar data is shown in Fig. 25. The ozone distribution reflects the ML height, although there appears to be significant ozone concentration even above the ML. Again, the agreement between the two instruments is good, given the variability in the surface defined by the ML height. Examples of the altitude profiles of other major air pollutants is shown in Appendix E. Some stable pollutants like $\mathrm{CO}$ do not appear to be very sensitive to the presence of a temperature inversion.

\section{NCAR Ascent of February 26, 1991}

Fig. 26 shows the NCAR aerosol data (solid line) obtained during the ascent portion of the flight on February 26 in the vicinity of the airport. Superimposed on the same plot is the range corrected lidar return signal (dotted line, scaled and shifted for comparison purposes) obtained at an elevation angle of $30^{\circ}$ during a 2-D scan taken at the UNAM site (approximately $20 \mathrm{~km}$ from the airport) at a slightly later time. There is good agreement in the altitude at which the particle density drops rapidly. The 2-D scan itself is shown in Fig. 27. Again, note the structure that is developing in the ML. The potential temperature data for this flight is shown in Fig. 28. The temperature inversion does not become strong until about $500 \mathrm{~m}$ of altitude which agrees with the ASAS probe and the lidar system data.

Fig. 29 is a comparison between the lidar data and the NCAR ozone information. In this case the distribution of ozone with altitude does not agree as well with the aerosol distribution (NCAR or lidar) as the previous example.

\section{Comparison of Lidar Data to Rawinsonde Results}


Instrumented free-ascending balloons (rawinsondes) were released at the Mexico City International Airport 6 or 7 times a day throughout the month of February. The instrument package monitors air temperature, pressure, potential temperature, relative humidity, wind speed and wind direction and radios the data back to the receiving station at the release point. Typical ascent rates are $5-10 \mathrm{~m} / \mathrm{s}$. Examples of some rawinsonde data compared to lidar data are presented in the material in this section. The comparisons will focus on the potential temperature (PT) measured by the balloon releases that occurred close in time to the NCAR flights. Additional examples of the rawinsonde data can be found in Appendix E. It must be kept in mind that the rawinsonde data is being taken at a location that is far removed ( $>10 \mathrm{~km}$ ) from the lidar sites. In addition, the rawinsonde balloon rises very quickly, thus effectively sampling the atmosphere in a narrow region of space and time. Time-sequences of PT profiles obtained throughout the days selected for analysis can be found in Appendix F.

\section{Rawinsonde of February 17}

On this date, the NCAR aircraft had a flight at about 10 am. Unfortunately, there was no electrical power available at this particular time at thermo-electric power plant site which prevented the lidar system from taking data. Thus, the lidar data obtained close in time to an earlier rawinsonde flight will be examined. Fig. 30 shows the PT vs altitude measured by the 8 am rawinsonde flight. Superimposed on the temperature data is the lidar range-corrected backscatter return signal observed at an elevation angle of $10^{\circ}$, scaled and shifted for comparison purposes. The PT profile increases with altitude indicating a ground based thermal inversion, most likely caused by radiation cooling of the earth's surface throughout the night. This atmospheric condition implies very stable air with little mixing or upward movement of ground-generated particles and pollutants. The 2-D vertical scan color plot obtained at this time is shown in Fig. 31 and clearly shows many aerosol layers or bands, indicating a highly stratified atmosphere. The $10^{\circ}$ lidar return signal shows at least two layers or particles at low elevations confirming the lack 
of upward mobility at this time. If the altitude of the lowest layer is taken as the mixing-layer height for particles being produced at this time, then the lidar estimate of the mixing-depth is on the order of $100 \mathrm{~m}$ above ground. Note that due to the restricted field-of-view at this site $\left(8^{\circ}\right.$ minimum elevation angle at this site), the lidar instrument cannot easily detect the presence of layers at altitudes less than about $75 \mathrm{~m}$. Fig. 32 shows the same potential temperature profile shown in Fig. 30, but superimposed with lidar data obtained at a higher elevation angle $\left(30^{\circ}\right.$, same 2-D vertical scan). Fig. 32 shows the effect that a sharp increase in PT has on the particle distribution at elevated altitudes. The elevated inversion occurring at $1800-1900 \mathrm{~m}$ also acts as a lid to prevent the upward dispersal of particles at higher elevations.

\section{Rawinsonde of February 22}

The rawinsonde data obtained at noon will be used for this day. Fig. 33 shows PT vs altitude along with $30^{\circ}$ elevation lidar data extracted from a 2-D elevation scan taken at about the same time (scaled and shifted). The PT profile indicates highly unstable (turbulent) atmosphere to an altitude of about $400 \mathrm{~m}$, becoming less so or neutral between 400 and $1000 \mathrm{~m}$, and finally changing to very stable conditions at altitudes greater than about 1000-1300 m. Taking the first increase in PT as the ML height, it occurs at about 1000-1100 m. The lidar 2-D elevation scan shown in Fig. 34 indicates that the ML surface is substantially convoluted at this time ranging in height from 1100 to $1500 \mathrm{~m}$, entirely consistent with the PT profile. Note the presence of localized aerosol features in the lidar 2-D scan. This points out the fact that although things are supposed to be well mixed within the ML, there can still be substantial structure present.

\section{Rawinsonde of February 26}

The 11 am rawinsonde sounding will be used for this day. Figs. 35 and 36 show PT vs altitude along with $10^{\circ}$ and $30^{\circ}$ elevation angle lidar data, respectively, extracted from a 2-D elevation angle scan taken at about 
the same time (Fig. 37). The PT profile indicates two strong temperature inversion regions : one occurring at an altitude of about $700 \mathrm{~m}$ (which is identified as the height of the ML) and a second inversion at an altitude of about $1900 \mathrm{~m}$. The raw lidar data reflects both of these features. The effect of the first inversion is most easily seen in the $10^{\circ}$ data (see Fig. 35), whereas the effect of the elevated inversion is readily apparent in the $30^{\circ}$ data.

\section{Conclusion}

In the selected examples, the lidar aerosol backscatter return data reflects the presence of temperature inversions in the atmosphere, both at low and elevated altitudes. A more detailed comparison between rawinsonde and lidar data focusing on atmospheric structure and turbulence information is in progress and will be available at a later time. 


\section{References}

1. "Lidar Observations of the Urban Aerosol" by E. E. Uthe, Bulletin American Meteorological Society 53, 358 (1972).

2. "Experimental Study of the Urban Aerosol Structure and its Relation to Urban Climate Modification" by E. E. Uthe and P. B. Russell, Bulletin American Meteorological Society 55, 115 (1974).

3. "A Comparison of Atmospheric Structure as Observed With Monostatic Acoustic Sounder and Lidar Techniques" by P. B. Russell, E. E. Uthe, and F. L. Ludwig, and N. A. Shaw, Journal of Geophysical Research 79, 5555 (1974).

4. "Lidar Observations of the Convective Boundary Layer" by K. E. Kunkel, E. W. Eloranta, and S. T. Shipley, Joumal of Applied Meteorology 16, 1306 (1977).

5. "A Comparison of Three Methods for Measuring Mixing-Layer Height" by R. C. Coulter, Journal of Applied Meteorology 18, 1495 (1979).

6. "Estimating the Depth of the Daytime Convective Boundary Layer" by J. C. Kaimal, N. L. Abshire, R. B. Chadwick, M. T. Decker, W. H. Hooke, R. A. Kropfli, W. D. Neff, F. Pasqualucci, and P. H. Hildebrand, Journal of Applied Meteorology 21, 1123 (1982).

7. "Convective Cell Structures Revealed by Mie Laser Radar Observations and Image Data Processing" by Y. Sasano, H. Shimizu, and N. Takeuchi, Applied Optics 21, 3166 (1982).

8. "Lidar Observations of Mixed Layer Dynamics: Tests of Parametrized Entrainment Models of Mixed Layer Growth Rate" by R. Boers, E. W. Eloranta, and R. L. Coulter, Journal of Climate and Applied Meteorology 23, 247 (1984). 
9. "Lidar Measurements of Wind in the Planetary Boundary Layer: the Method, Accuracy and Results from Joint Measurements with Radiosonde and Kytoon" by W. P. Hooper and E. W. Eloranta, Journal of Climate and Applied Meteorology 25, 990 (1985).

10. "Three-Dimensional Numerical Study of the Height and Mean Structure of a Heated Planetary Boundary Layer" by J. W. Deardorff, Boundary-Layer Meteorology 7, 81 (1974).

11. "Lidar Measurement of Particles and Gases" by R.T.H. Collis and P. B. Russell, in "Laser Monitoring of the Atmosphere", Ed. E. D. Hinkley, Topics in Applied Physics, Vol. 14, Springer-Verlag, 1976.

\section{Acknowledgements:}

The lidar operation was conducted with the assistance of IMP personnel (primarily) and other local organizations. Special thanks go to Drs. Javier Tejeda and Francisco Guzman, and Victor Aquino from the Mexican Petroleum Institute for their assistance. The photographs shown in Figs. 2 and 3 were taken by Dr. J. Tejeda.

The NCAR data was processed with the assistance of Mary Alice Garcia and the rawinsonde data was taken by Servicio Meteorologico Nacional personnel operating out of the Mexico City International Airport. Dyan Seville-Jones assisted with the lidar plot generation process. 


\section{Figures}




\section{Figure Captions}

1. Schematic of basic elastic lidar technique as applied to aerosol scattering.

2. Photograph of the elastic lidar truck deployed in Mexico City. The movable telescope/detector assembly sit on top of the roof. A Nd:YAG laser system operating at $1.06 \mu \mathrm{m}, 10 \mathrm{~Hz}$ sits inside. The laser beam exits the truck through the roof and is made collinear with the optical axis of the telescope. The entire assembly moves under microcomputer control to execute a variety of scan patterns. Photograph courtesy of Dr. Javier Tejeda, Instituto Mexicano del Petroleo.

3. Photograph exemplifying a vertical scan over Mexico City. The laser wavelength was changed to $0.532 \mu \mathrm{m}$ ( $2^{\text {nd }}$ harmonic of the $1.06 \mu \mathrm{m}$ fundamental), so that the laser beam path could be observed and photographed. The image is a multiple exposure. After taking data at the initial angular setting, the laser/telescope assembly moves upward in a series of elevation-angle steps, pausing at each location to take data. This scan pattern generates a two dimensional view of the vertical structure of atmospheric aerosols along a particular azimuth direction. Photograph courtesy of Dr. Javier Tejeda, Instituto Mexicano del Petroleo.

4. Map of the Mexico City basin area showing the three different sites selected for lidar measuremerits : the thermo-electric power plant in the northeast area, the CINVESTAV site near the National Politecnic Institute just north of city center, and the Botanical Gardens site at the National Autonomcus University of Mexico (UNAM) in the southwest corner of the basin.

5. Expanded scale city map the of thermo-electric power plant lidar site.

6. Expanded scale city map of the CINVESTAV lidar site looking south, towards the tethersonde location.

7. Expanded scale city map of the CINVESTAV lidar site looking north, towards an industrial area of the city.

8. Expanded scale city map of the botanical gardens site at UNAM, looking north. 
9. Example of an elastic aerosol lidar return signal taken at an elevation angle of $30^{\circ}$, plotted as a function of altitude. This trace is one of many that make up a complete scan. The data is the average of 50 laser shots and was subjected to a 10 point smoothing routine. The data is presented in a range-corrected format. No attempt was made to remove the effects of atmospheric extinction. The rising part of the signal (up to about $400 \mathrm{~m}$ in this example) does not indicate a low concentration of aerosols but rather reflects an instrumental characteristic related to how the laser beam enters the field-of-view of the telescope/detector assembly. This particular example shows that there are two strong gradients in aerosol concentration: one at an altitude of $450 \mathrm{~m}$, and a second transition at about $1.9 \mathrm{~km}$.

10. Example of a vertical scan taken at the thermo-electric power plan. site made up of an angular sequence of 96 traces. The color bar roughly indicates the relative concentration of aerosol particles (in arbitrary units). The scan shows the strong atmospheric stratification that is occurring at this particular time. Many layers or bands of aerosol particles are visible.

11. Example of a vertical scan taken at about 7:21 am at the CRrVESTAV site that shows the height of the mixing layer as being approximately 225 m

12. Example of a vertical scan taken at about $10: 47$ am at the CINVESTA.V site illustrating how the mixing layer has become extremeiy convoluted, reaching altitudes as high as $900-1000 \mathrm{~m}$.

13. Example of a horizontal scan taken at the CINVESTAV site over an industrial area of the city. Overlaying this scan on a city map showed that the bright plumes observed here (shown in red) are connected with activities at a glass manufaciuring plant and a steel making operation.

14. Example of a vertical scan taken at the UNAM botanical gardens site. Huge plumes are seen rising from the city at various locations. At this time of day, aerosols released into the atmosphere can be lofted up towards the top of the mix-layer which is at about $2.5 \mathrm{~km}$. Note the structure in the elevated boundary layer compared to the relatively flat case in Fig. 10. Clean cool air from above can be seen mixing with the polluted air below. 
The aerosol patterns give the impression that wind circulation is occurring as part of the entrainment process.

15. Example of a vertical scan taken at 11:40 am at the UNAM site showing the convoluted mixing layer produced by the entrainment process, as well as the visual estimate of the average mixing layer height.

16. Example of a time sequence of vertical lidar soundings obtained at the CINVESTAV site looking directly over the tethersonde location. To generate this plot, range-corrected data from a single azimuth $\left(90^{\circ}\right)$ and elevation $\left(50^{\circ}\right)$ angle was extracted from a temporal sequence of 2-D vertical scans and placed into a matrix with time as the horizontal axis, altitude as the vertical axis, and aerosol return signal amplitude indicated via a color bar as shown. The matrix data was subjected to a nearest neighbor smoothing routine. The height of the mixing layer (ML) stays within the first few hundred meters until about 7 am. As the rising sun starts to warm the surface and convective cells start to move upwards, the height of the ML starts to increase, slowly at first. By 12 noon the ML has reached altitudes higher than $1 \mathrm{~km}$.

17. Example of a time sequence of vertical lidar soundings obtained at the UNAM site. To generate this plot, range-corrected data from a single azimuth and elevation angle was extracted from a temporal sequence of 2$D$ vertical scans and placed into a matrix with time as the horizontal axis, altitude as the vertical axis, and aerosol return signal amplitude indicated via a color bar as shown. The matrix data was subjected to a nearest neighbor smoothing routine. Although this example follows the mixing layer height pattern discussed in the Fig. 16, it differs in that there was a large concentration of particles aloft during the early morning hours which appears to have disappeared fairly quickly by sun-up.

18. Example of a range corrected lidar return signal for $0^{\circ}$ elevation extracted from a vertical scan taken on February 26 at approximately 11:52 am at the UNAM site. 
19. Example of a segment of range corrected lidar return signal obtained at $0^{\circ}$ elevation extracted from a vertical scan taken on February 26 at approximately 11:52 am at the UNAM site. The solid line represents a least-squares-fit to the data and yields an extinction coefficient of approximately $0.27 \mathrm{~km}^{-1}$ at $1.06 \mu \mathrm{m}$.

20. Temporal variation of the atmospheric extinction coefficient at 1.06 mm near the UNAM lidar site on February 26, 1991, at an altitude of 80$100 \mathrm{~m}$ above ground, in a direction looking primarily towards the city ( $\mathrm{Az}$ $=40^{\circ}$ true north). The increase in extinction at about $7 \mathrm{am}$ and again at about $6 \mathrm{pm}$ may be correlated to the morning and evening traffic rush hours.

21. Temporal variation of the atmospheric extinction coefficient at 1.06 $\mathrm{mm}$ near the UNAM lidar site during the period of February 26-28, at an altitude of $80-100 \mathrm{~m}$ above ground, in a direction looking primarily towards the city $\left(\mathrm{Az}=40^{\circ}\right.$ true north $)$.

22. Comparison between the NCAR aerosol data (solid line) obtained during the ascent portion of the flight on the morning of February 22 (10:13-10:21 am) in the vicinity of the airport and the range corrected lidar return signal (dotted line, arbitrarily scaled and shifted for comparison purposes) obtained at an elevation angle of $30^{\circ}$ during a 2-D scan taken at the CINVESTAV site (approximately $13 \mathrm{~km}$ from the airport) at a slightly earlier time (10:06 am).

23. Two-D vertical lidar scan taken at the CINVESTAV site close in time to the time of the vertical ascent of the NCAR instrumented aircraft on February 22, 1991.

24. Potential temperature vs altitude measured by the NCAR aircraft during the ascent of February 22, 1991, 10:13-10:21 am.

25. Comparison between the NCAR vertical distribution of ozone concentration (solid line) obtained during the ascent portion of the flight on the morning of February $22(10: 13-10: 21 \mathrm{am})$ in the vicinity of the airport and the lidar aerosol return signal (dotted line, arbitrarily scaled and shifted for comparison purposes) obtained at an elevation angle of $30^{\circ}$ 
during a 2-D scan taken at the CINVESTAV site (approximately $13 \mathrm{~km}$ from the airport) at a slightly earlier time (10:06 am).

26. Comparison between the NCAR aerosol data (solid line) obtained during the ascent portion of the flight on the morning of February 26 $(10: 20-10: 31 \mathrm{am})$ in the vicinity of the airport and the range corrected lidar return signal (dotted line, arbitrarily scaled and shifted for comparison purposes) obtained at an elevation angle of $10^{\circ}$ during a 2-D scan taken at the UNAM site (10:32 am, approximately $24 \mathrm{~km}$ from the airport).

27. Two-D vertical lidar scan taken at the UNAM site close in time to the time of the vertical ascent of the NCAR instrumented aircraft on February $26,1991$.

28. Potential temperature vs altitude measured by the NCAR aircraft during the ascent of February 26, 1991, 10:20-10:31 am.

29. Comparison between the NCAR vertical distribution of ozone concentration (solid line) obtained during the ascent portion of the flight on the morning of February 26 (10:20-10:31 am) in the vicinity of the airport and the lidar aerosol return signal (dotted line, arbitrarily scaled and shifted for comparison purposes) obtained at an elevation angle of $10^{\circ}$ during a 2-D scan taken at the UNAM site (approximately $24 \mathrm{~km}$ from the airport, 10:32 am).

30. Comparison between the vertical profile of potential temperature measured by the airport rawinsonde (solid line) on the 8 am launch of February 17, 1991, and the lidar aerosol return signal (dotted line, arbitrarily scaled and shifted for comparison purposes) obtained at an elevation angle of $10^{\circ}$ during a $2-\mathrm{D}$ scan taken at the thermo-electric power plant site (approximately $29 \mathrm{~km}$ from the airport, 7:55 am).

31. Two-D vertical lidar scan taken at the thermo-electric power plant site close in time to the time of the February 17, 1991, 8 am launch of the rawinsonde from the Mexico City international airport.

32. Comparison between the vertical profile of potential temperature measured by the airport rawinsonde (solid line) on the 8 am launch of February 17, 1991, and the lidar aerosol return signal (dotted line, arbitrarily scaled and shifted for comparison purposes) obtained at an 
clevation angle of $30^{\circ}$ during a 2-D scan taken at the thermo-electric power plant site (approximately $29 \mathrm{~km}$ from the airport, 7:55 am).

33. Comparison between the vertical profile of potential temperature measured by the airport rawinsonde (solid line) on the $12 \mathrm{pm}$ launch of February 22, 1991, and the lidar aerosol return signal (dotted line, arbitrarily scaled and shifted for comparison purposes) obtained at an elevation angle of $10^{\circ}$ during a 2-D scan taken at the CINVESTAV site (approximately $13 \mathrm{~km}$ from the airport, $12 \mathrm{pm}$ ).

34. Two-D vertical lidar scan taken at the CINVESTAV site close in time to the time of the February 22, 1991, $12 \mathrm{pm}$ launch of the rawinsonde from the Mexico City international airport.

35. Comparison between the vertical profile of potential temperature measured by the airport rawinsonde (solid line) on the 11 am launch of February 26, 1991, and the lidar aerosol return signal (dotted line, arbitrarily scaled and shifted for comparison purposes) obtained at an elevation angle of $10^{\circ}$ during a 2-D scan taken at the UNAM site (approximately $24 \mathrm{~km}$ from the airport, 10:57 am).

36. Comparison between the vertical profile of potential temperature measured by the airport rawinsonde (solid line) on the 11 am launch of February 26, 1991, and the lidar aerosol return signal (dotted line, arbitrarily scaled and shifted for comparison purposes) obtained at an elevation angle of $30^{\circ}$ during a 2-D scan taken at the UNAM site (approximately $24 \mathrm{~km}$ from the airport, 10:57 am).

37. Two-D vertical lidar scan taken at the UNAM site close in time to the time of the February 26, 1991, 11 am launch of the rawinsonde from the Mexico City international airport. 


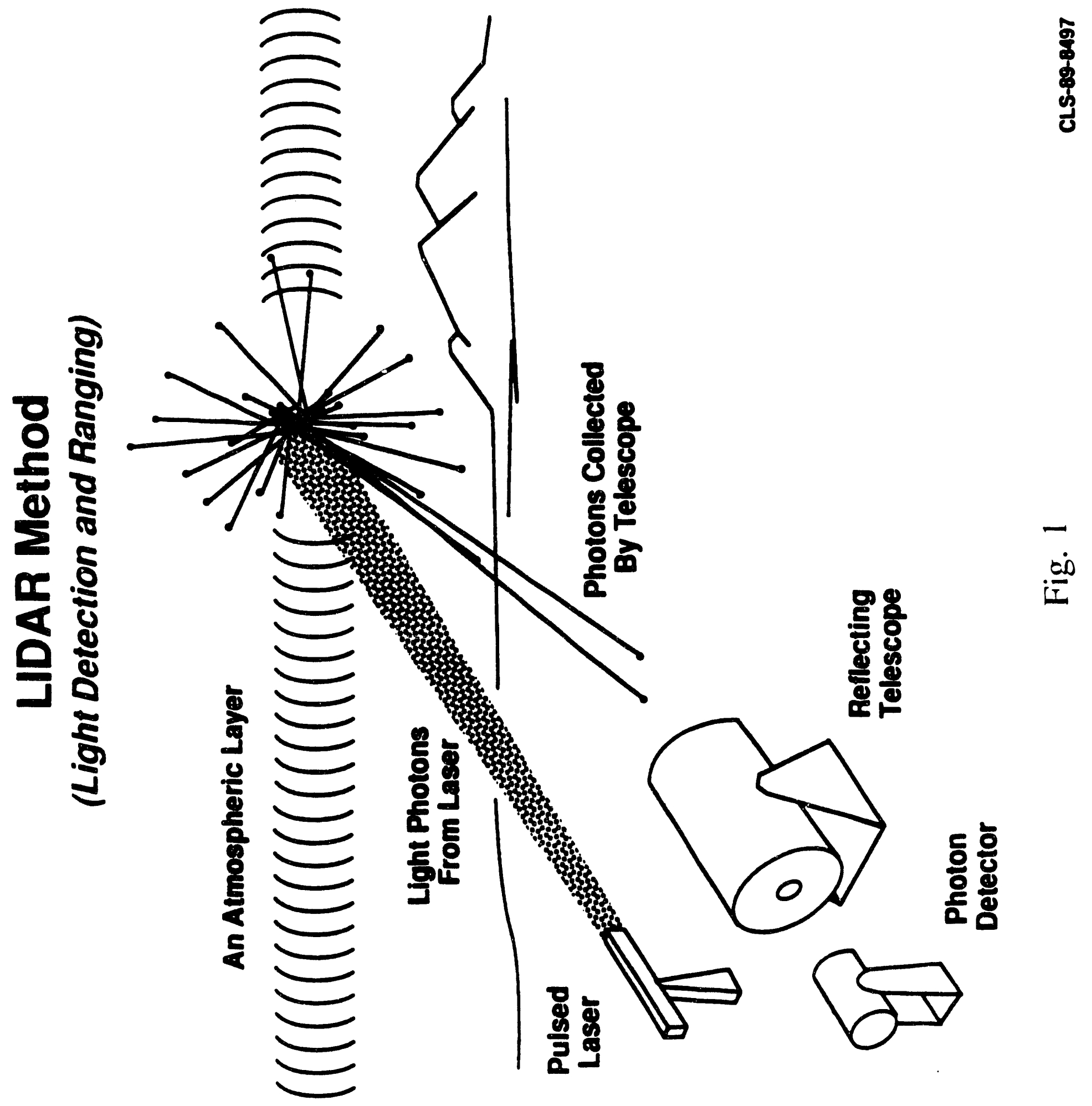




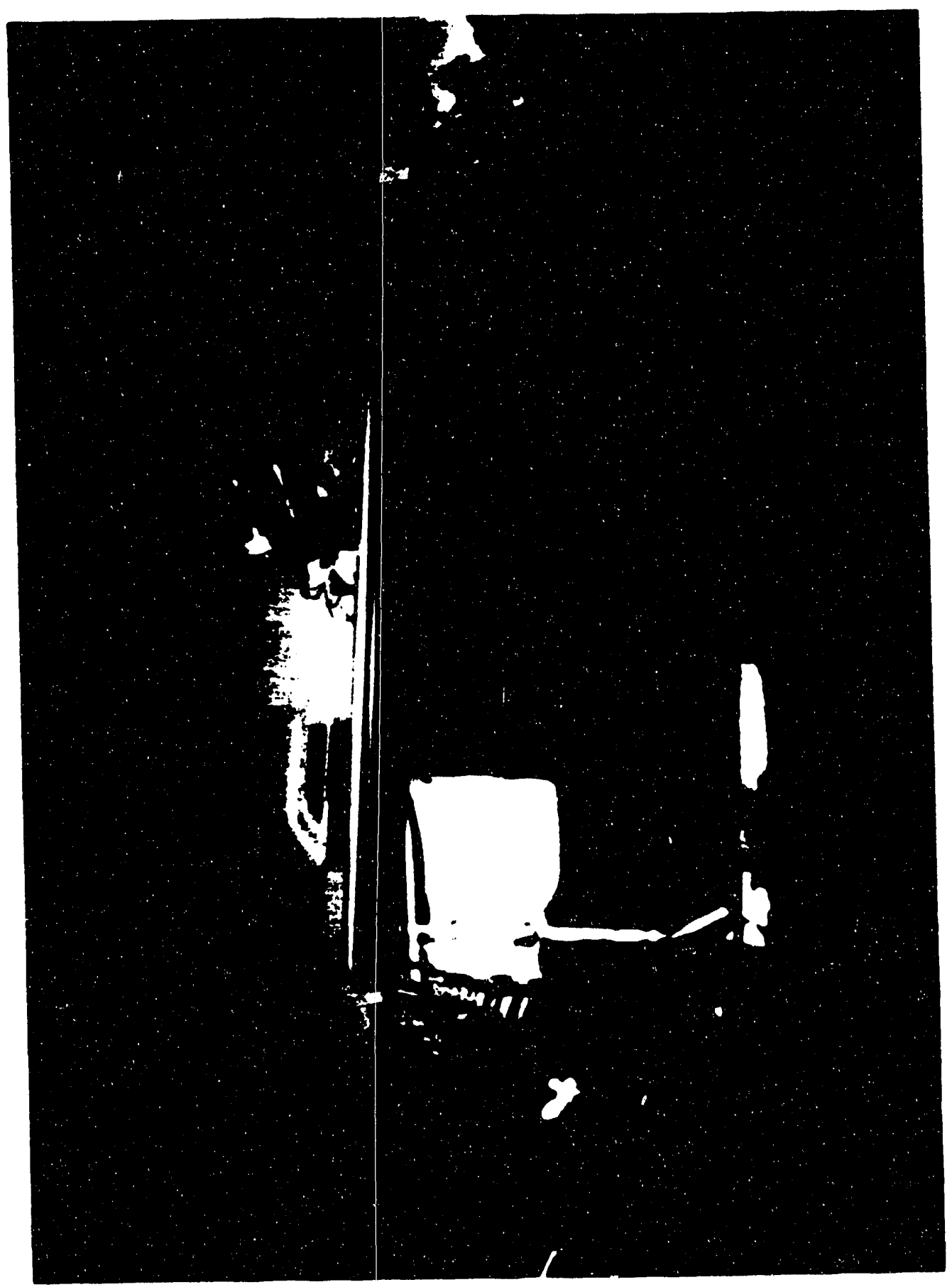

$N$
$\dot{0}$ 


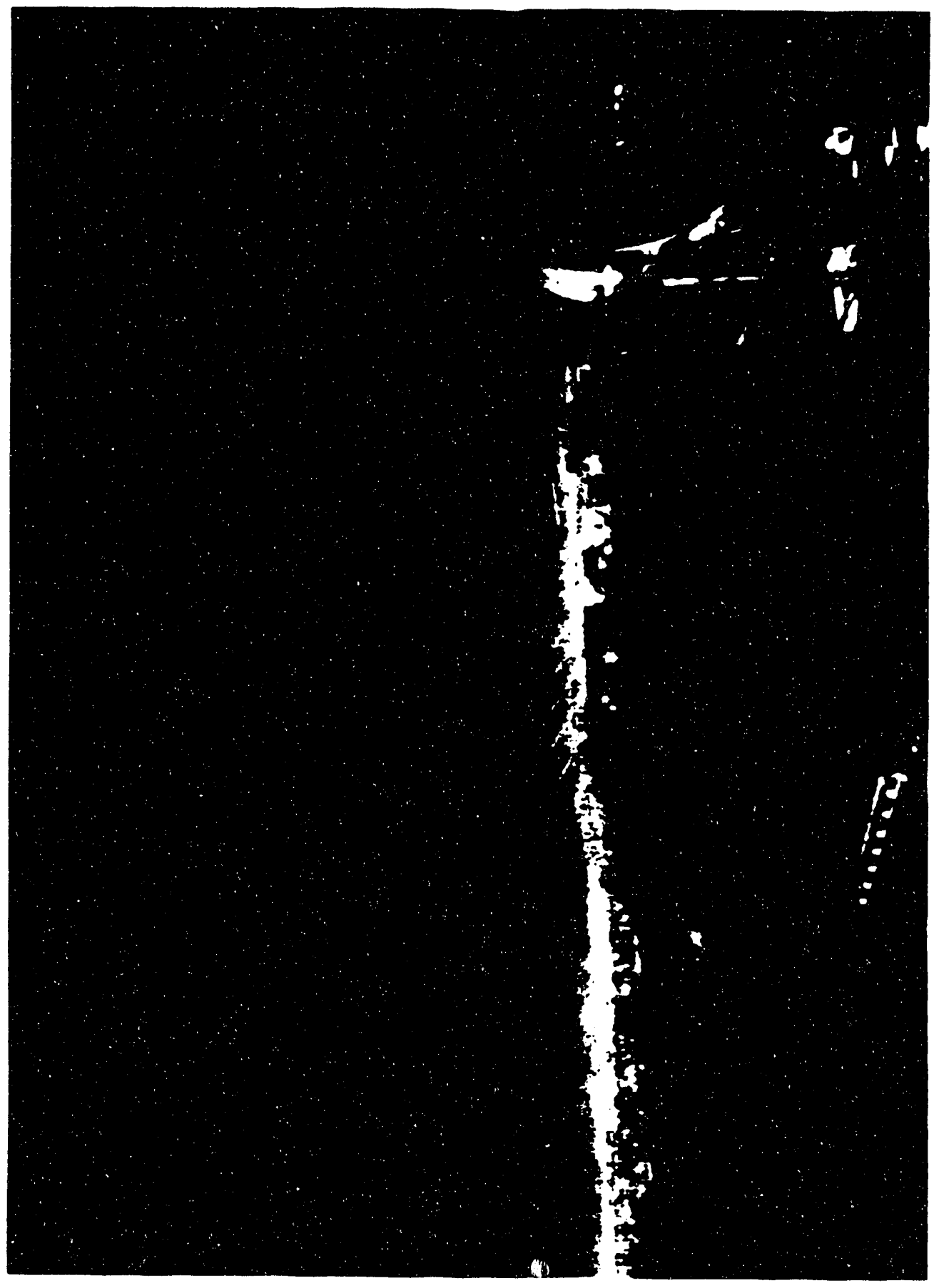

$m$ 


\section{Mexico City}

\section{Los Alamos Lidar Site Locations}

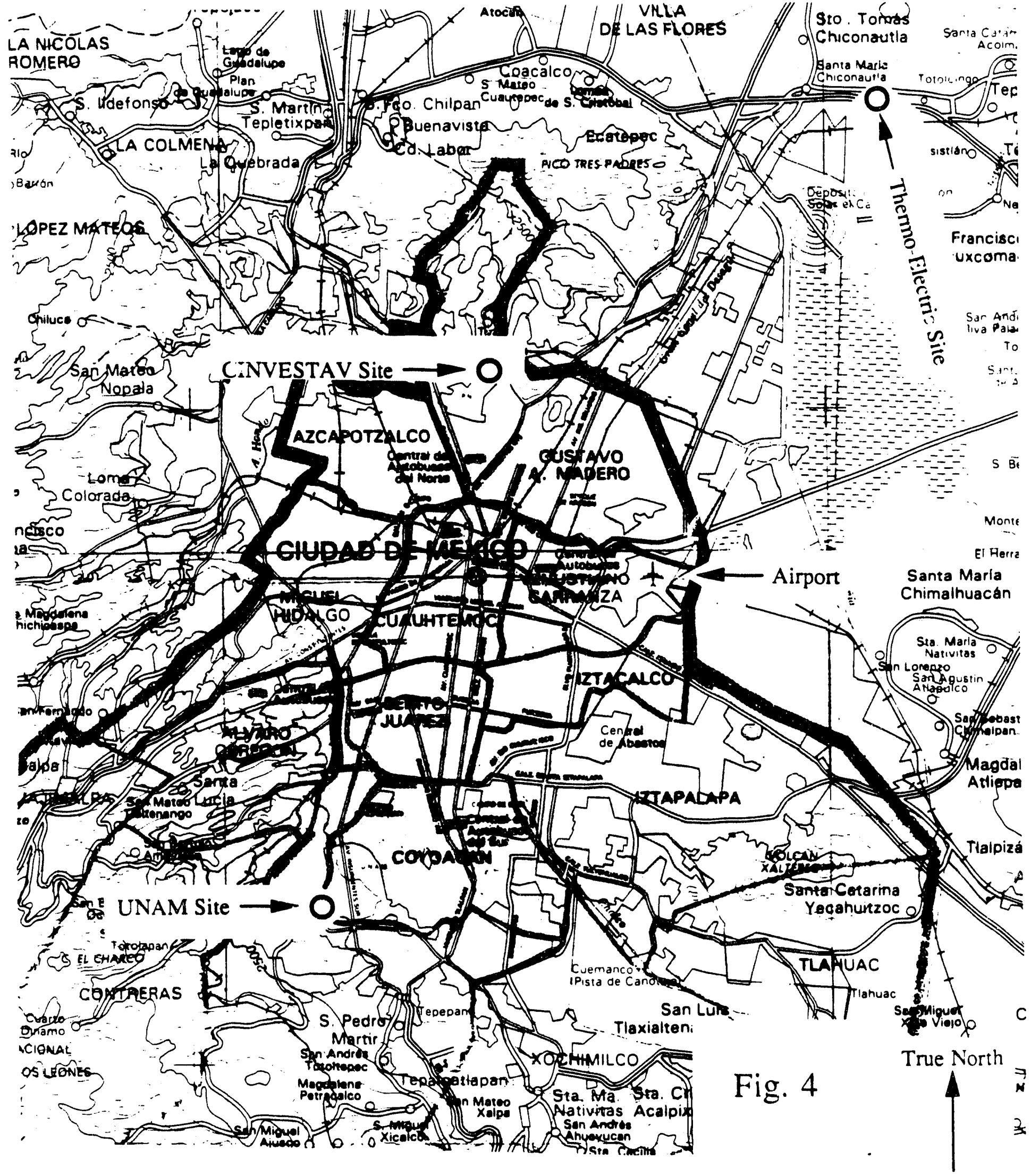

Scale $(\mathrm{km})$

\begin{tabular}{lllll}
\hline & 1 & 1 & & 1 \\
\hline
\end{tabular}




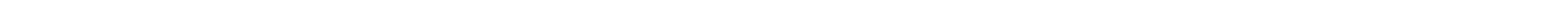




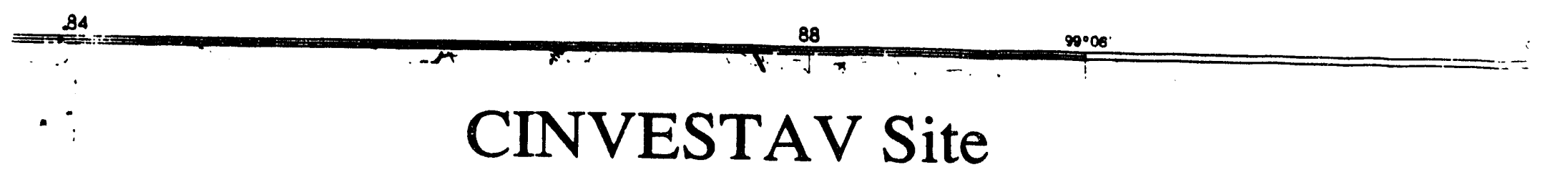

(National Polytechnic Institute)

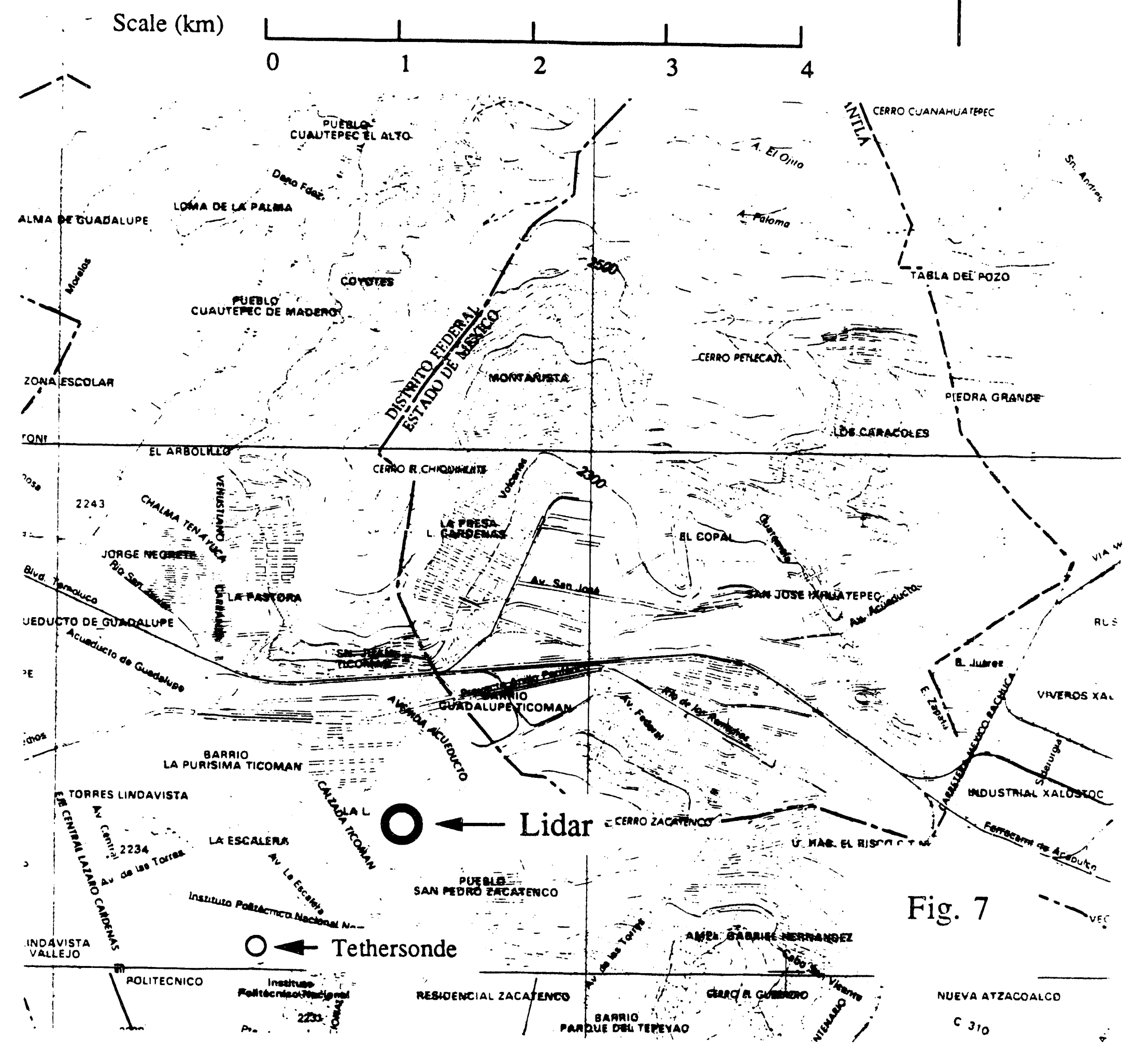



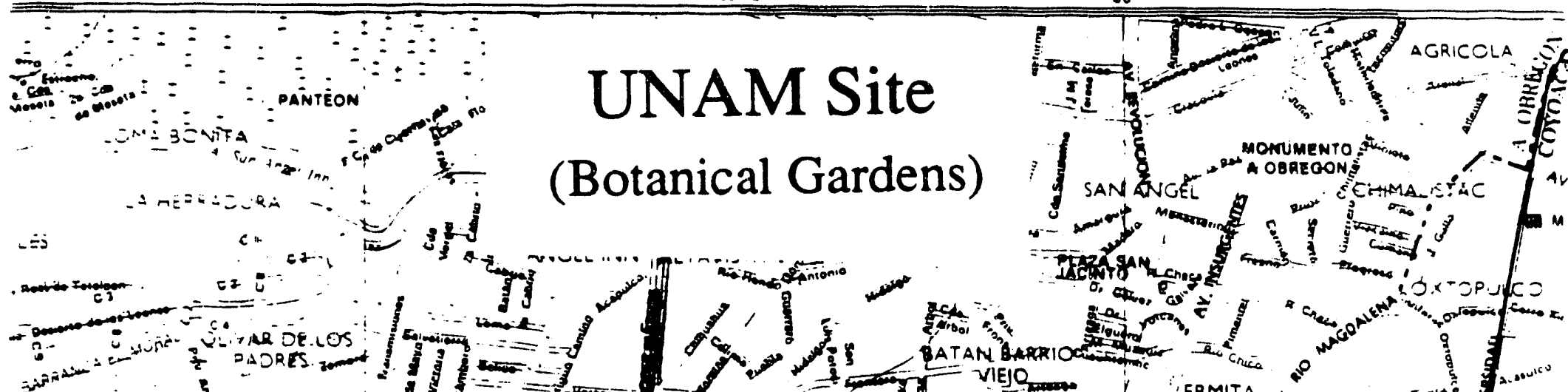

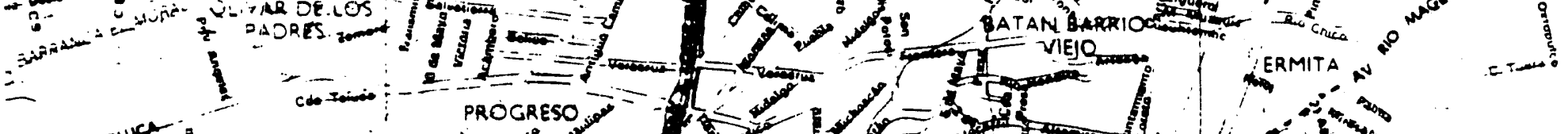
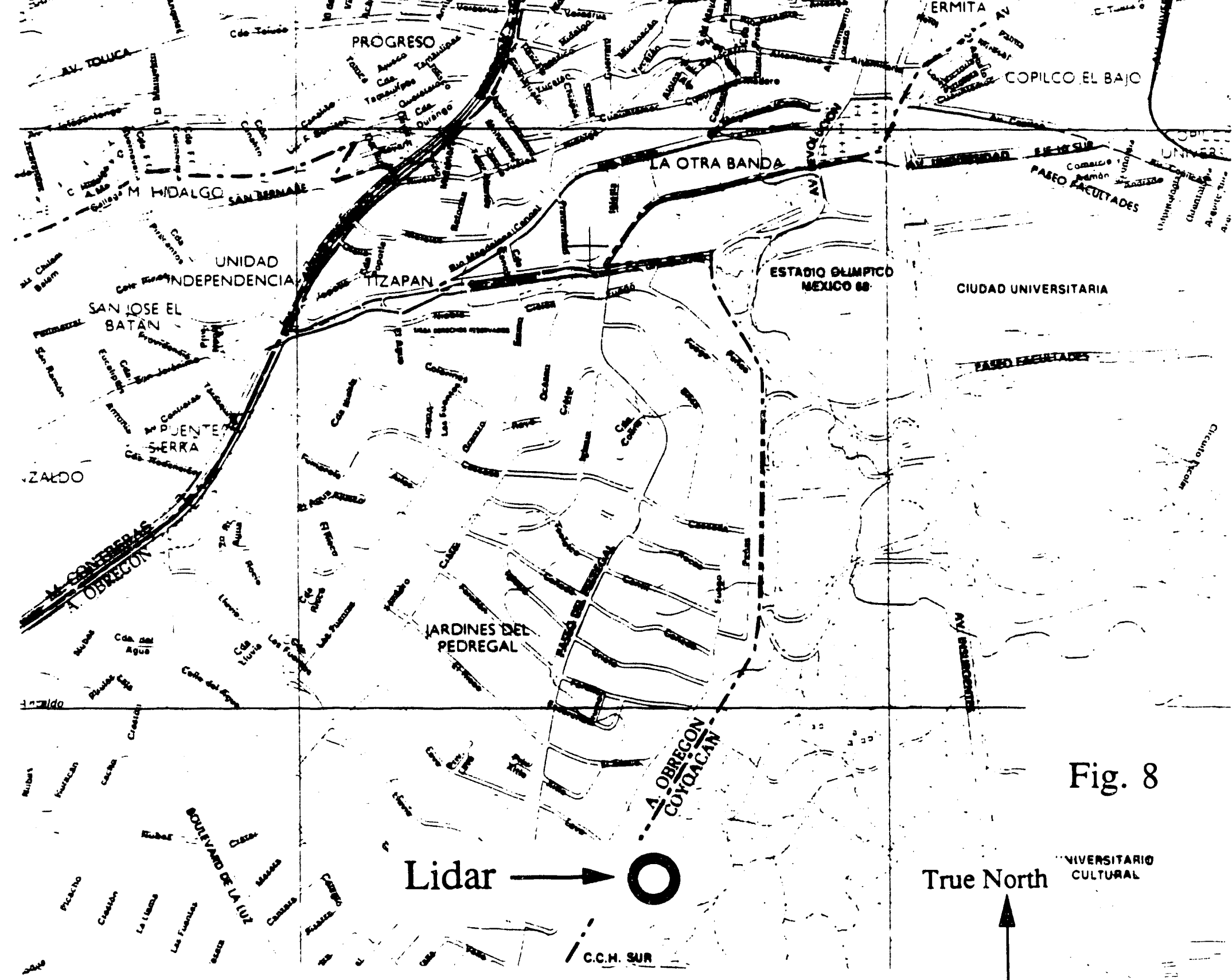

Scale $(\mathrm{km})$

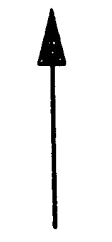

Fig. 8 


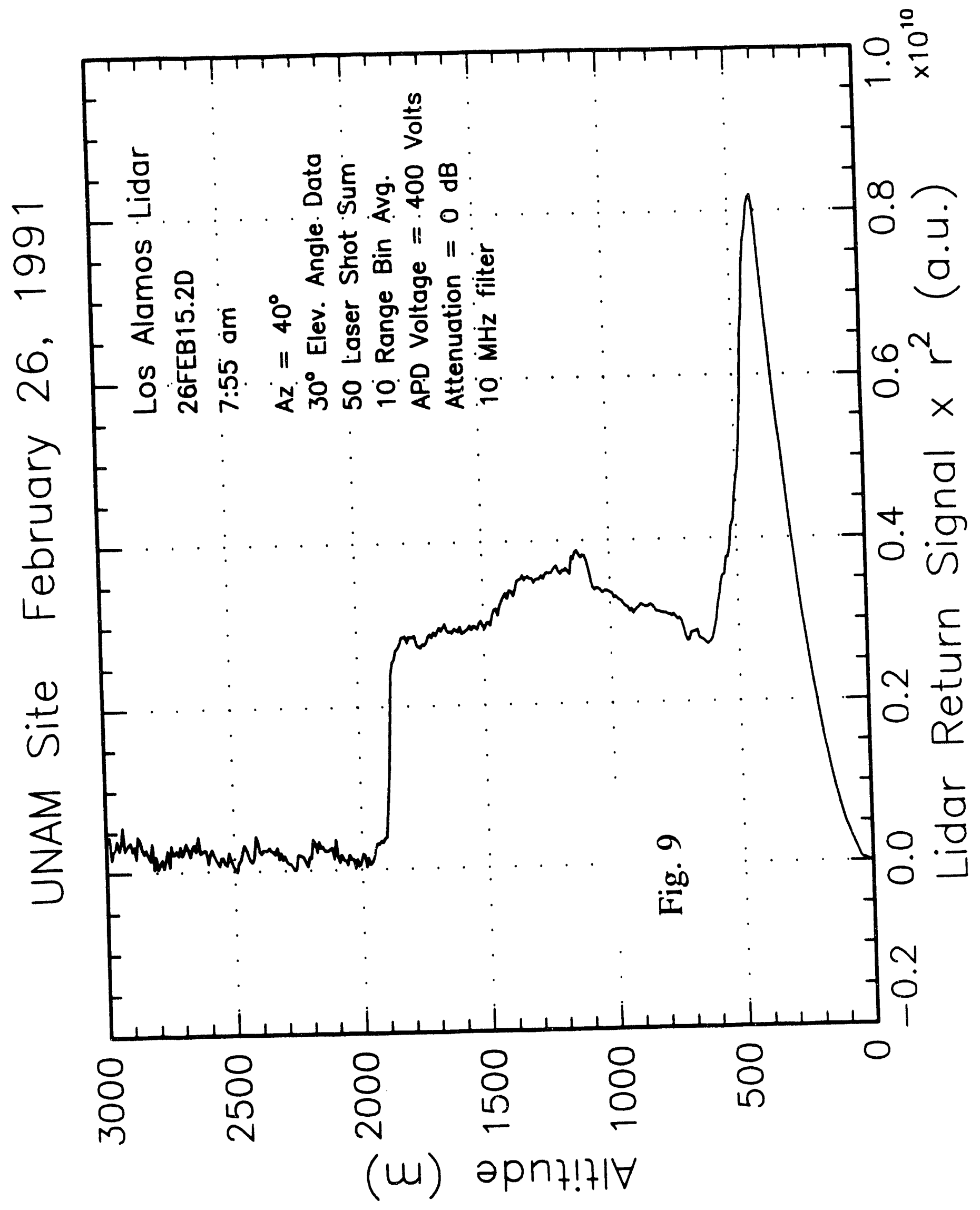




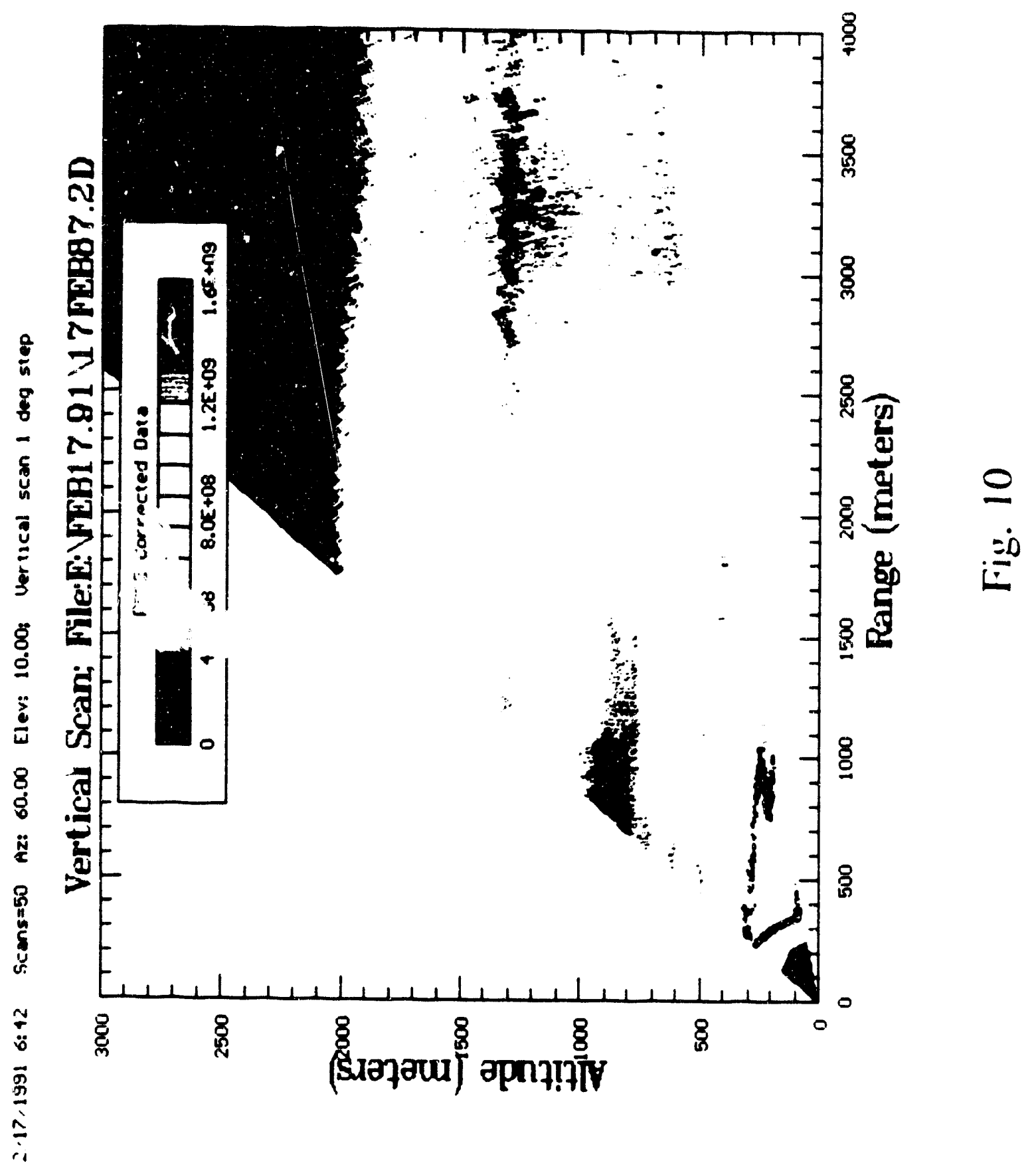




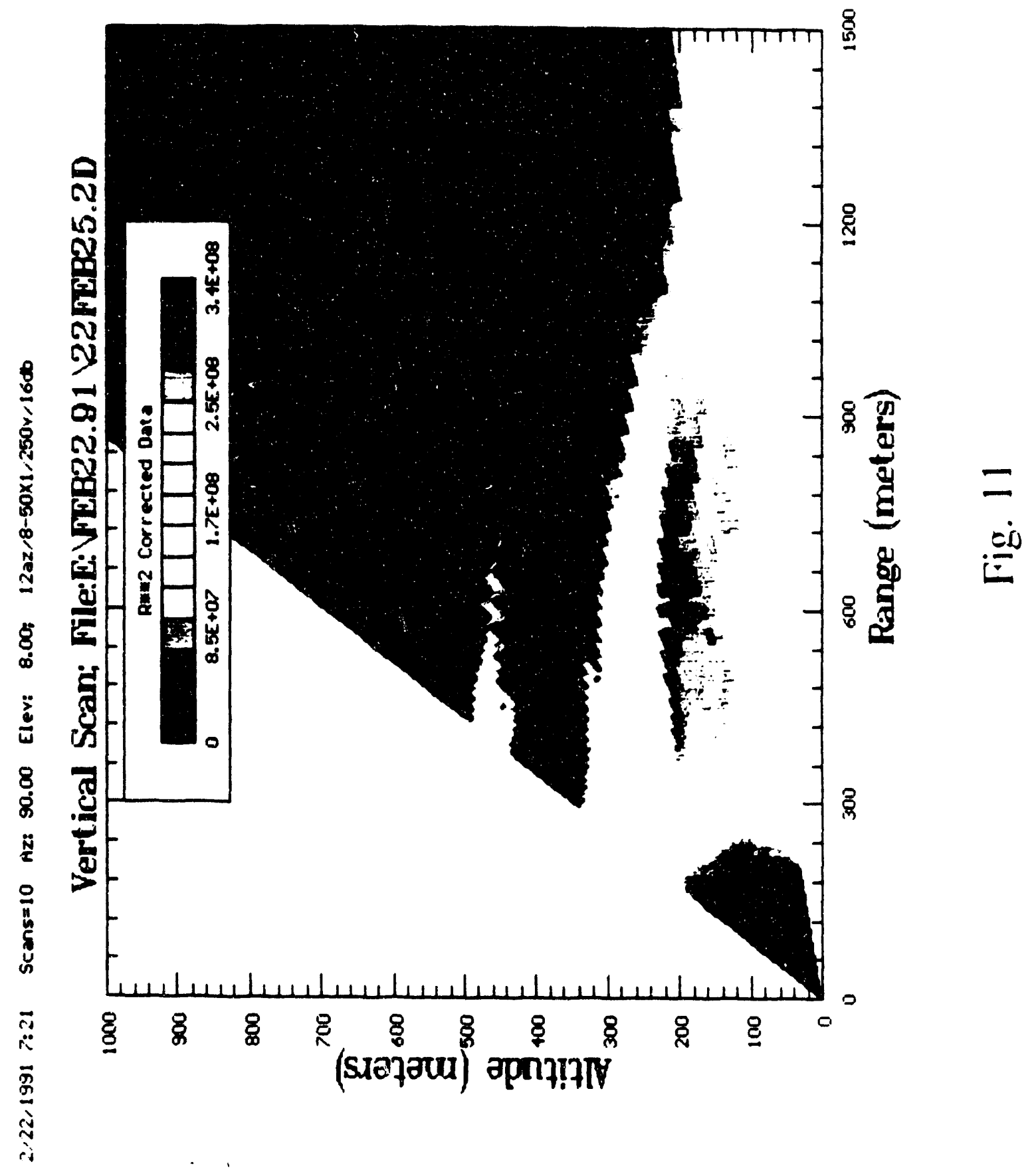




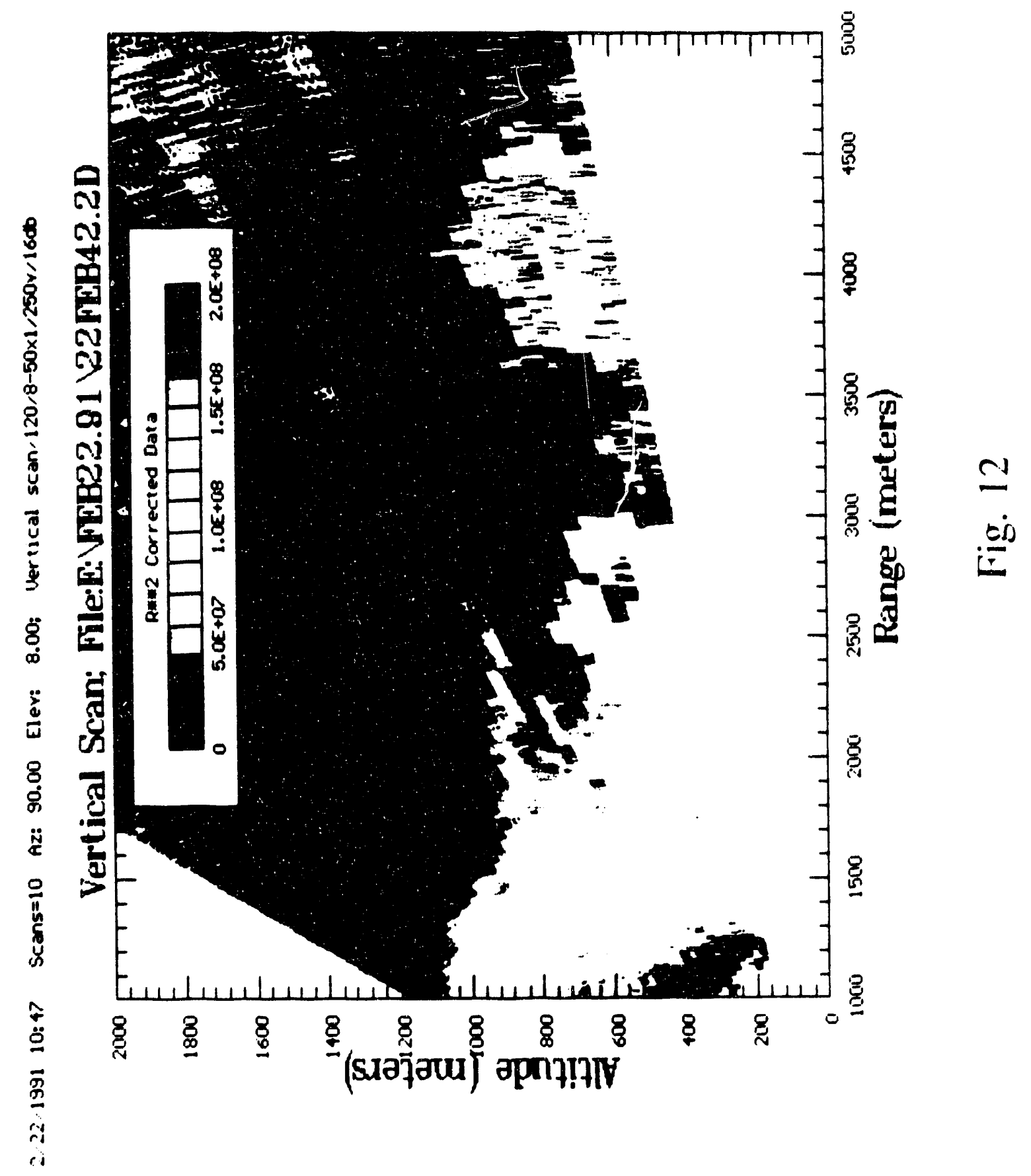




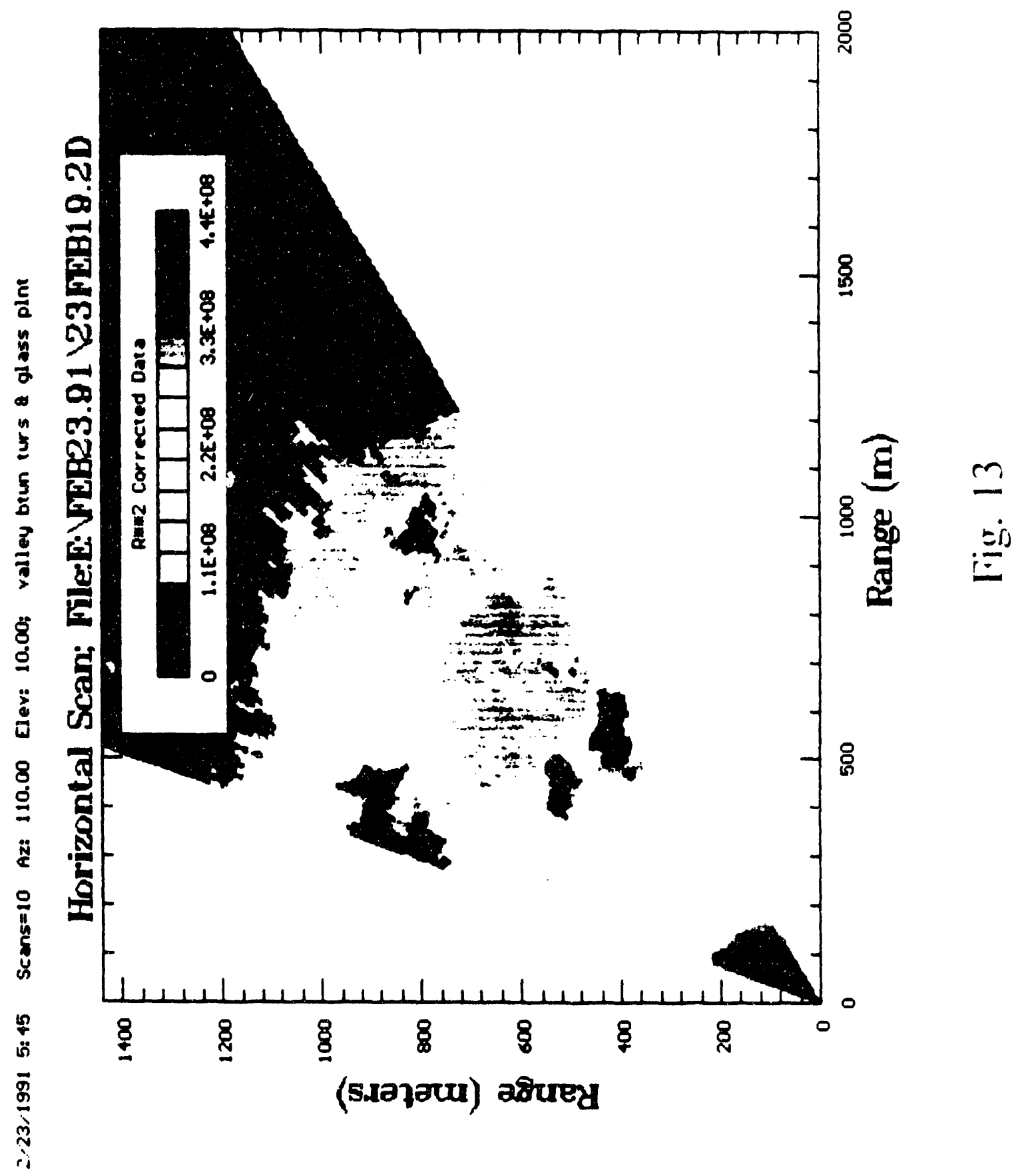




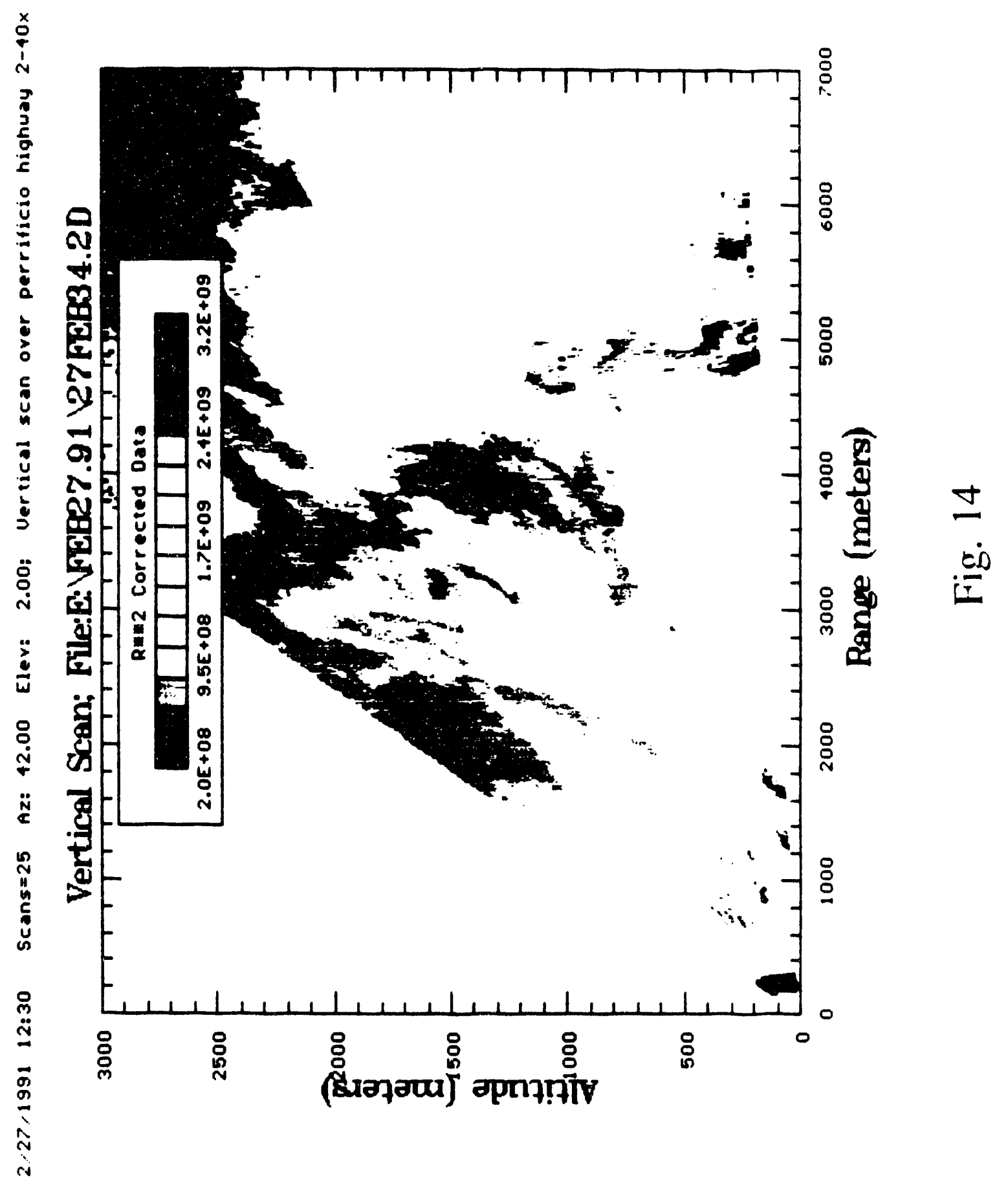




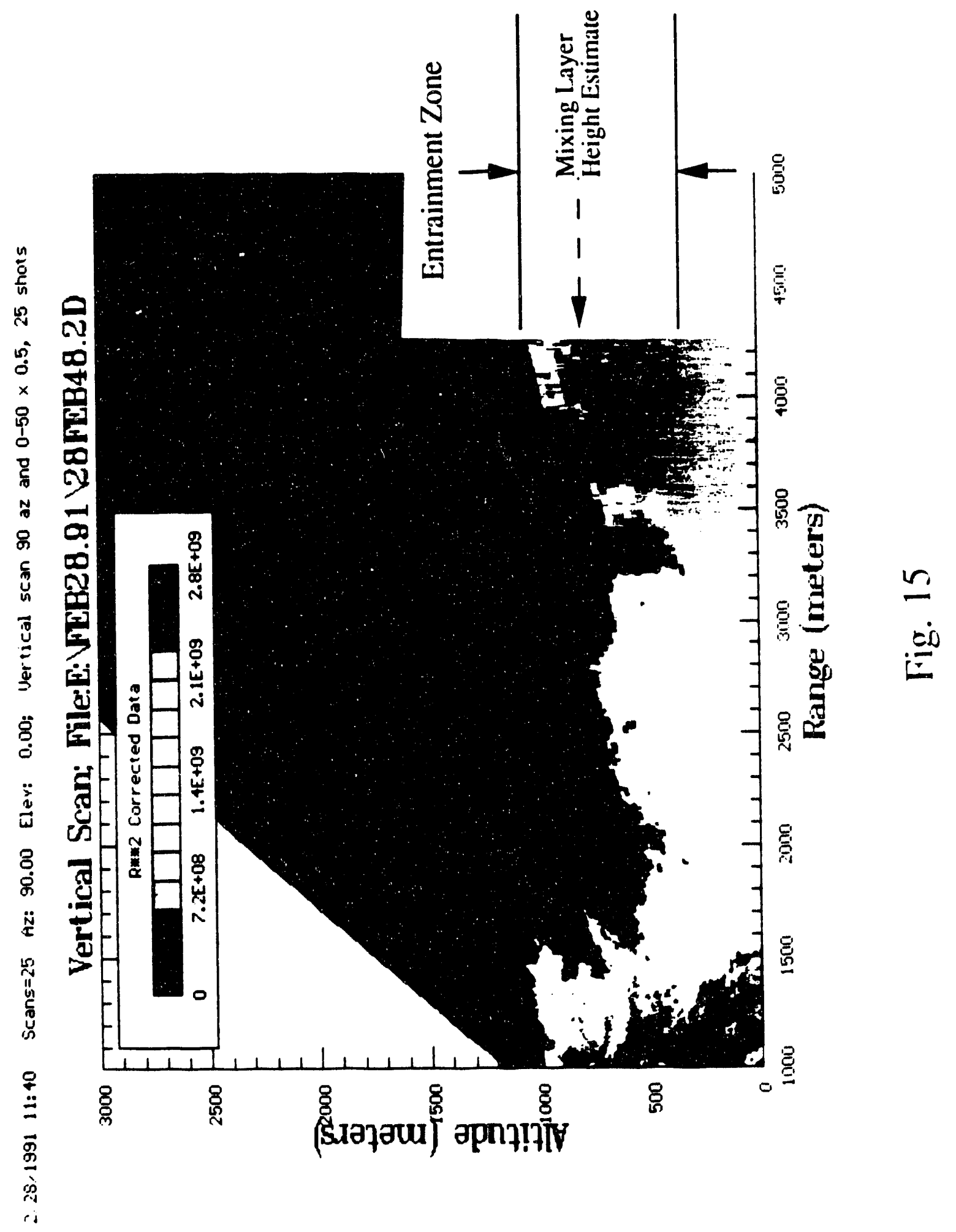



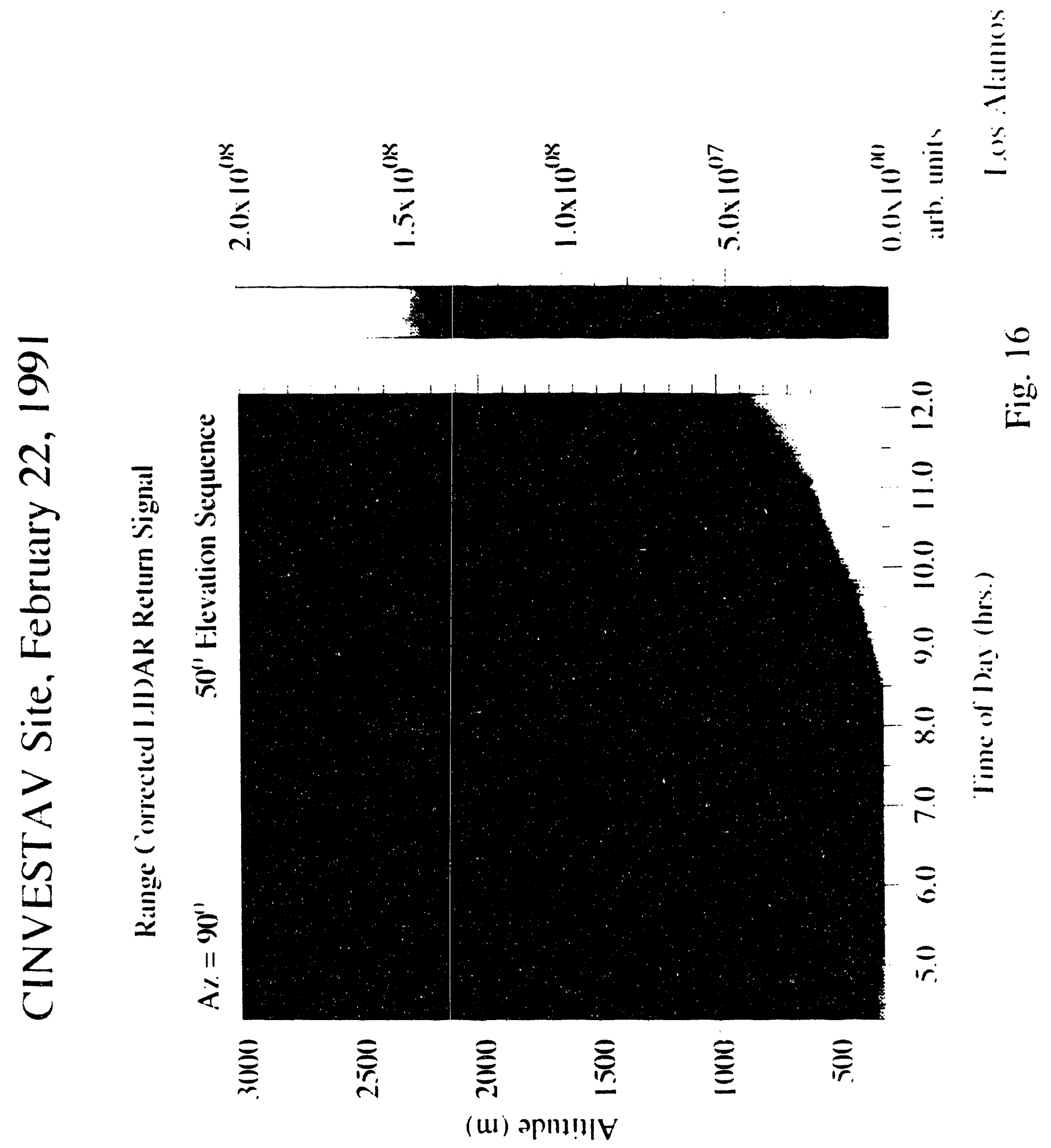

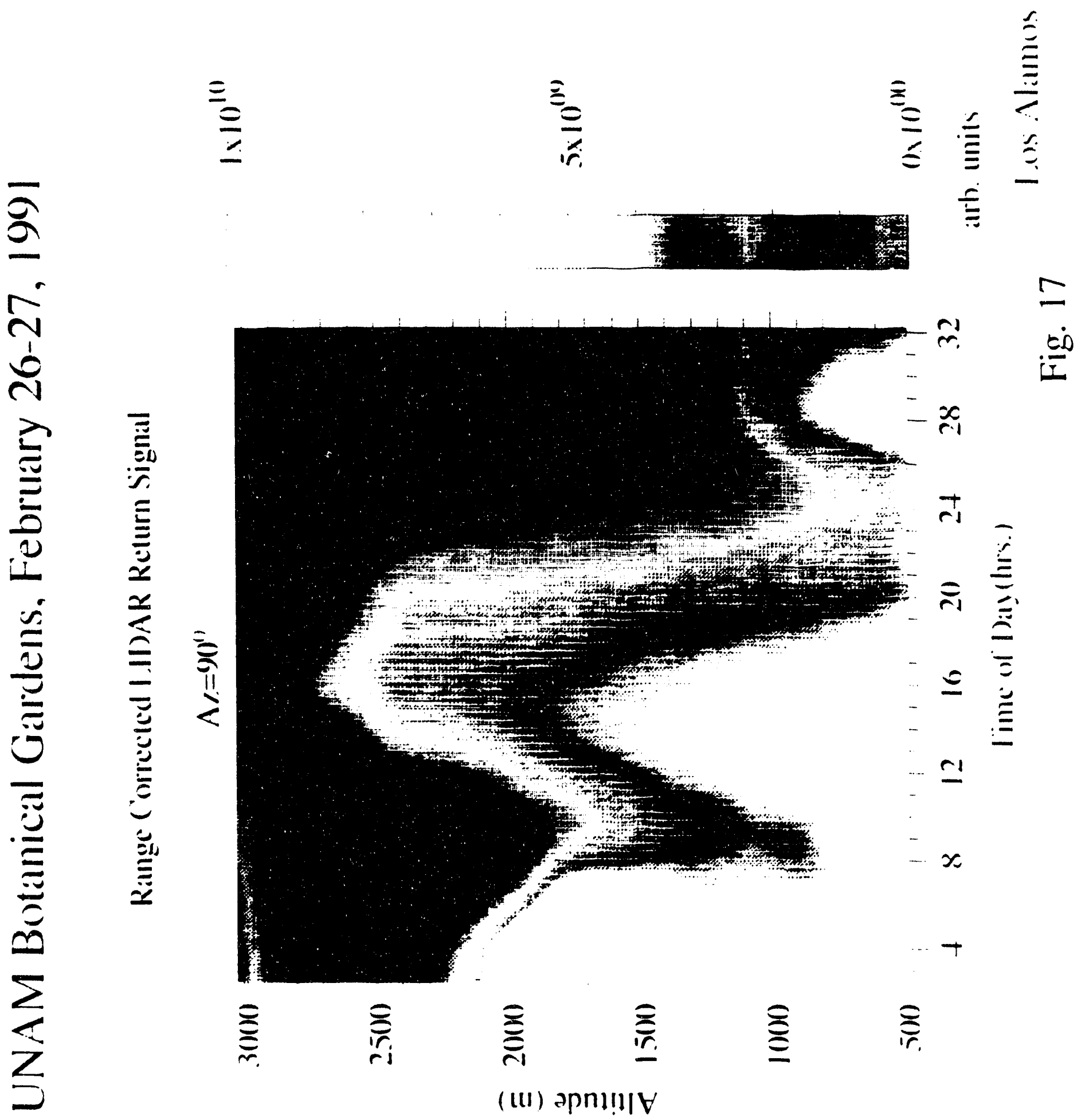


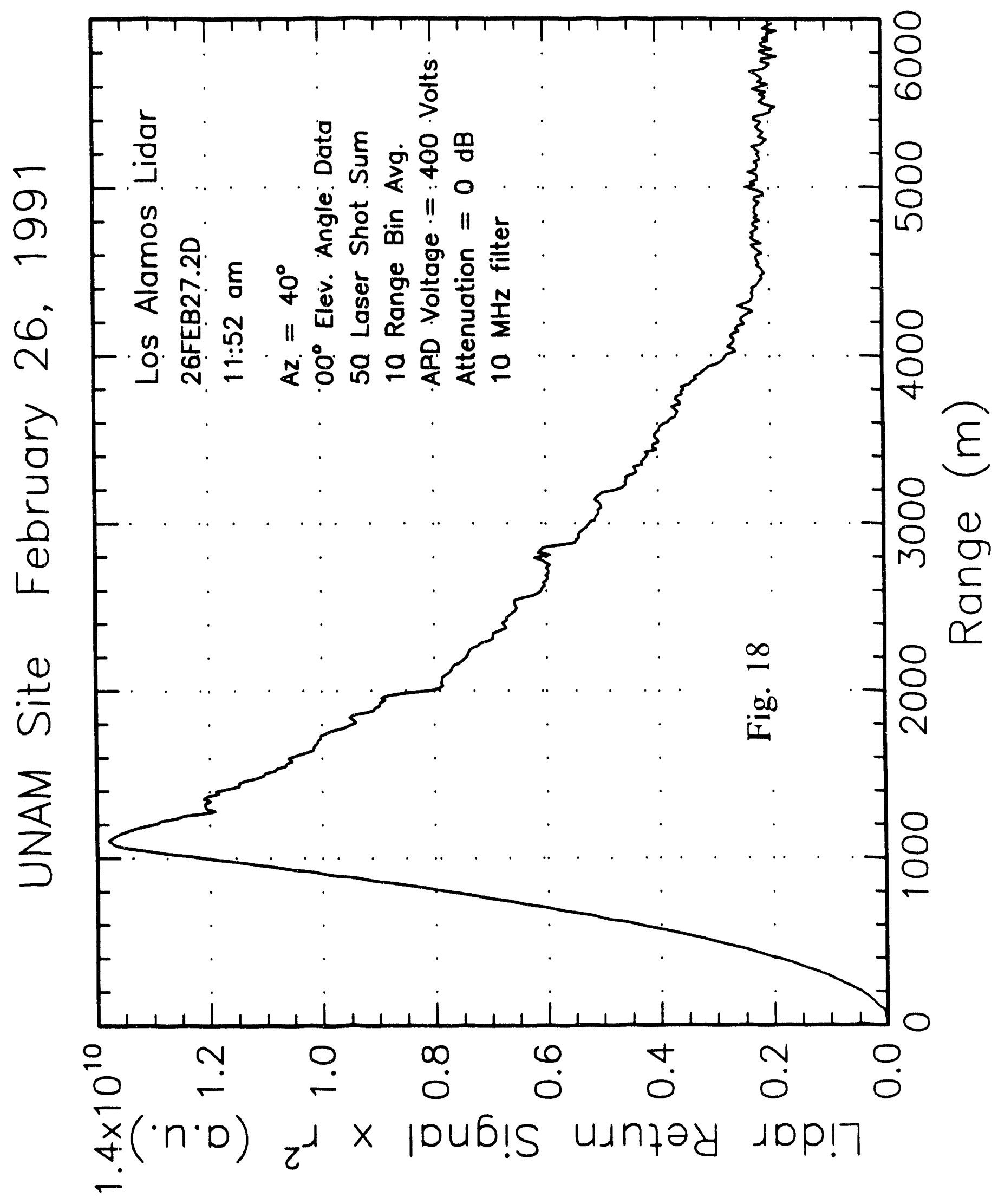




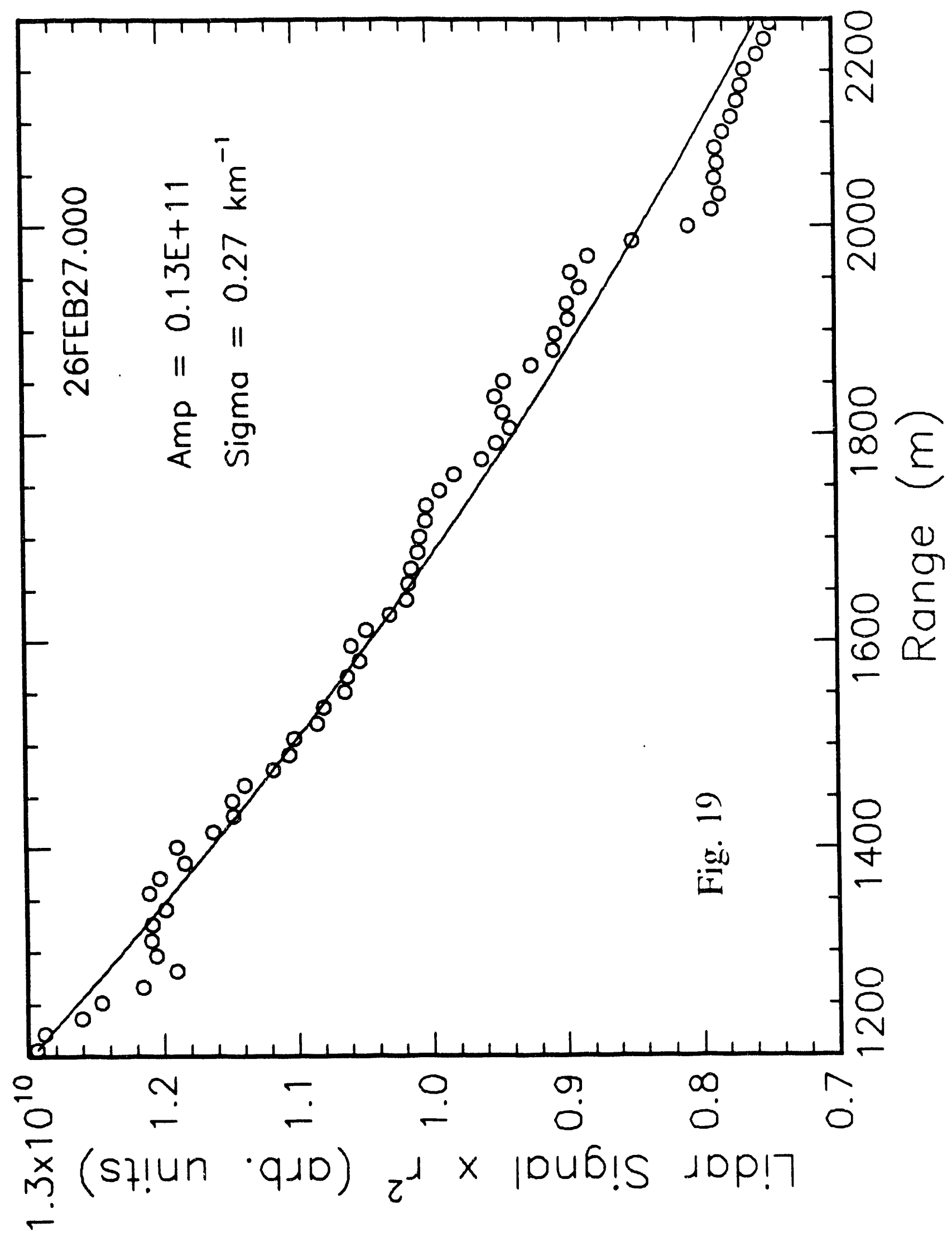




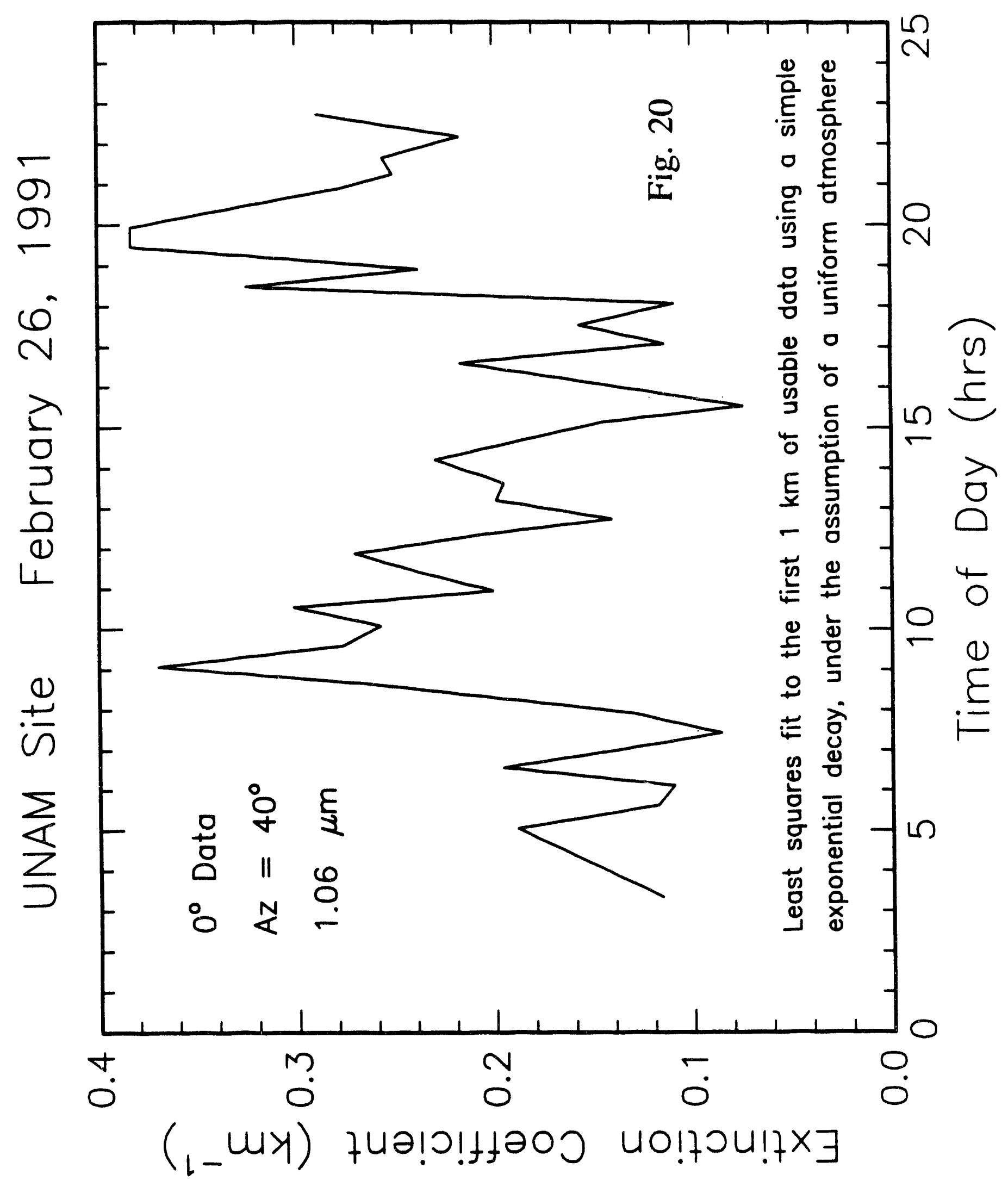




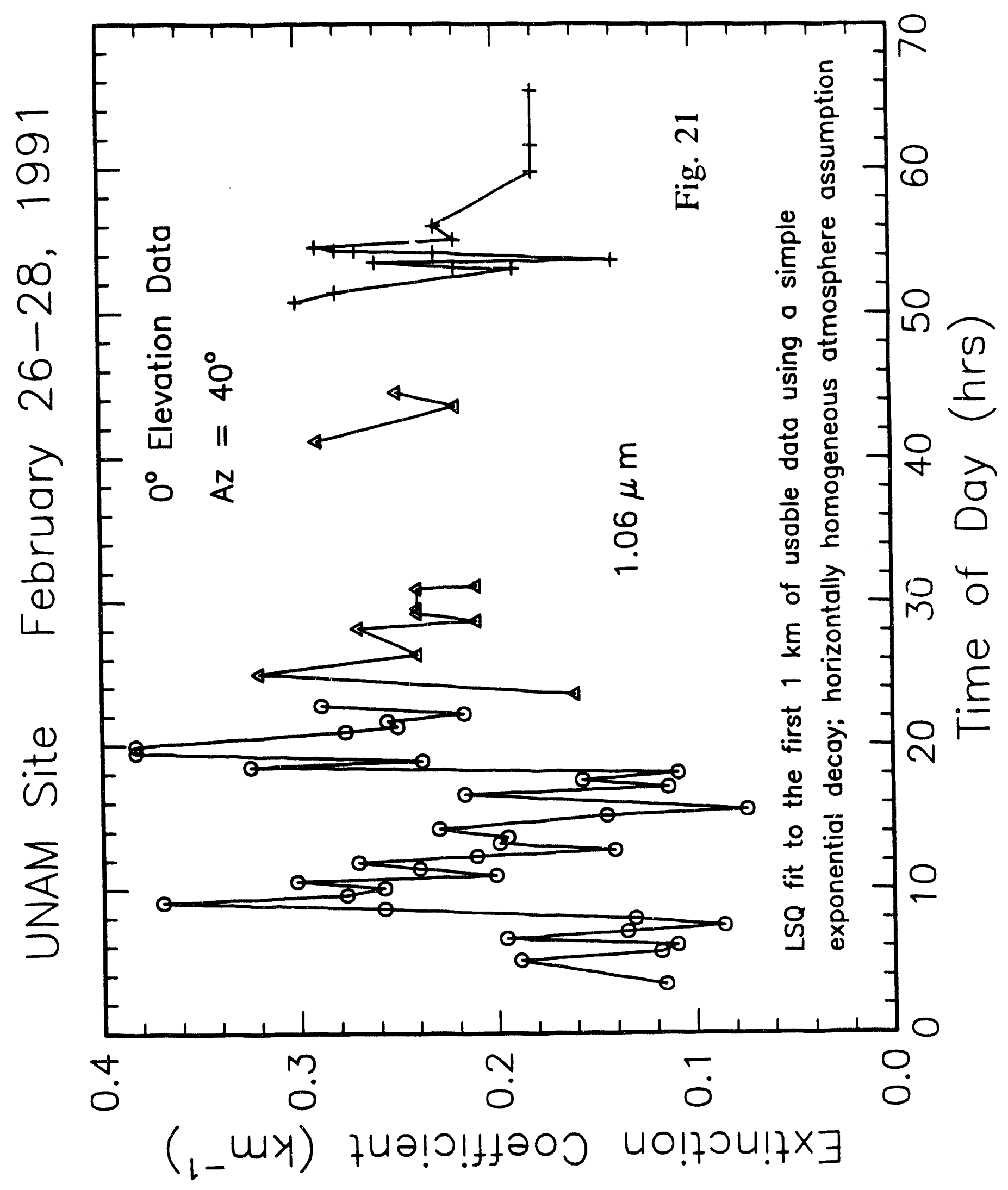




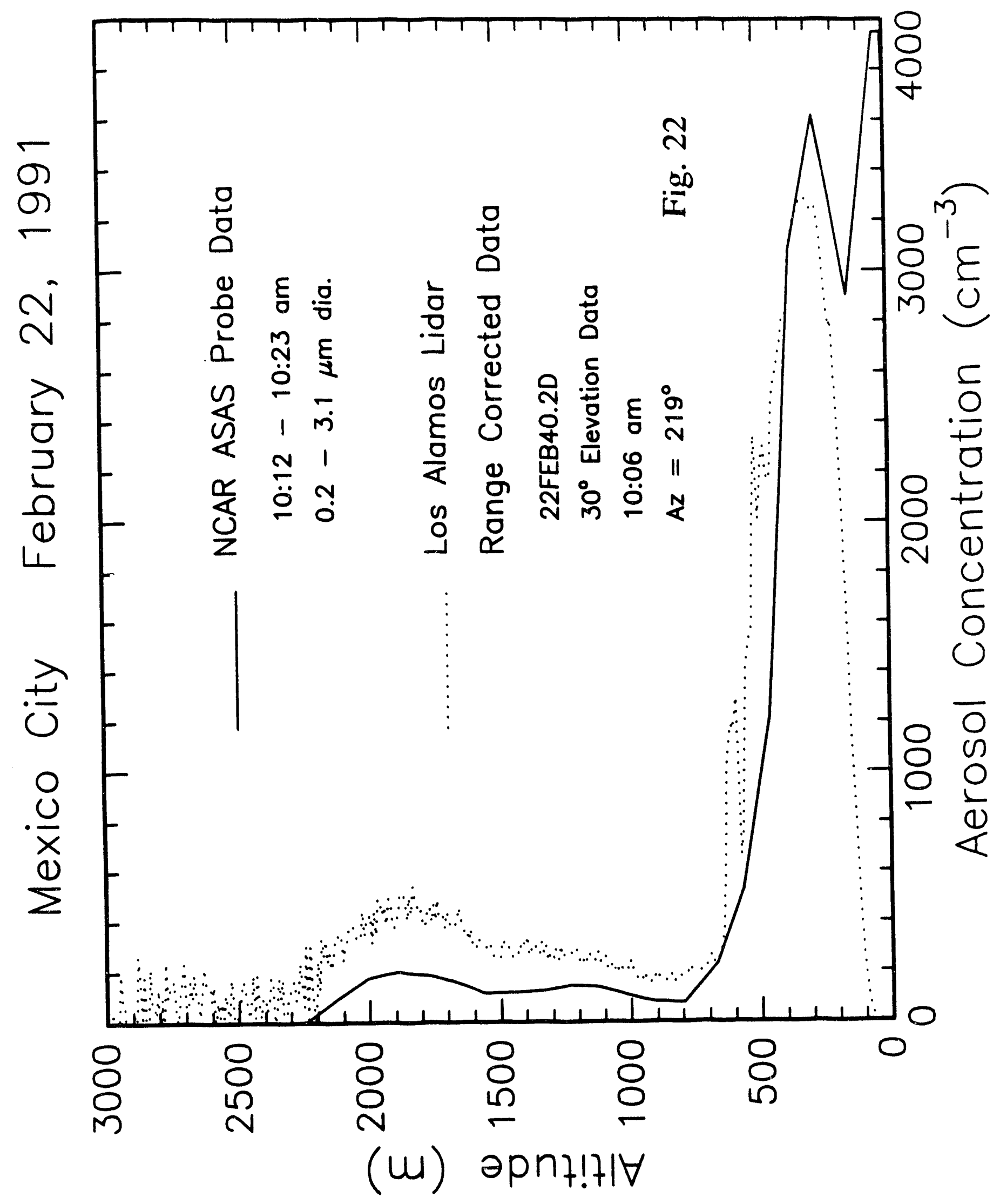




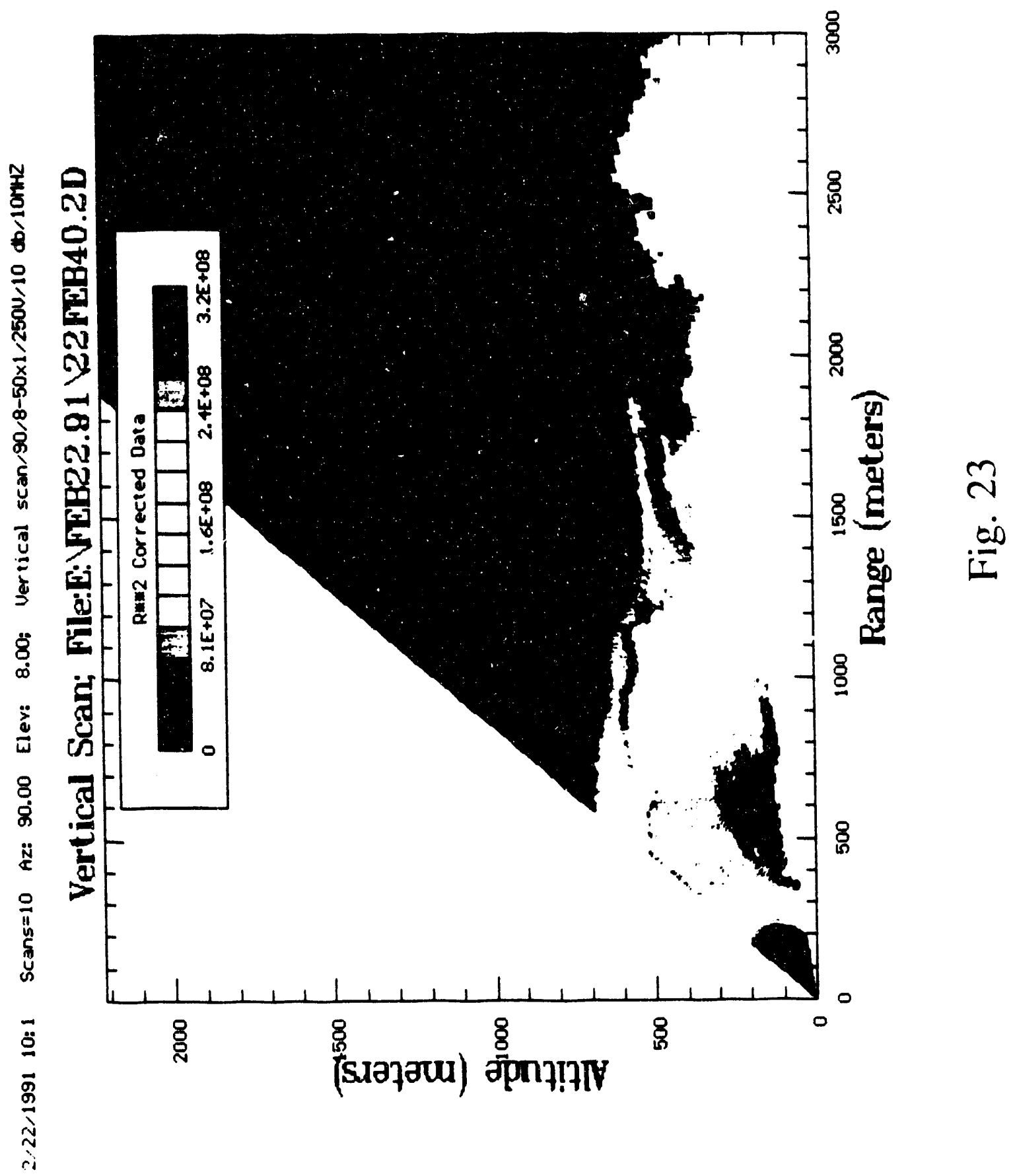




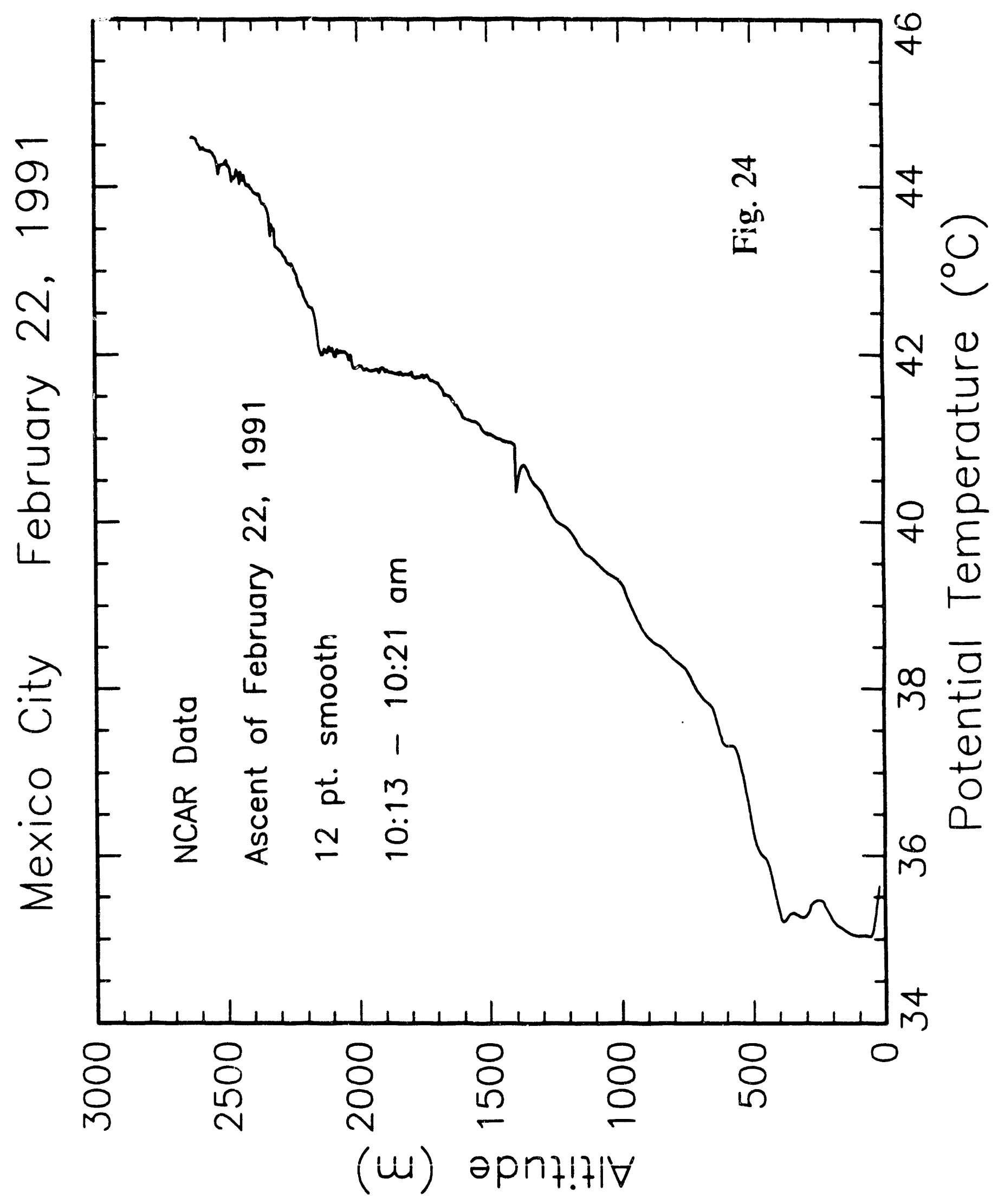




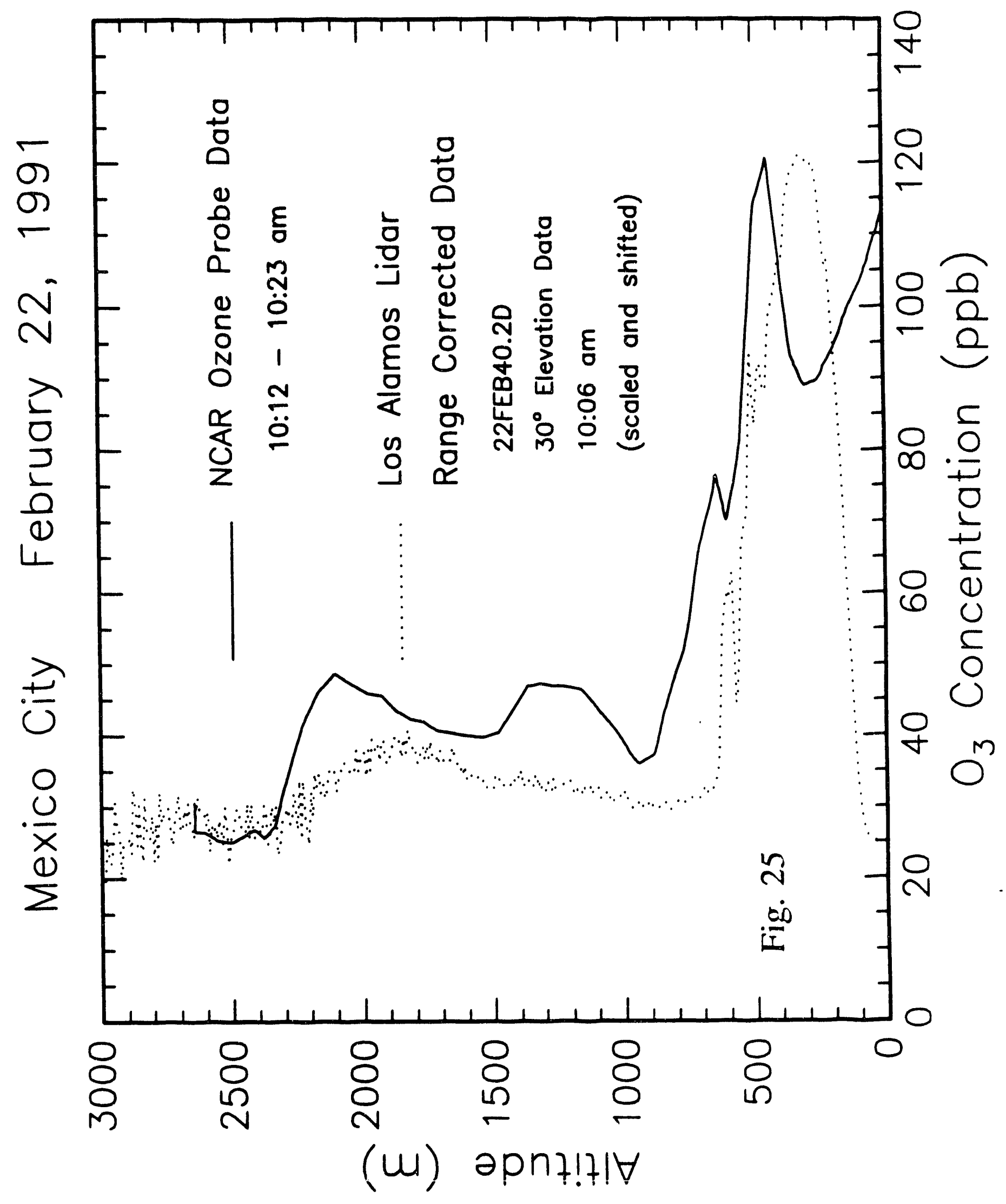




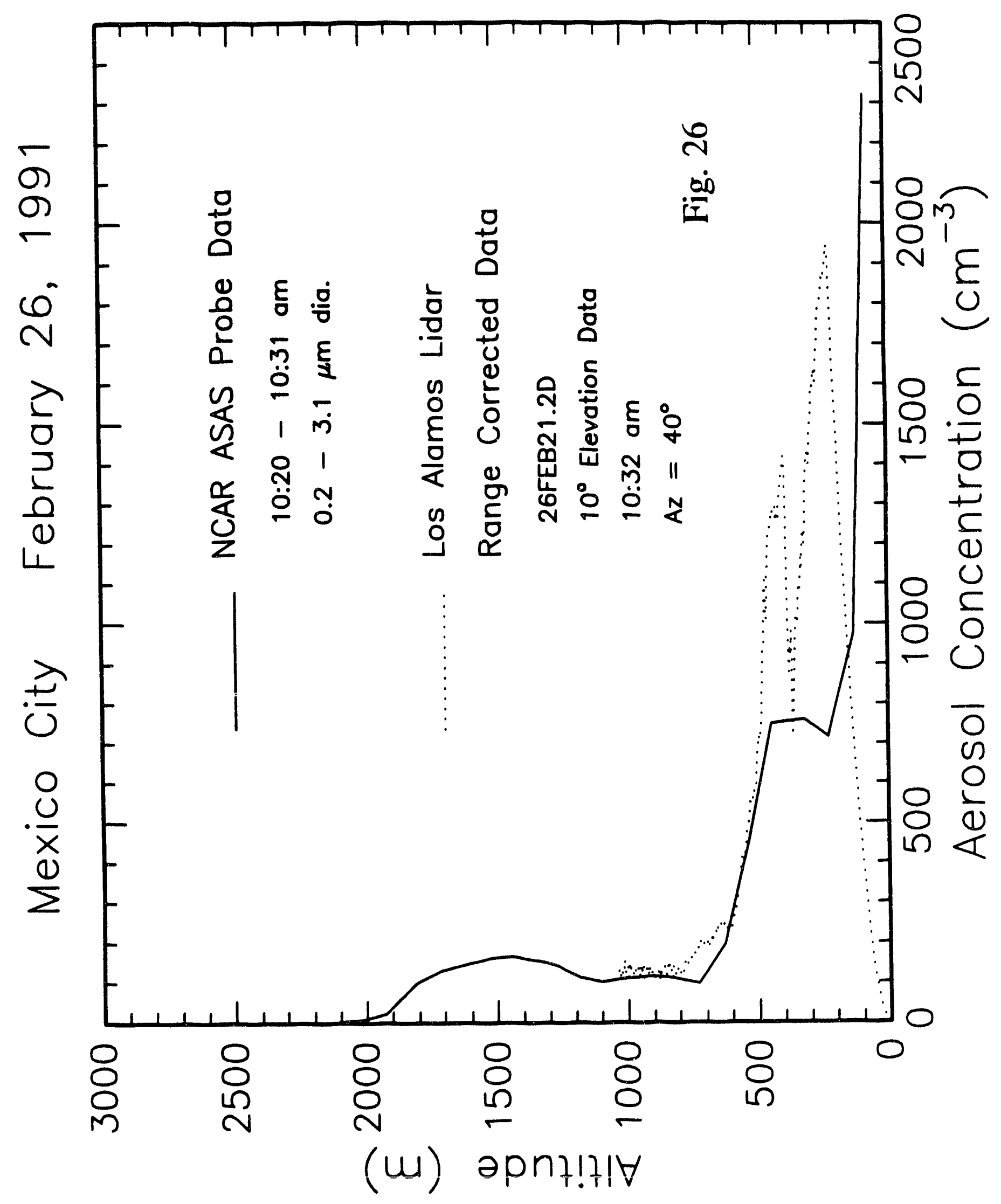




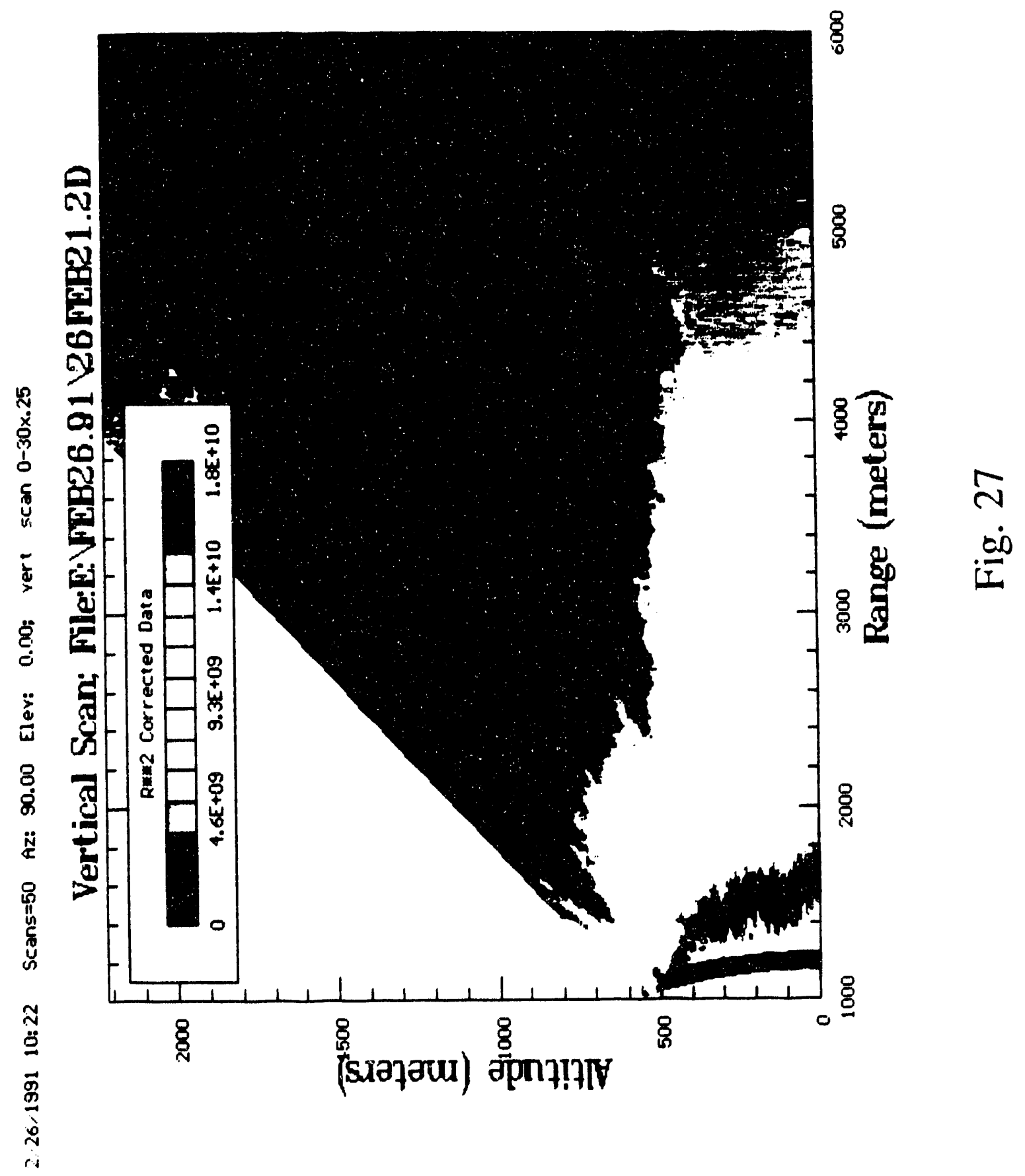




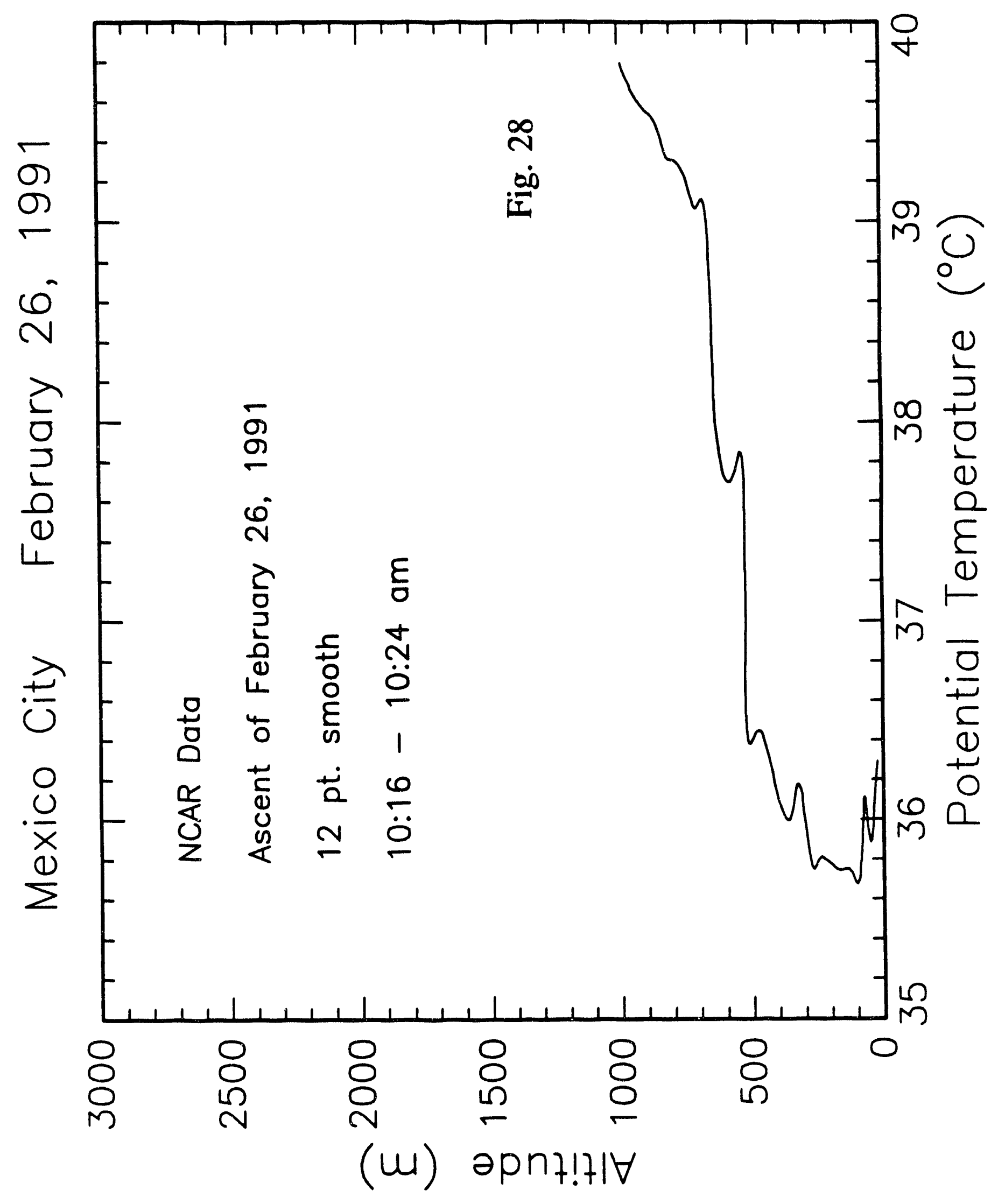




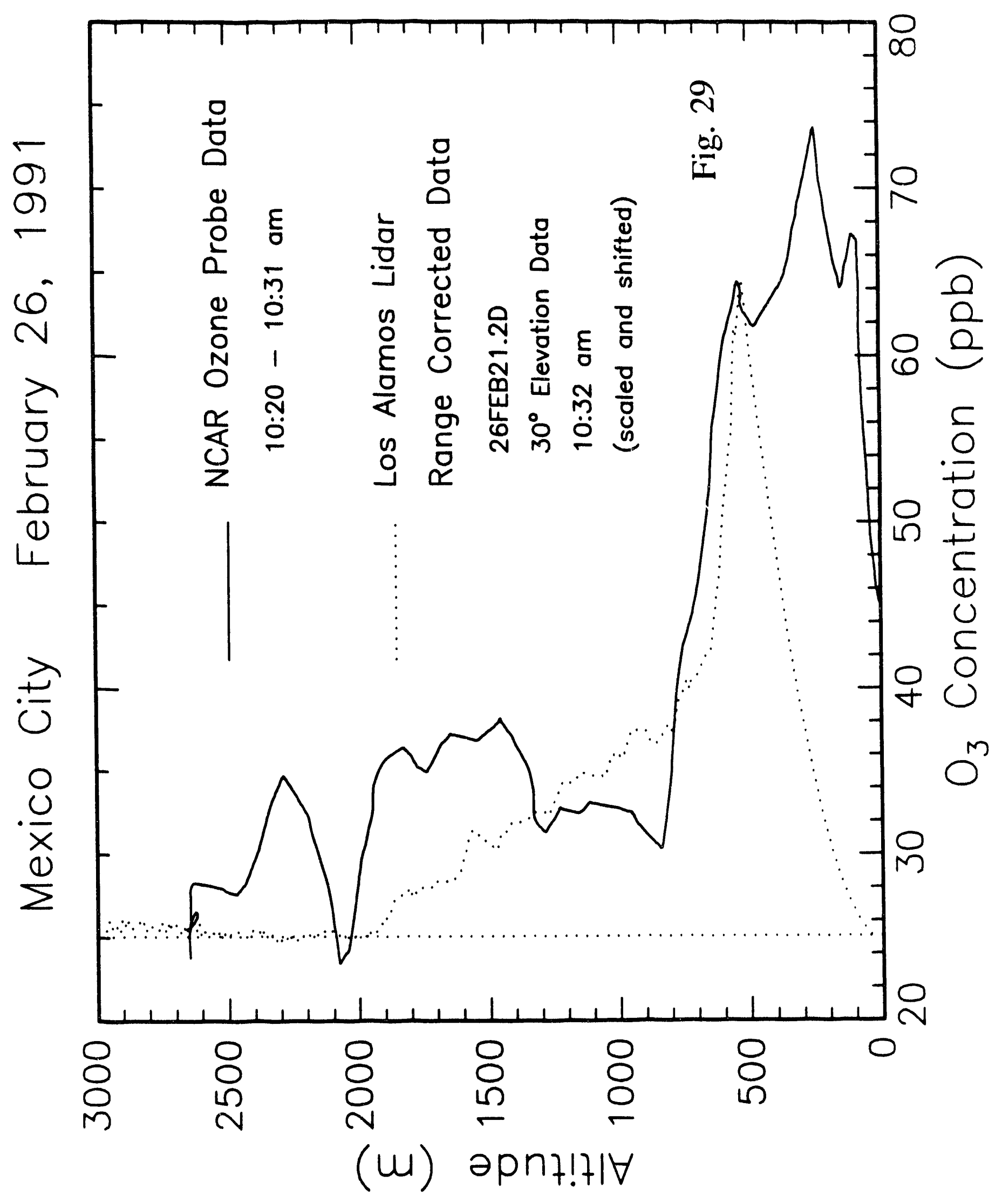




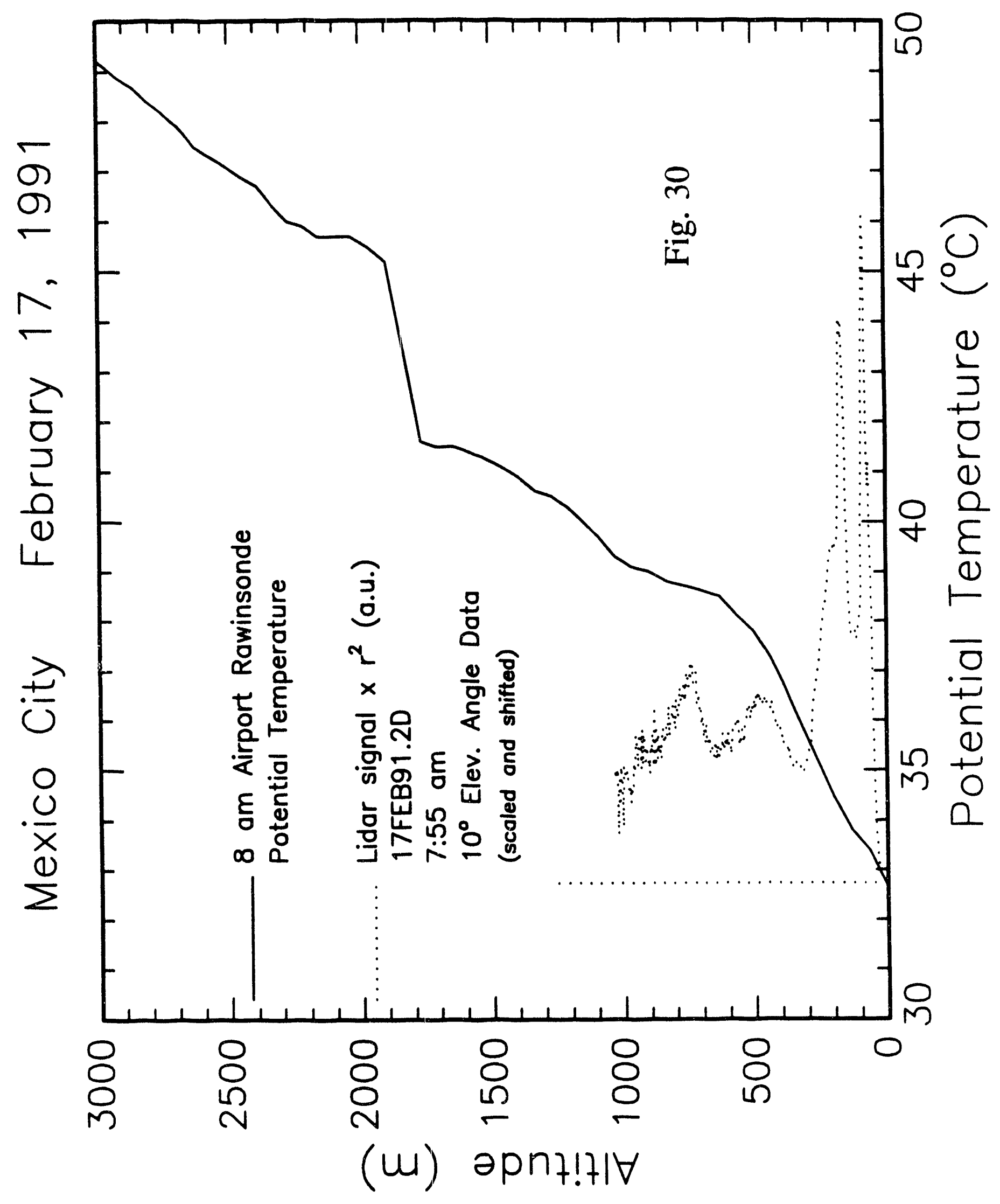




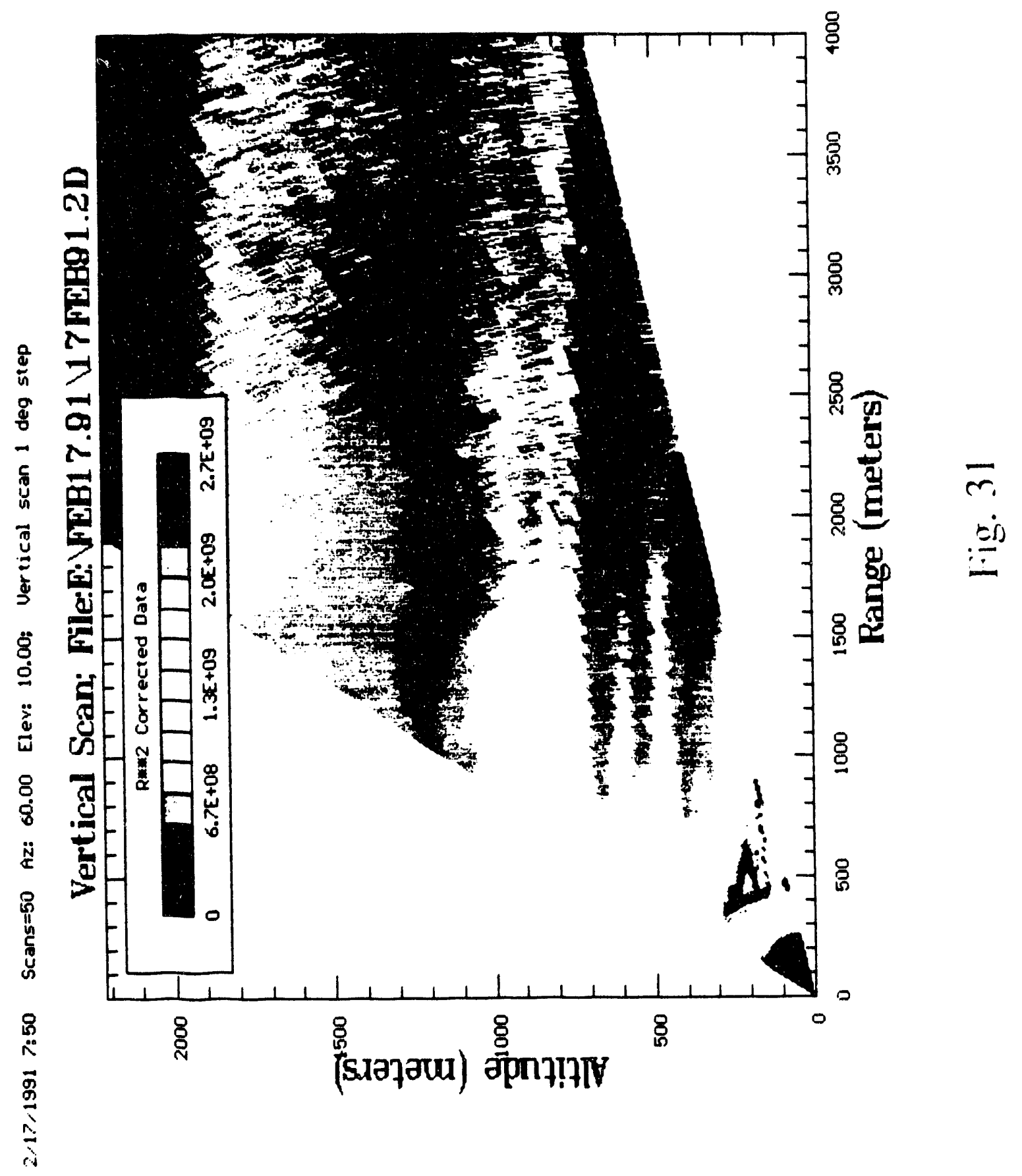




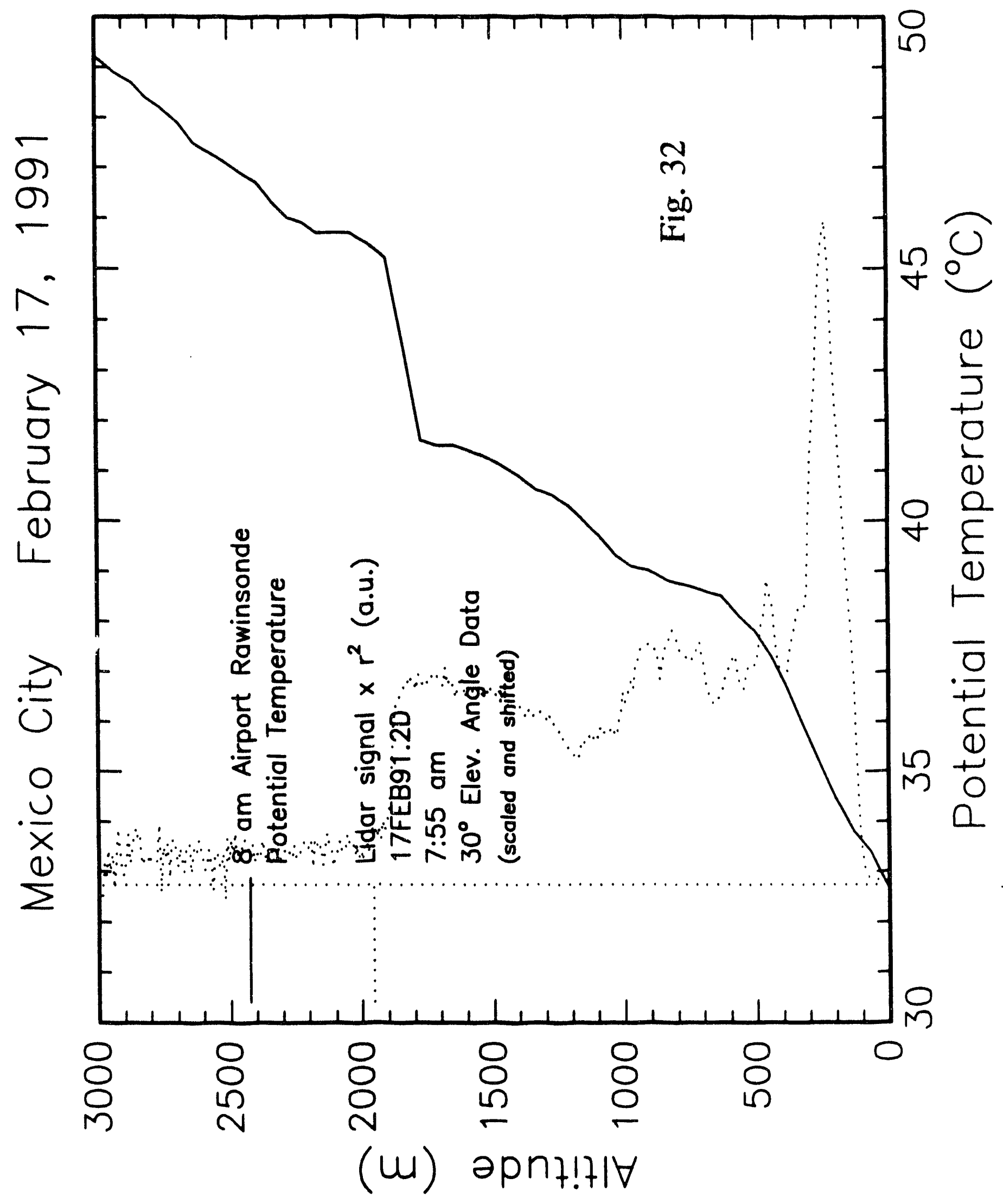




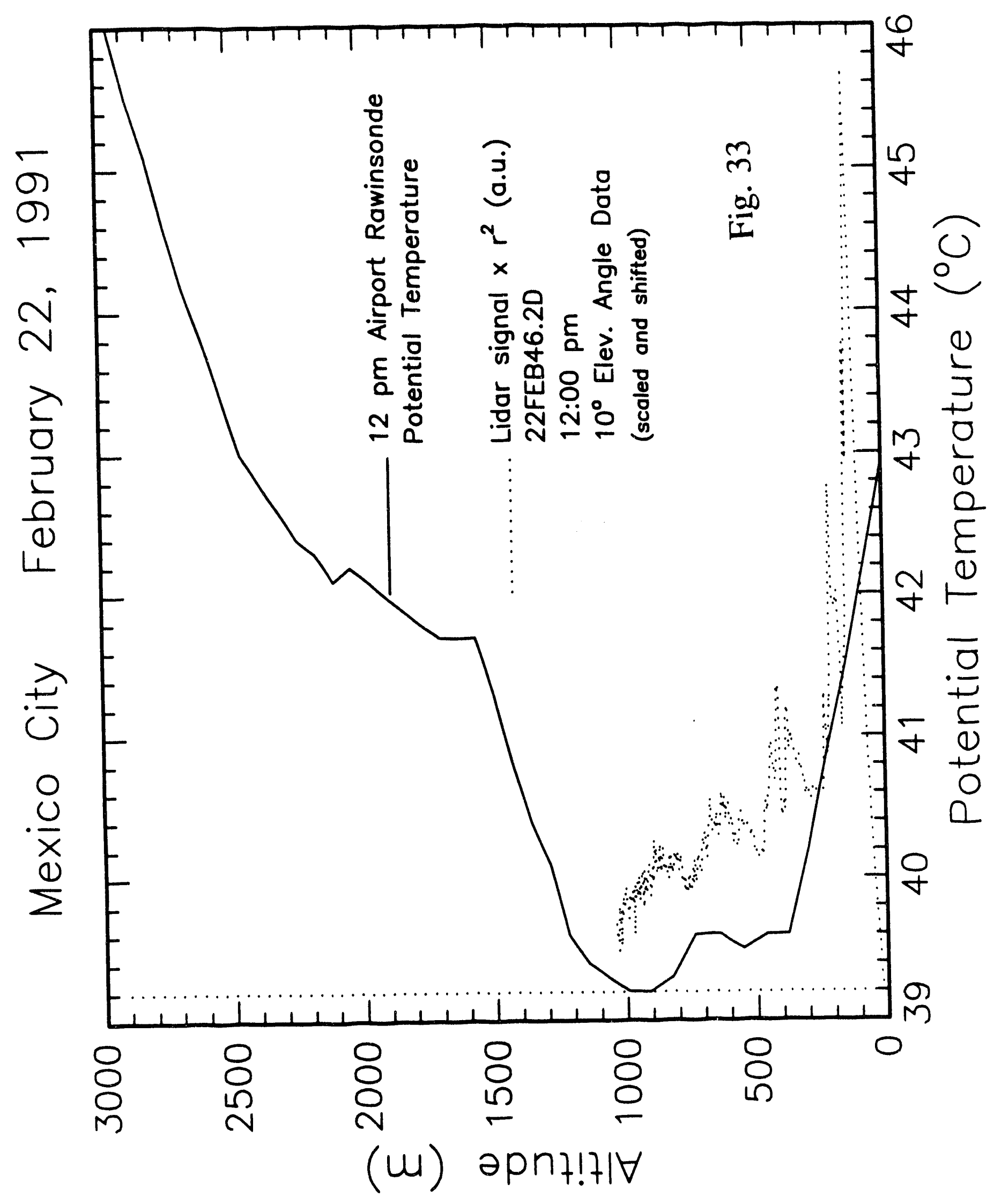




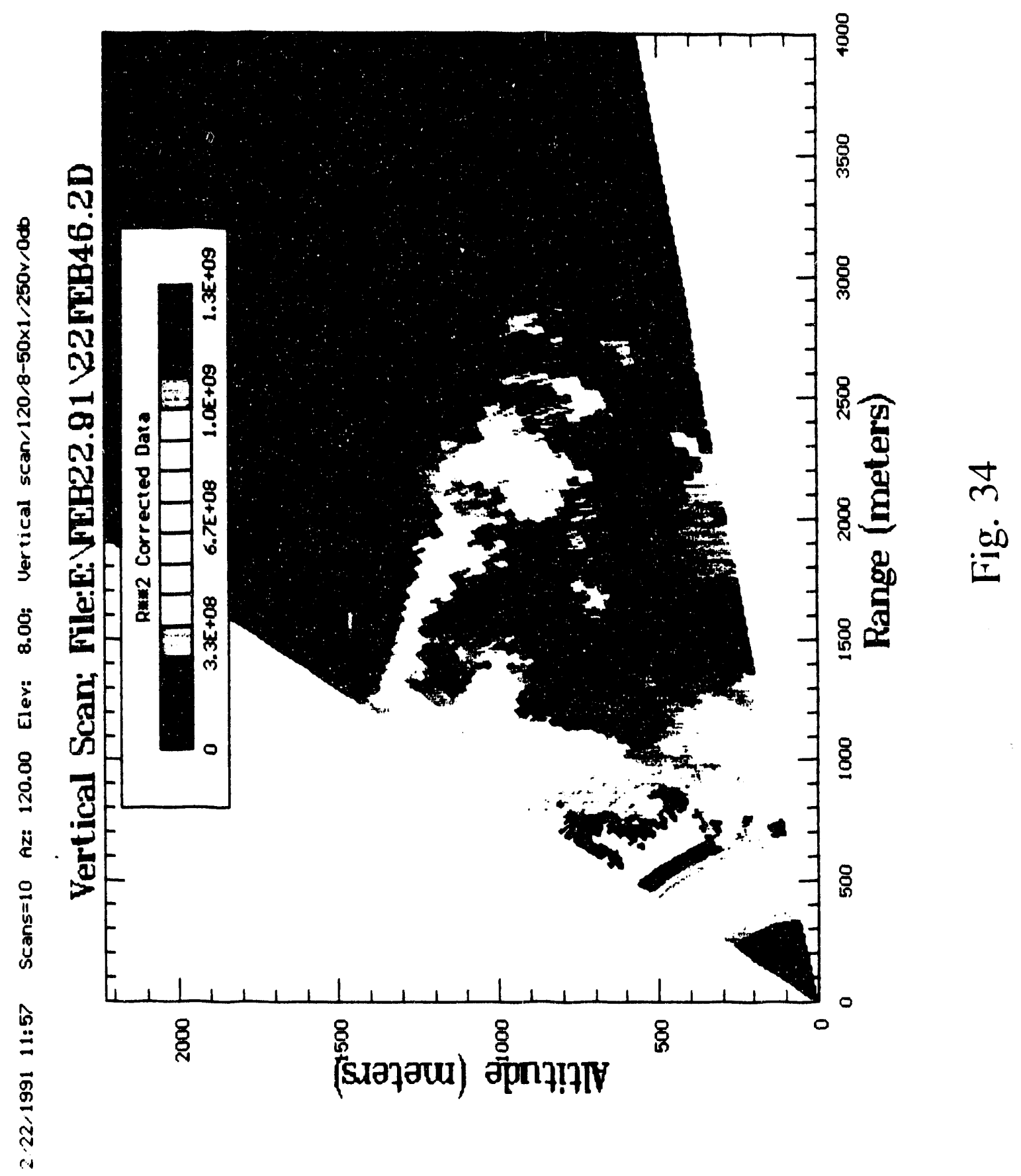




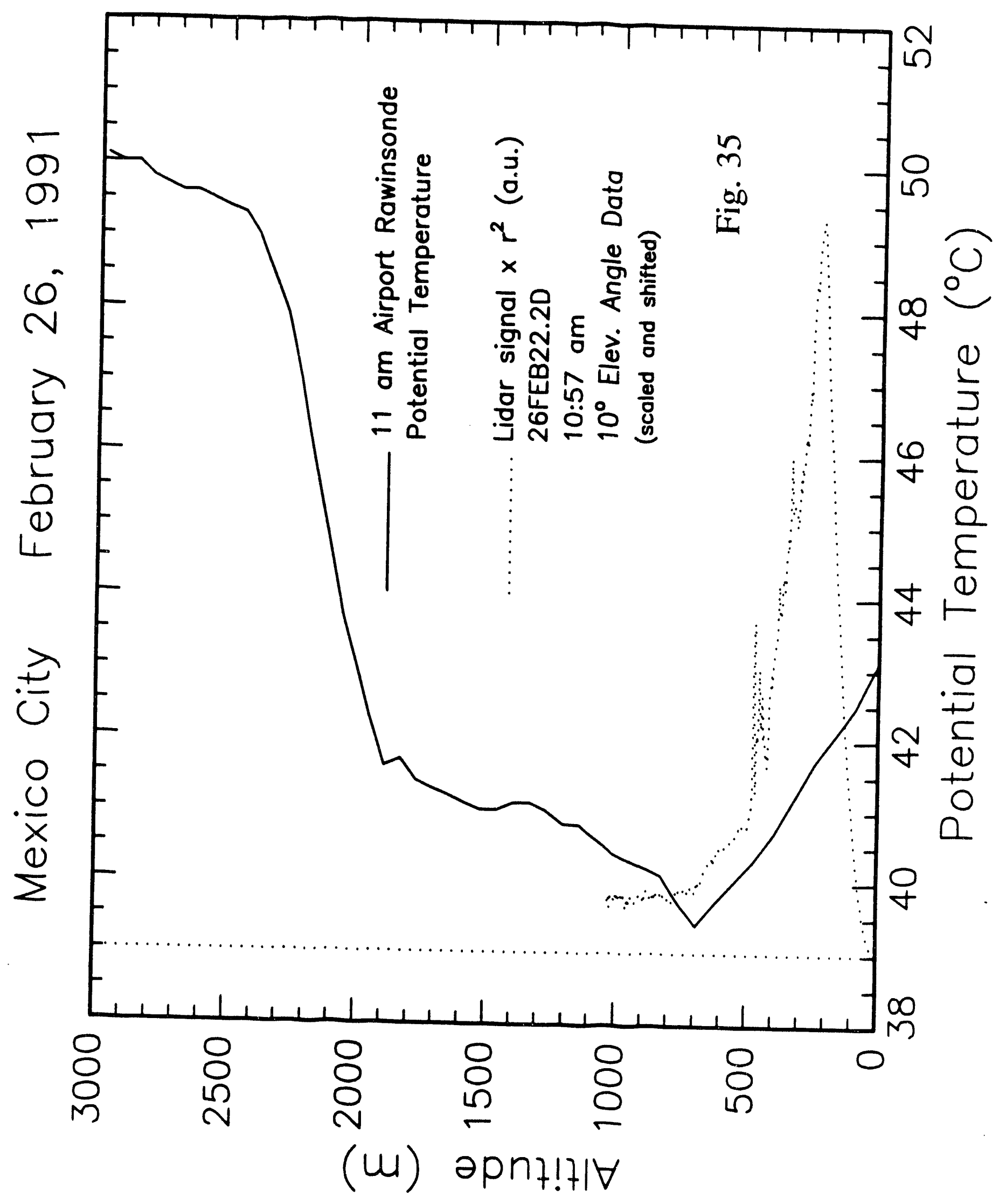




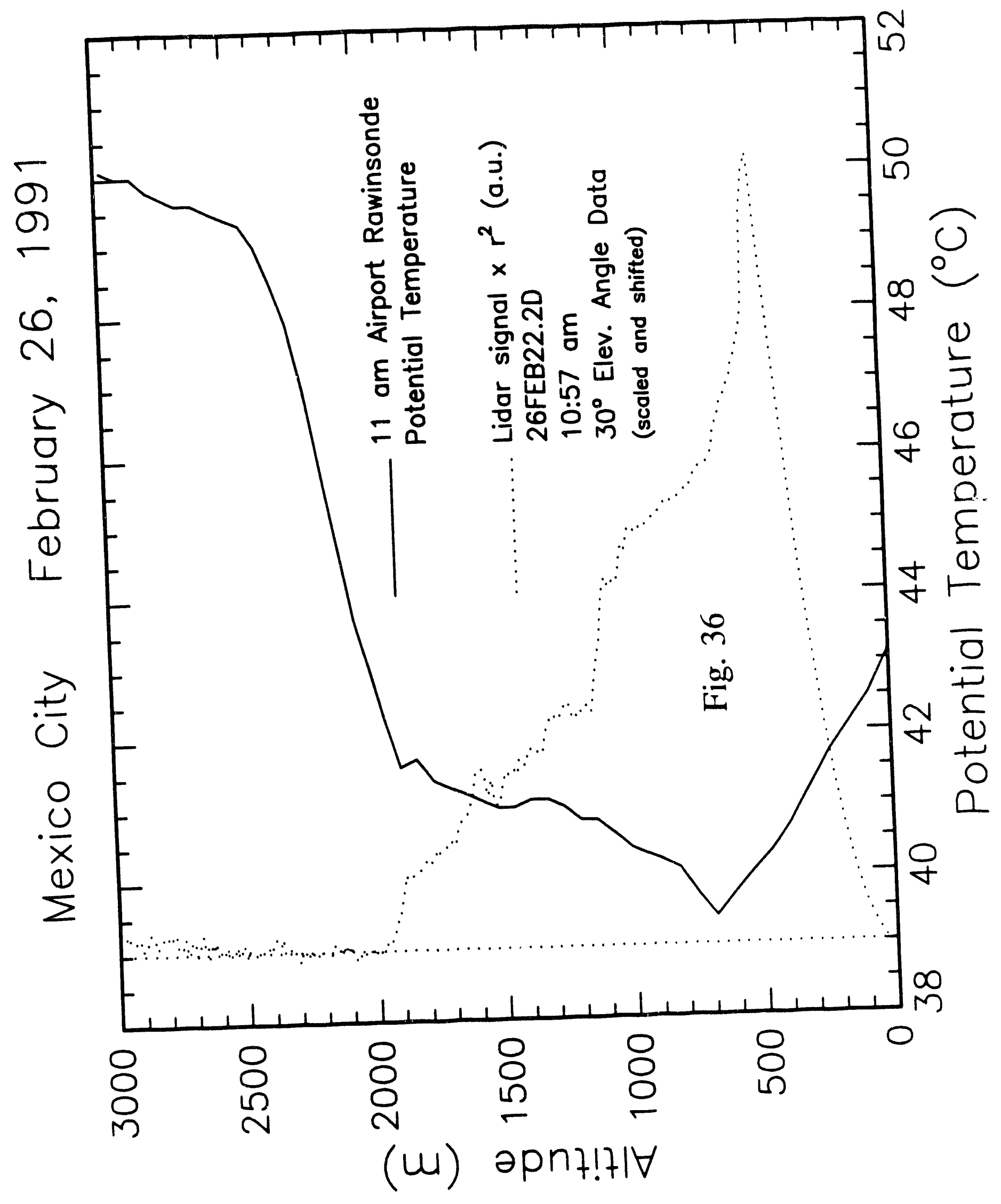




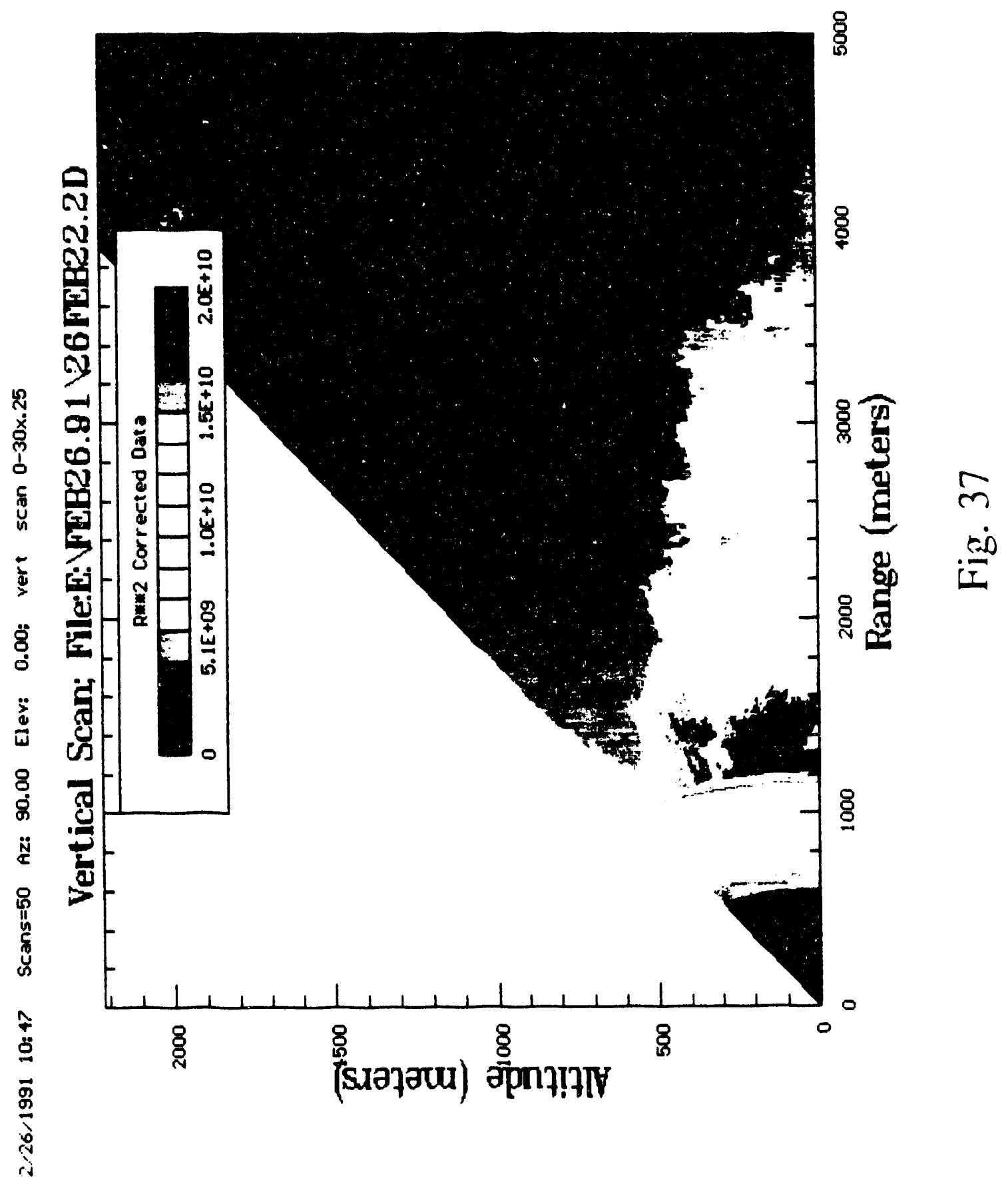


Appendix A

Data Logs 


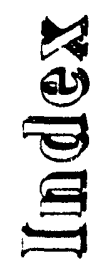

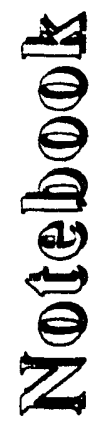

光

瞗

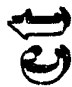

(2)

है

돌

运

8

a $\infty$

占

불 
오롫

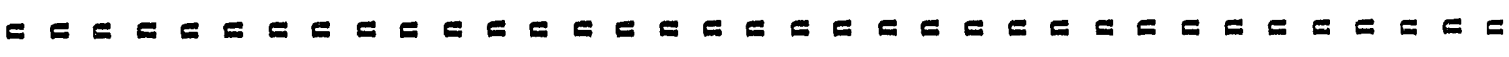

覀焉事 00000000000000000000000000000000000

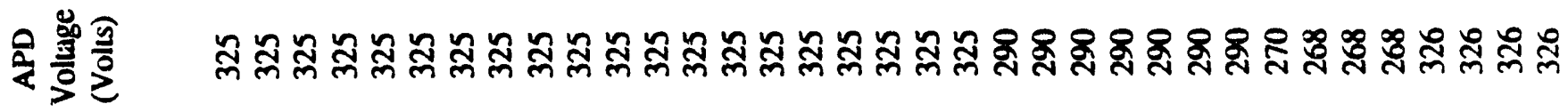

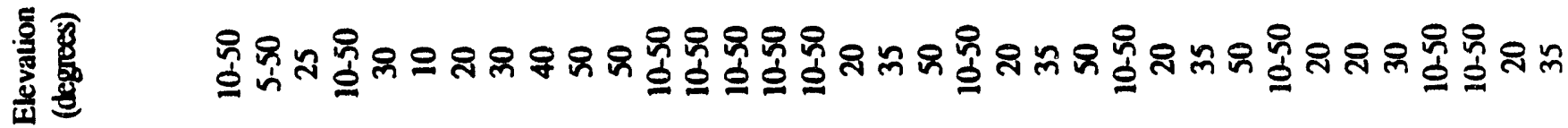

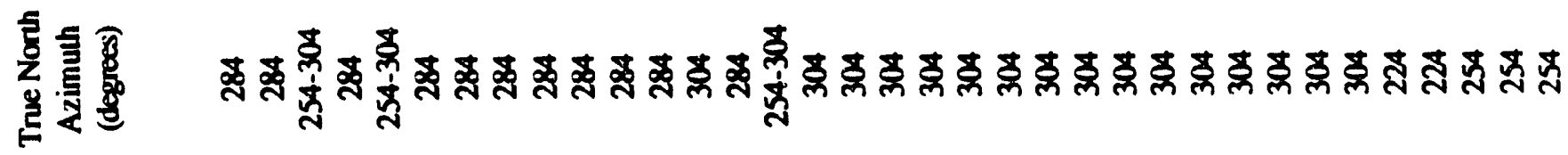

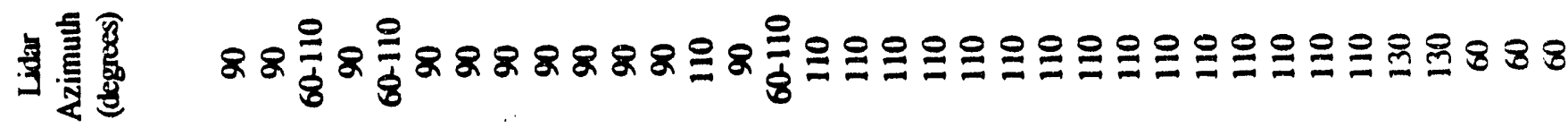
$\frac{\partial}{\infty}=$

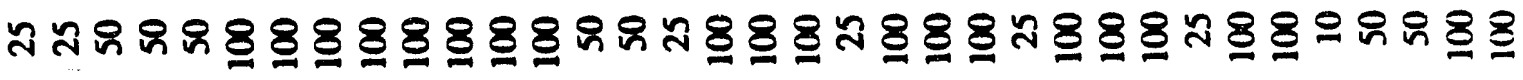

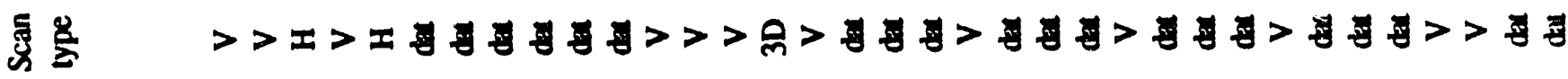
$\dot{\infty}=$

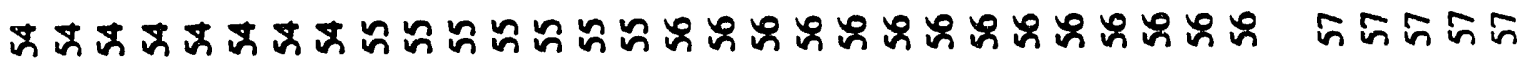

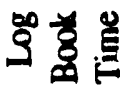

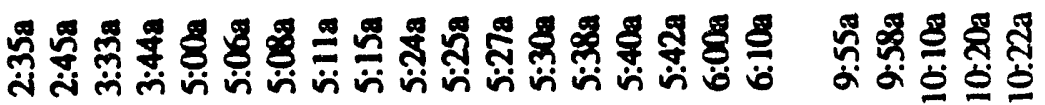

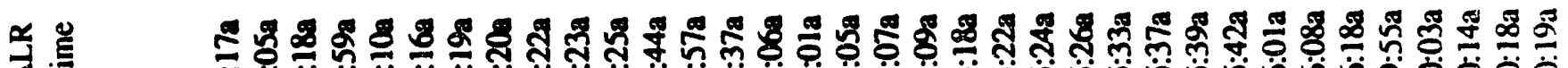

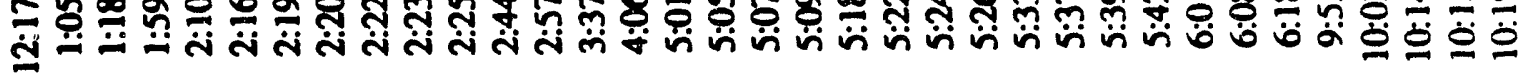

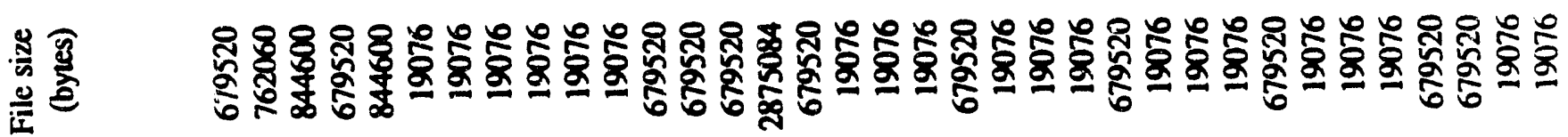

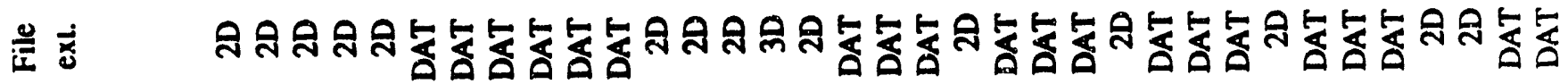




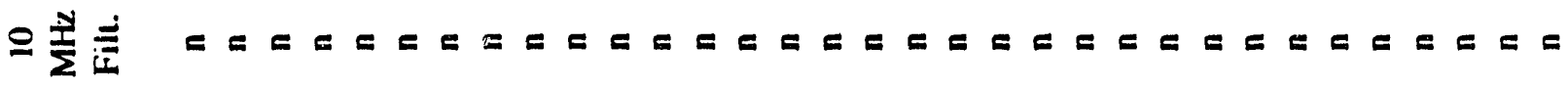

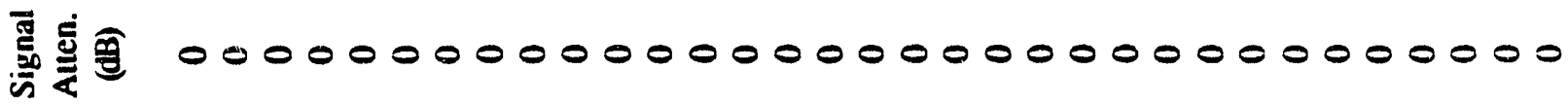

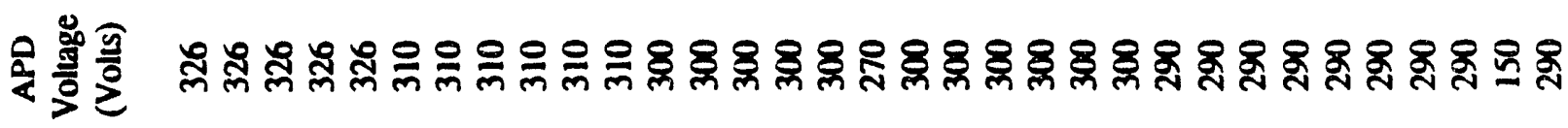

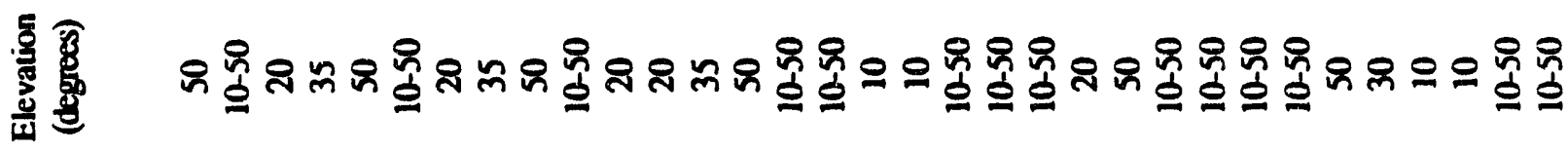

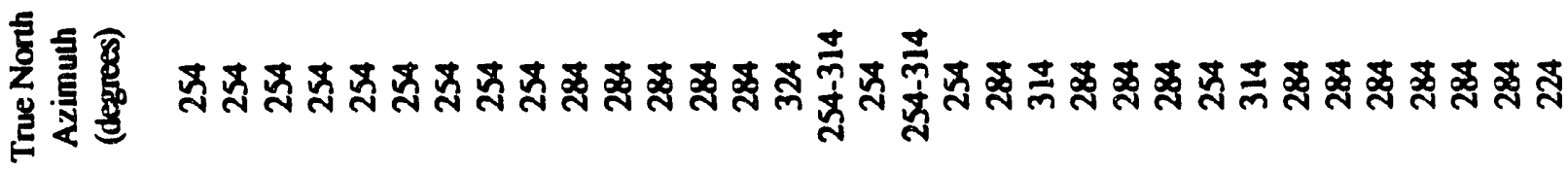

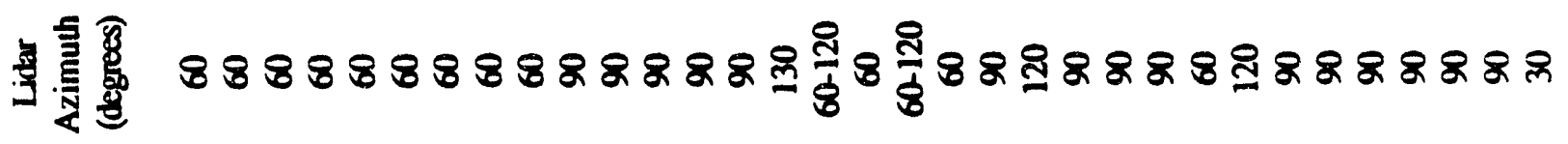

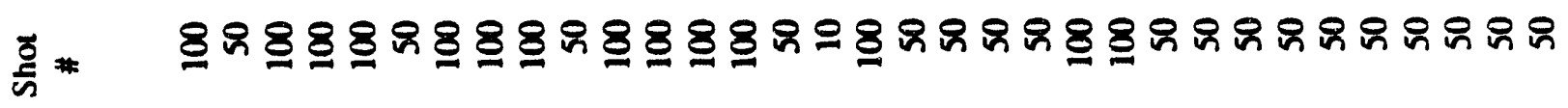

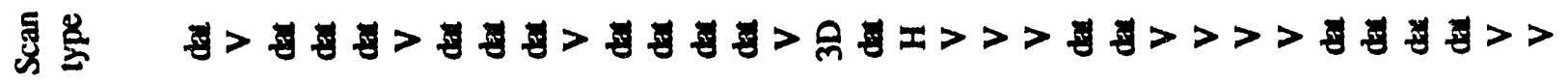

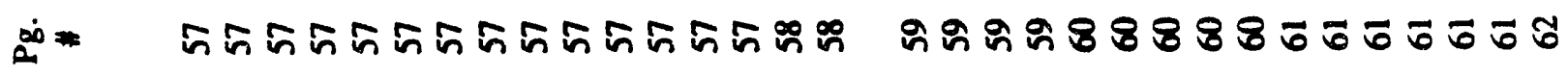

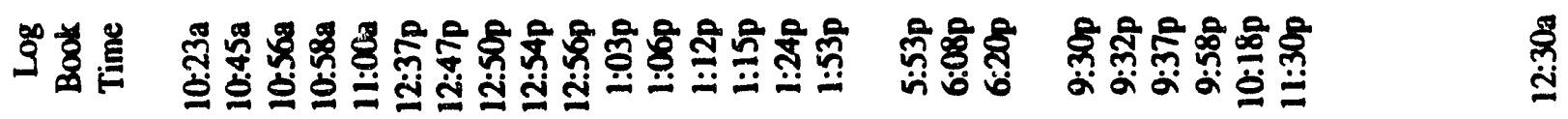

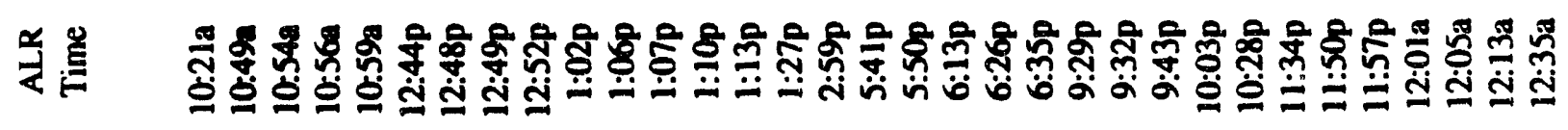

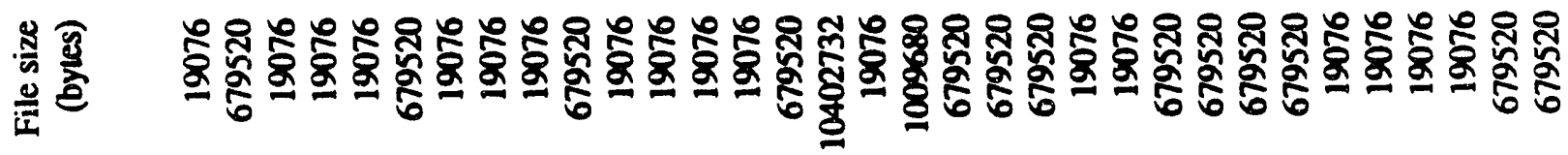

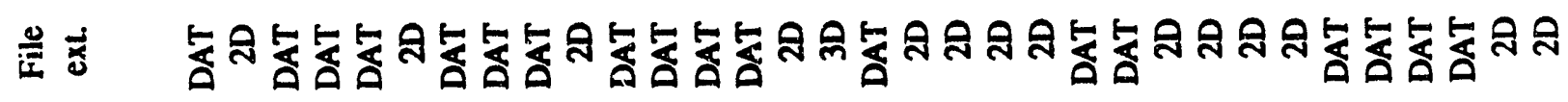

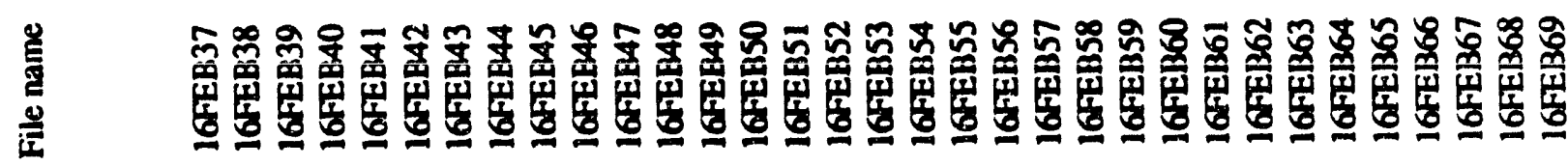




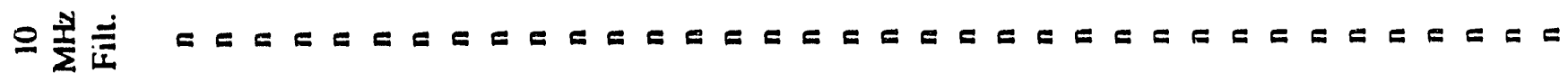
要焉 000000000000000000000000000000000000

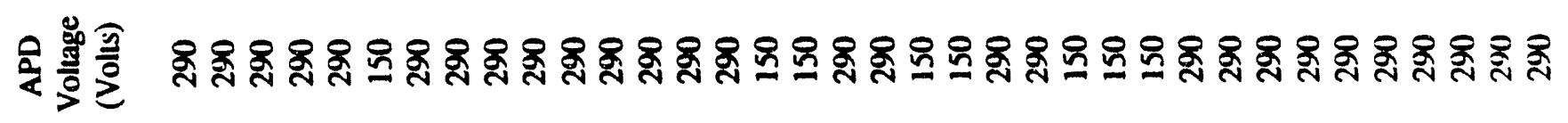

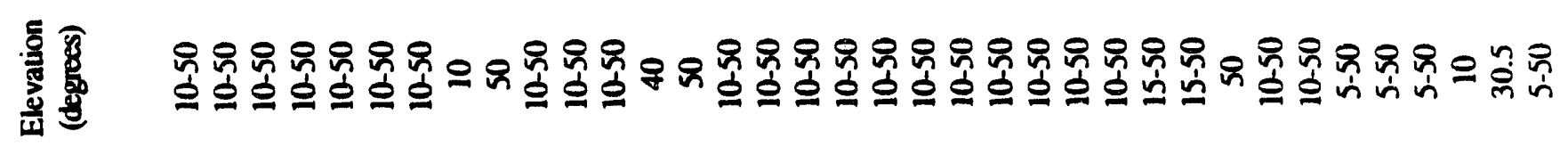

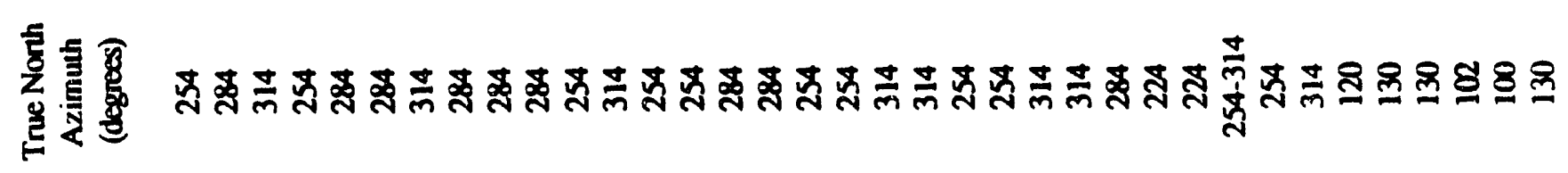

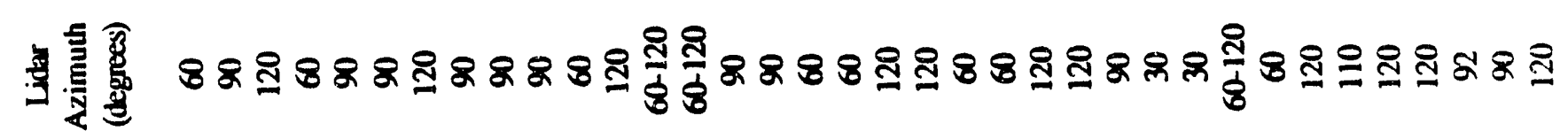

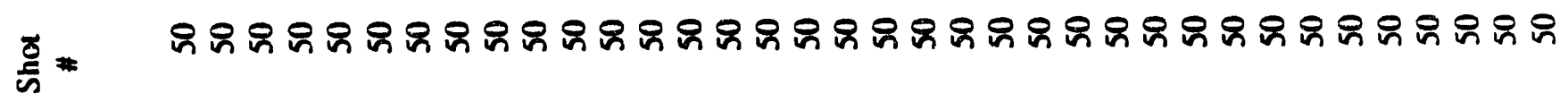

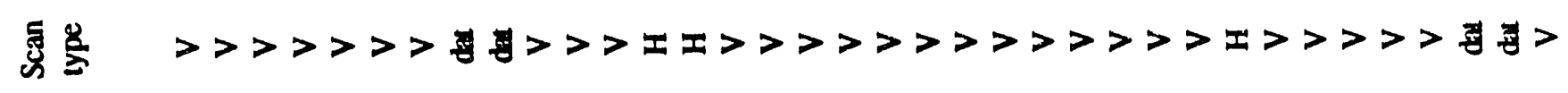

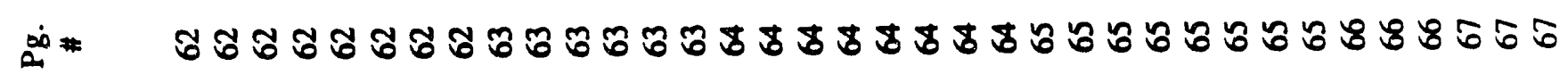

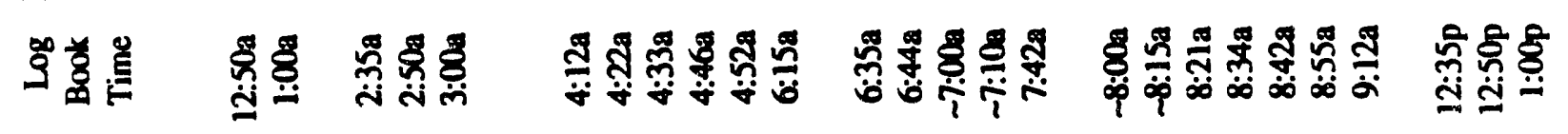

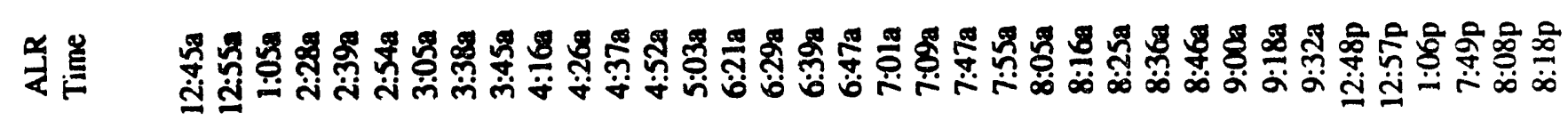

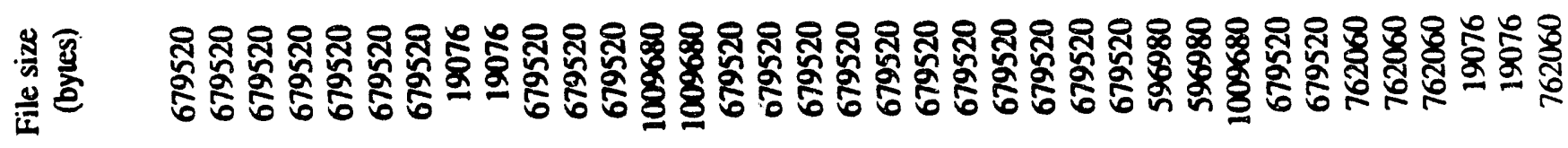

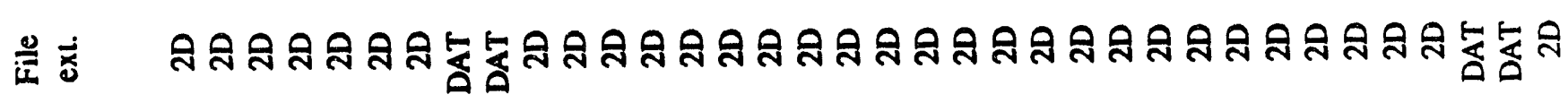

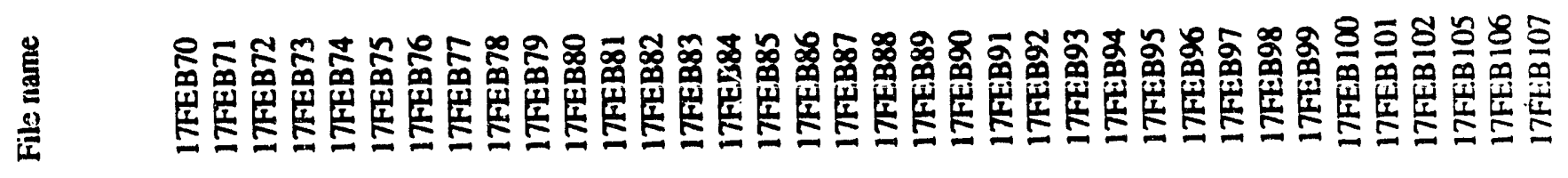


윌 站 $=E=E=E=E=$

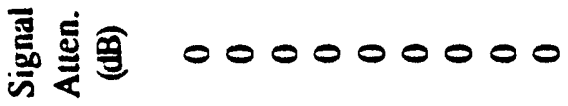

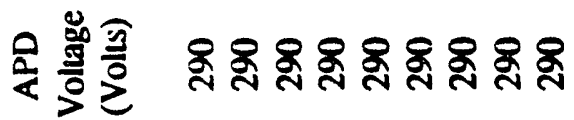

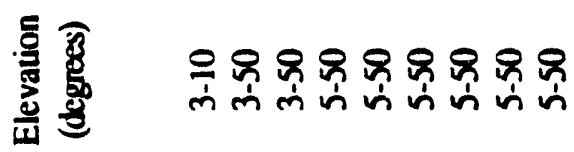

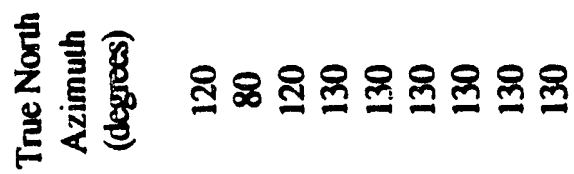

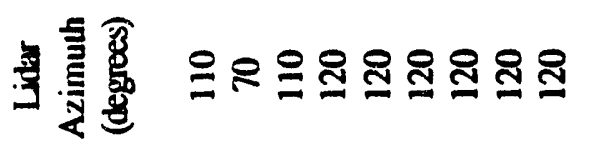

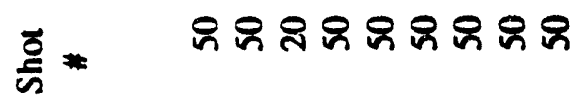

零望 $>>>>>>>$

क

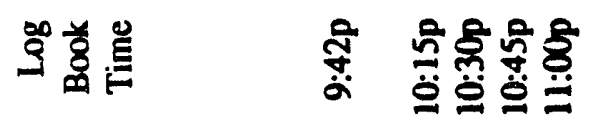

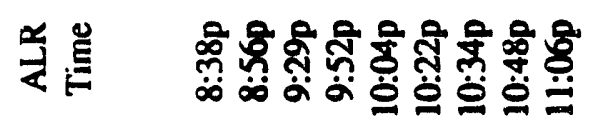

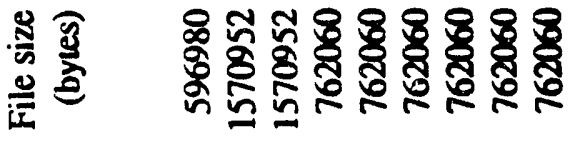

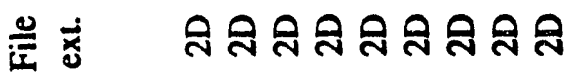

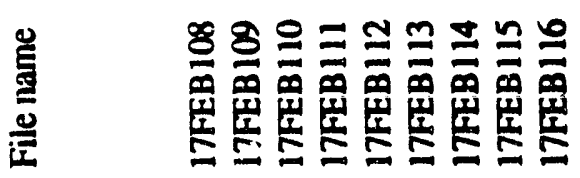

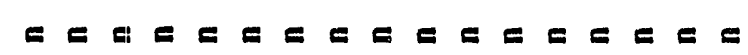

00000000000000000

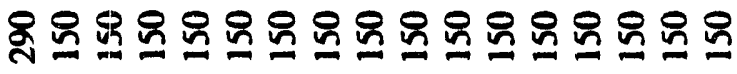

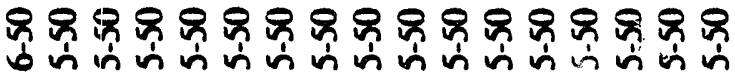

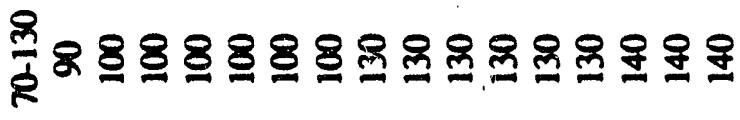

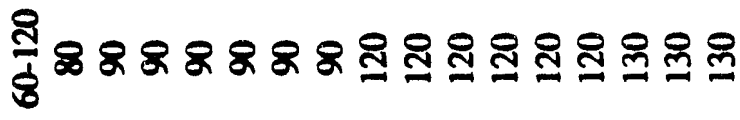

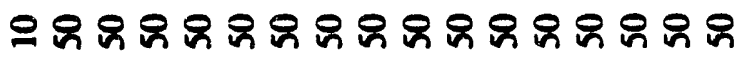

iि $>>>>>>>>>>>>>$

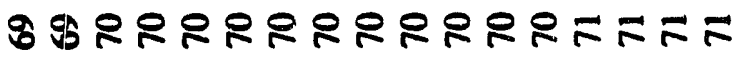

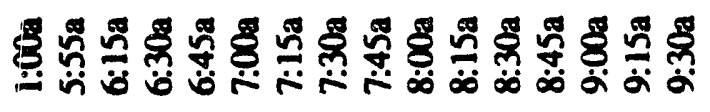

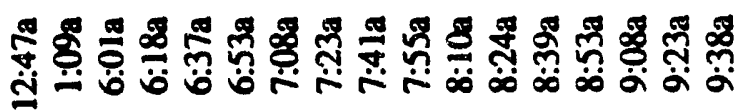

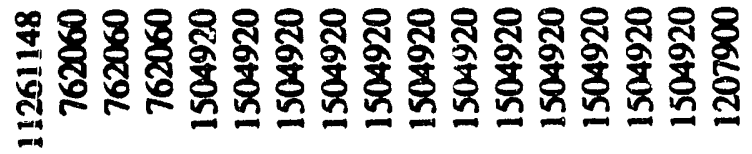
คิ สิ สิ สิ สิ สิ สิ สิ สิ สิ สิ สิ ลิ ิิ สิ

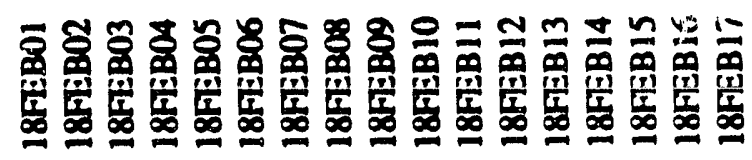




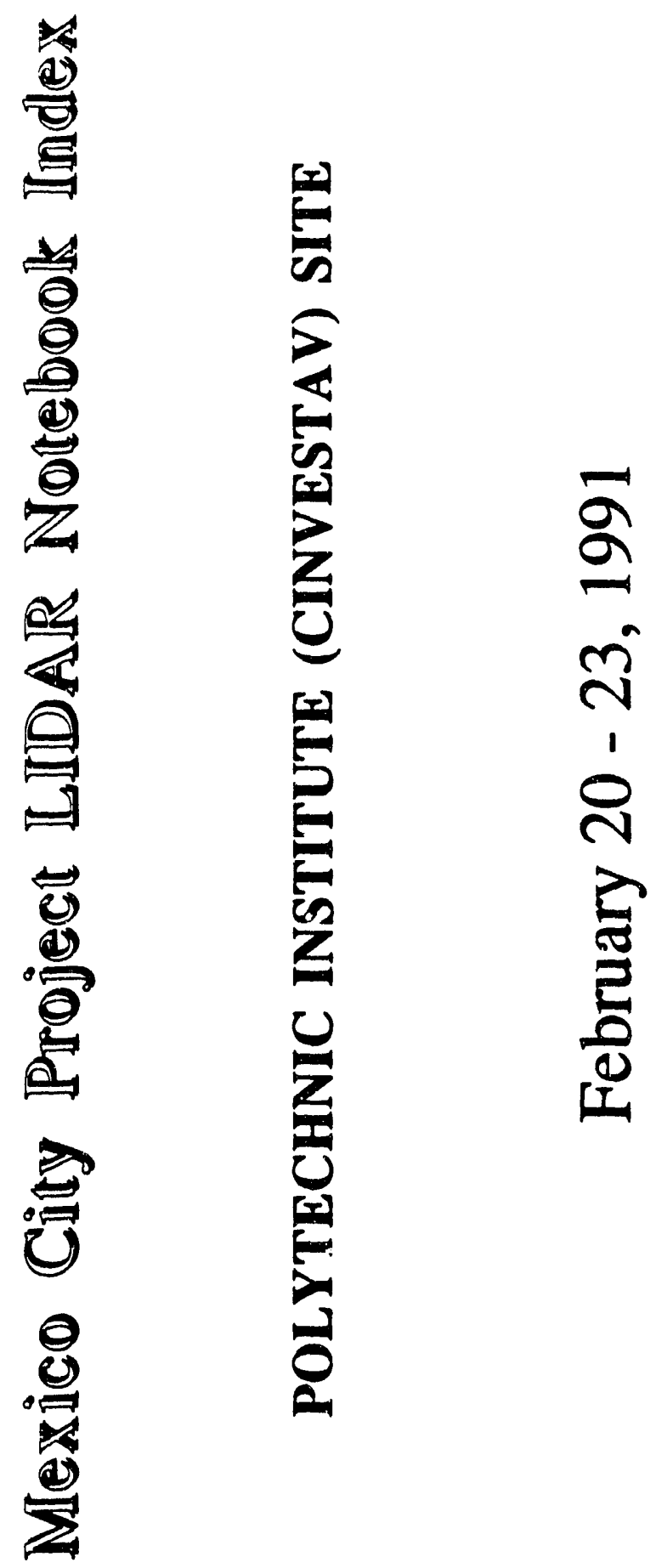




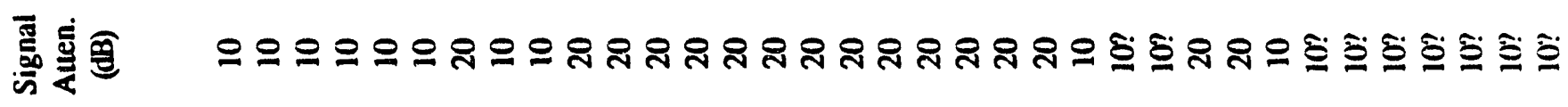

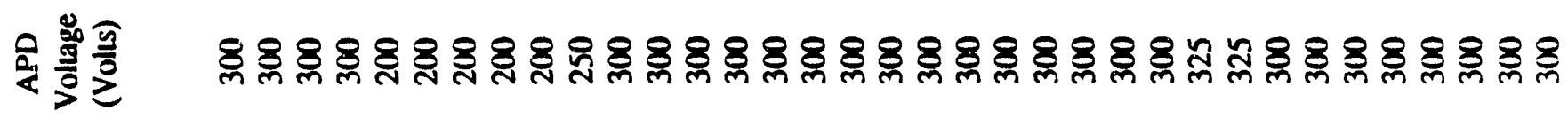

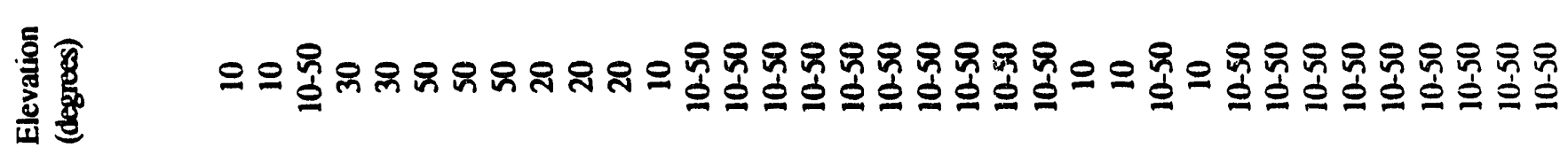

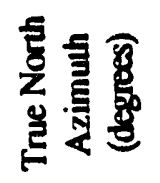

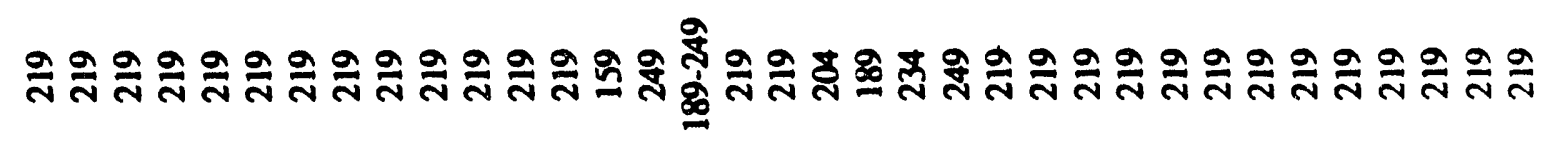

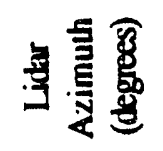

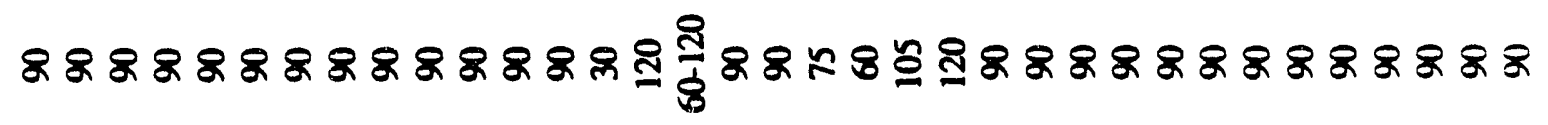
है

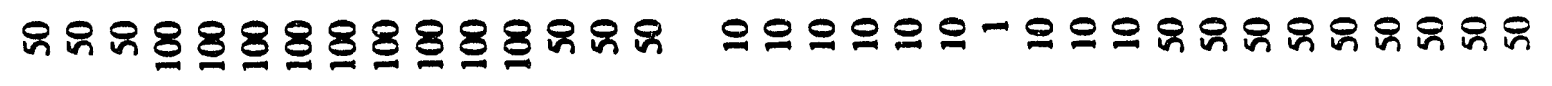

\section{S}

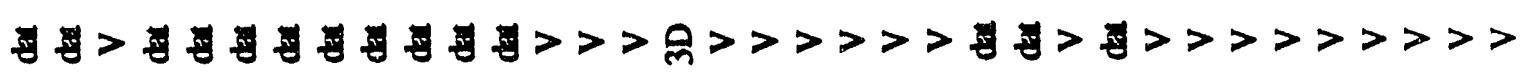
$\dot{0}=$ 荌总总

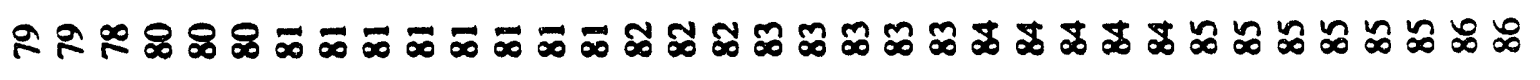

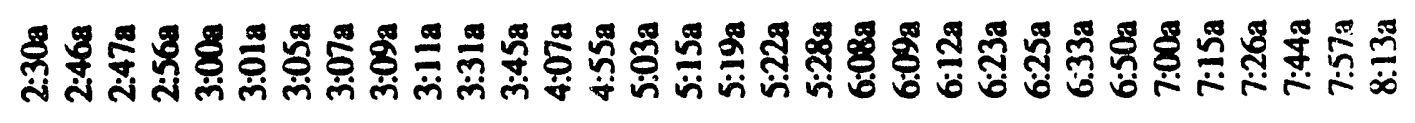
骂是

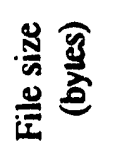

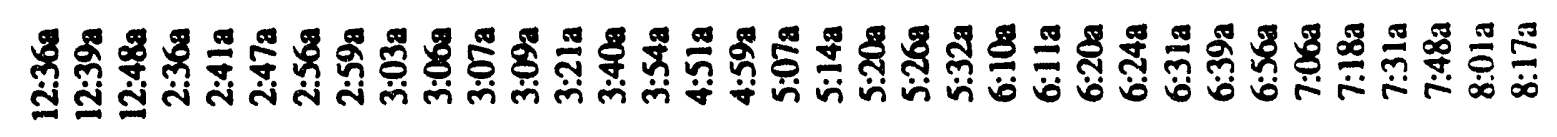

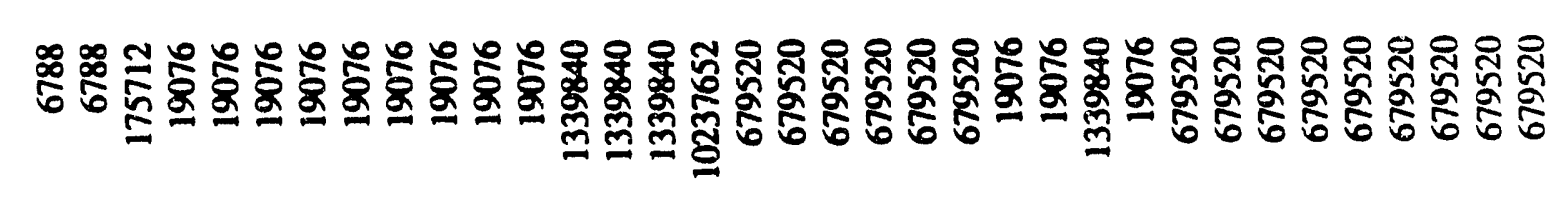

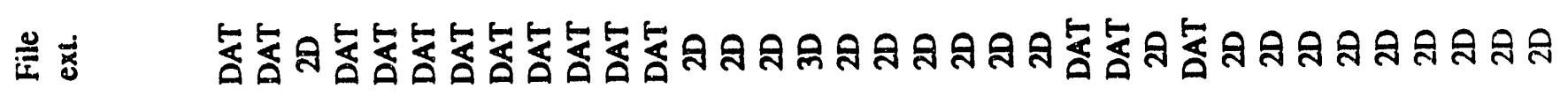


으롤

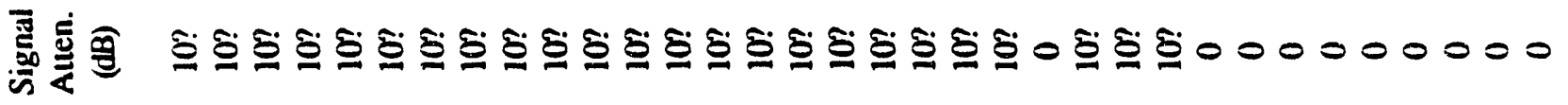

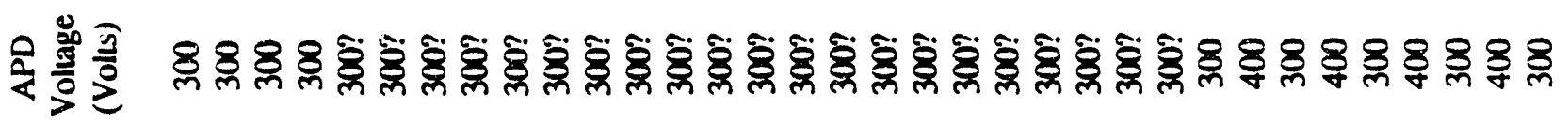

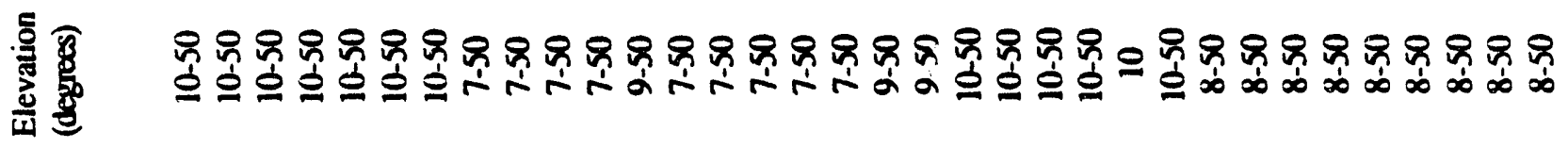

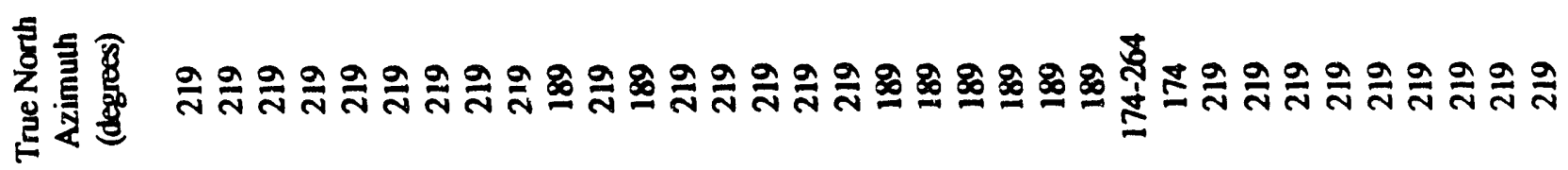
当售

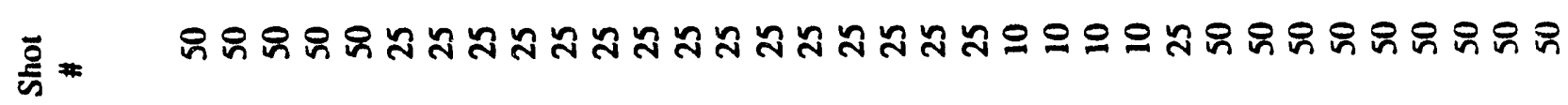

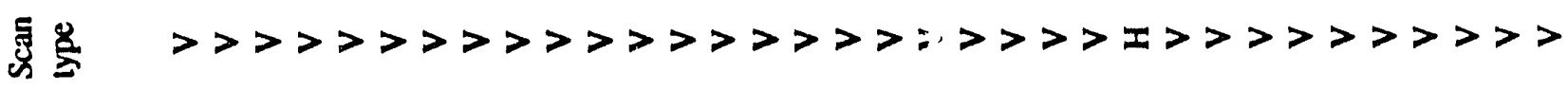
ம்

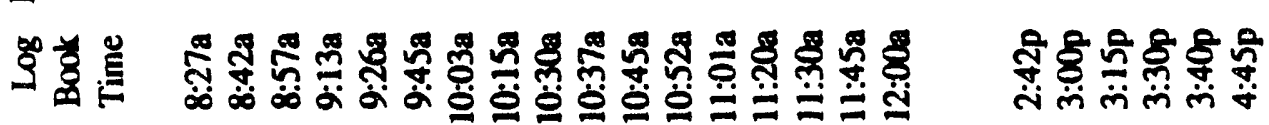

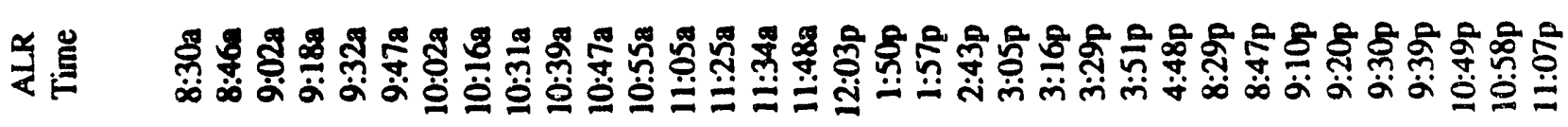

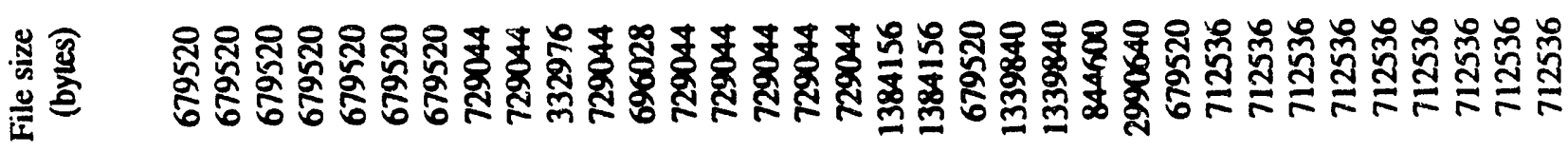

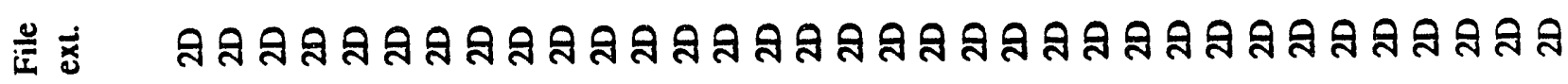

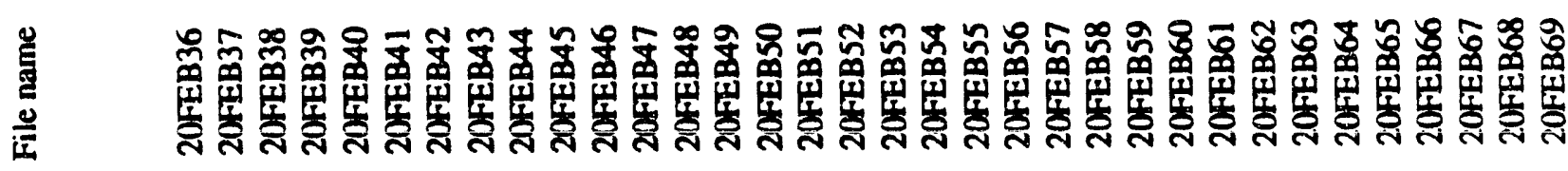


으롤

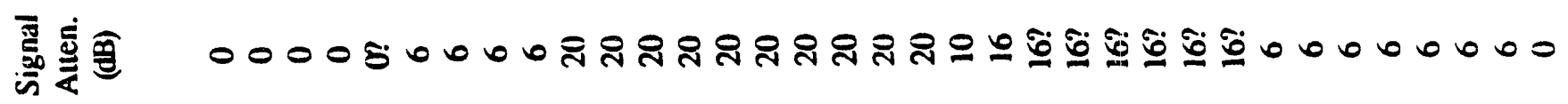

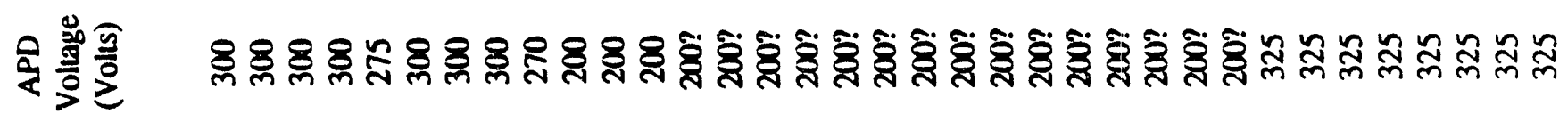

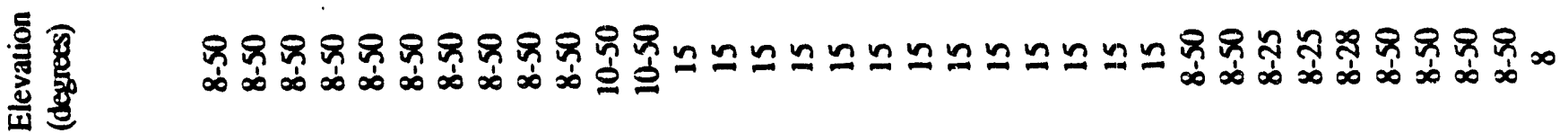

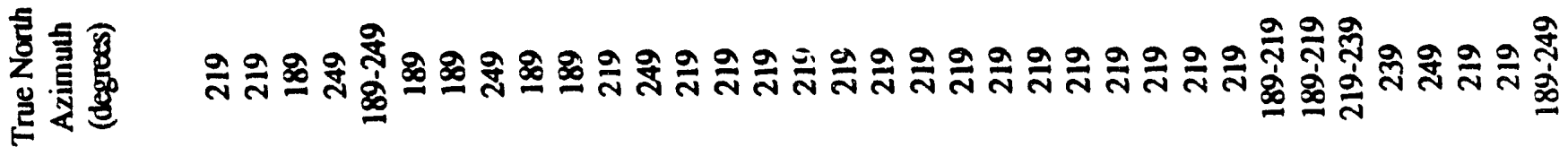

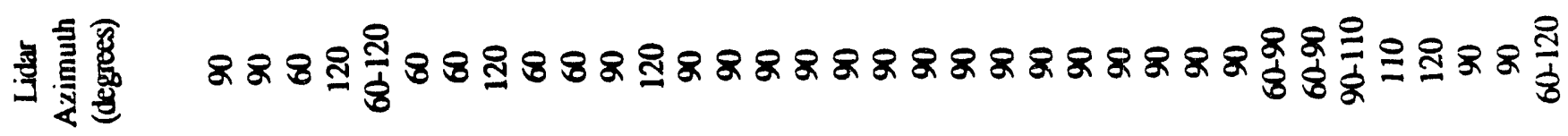
言 $=$

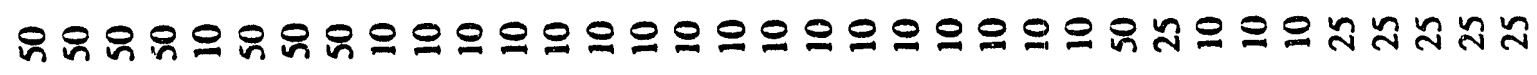

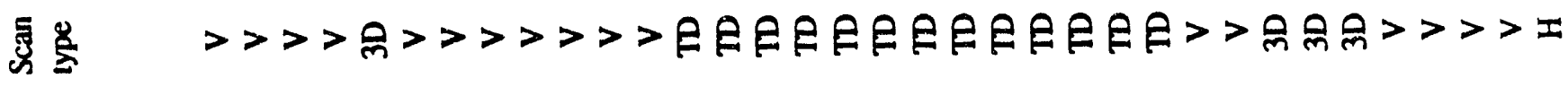
$\stackrel{\infty}{\infty} *$

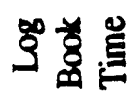

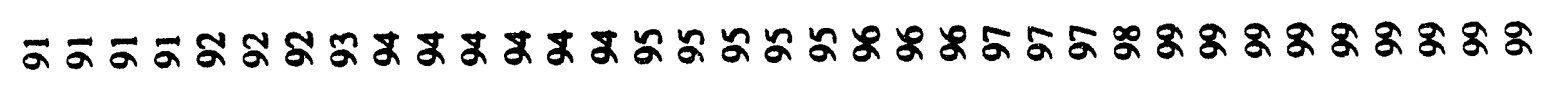

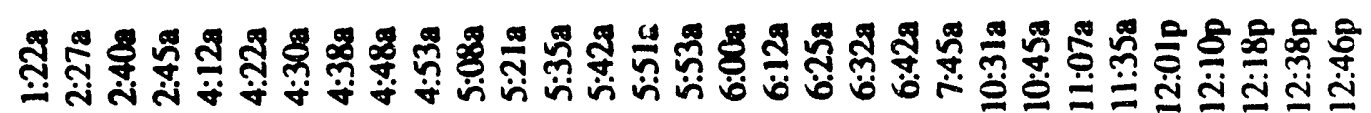
蓙兽

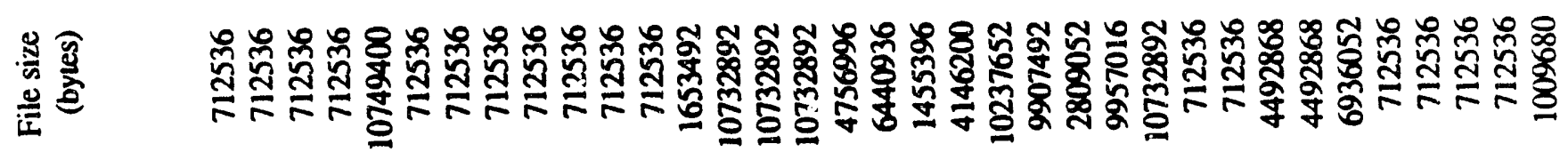
茞

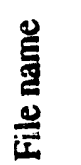

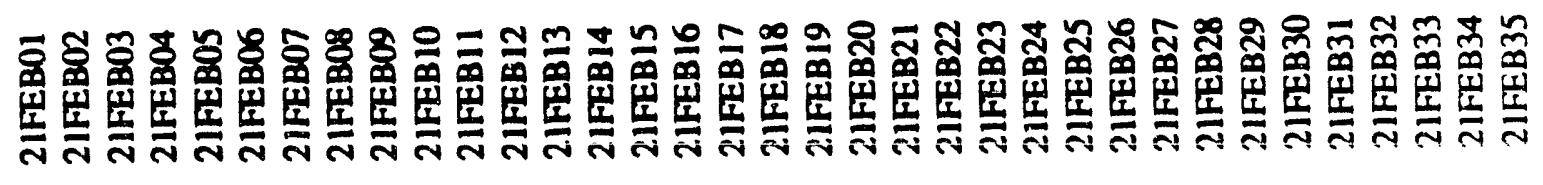




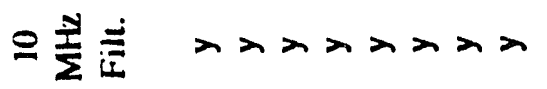

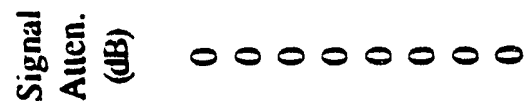

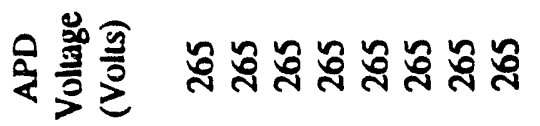

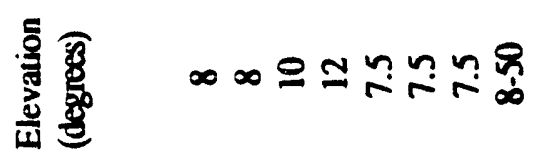

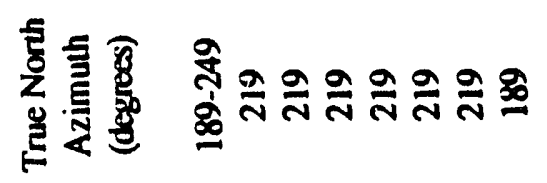

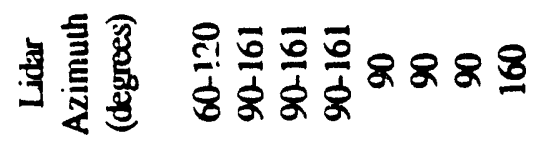

高 * ลงลงองทอ

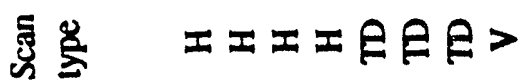

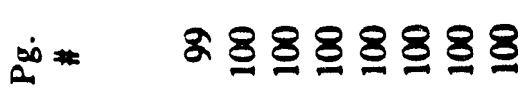

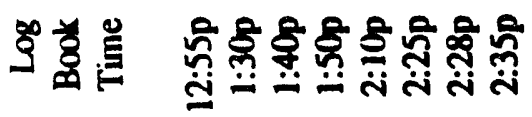

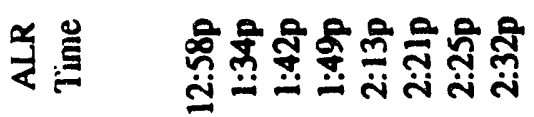

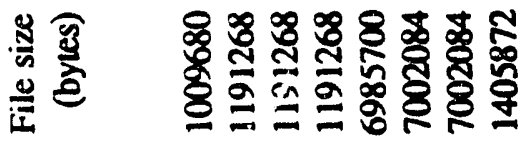

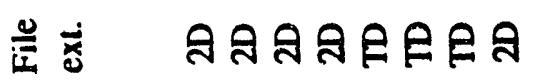

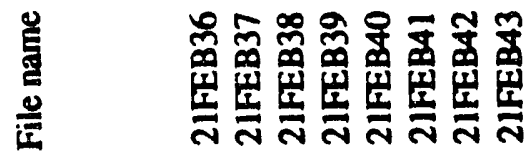

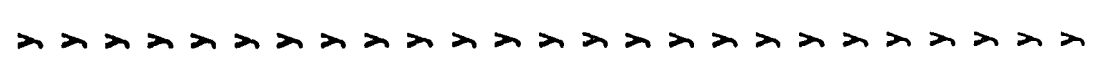

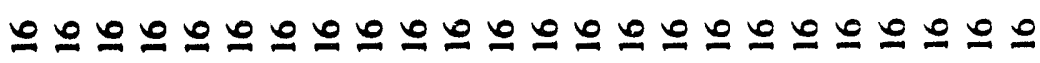

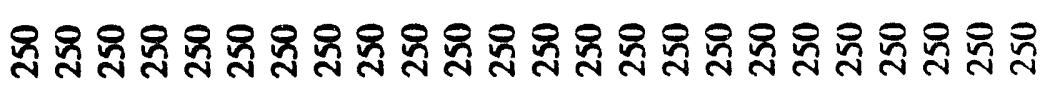

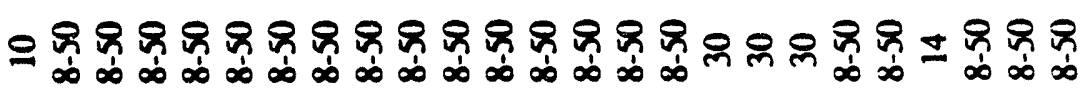

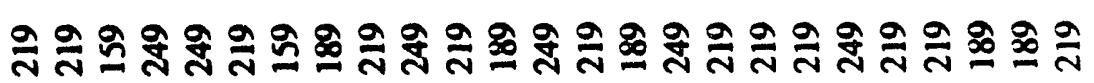

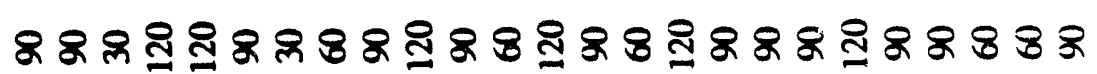

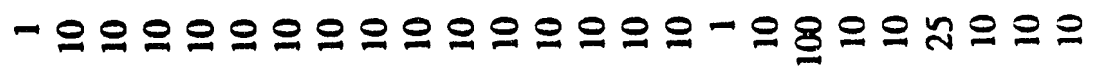

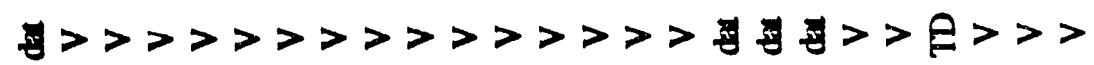

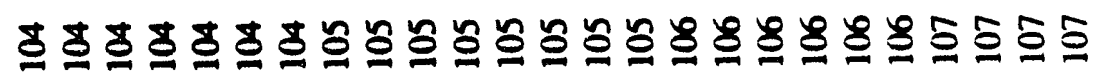

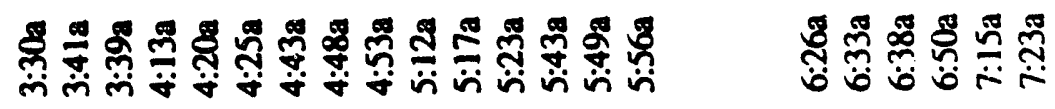

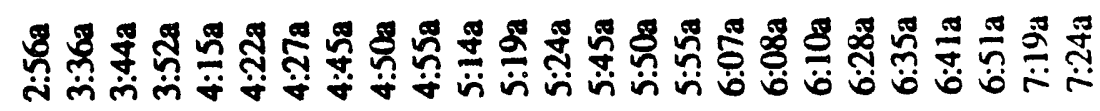

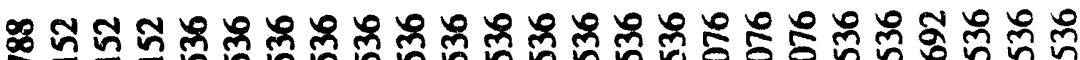

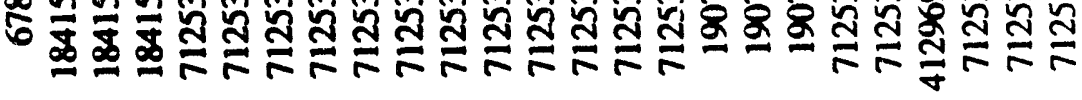

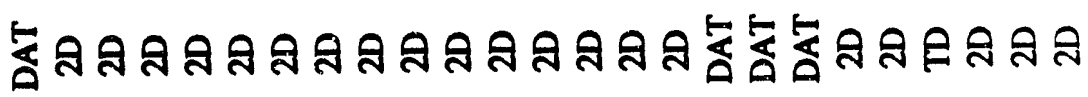

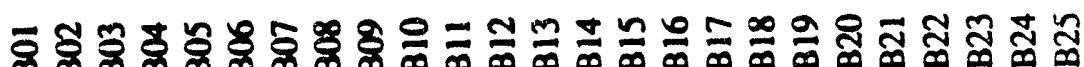

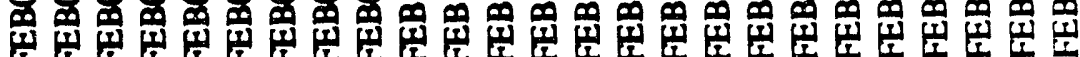
ลง 


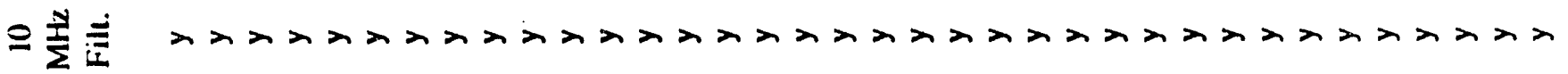

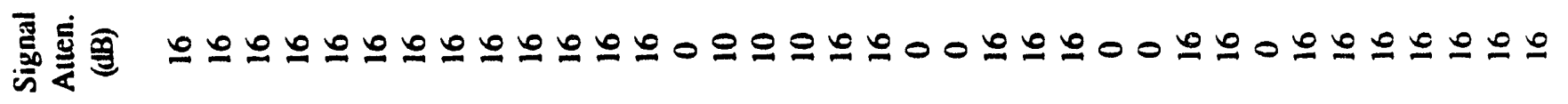
旁善爱

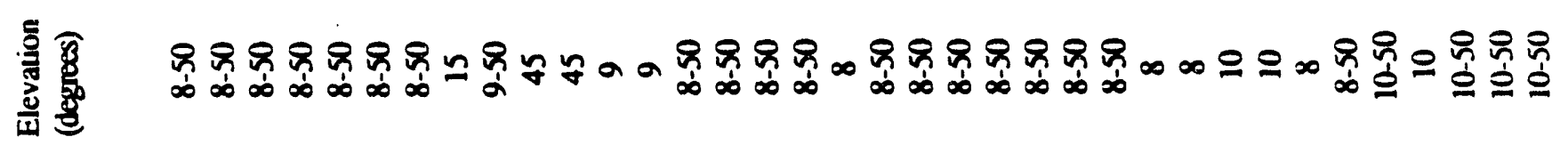

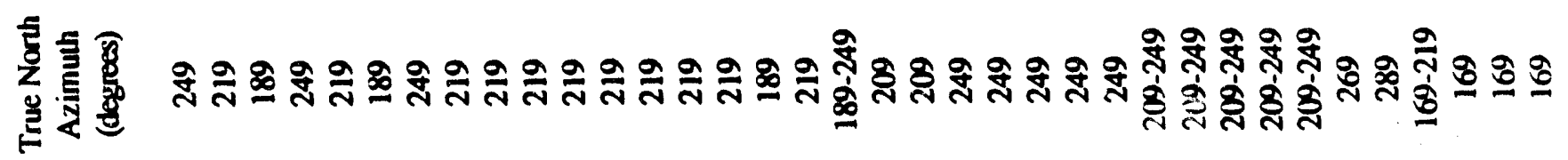

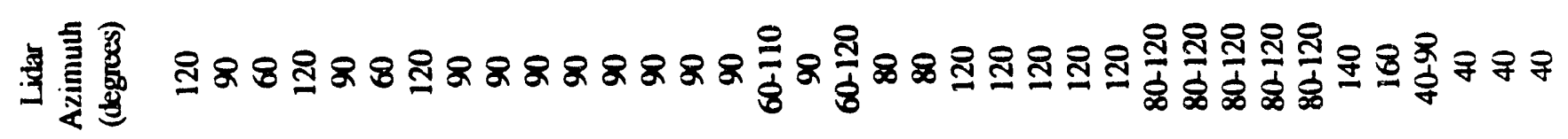

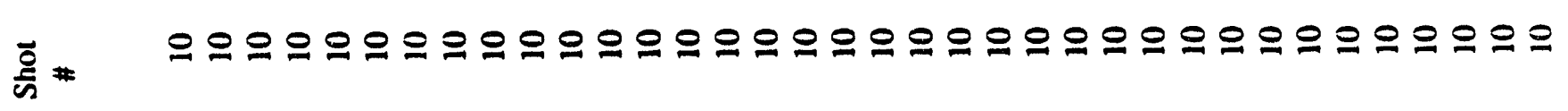

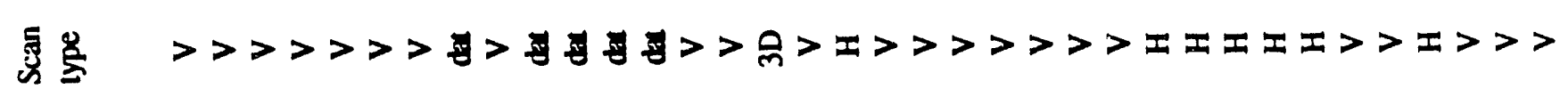
춘.

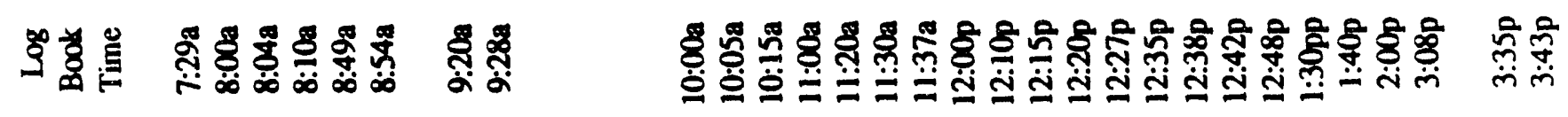

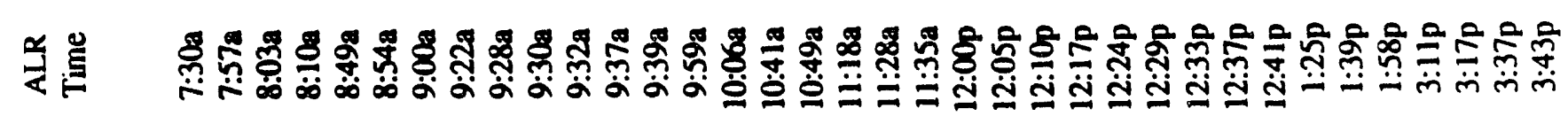

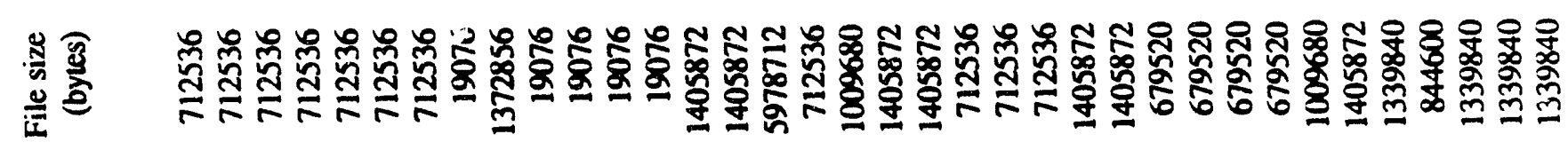

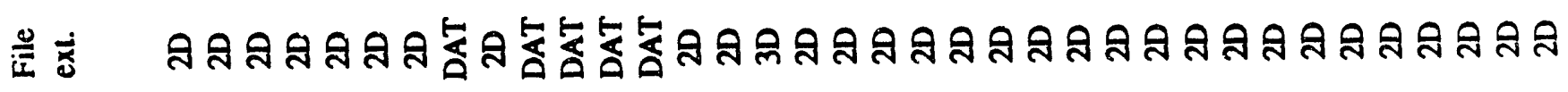

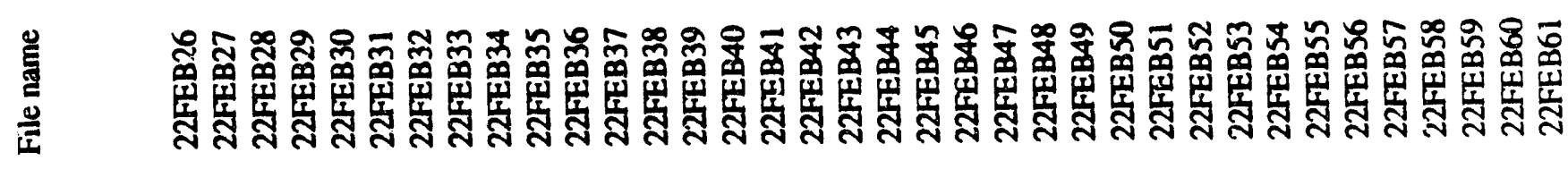




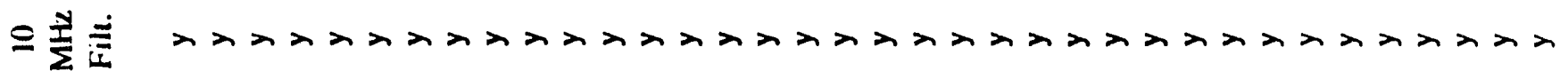

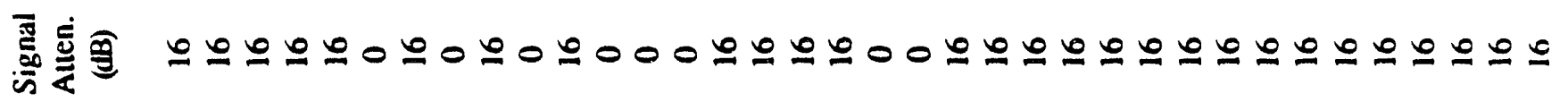

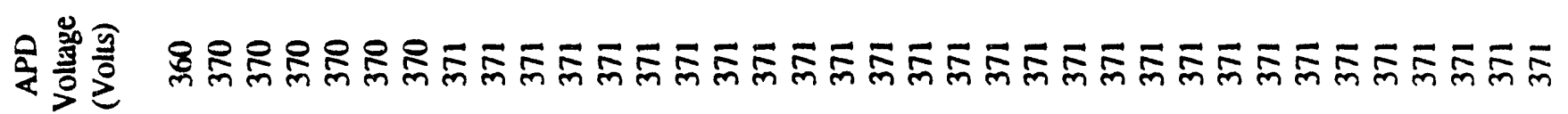

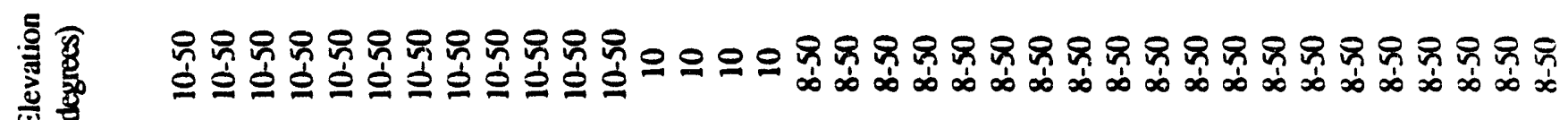

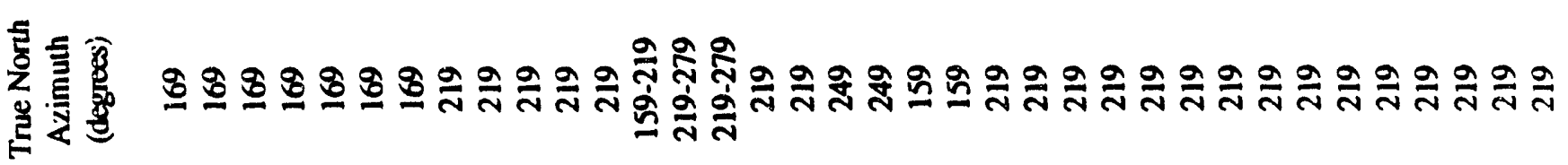

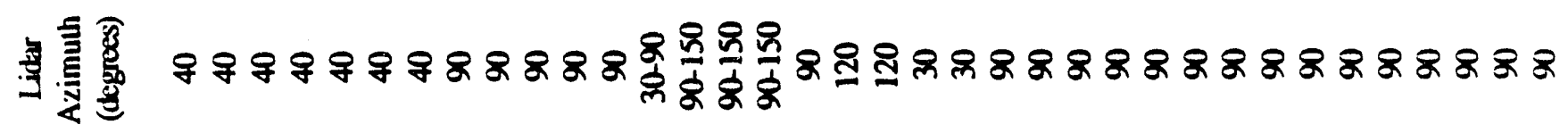

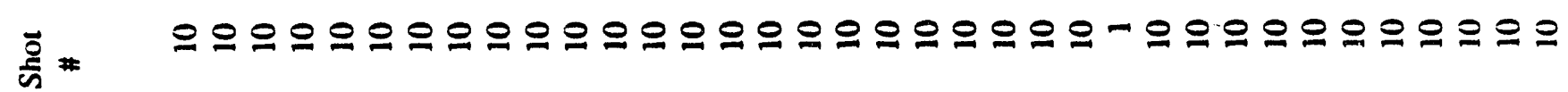

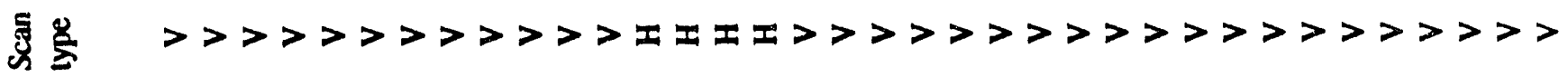

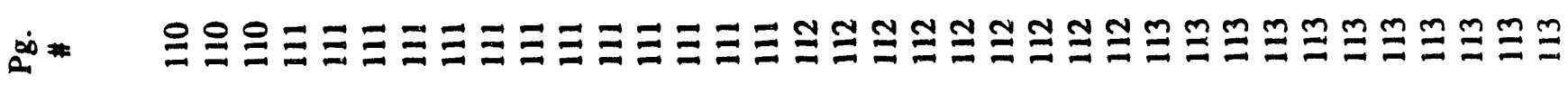

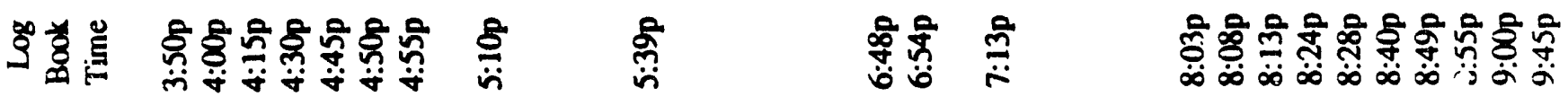

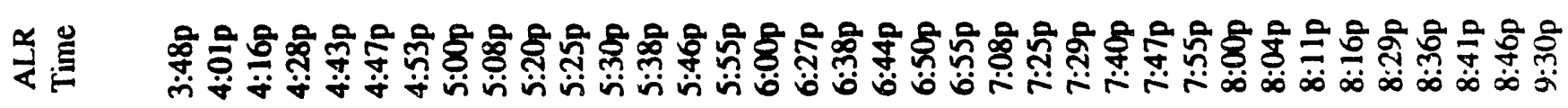

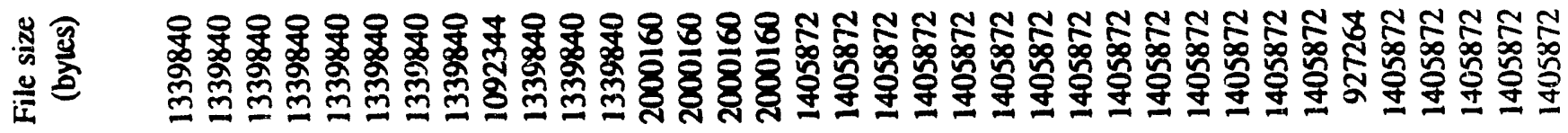
芒

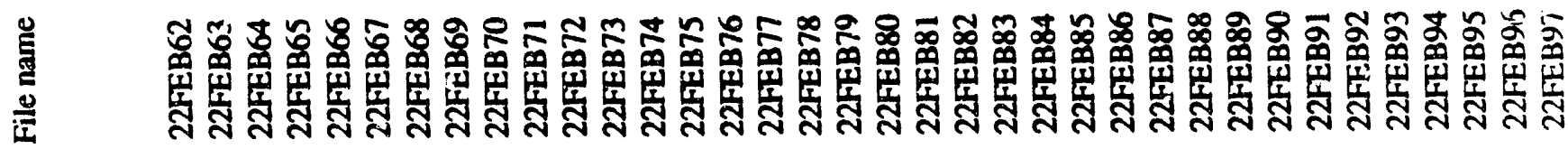




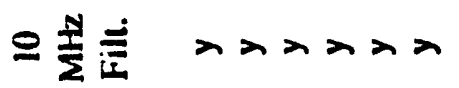

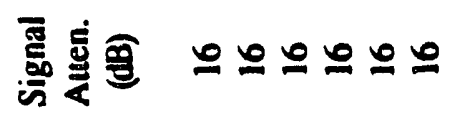

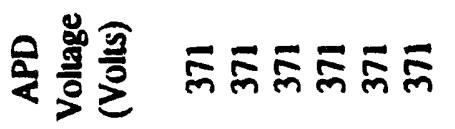

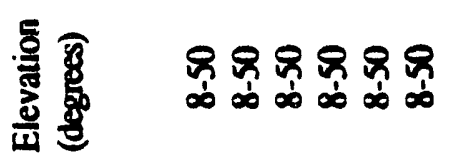

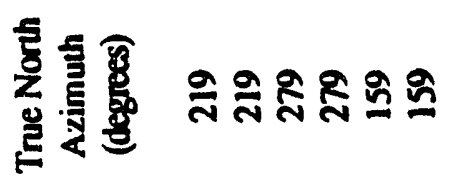

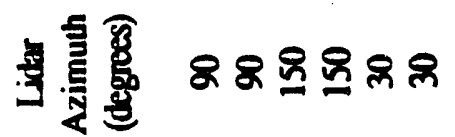

홇 * 으으으요으

震害 $>>>>>$

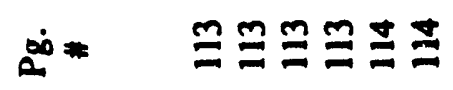

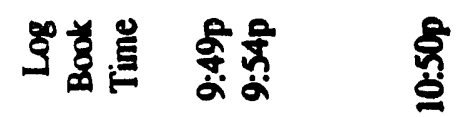

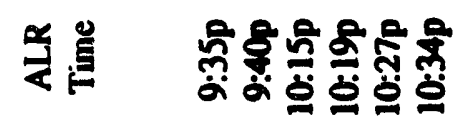

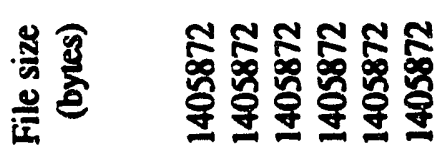

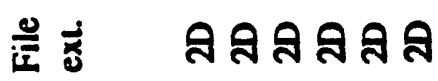

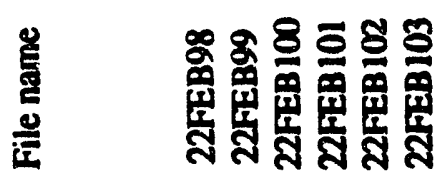

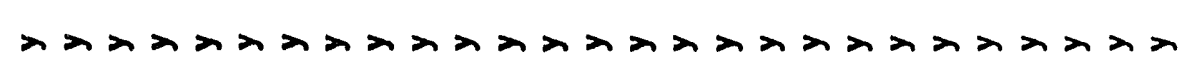

ㄴํํํำ

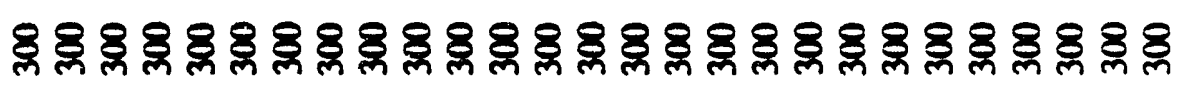

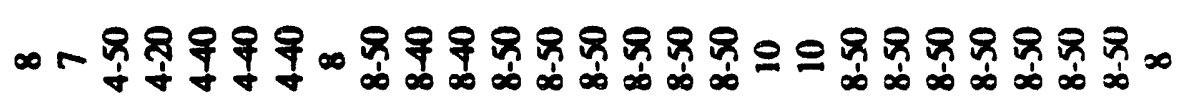

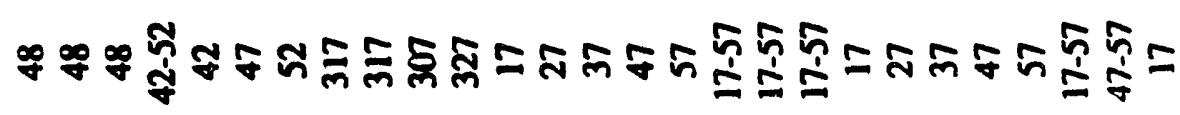

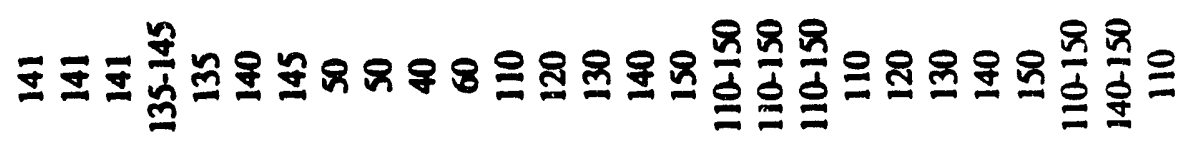
- 으으으으으으으으으으으응ㅇㅇ으으으오으으

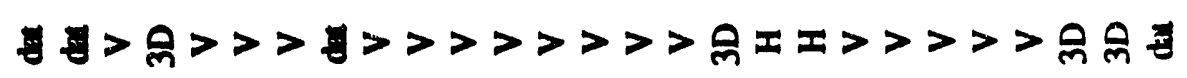

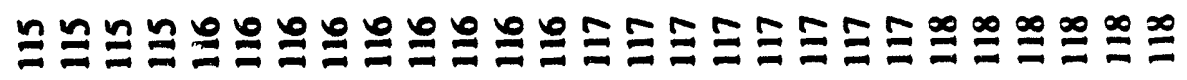
ฟ

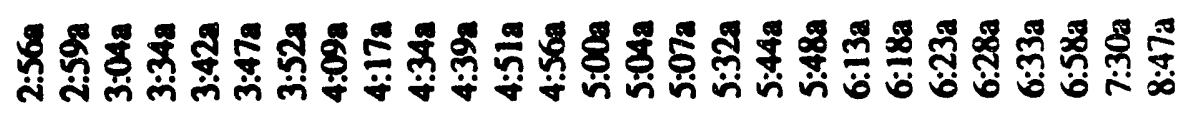

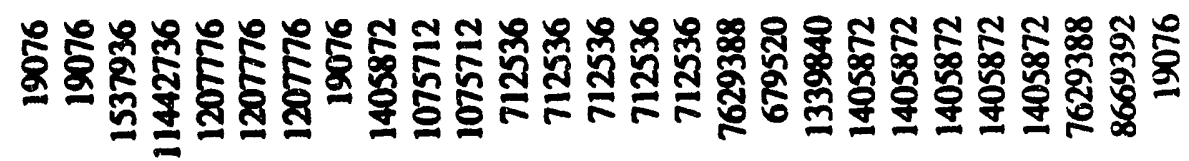

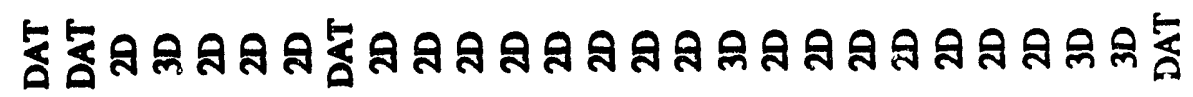

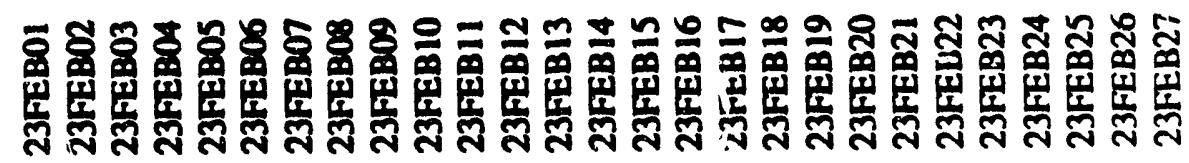


올

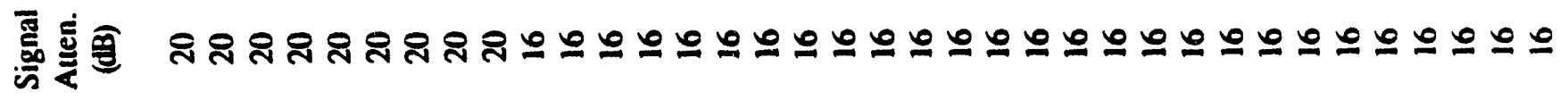

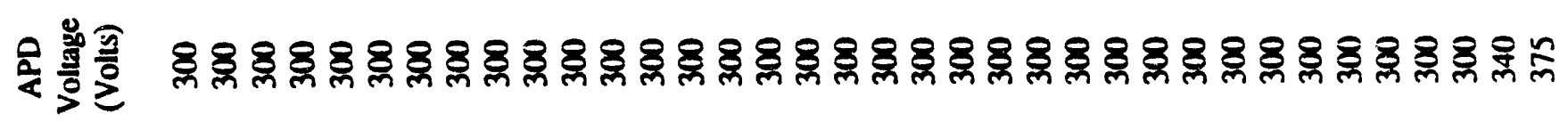

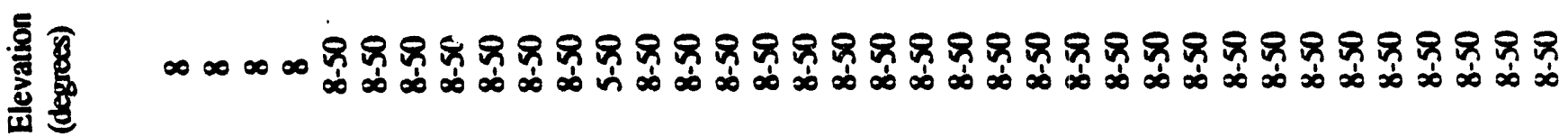

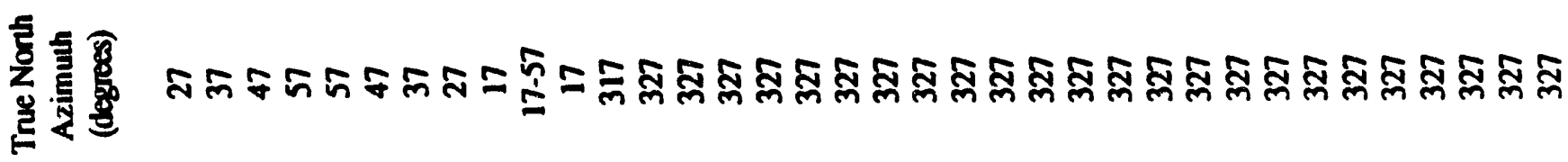

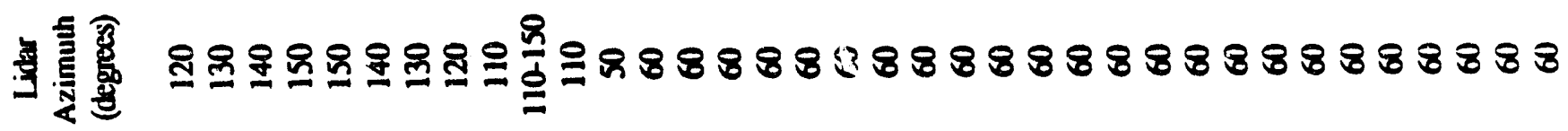

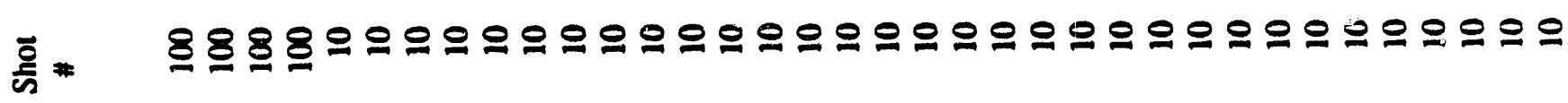

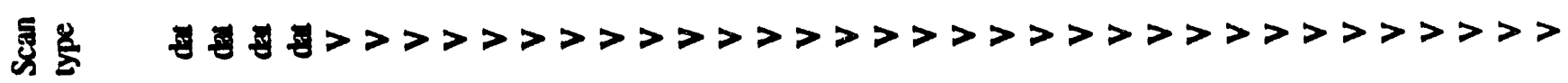

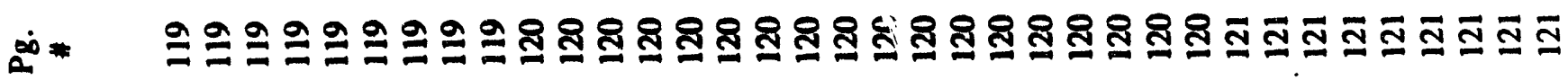

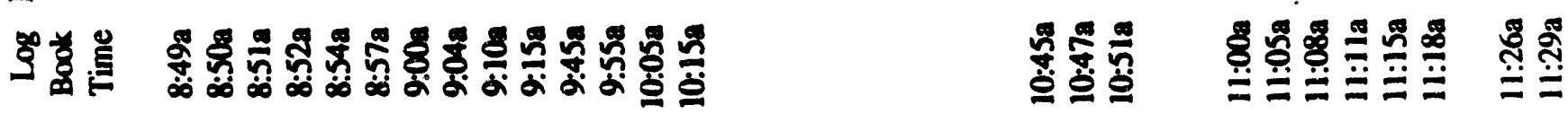

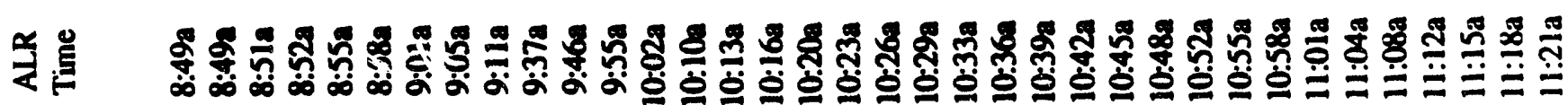
ษ

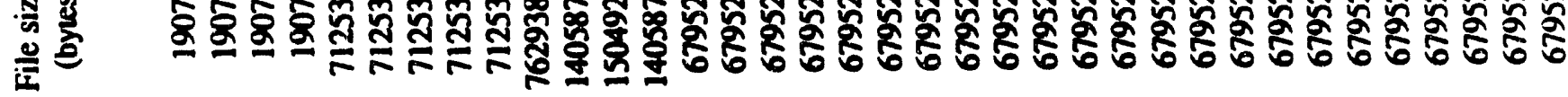

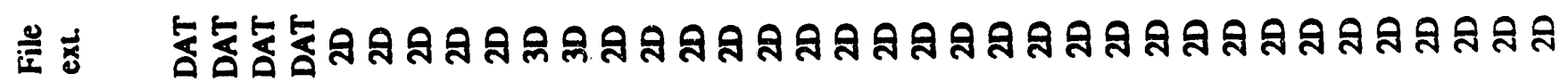

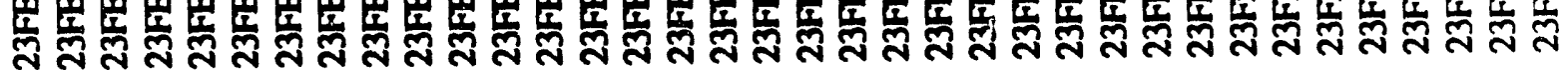




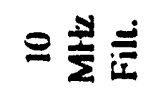

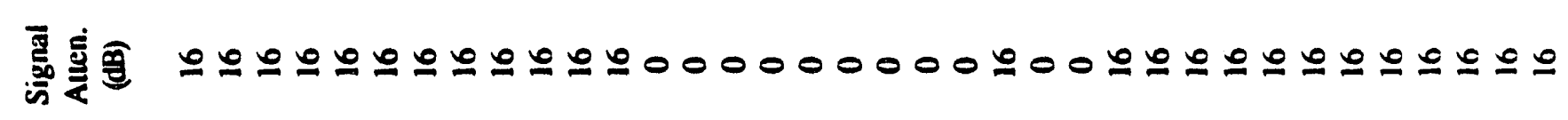

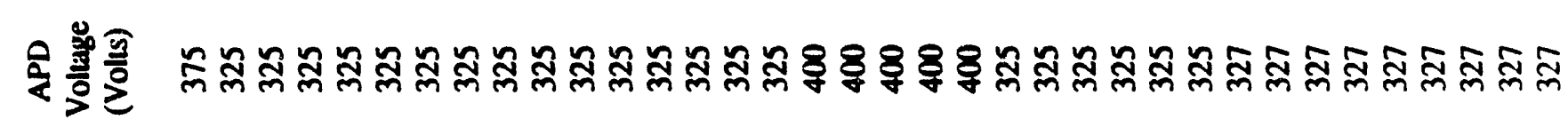

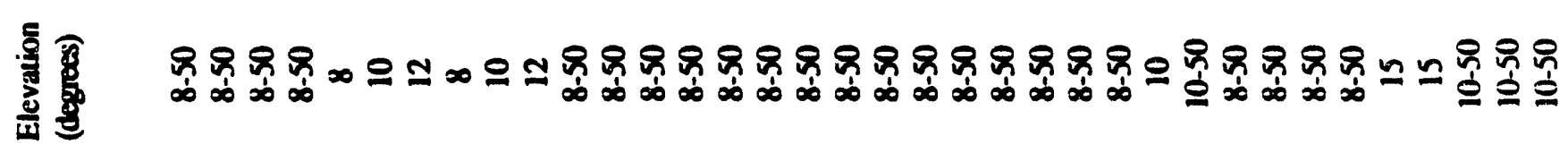

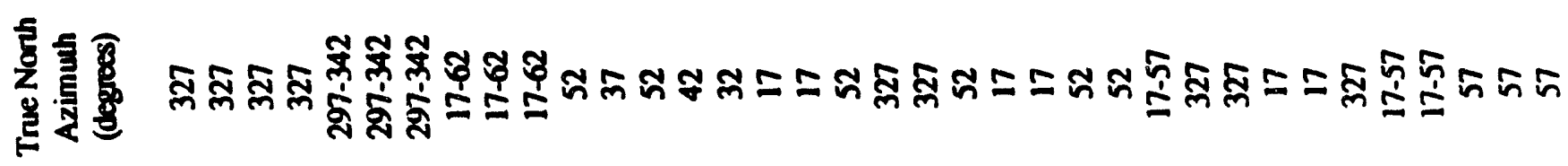

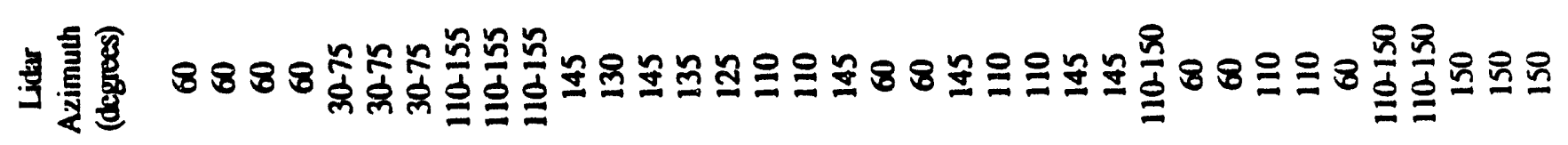

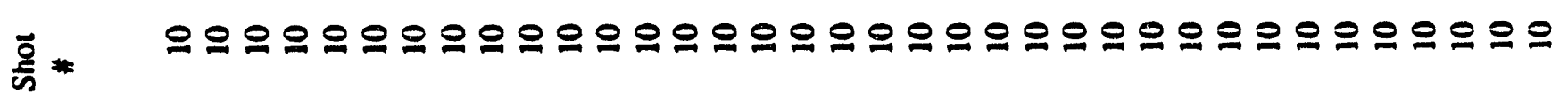
S:

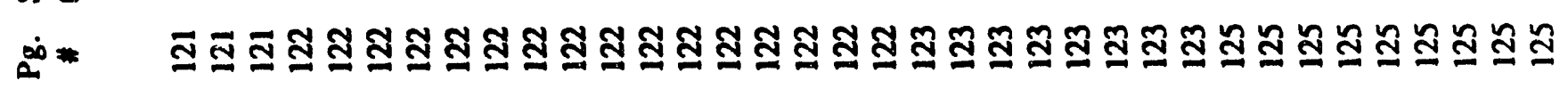

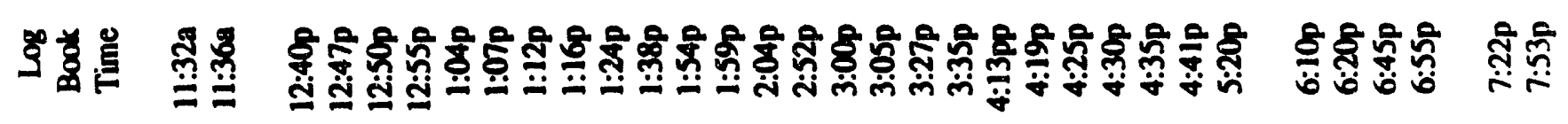

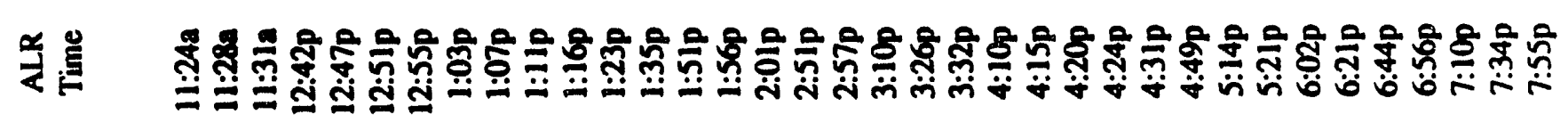

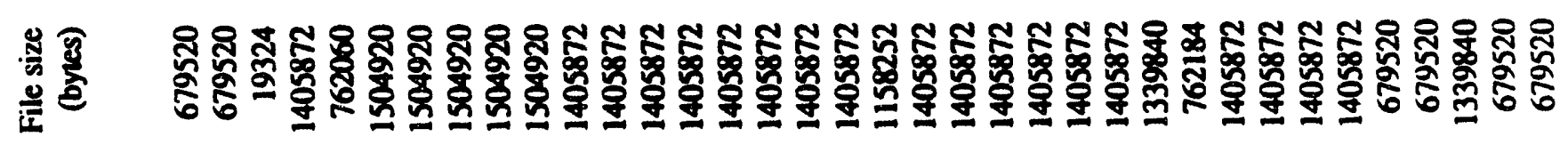

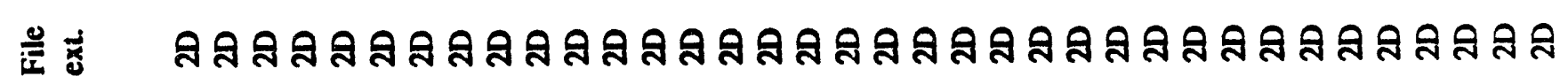

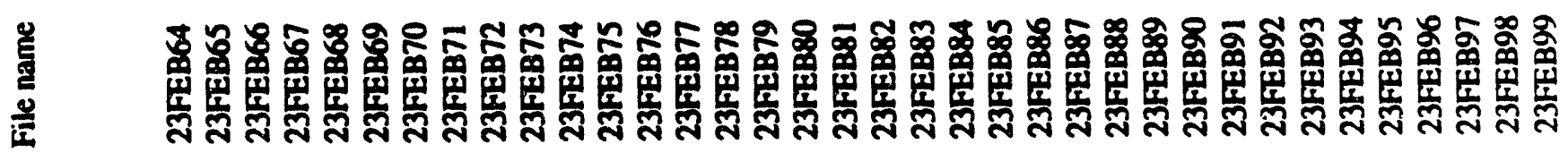


올게

言暨零

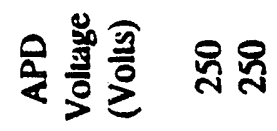

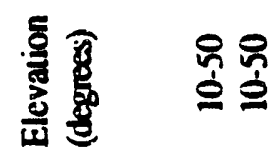

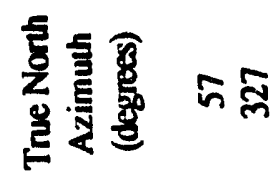

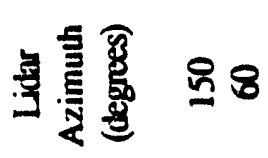

言= $\varrho$

क्ष

ฌ *

写兽兽

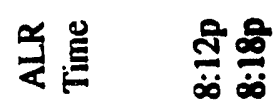

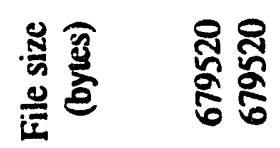

ำ ลว

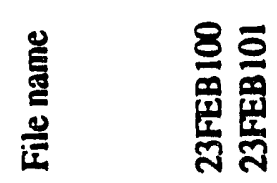




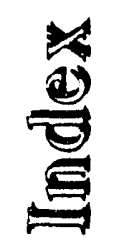

$\frac{4}{9}$

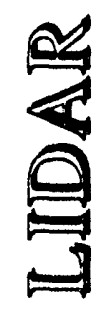

$\rightleftarrows$

(4)

है

$\stackrel{0}{0}$

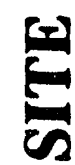

(2) हो

(2)

8

$\frac{1}{2}$

0

$2 \sum$

01

2

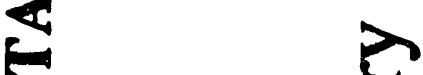

0 हु

- 훙

$\sum_{i}^{4}$

$\frac{9}{25}$ 


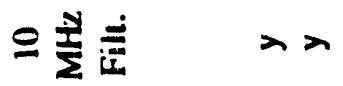

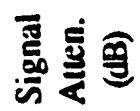

000000000000000000000000000000

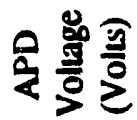

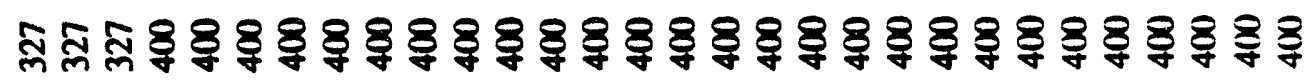

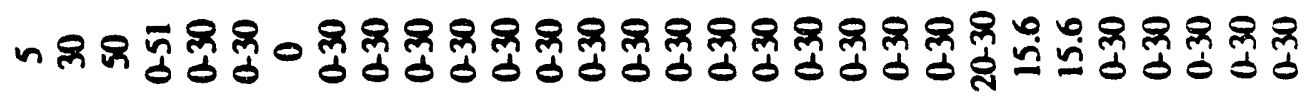

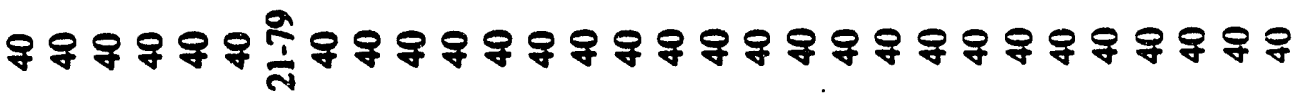

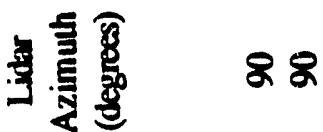

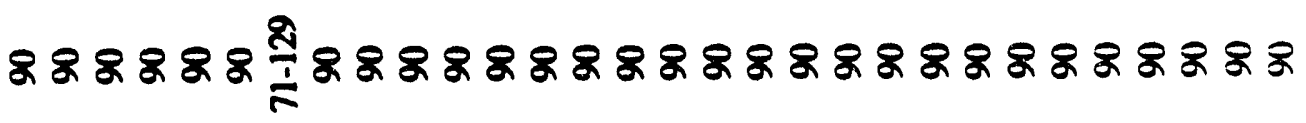
递

으요

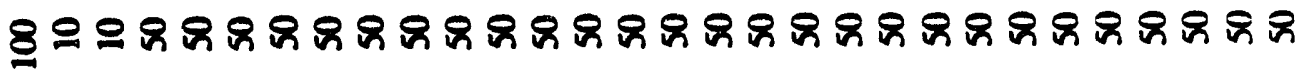

氖 产 죵 좡

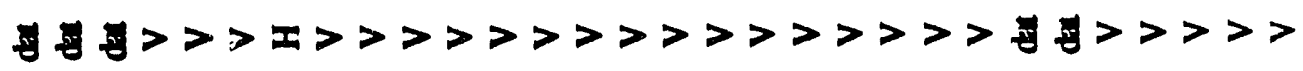
$\dot{\infty}=$ తి జి

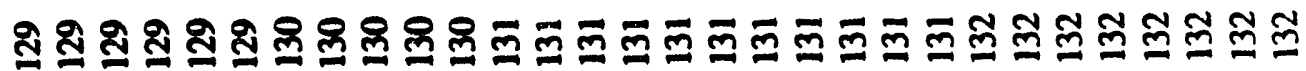

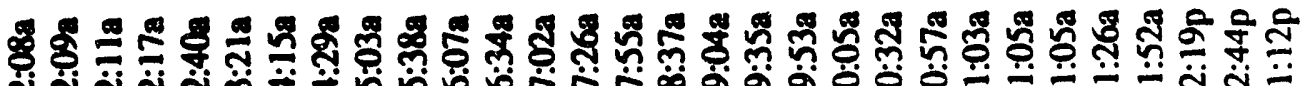


으롤 롤

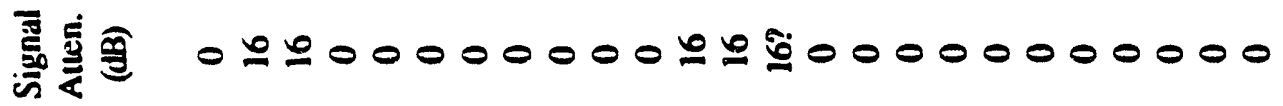

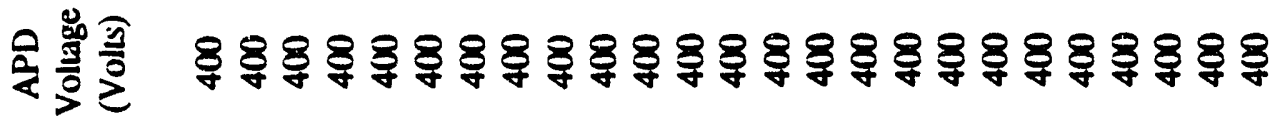

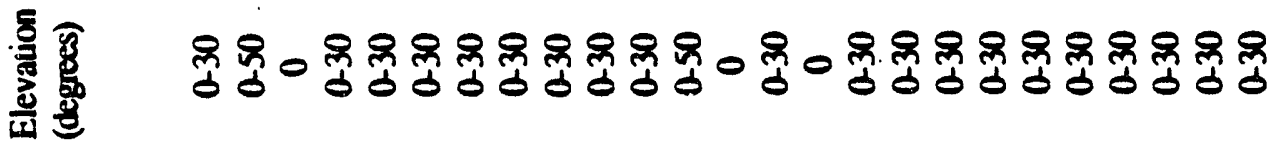

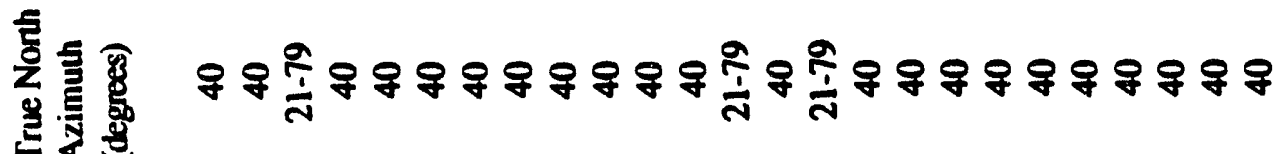

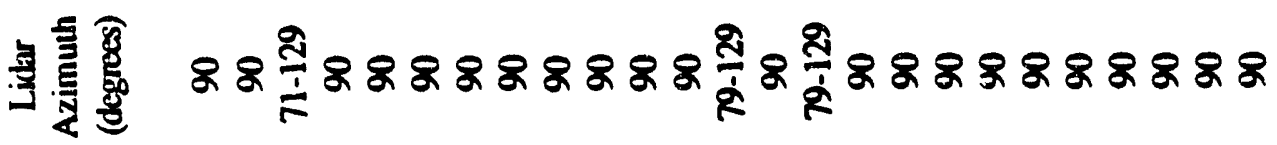

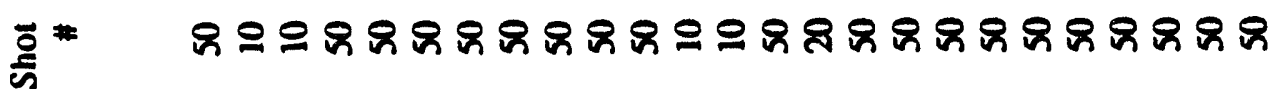

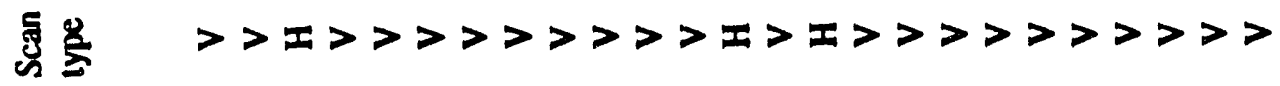

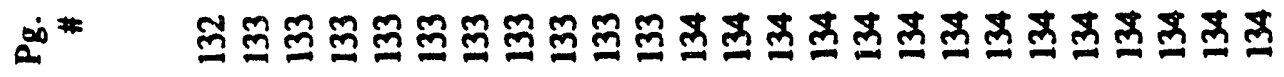

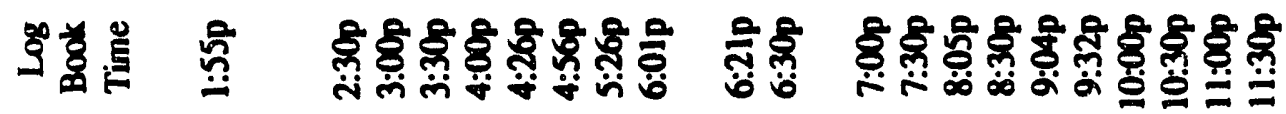

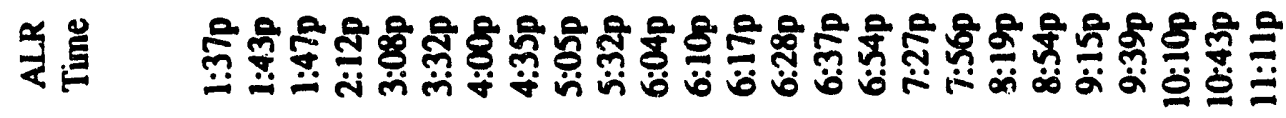

ॠ承

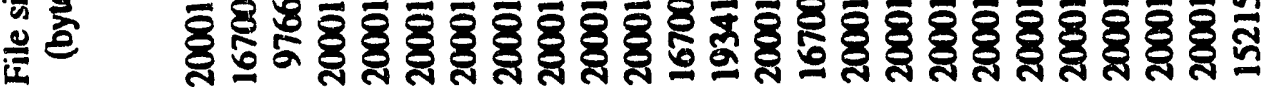

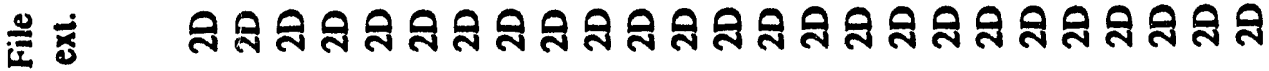

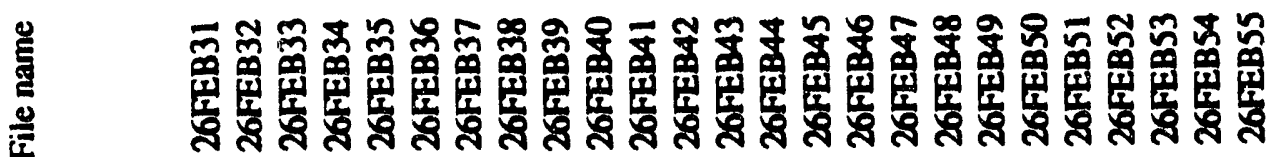


으롤

谭焉争 000001000000000000000000000000000000

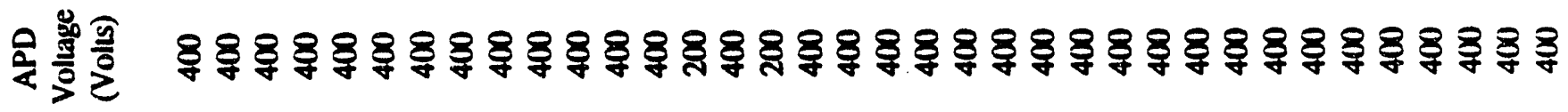

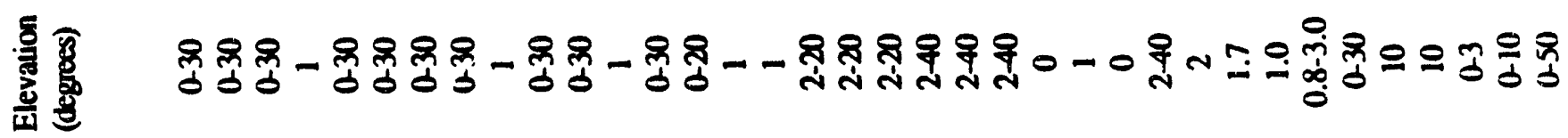

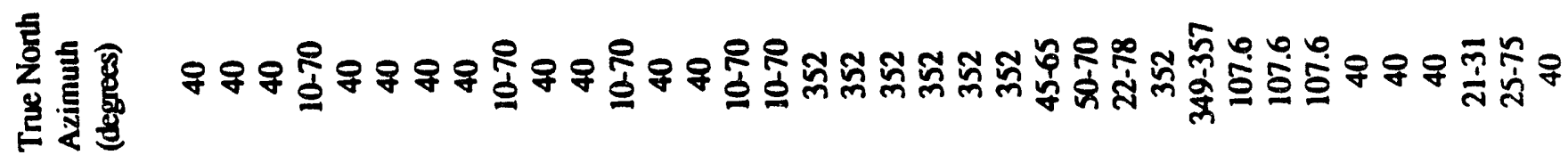

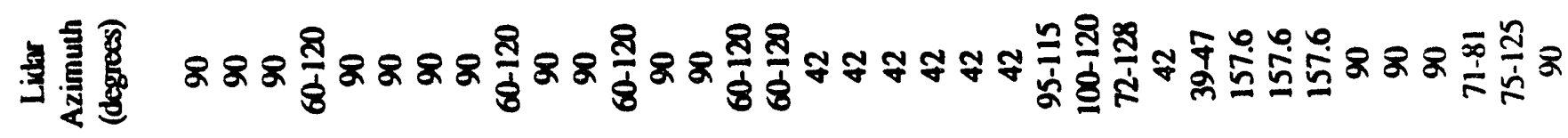

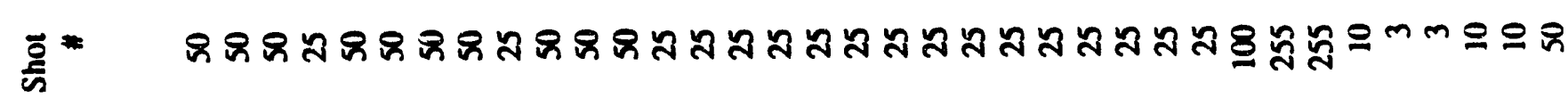

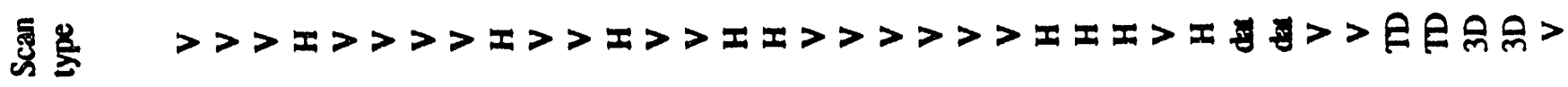

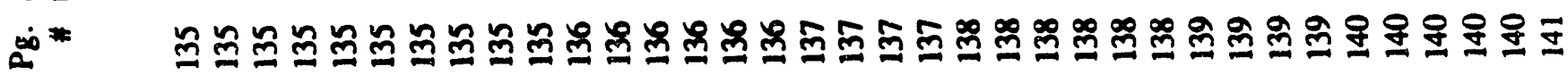

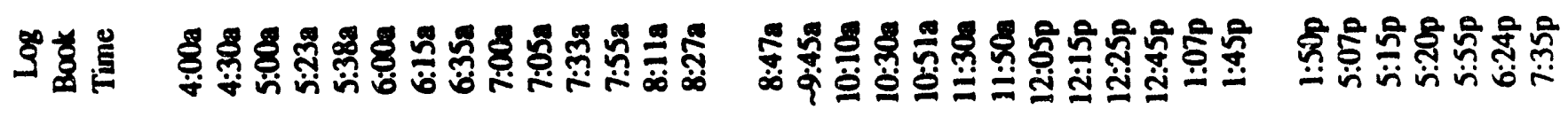

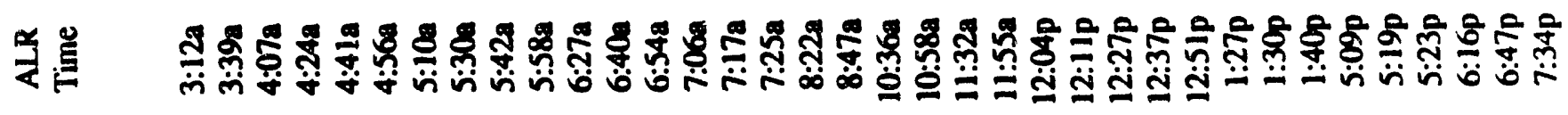

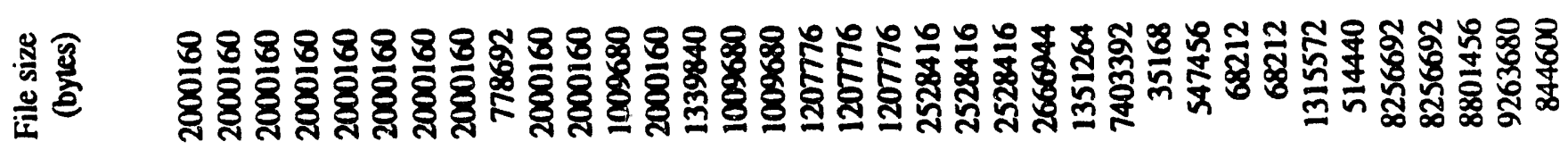

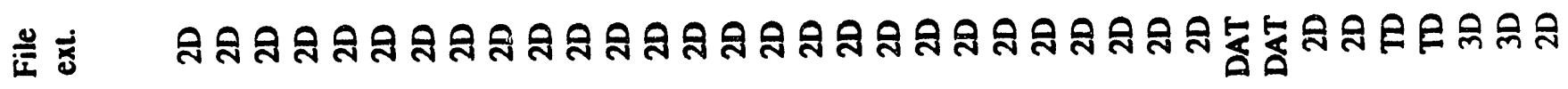

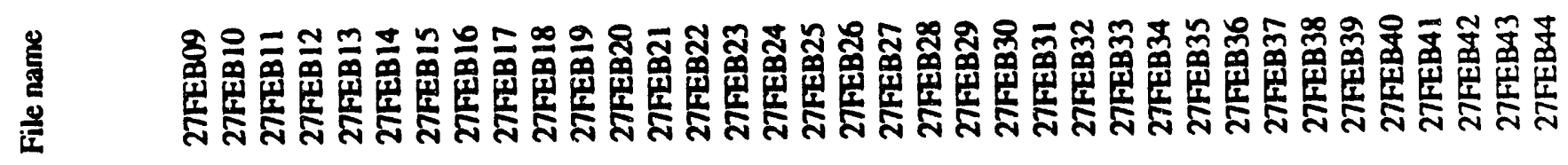




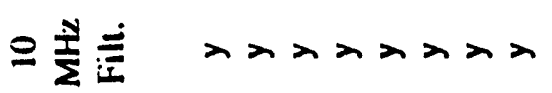

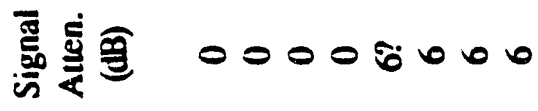

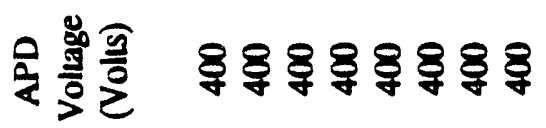

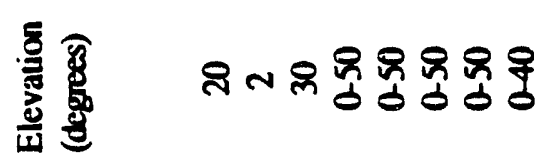

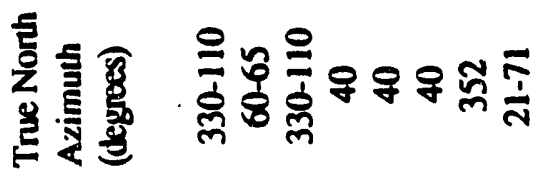

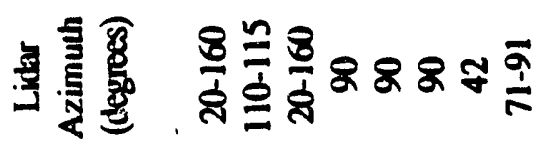

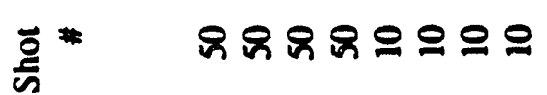

零 $匚 x=>>>0$

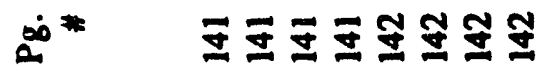

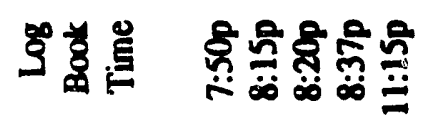

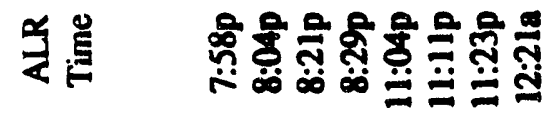

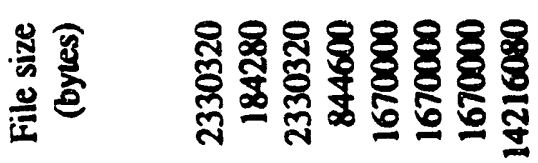

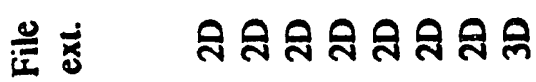

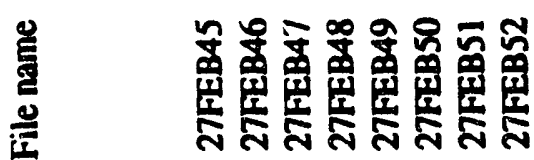

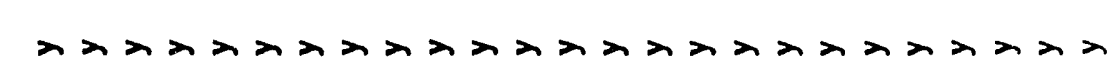
๑

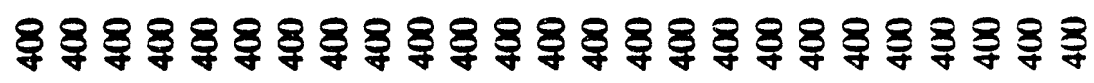

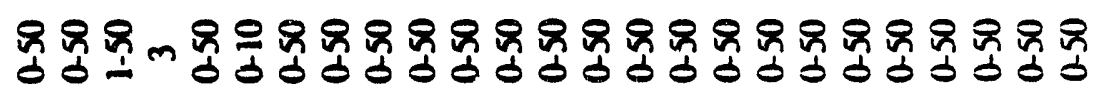

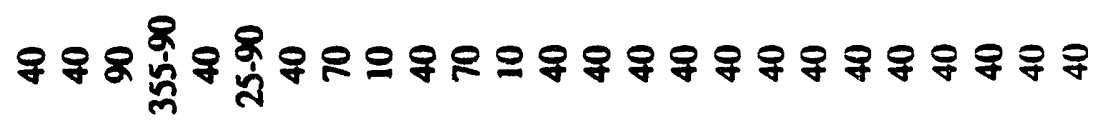
ระ镂8

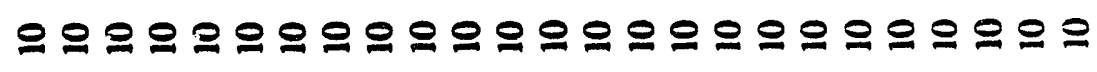
$>>>$ I

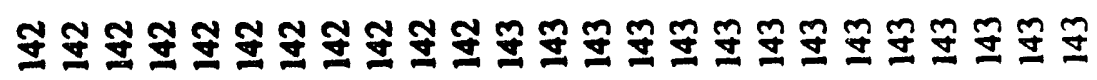

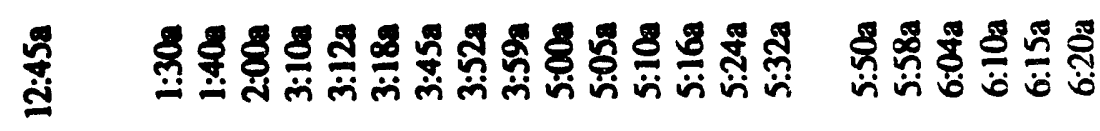

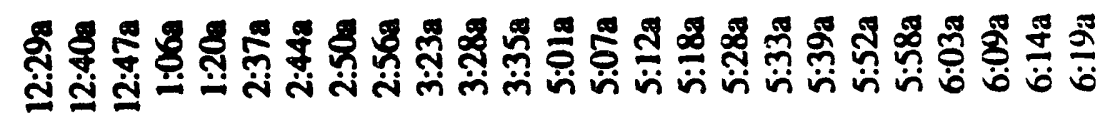

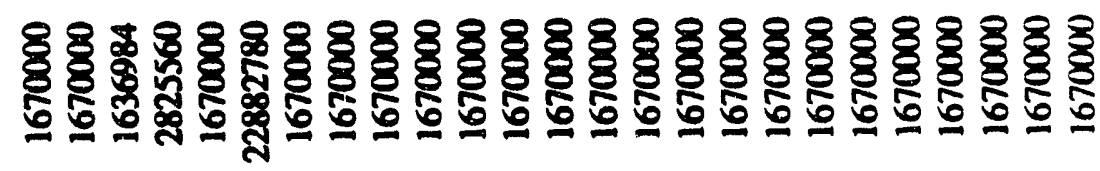
ลวลลวลว

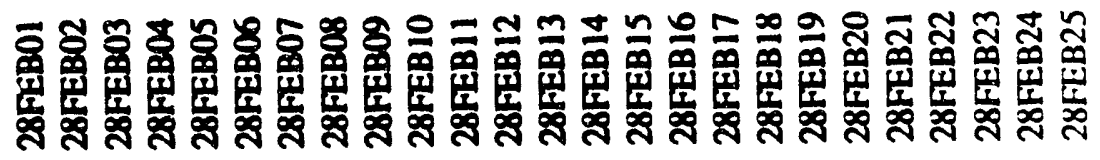




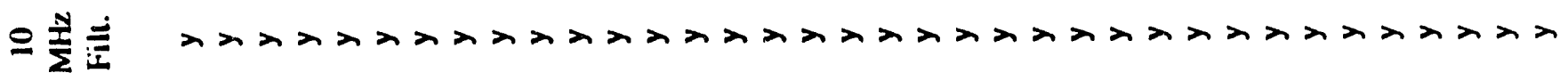
霹茛 000000000000000000000000000000000000

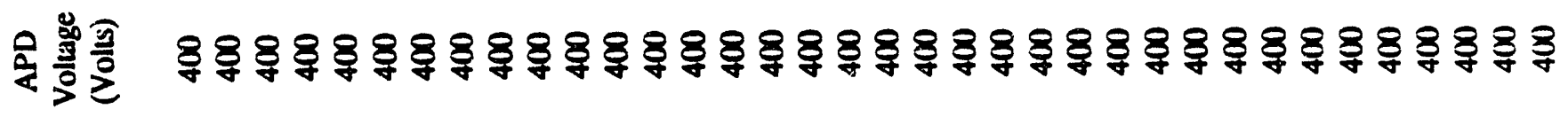

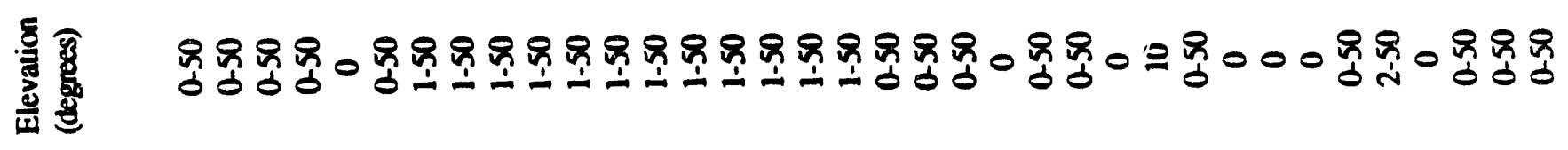

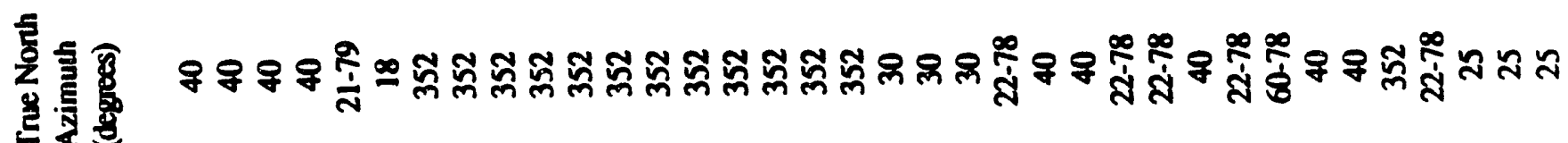

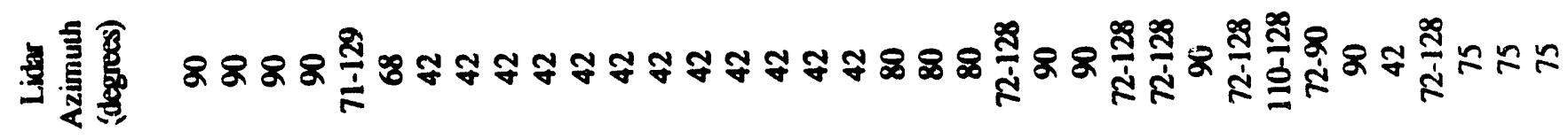

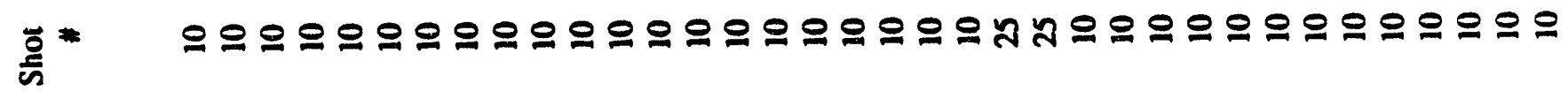
总

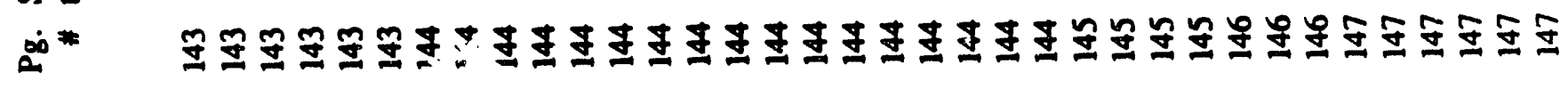

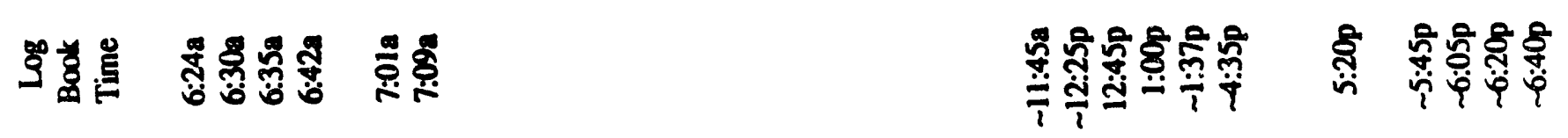

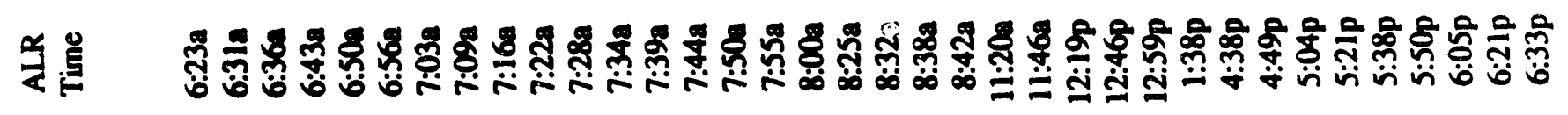

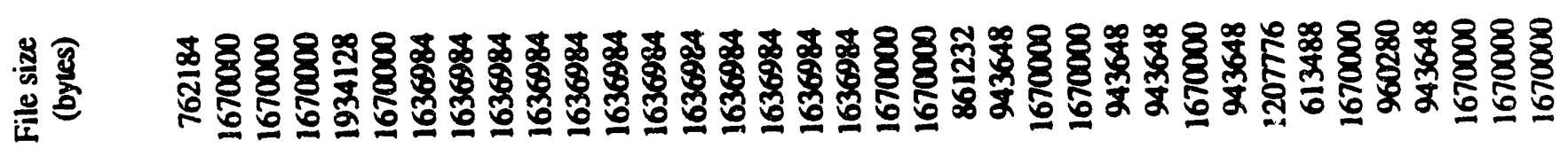
这

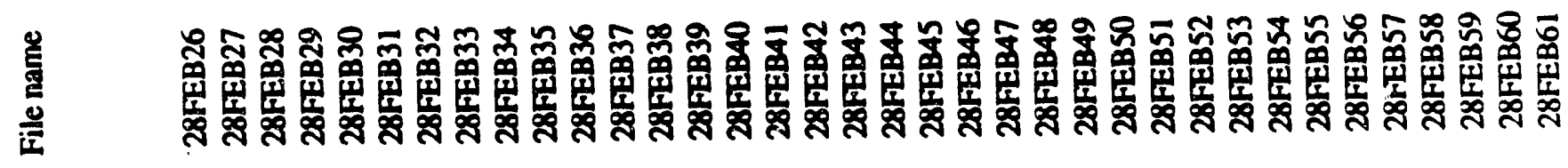


里衰定

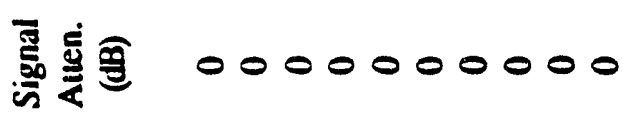

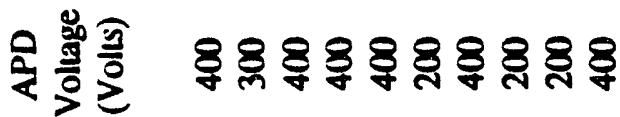

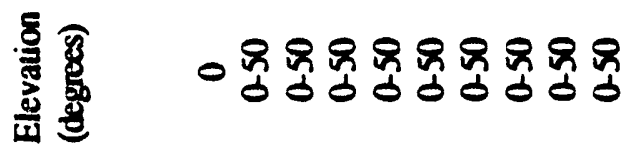

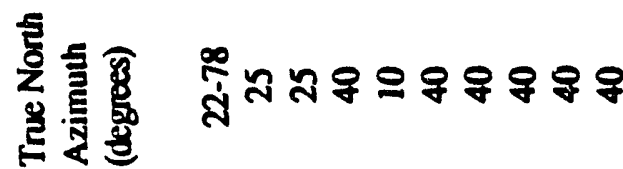

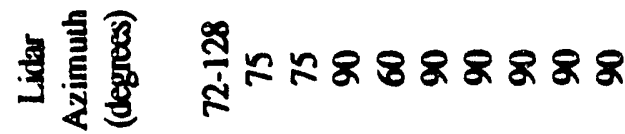

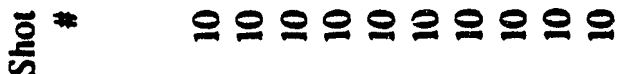

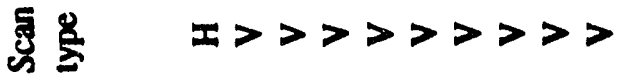

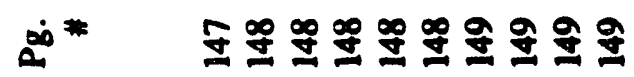

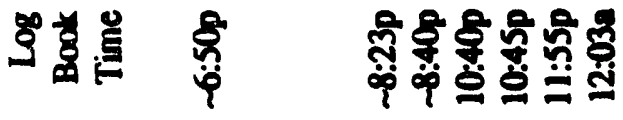

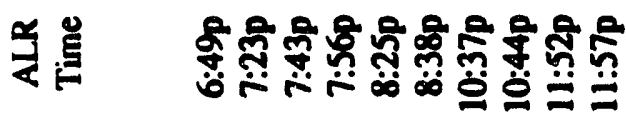

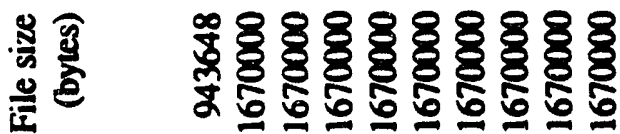

ํํำ สิ สิ สิสิ สิ สิ สิ สิ

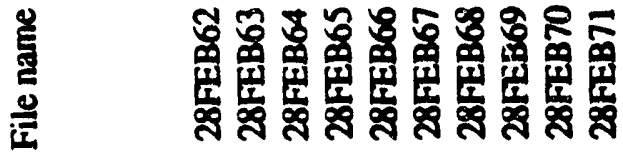

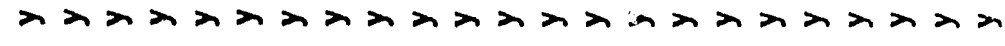

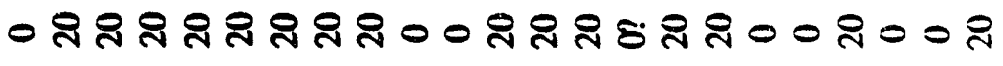

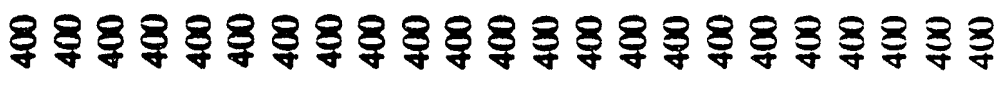

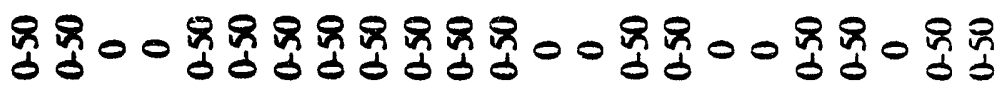

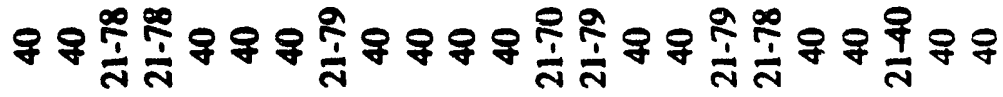

ร8

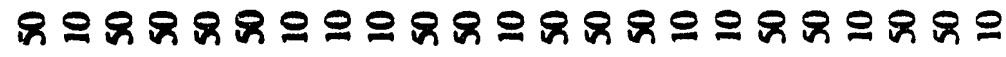

> $>I x>>>I>>>I I>>I I>>I>>$

nnn nnn n

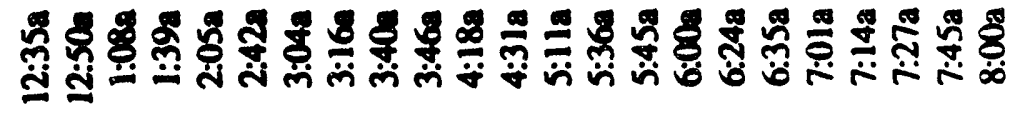

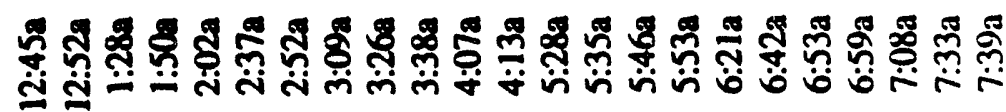

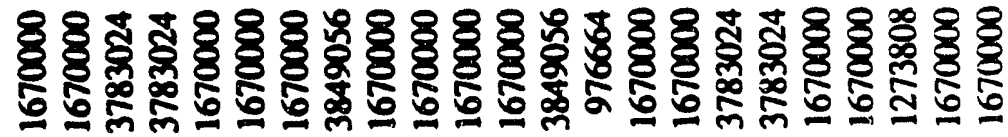

ลิ สิ สิ สิ สิ สิ ลิ สิ สิ สิ สิ สิ สิ สิ สิ สิ สิ สิ สิ ลิ สิ สิ สิ

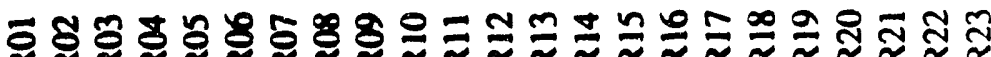

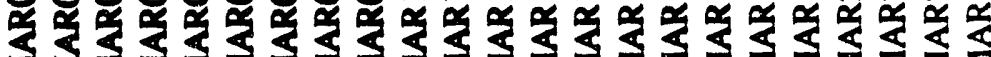

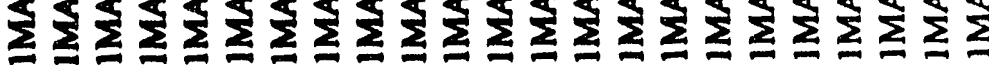


을

要离离。

定器旁

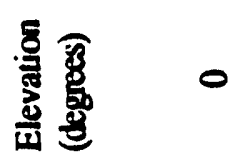

喜变

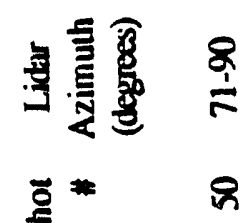

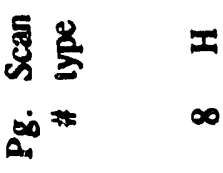

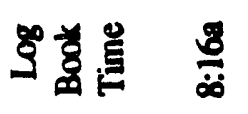

学害

密高 离

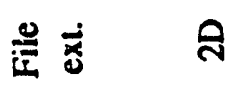

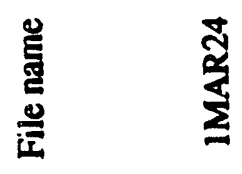




\section{Appendix B}

APD Sensitivity vs Bias Voltage 


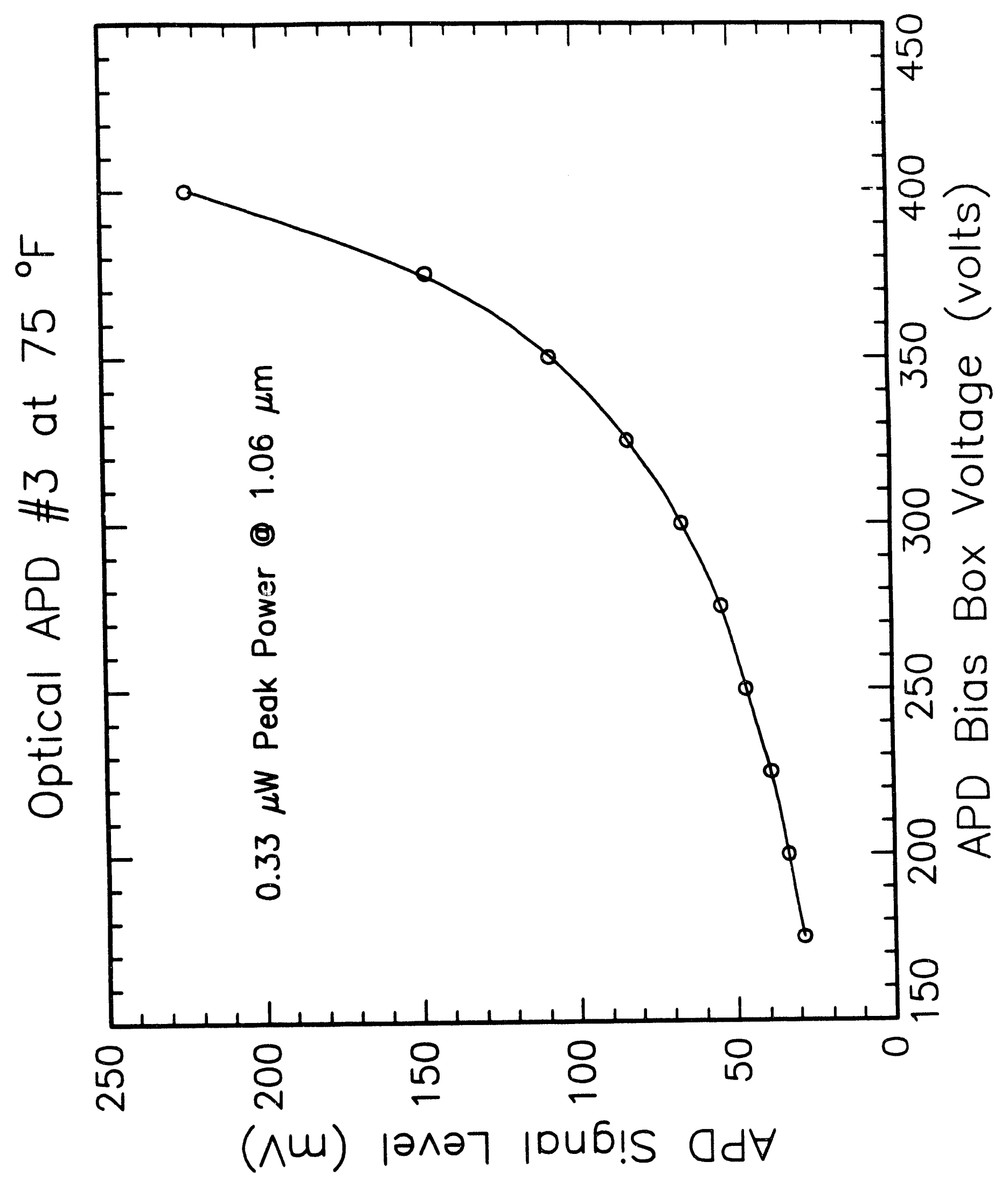




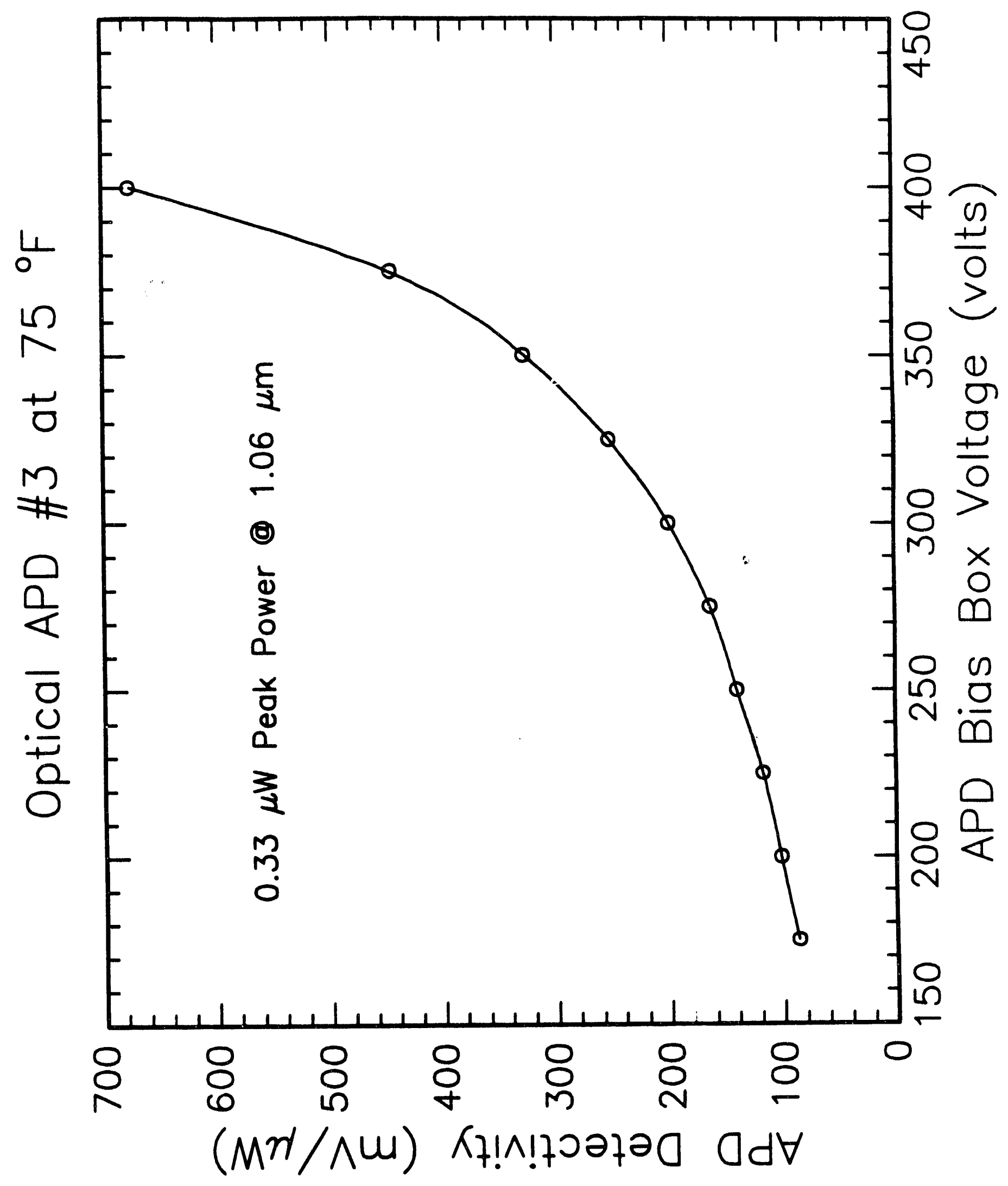




\title{
Appendix C
}

\author{
Atmospheric Extinction Effects, \\ Systematic and Random Noise in the Data
}


Detailed analysis of the lidar data revealed various types of random and systematic noise. Some, but not all, of the noise sources have been identified and are discussed in the material that follows.

The most obvious source of systematic noise occurred during the digitization process. An 8-bit transient digitizer (least significant bit $=2$ $\mathrm{mV}$ ) was used to input the analog APD signals into the computer. The 10 shot average APD random noise level was typically less than $2 \mathrm{mV}$ so that the errors connected with the digitization process are easily visible when the lidar return signal is featureless and slowly changing, leading to a "staircase" appearance in the individual angle traces. Unusually large nonlinear behavior was observed in the neighborhood of the 15th digitizer count (i.e. the transition from $(00001111=15)$ to $(00010000=16)$ which occurs at an input voltage level of about $30 \mathrm{mV}(2 \mathrm{mV} /$ count). The APD dc level and digitizer input offset was such that the zero signal level normally occurred at about 13-14 digitizer counts (or about $26-28 \mathrm{mV}$ ). Thus, the last $2-4 \mathrm{mV}$ of signal tend to be noticeably corrupted by the digitizer non-linearity, resulting in peculiar signal shapes. An example of this digitizer non-linearity is shown in Fig. $\mathrm{Cl}$, which is a single trace composed of a 10 laser shot average extracted from a two-dimensional scan It shows that as level 15 is approached two things happen : 1) the signal level suddenly drops to level 15 from level 16 instead of executing a smooth transition, and 2) the signal appears to become very smooth while it is close to the 15th level, lacking the randomness that precedes and follows the 15 th level. When this type of signal is multiplied by $\mathrm{r}^{2}$ to eliminate the $1 / \mathrm{r}^{2}$ fall-off, it tends to produce signals like the one shown in Fig. C2. This systematic dip leads to the appearance of what can look like an atmospheric structure in the 2-D vertical and horizontal scans. Since the non-linearity causes a "sag" in the true signal, the $\mathrm{r}^{2}$ corrected 2-D color plots will show this feature as a sudden decrease in signal which can be erroneously interpreted as a decrease in aerosol concentration (i.e. an area of relatively cleaner air surrounded by dirtier air). An obvious example of this effect is shown in Fig. C3. A more subtle example is shown in Fig. C4, where one might think there is a column of clean air from above reaching down to mix with the dirty air below. The visibility of this digitizer effect in the 2- 
D color plots presented in this report depends greatly on the atmospheric situation at the time the data was taken. In general, when the atmosphere is rich with structures, the structures themselves will tend to mask the effect. On the other hand, when the atmosphere is very uniform, with slowly varying spatial aerosol distributions the effect can be quite noticeable, tending to produce radially symmetric features in the 2-D plots. In summary, atmospheric structures that occur close to the 15th digitizer count level are contaminated and should be very carefully interpreted.

A second type of noise that occasionally produced very noticeable effects on the single angle extracted data files was due to the laser system firing circuitry and power supply. A short burst of high-frequency (HF) noise would, from time-to-time, fall within the time period being digitized. This type of nuise is not easily seen in the 2-D plots because the bursts occurs at random places along the signals that make up an entire 2-D scan.

The fact that atmospheric extinction has not been removed from the data leads to several systematic effects in the plots. In the color plots, atmospheric attenuation often shows up as a slow fade in the colors being used to depict signal amplitude. This makes it appear as if the lidar truck is always in a zone of higher aerosol concentration than zones at farther ranges. Often the slow fade exhibits a staircase-like appearance which is due to the fact that only 16 colors can be printed and the data has to be binned into the available slots. The slow color fade effect is sometimes obscured by the rich and varied aerosol structures that are found in the atmosphere. Occasionally, the laser beam will pass through an optically thick atmospheric structure, such as a dense plume, that will cause the aerosol signal beyond the plume to appear smaller than the signal at the same elevation at different locations, giving rise to "shadows" in the color plots. An example of the "shadows" phenomenon is shown in Fig. C5. The visibility of the shadows also depends strongly on the exposure level of the color print.

The presence of clouds in the scanned region caused another type of problem in the 2-D color plots. Clouds can produce very large signals in the APD detector. If per chance the elevation angle and the cloud height are such that the cloud retum occurs near the end of the file where the baseline calculation is performed, the baseline subtraction operation leads to nonsensical results for that particular scan angle (or group of angles). 
An example of this situation is shown in Fig. C6. This problem can be easily remedied by selecting a different region for the baseline substraction for the affe

cted angles. Strong retums from clouds also cause the APD detector to ring, giving rise to ripples in the data recorded behind the struck cloud.

Careful examination of the color plots shows that the last color in the color scale (corresponding to the highest signal value) never appears within the plot. This is due to a "bug" in the software so that in fact, only 15 colors are being plotted.

Sometimes the APD voltage and atmospheric conditions were such that the aerosoi return signals for ranges as high as $800-1000 \mathrm{~m}$ were larger in amplitude than the transient digitizer could accommodate $(0.512$ $\mathrm{V}$ max.). This signal "saturation" process produces a very smoothly rising signal when the $r^{2}$ correction is applied. 


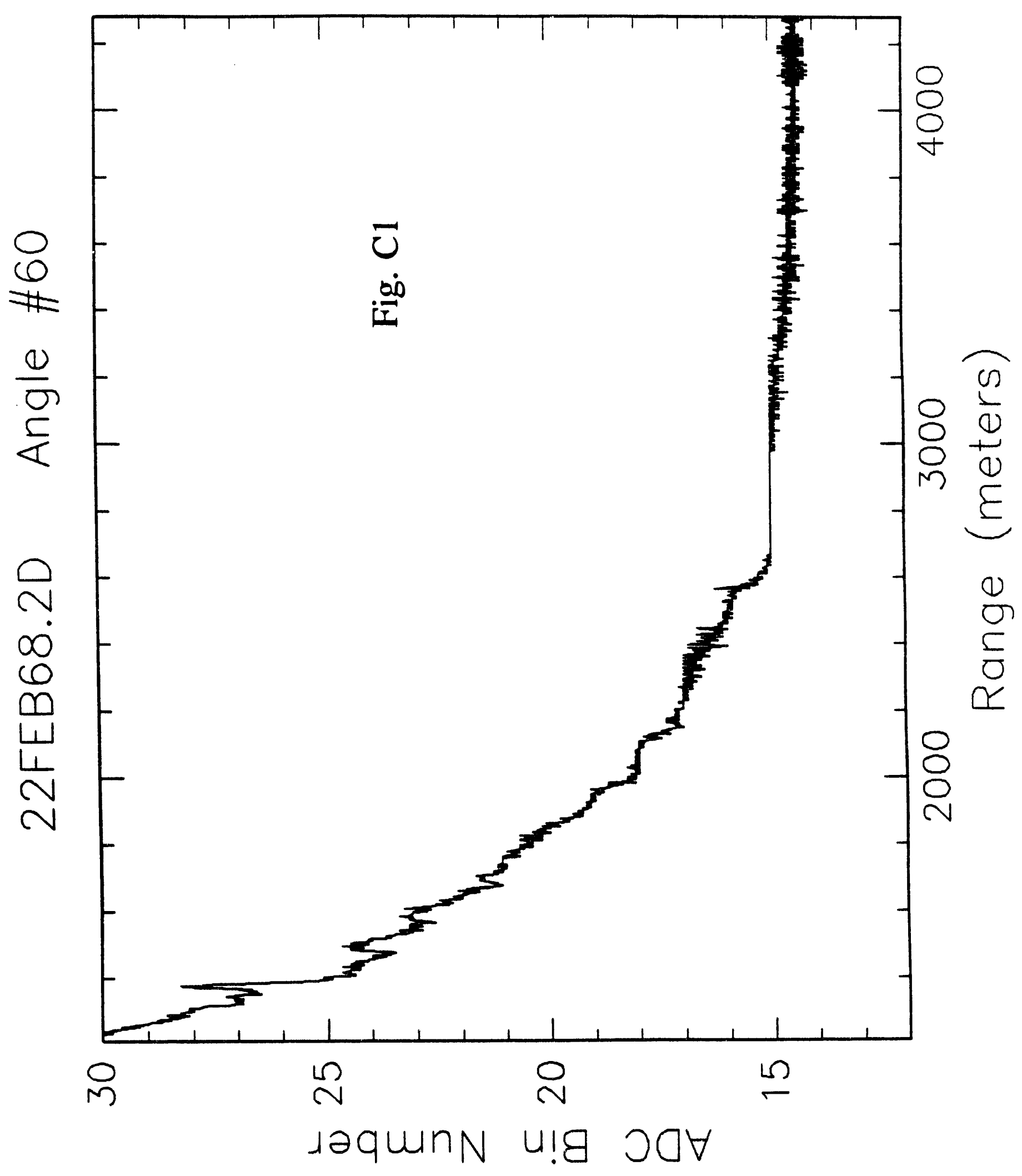




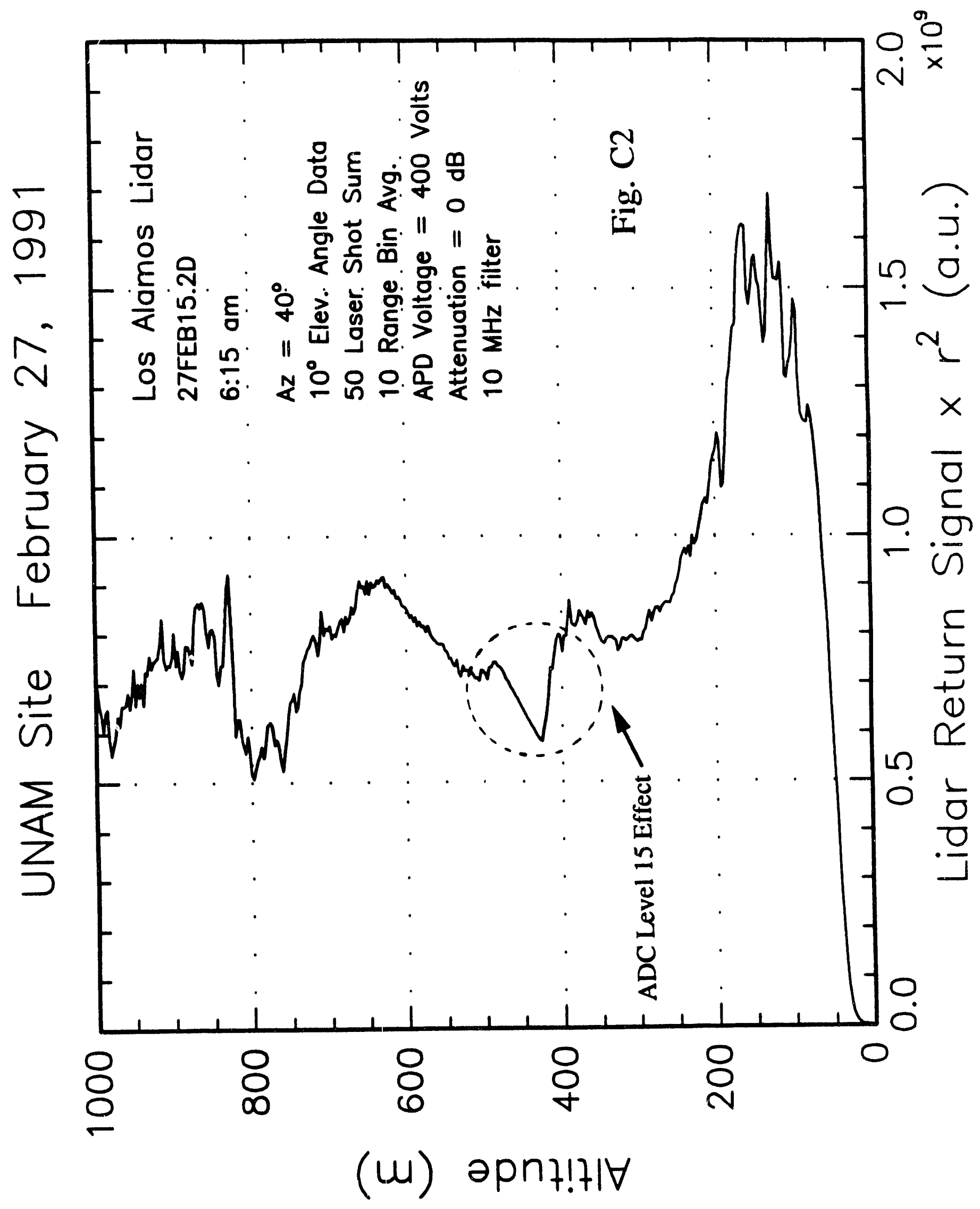




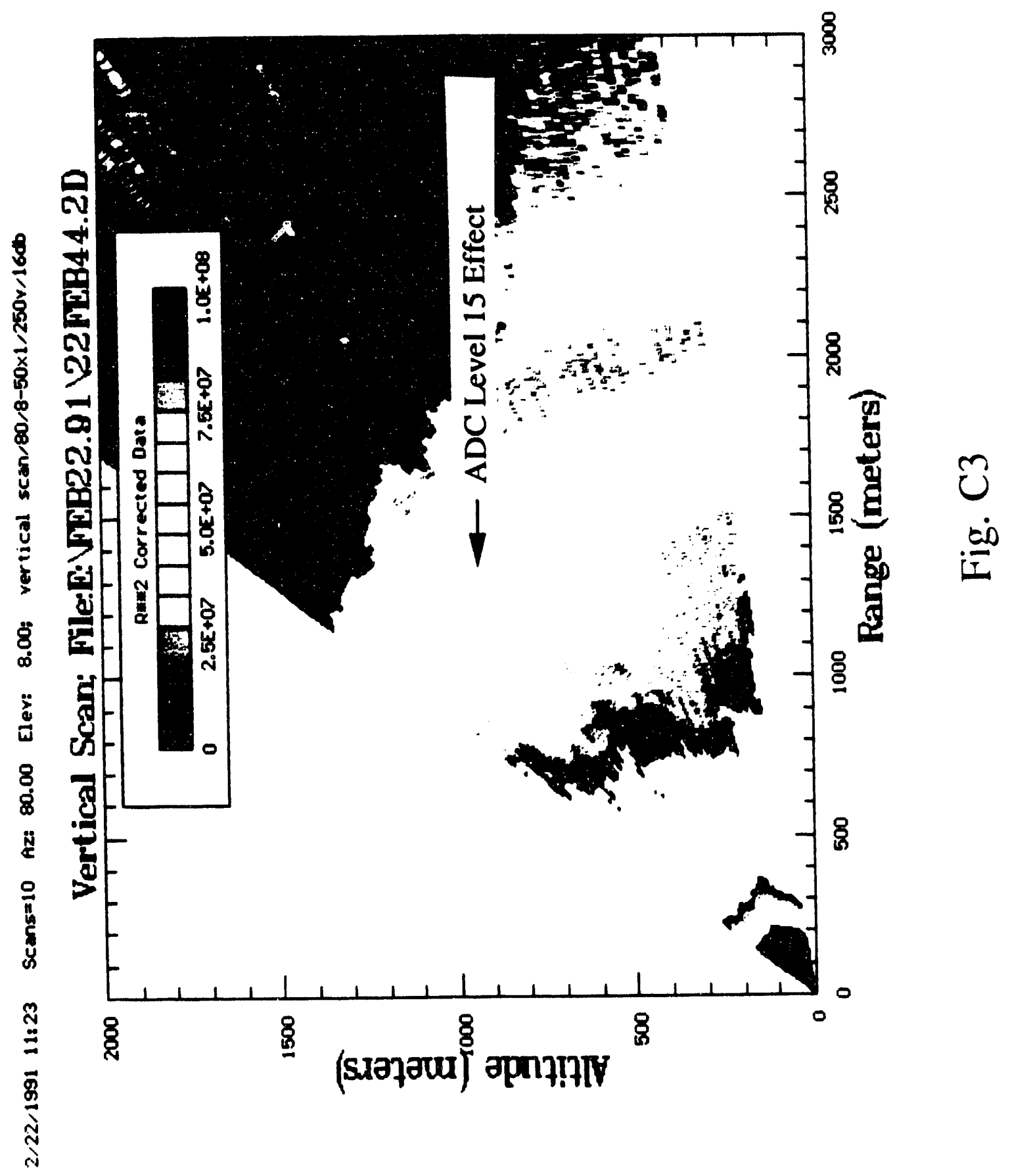




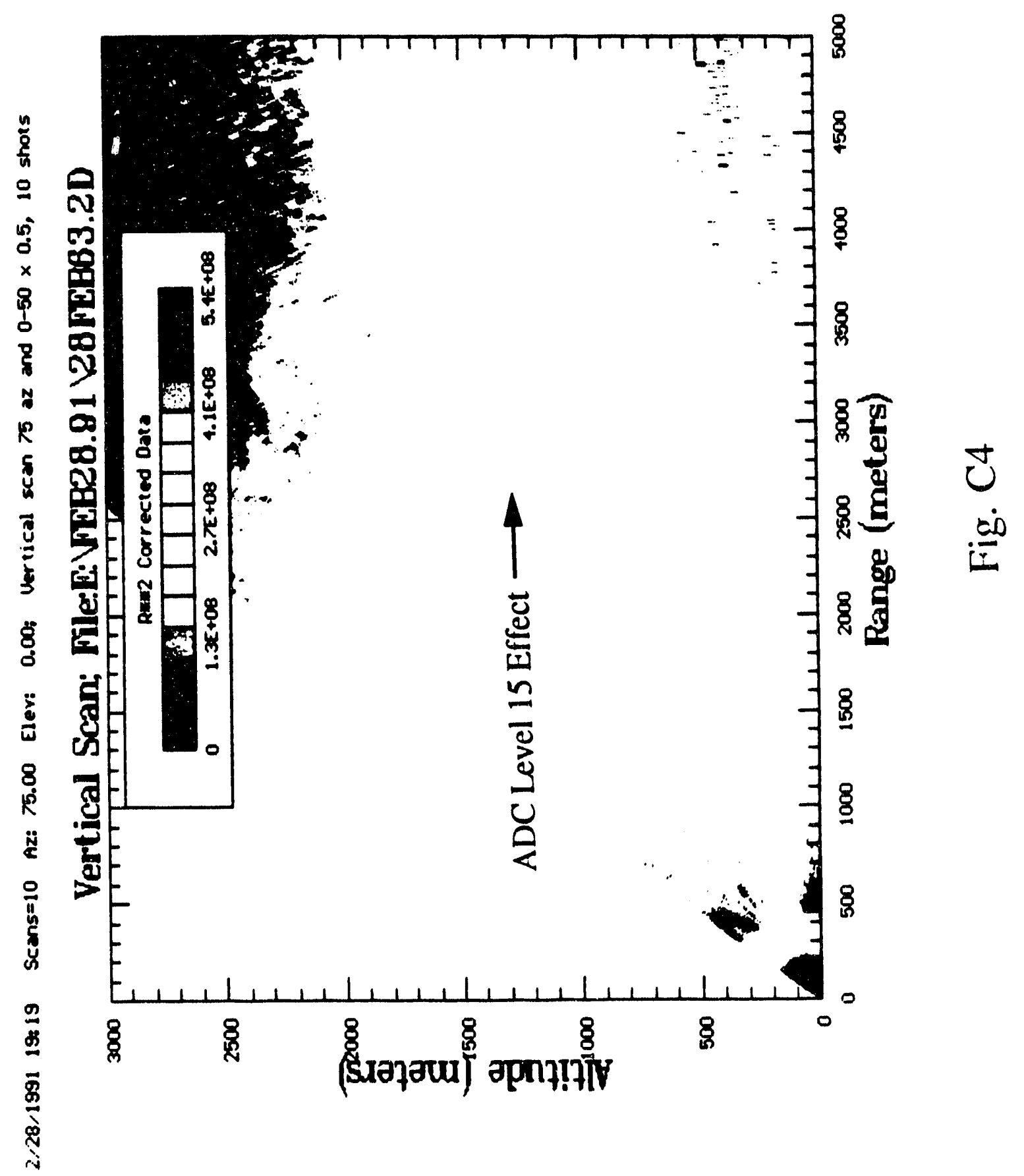




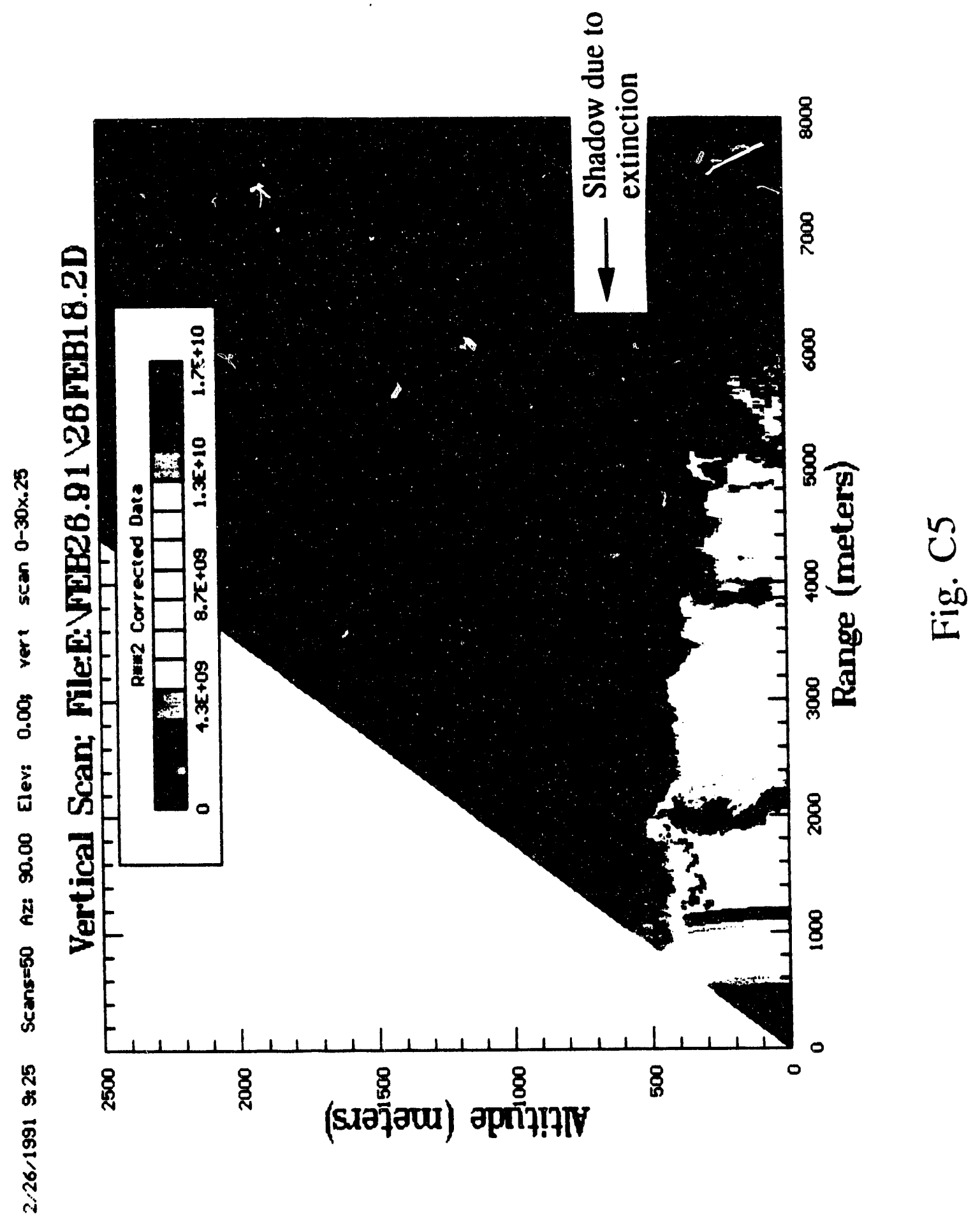




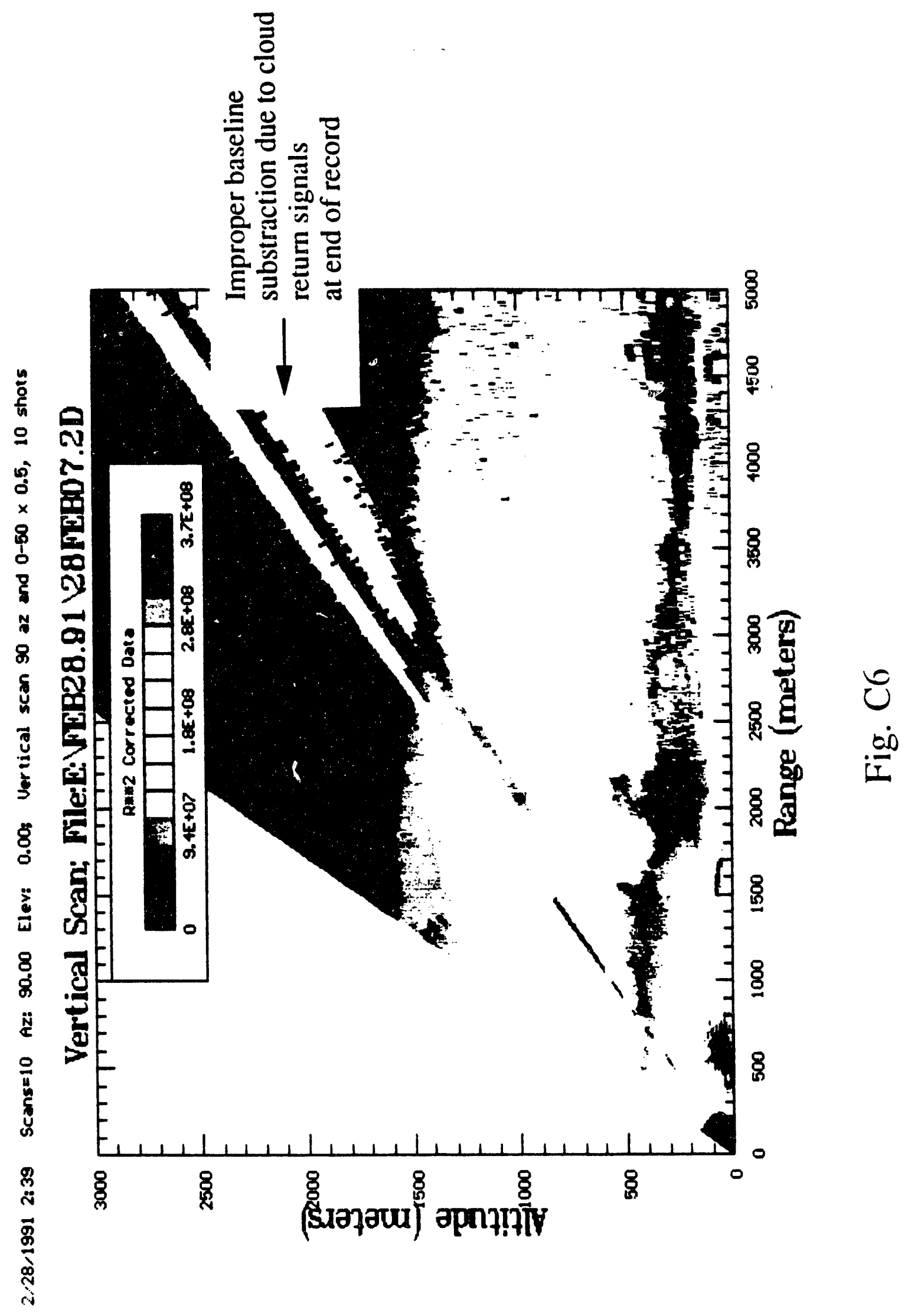




\section{Appendix D}

NCAR ASAS Aerosol Probe Data 


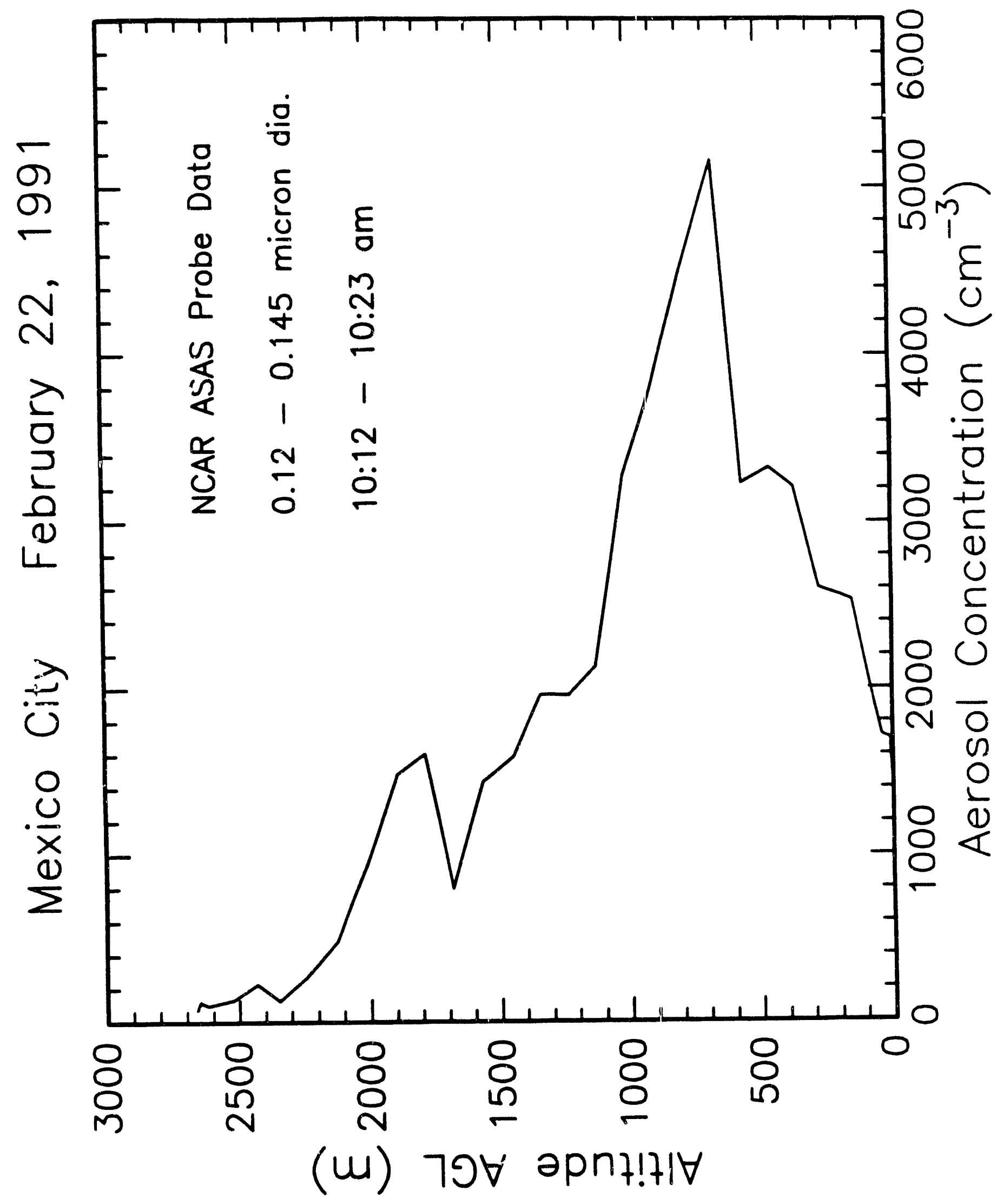




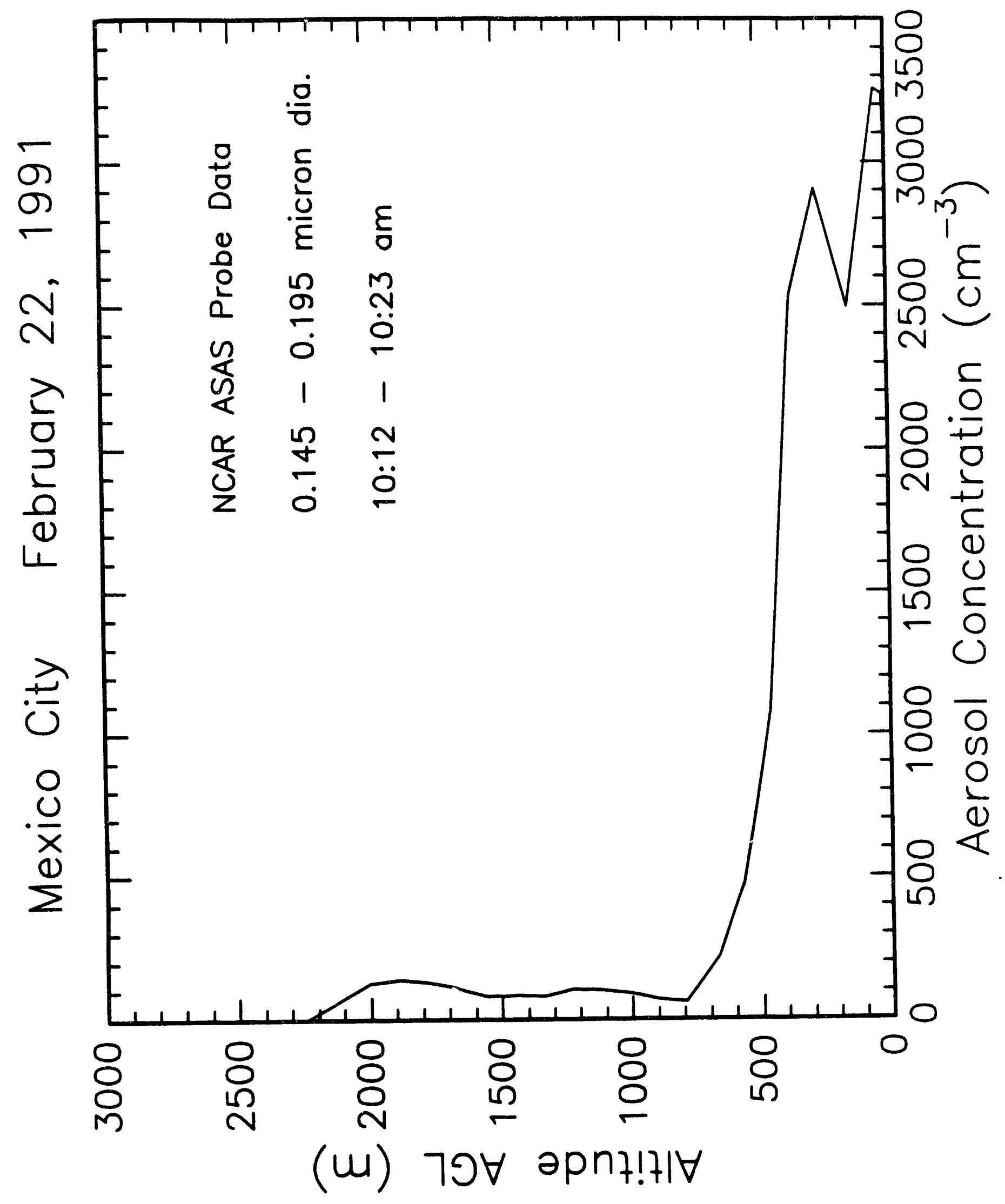




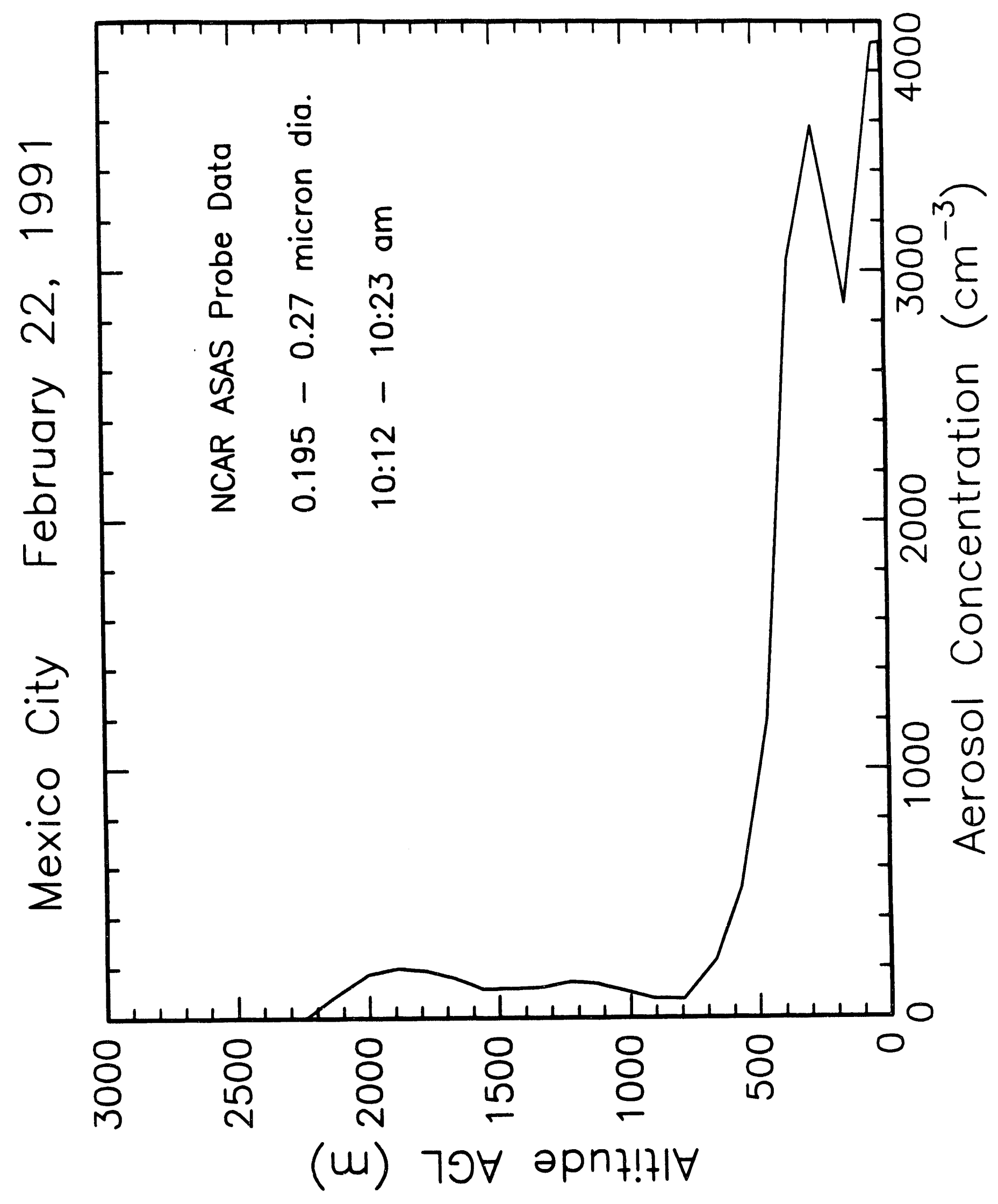




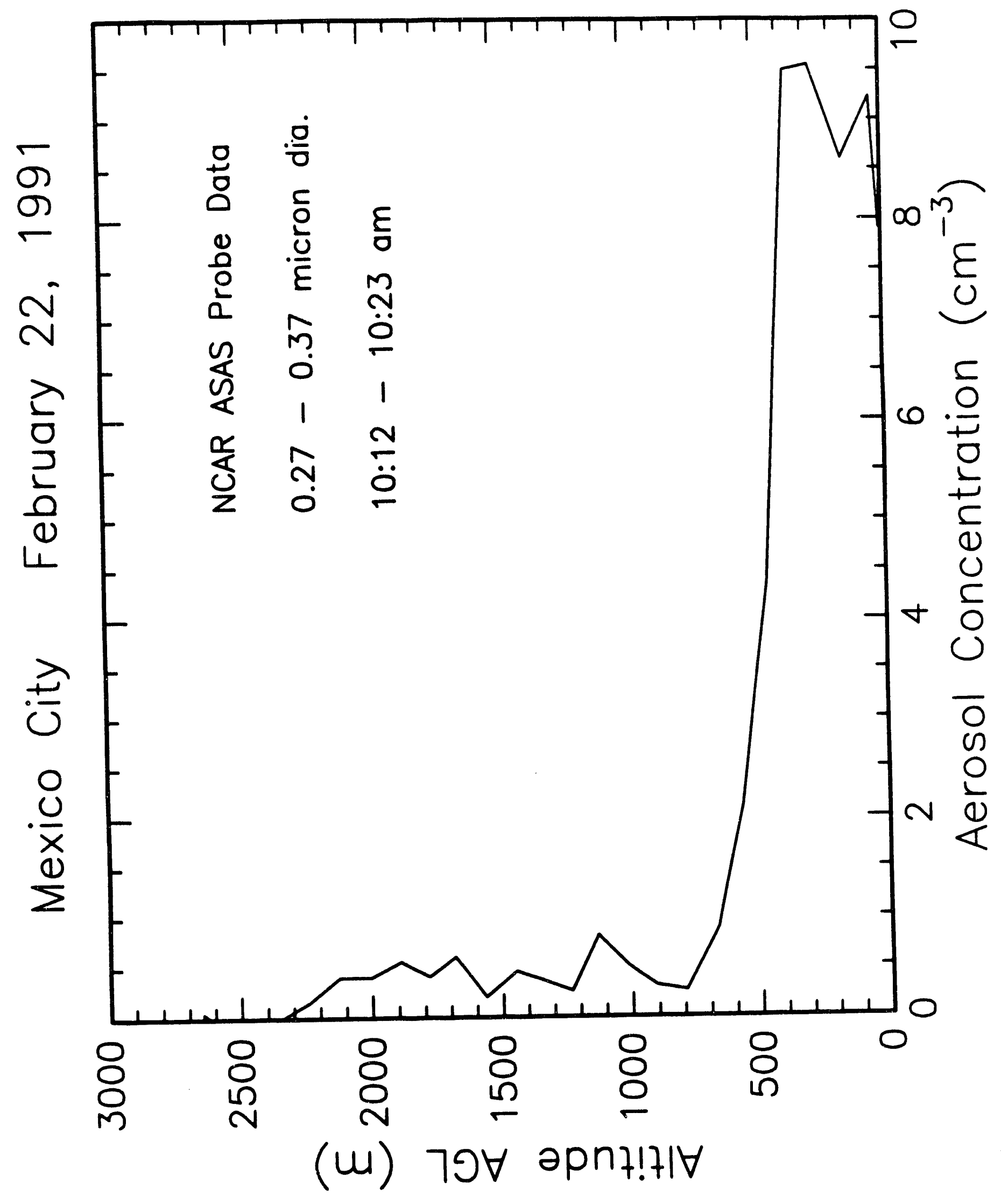




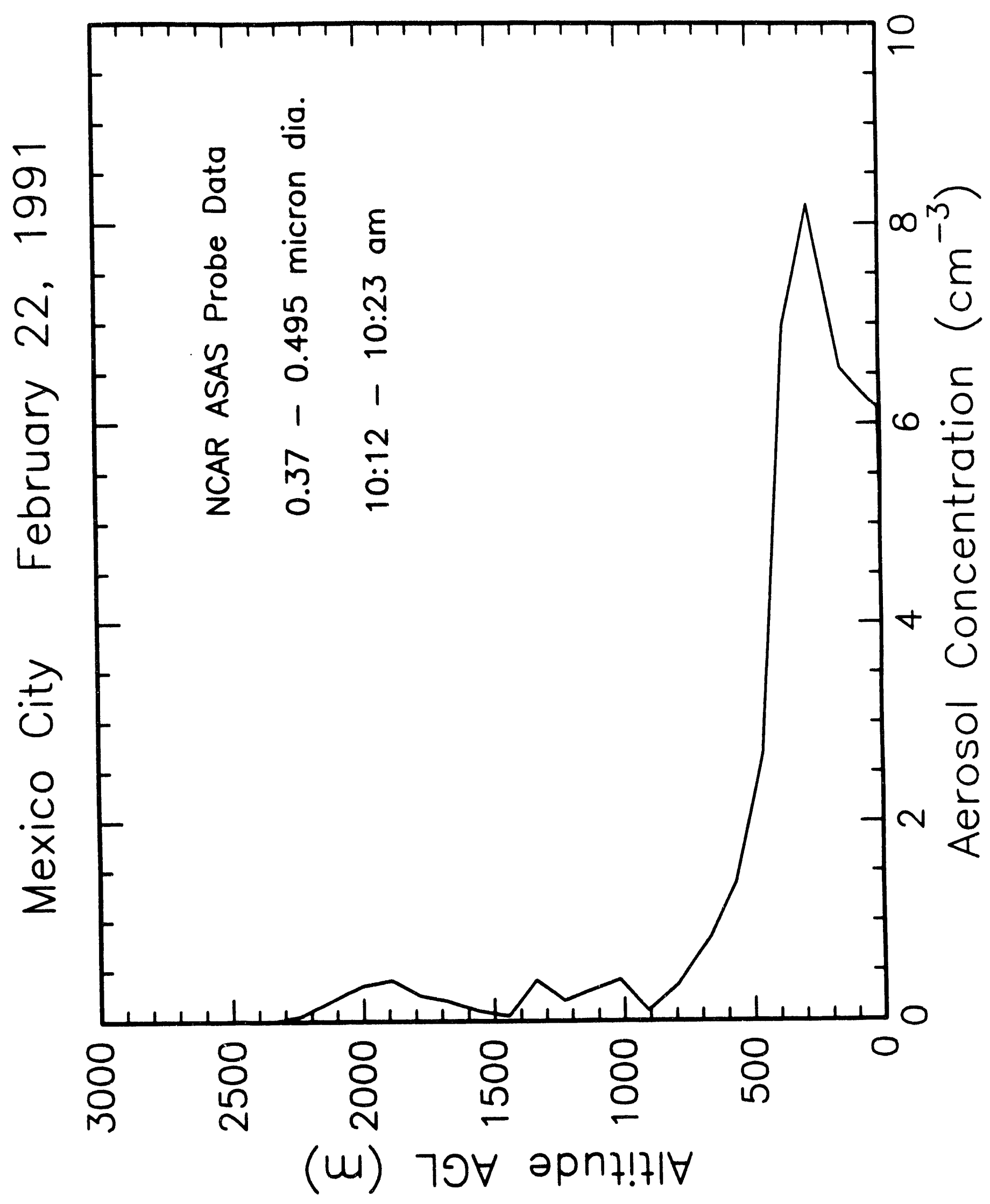




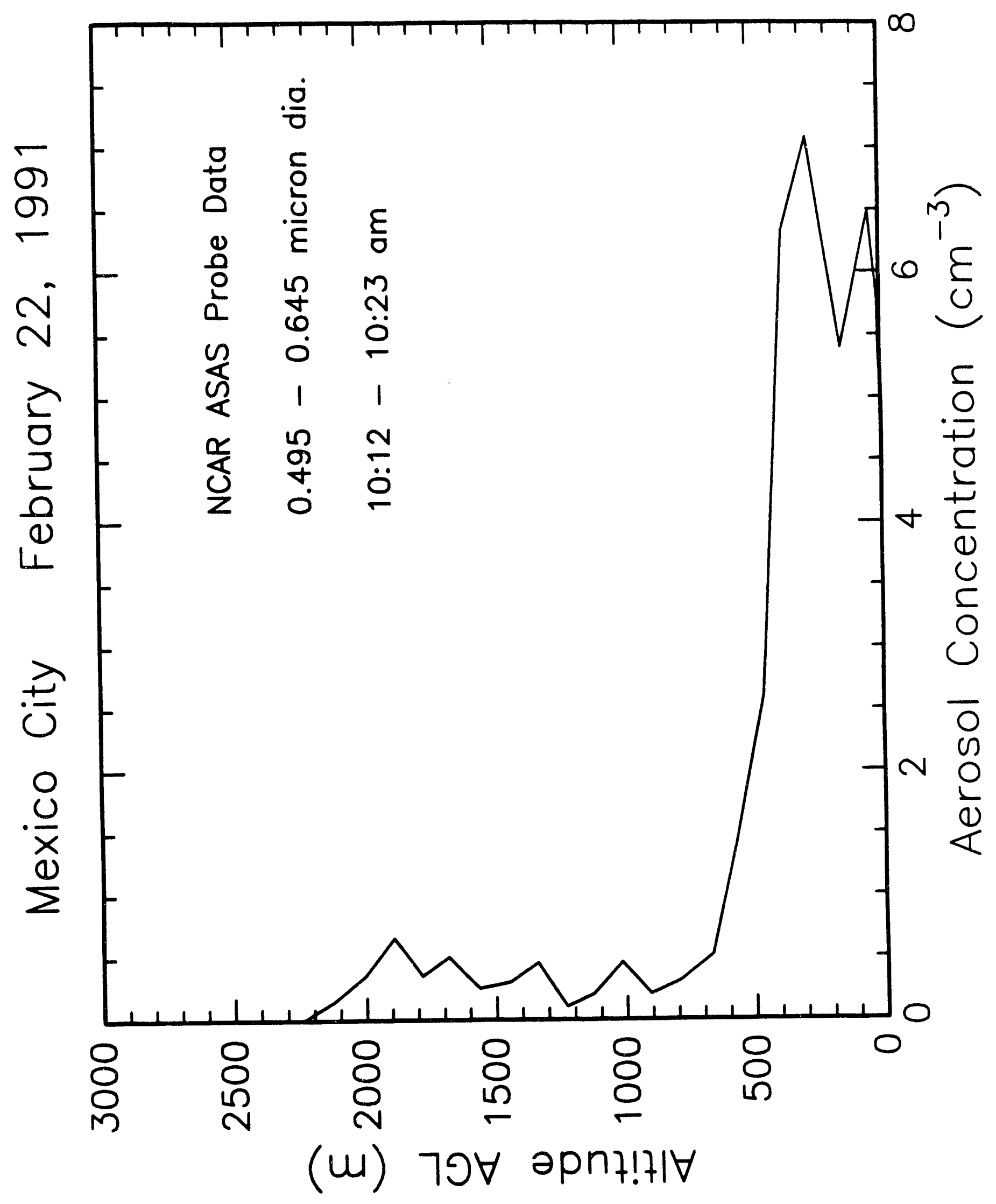




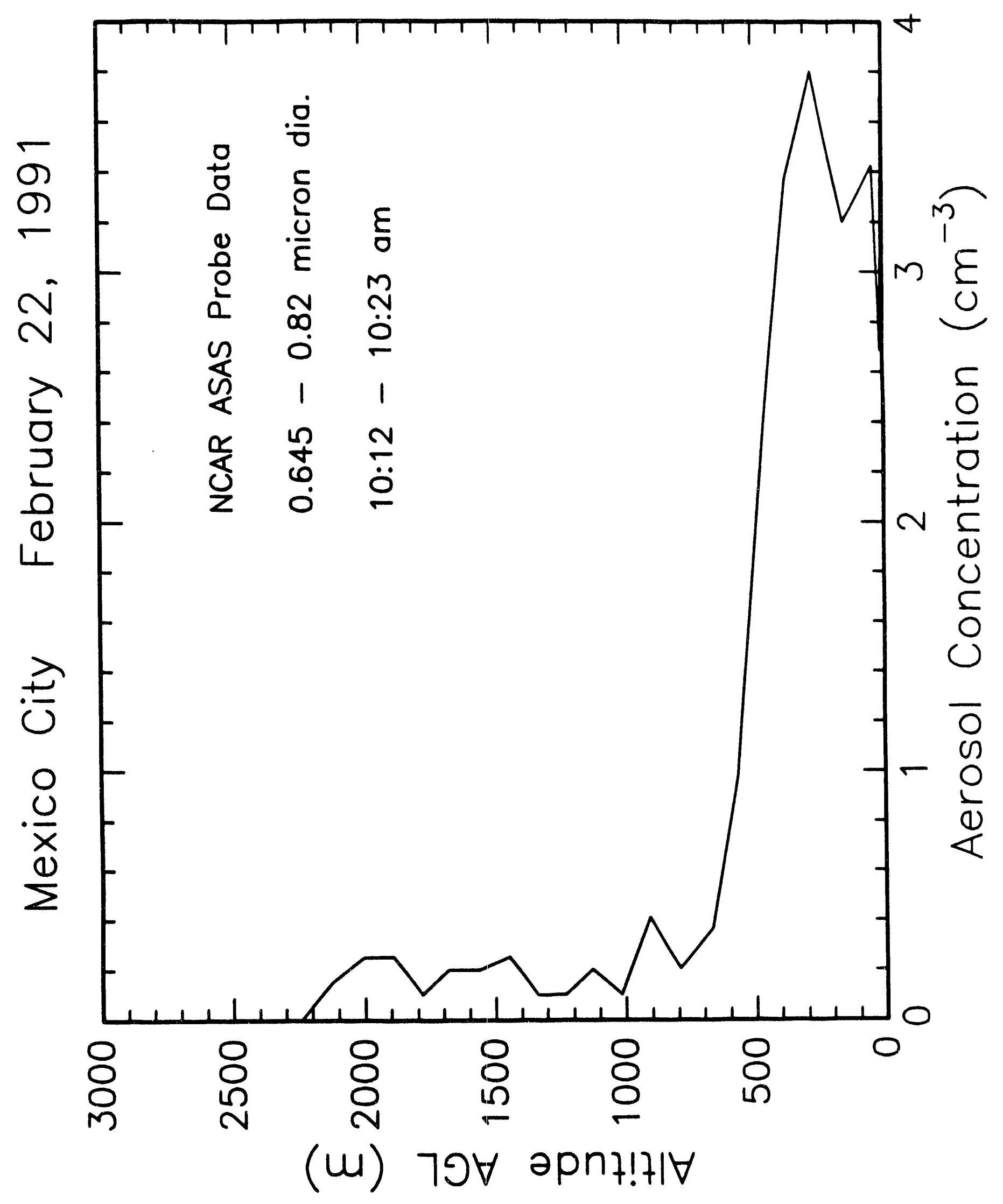




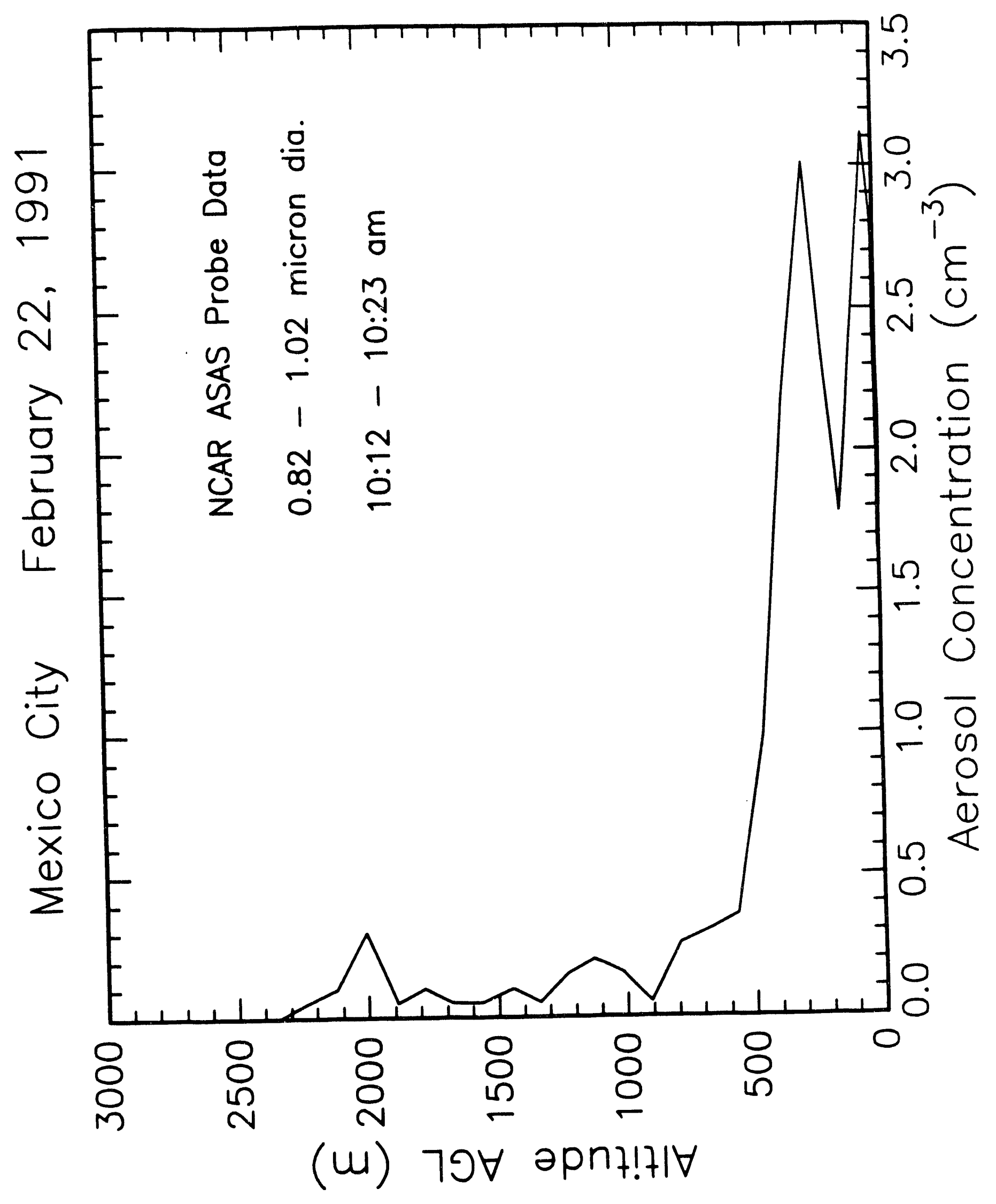




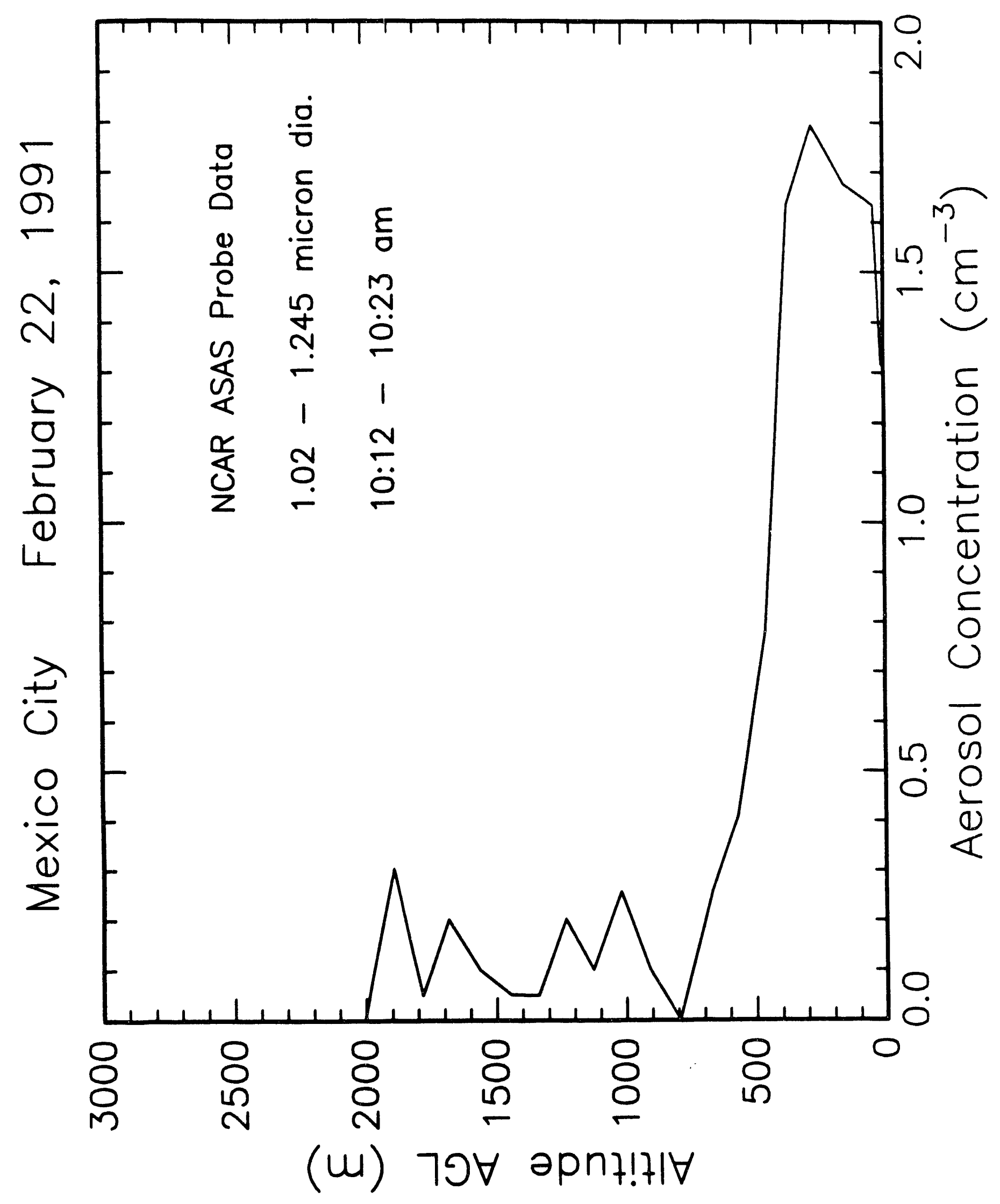




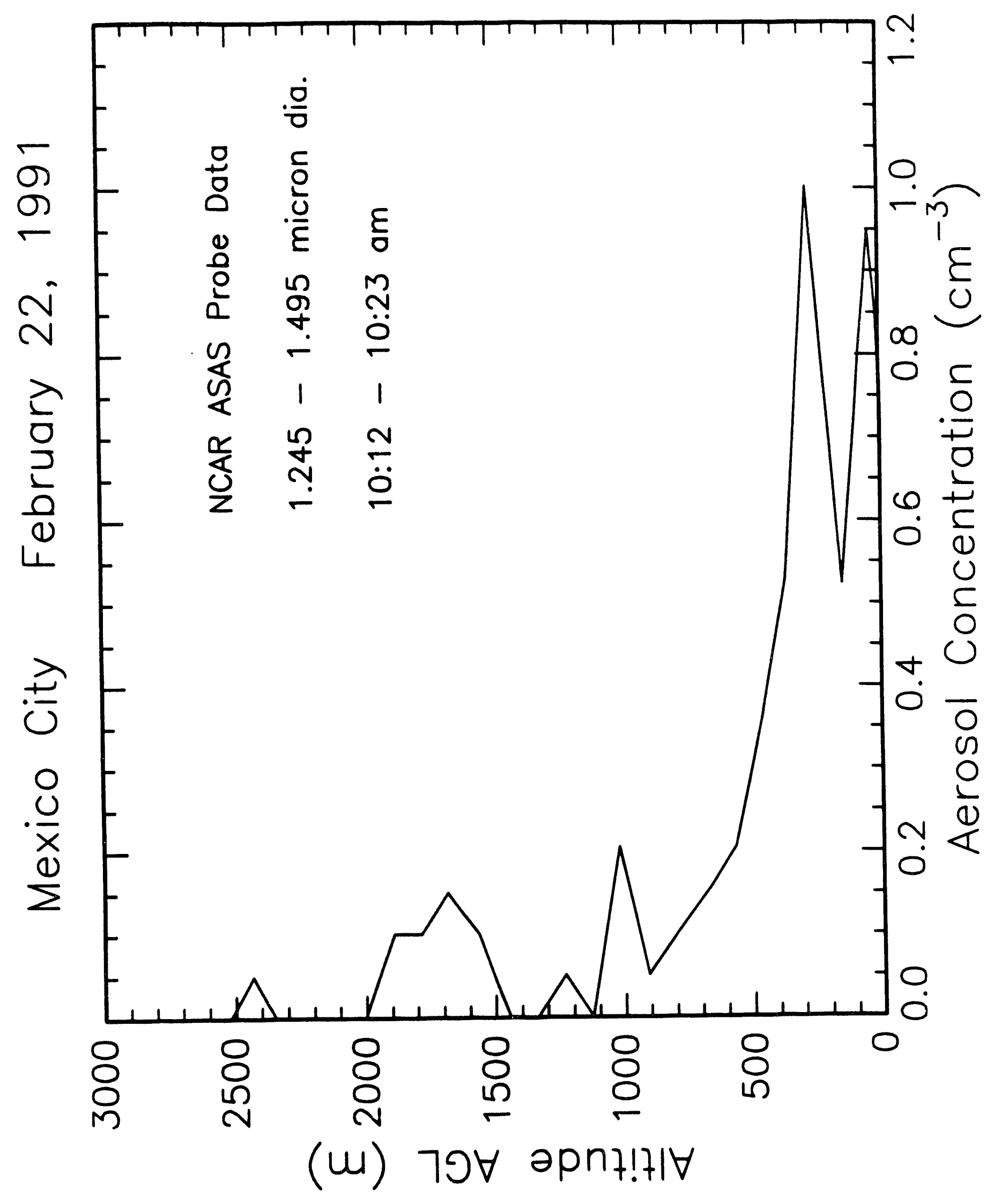




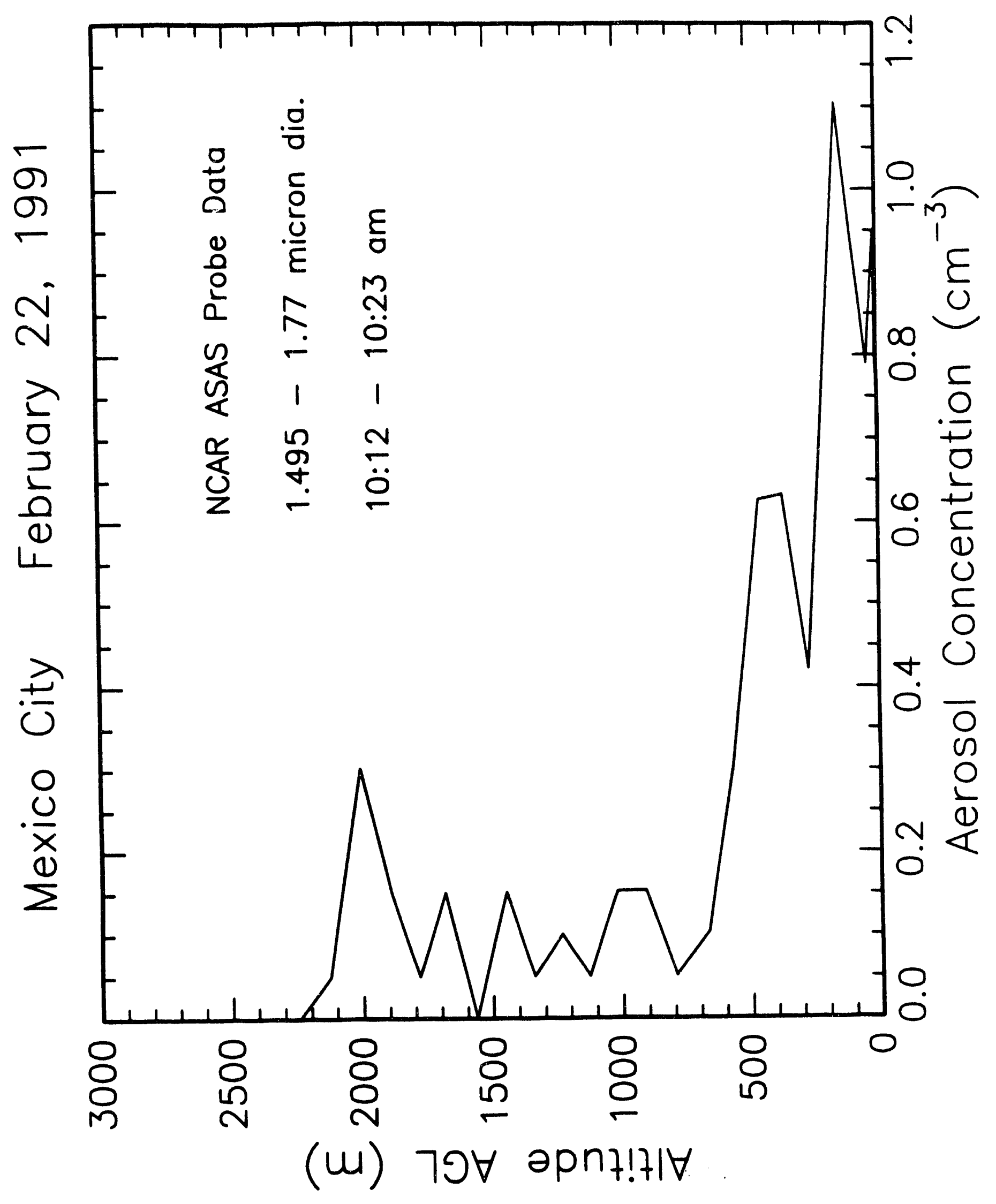




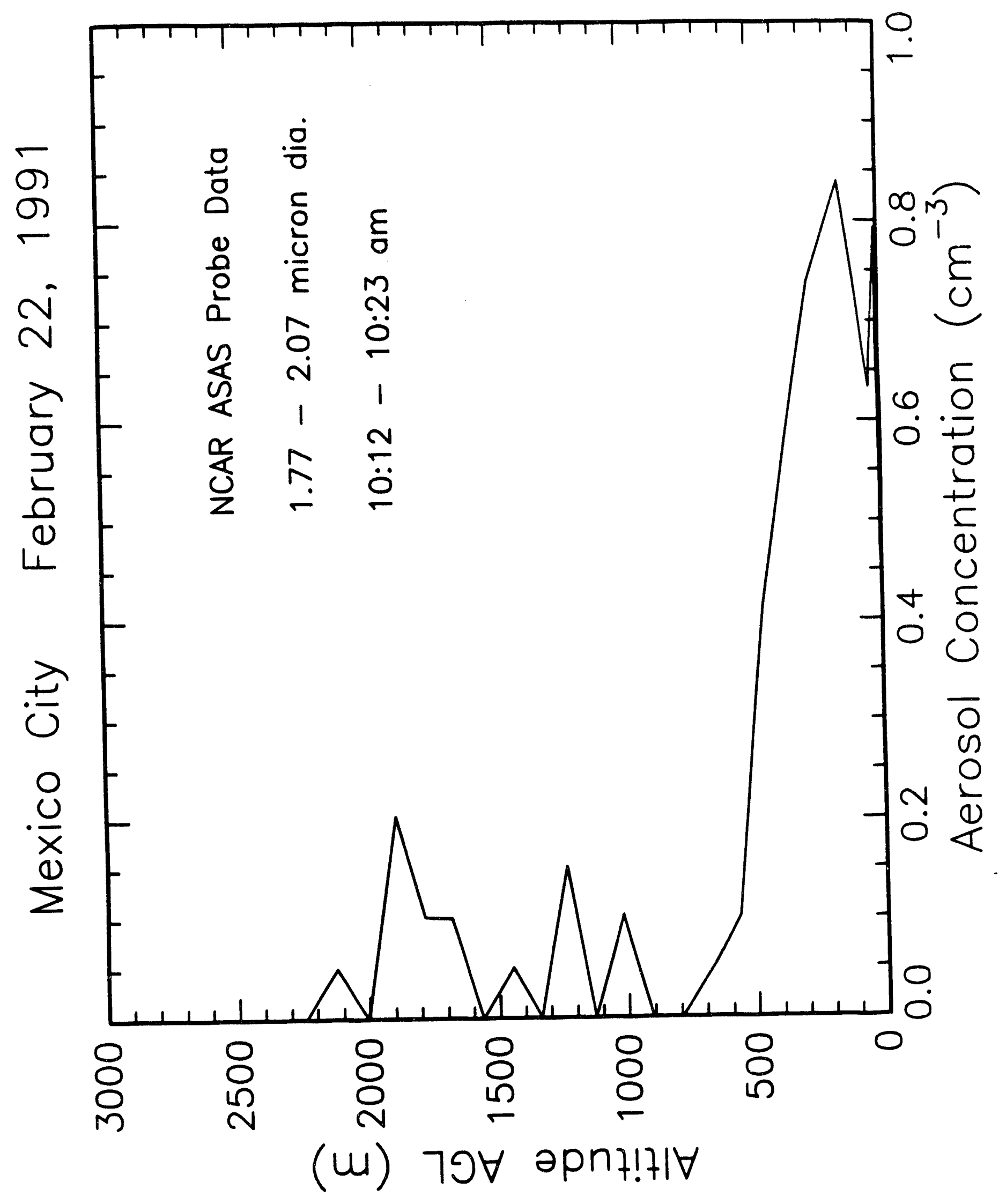




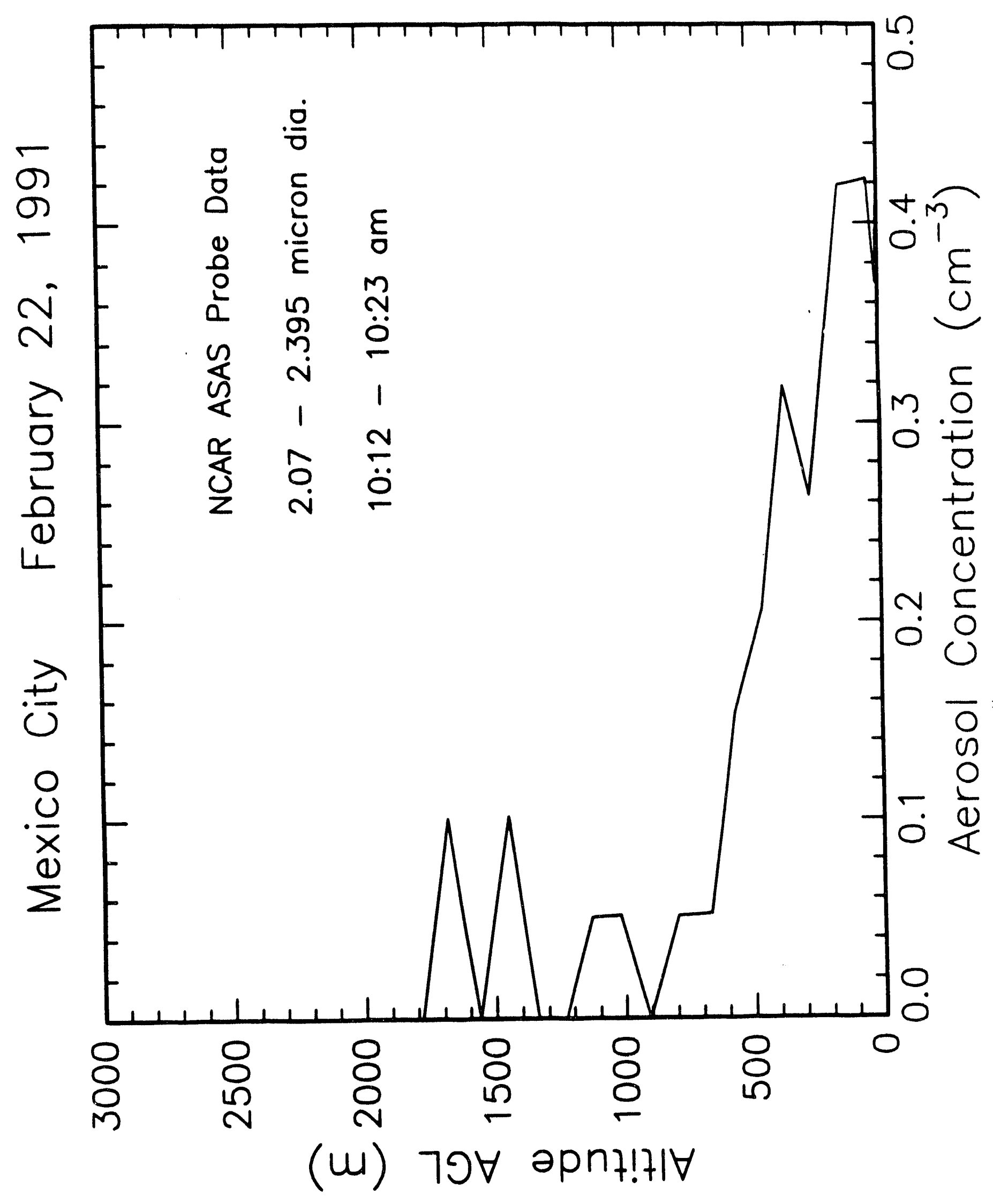




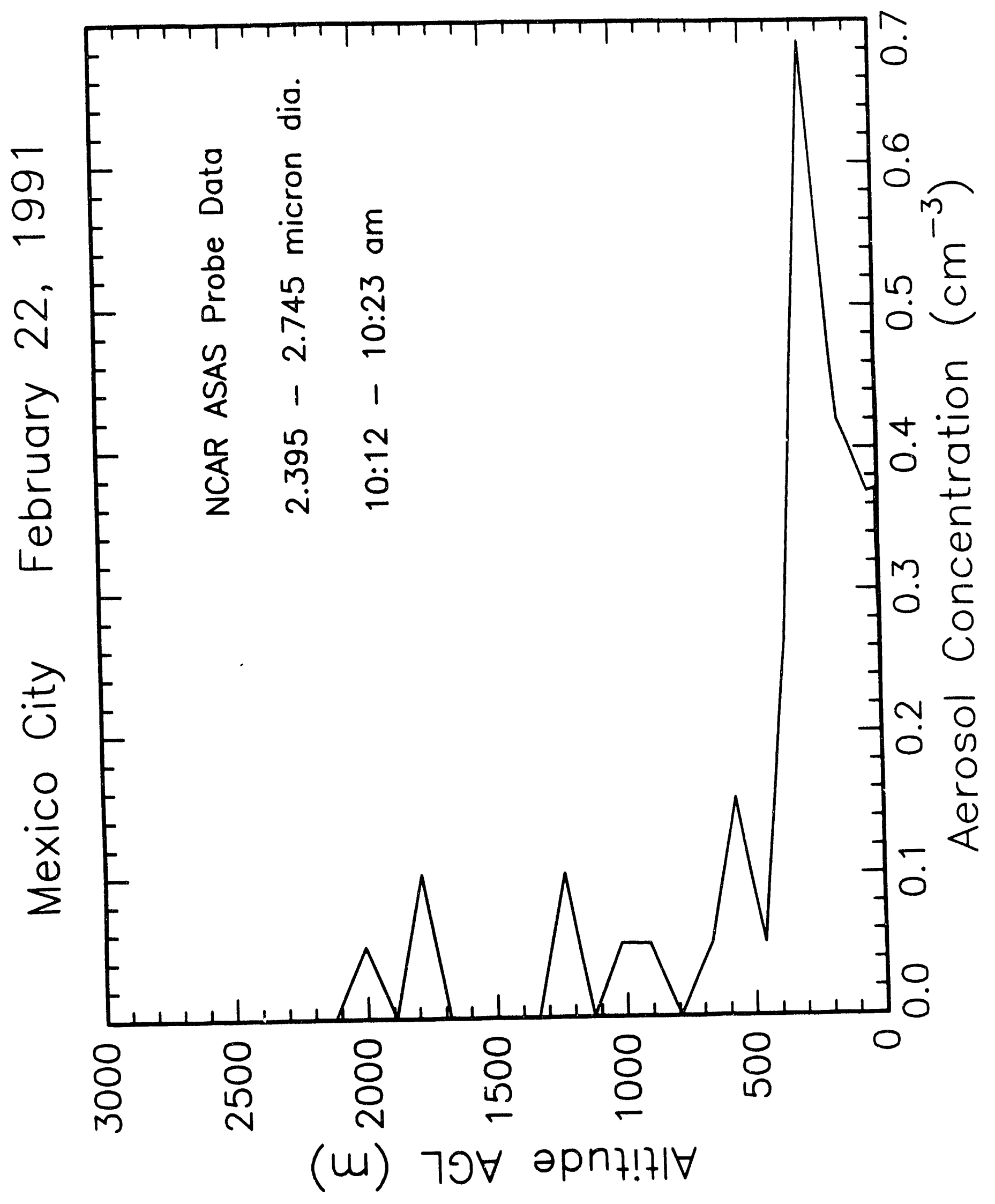




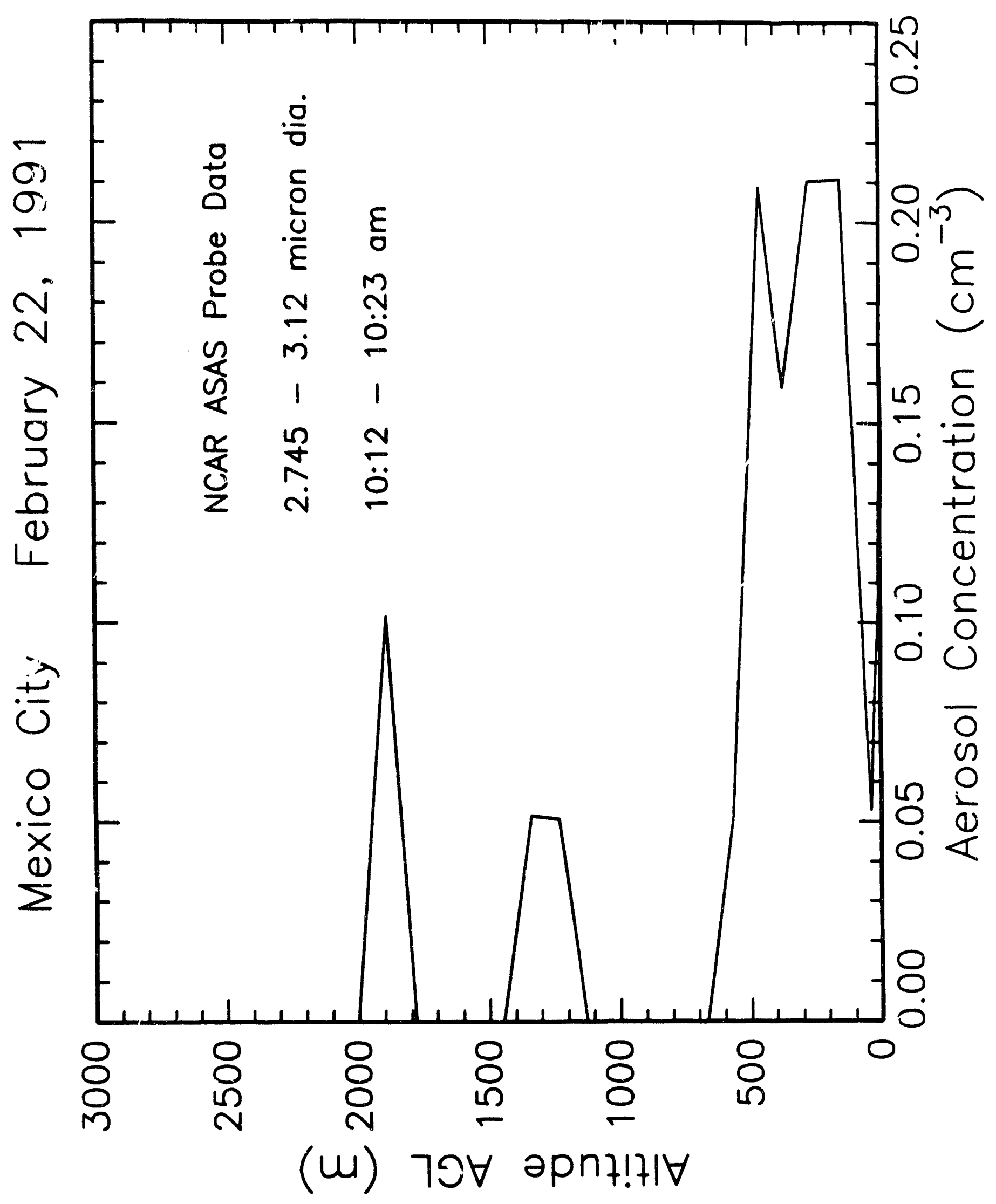




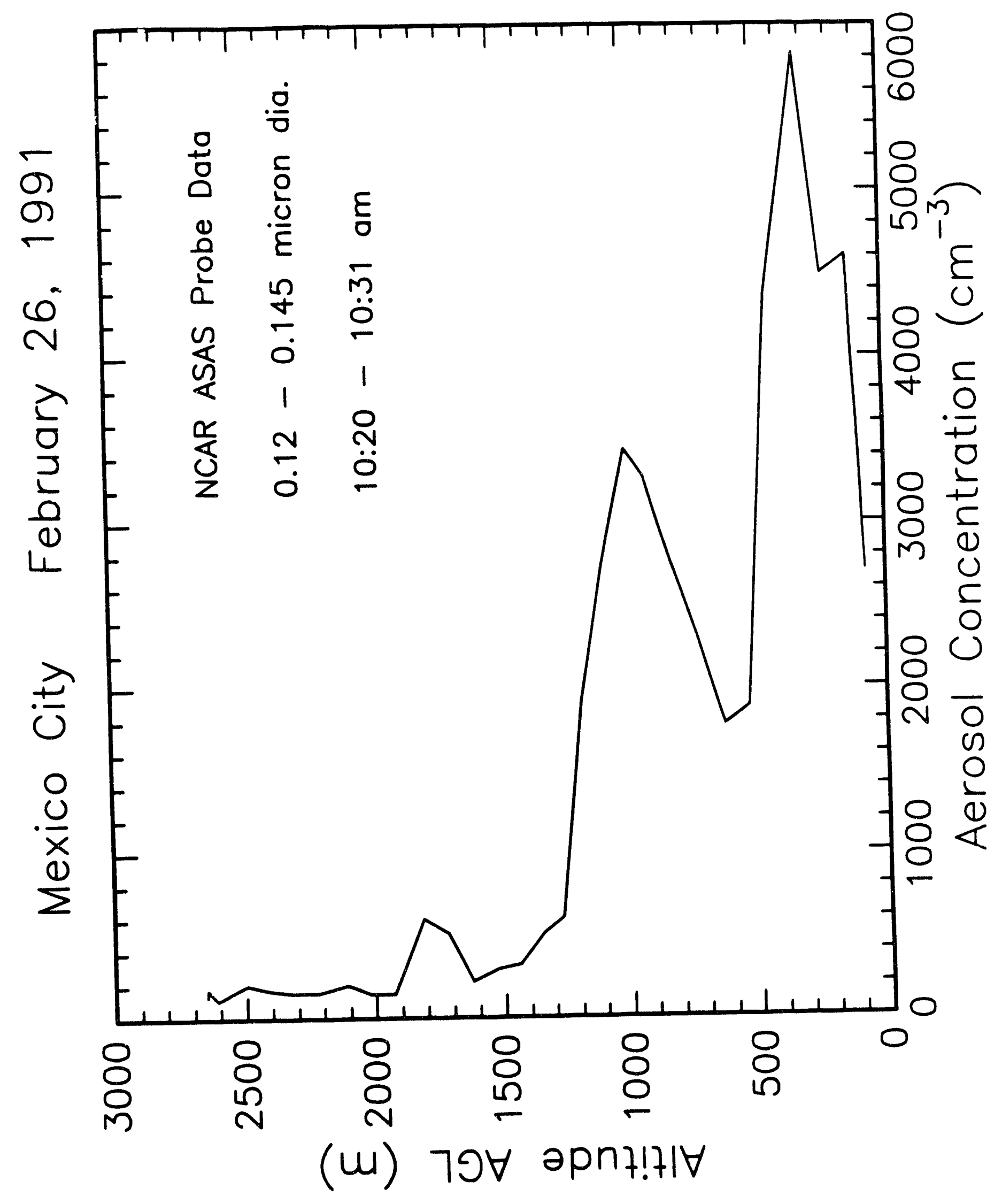




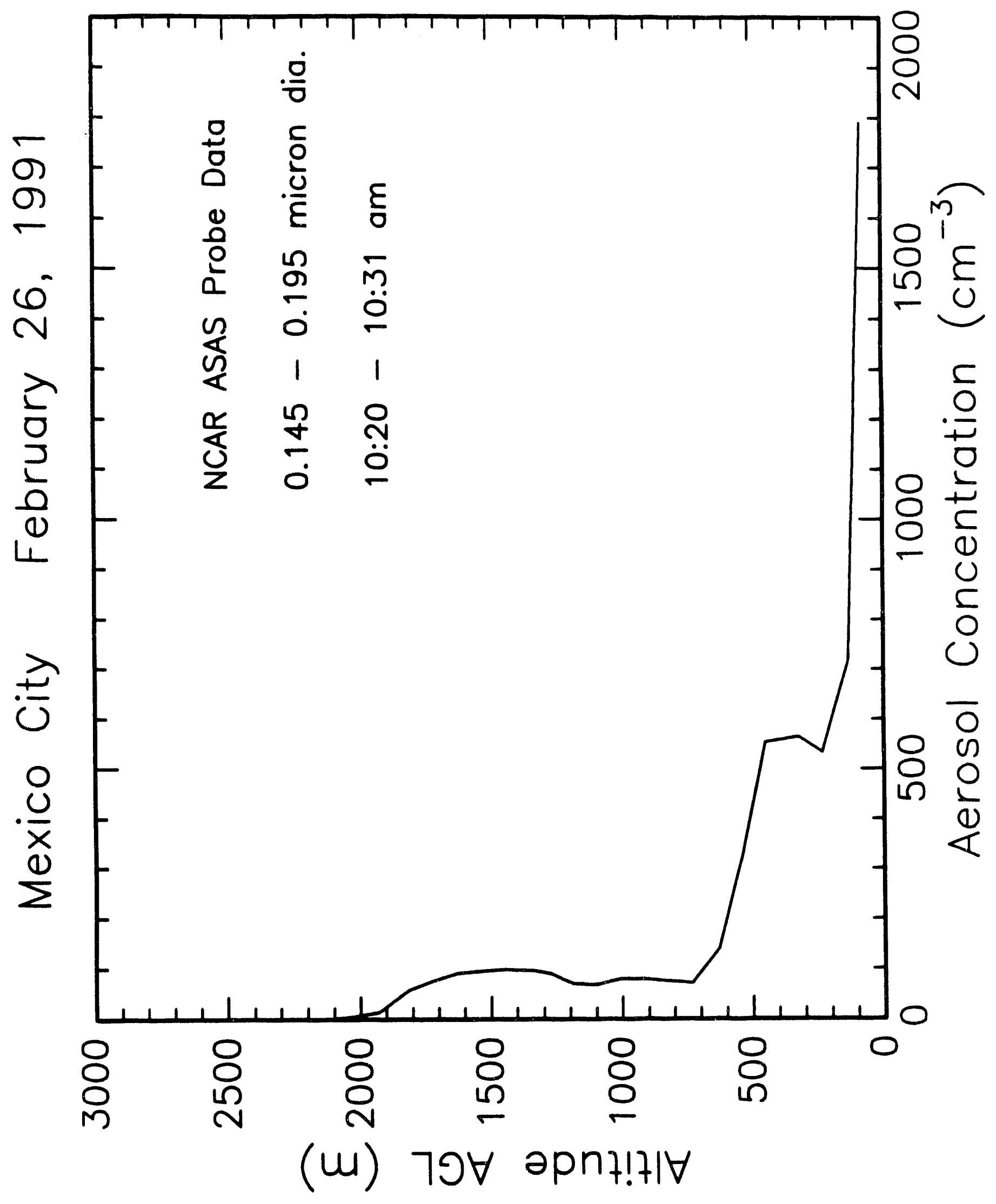




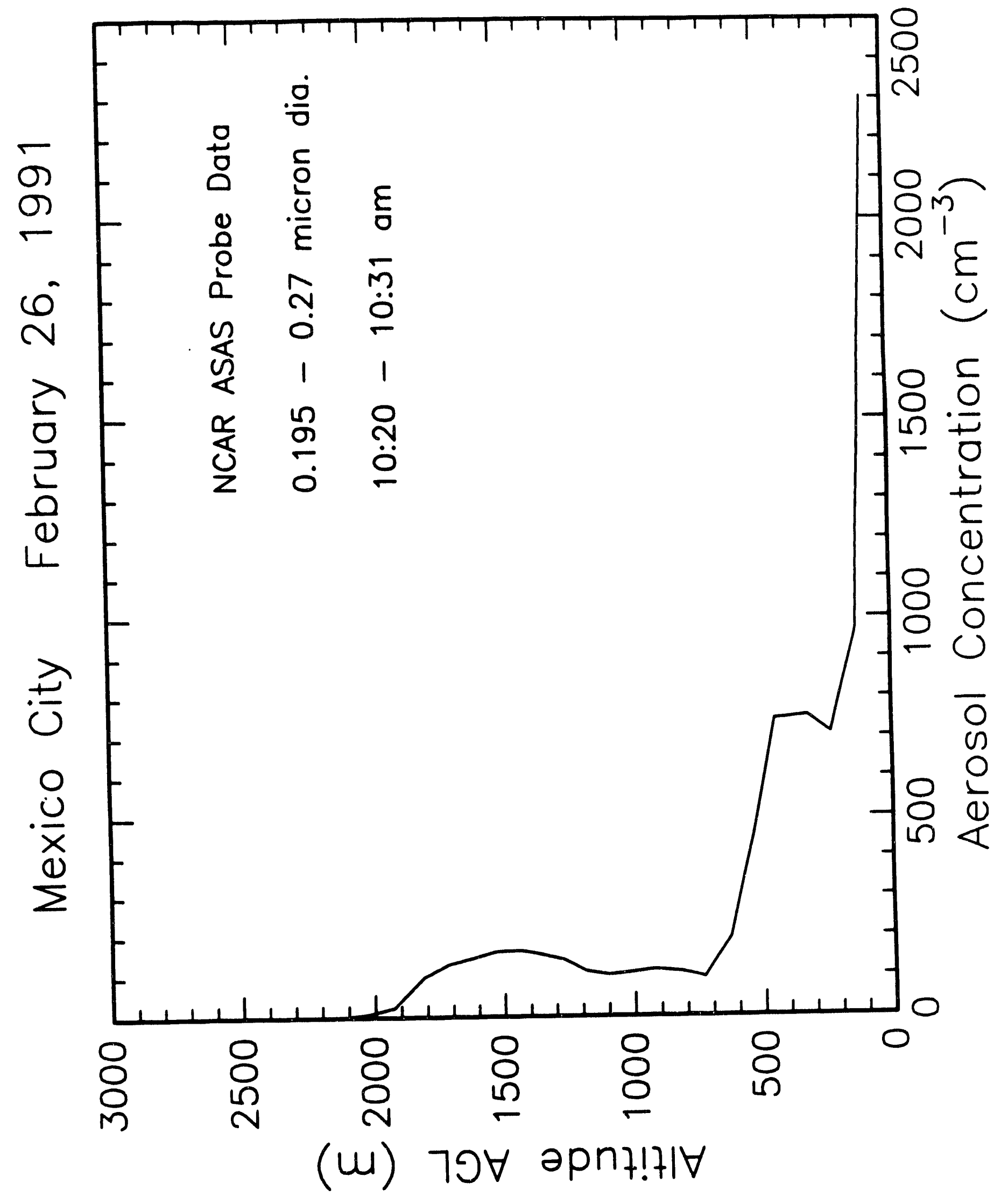




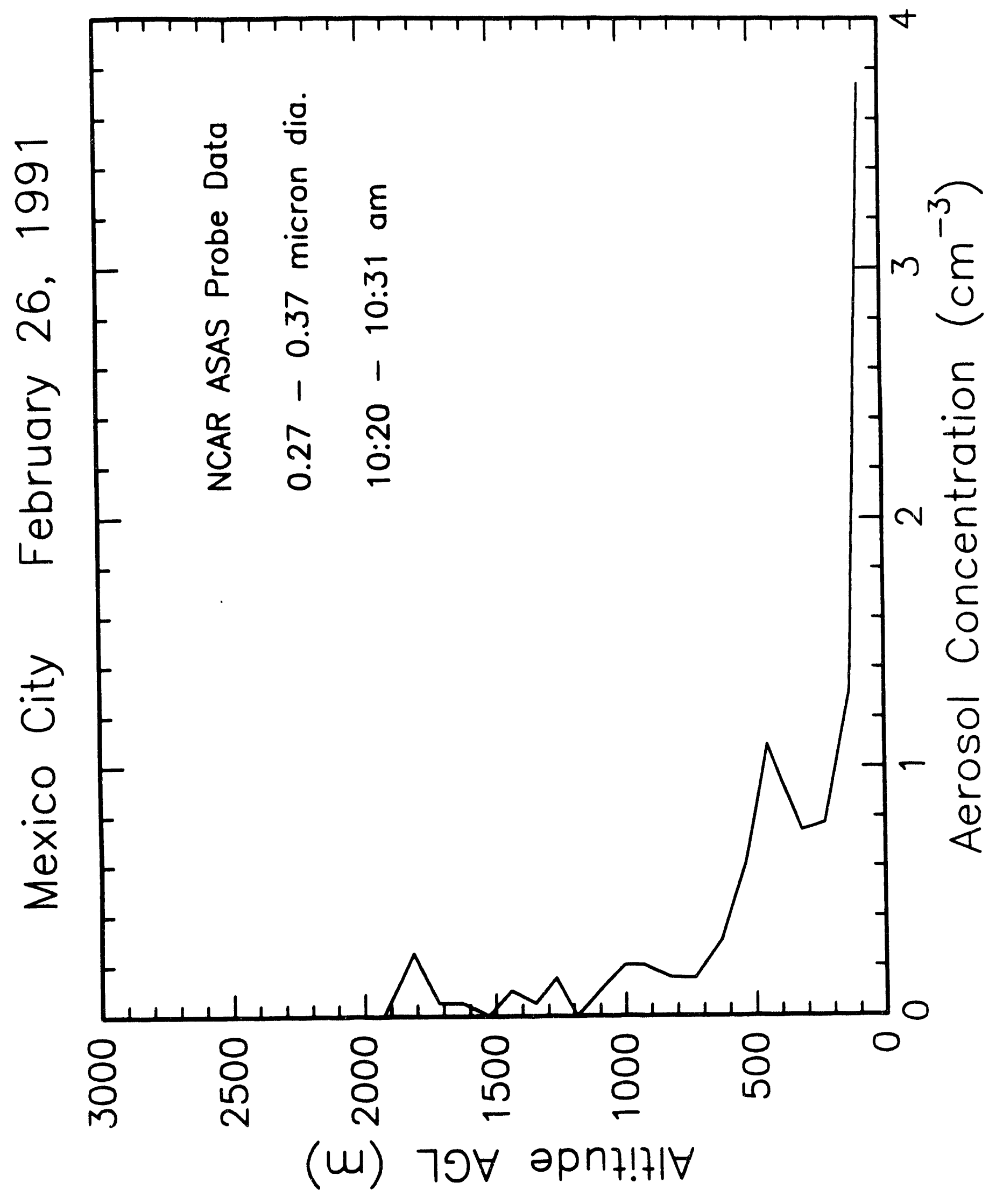




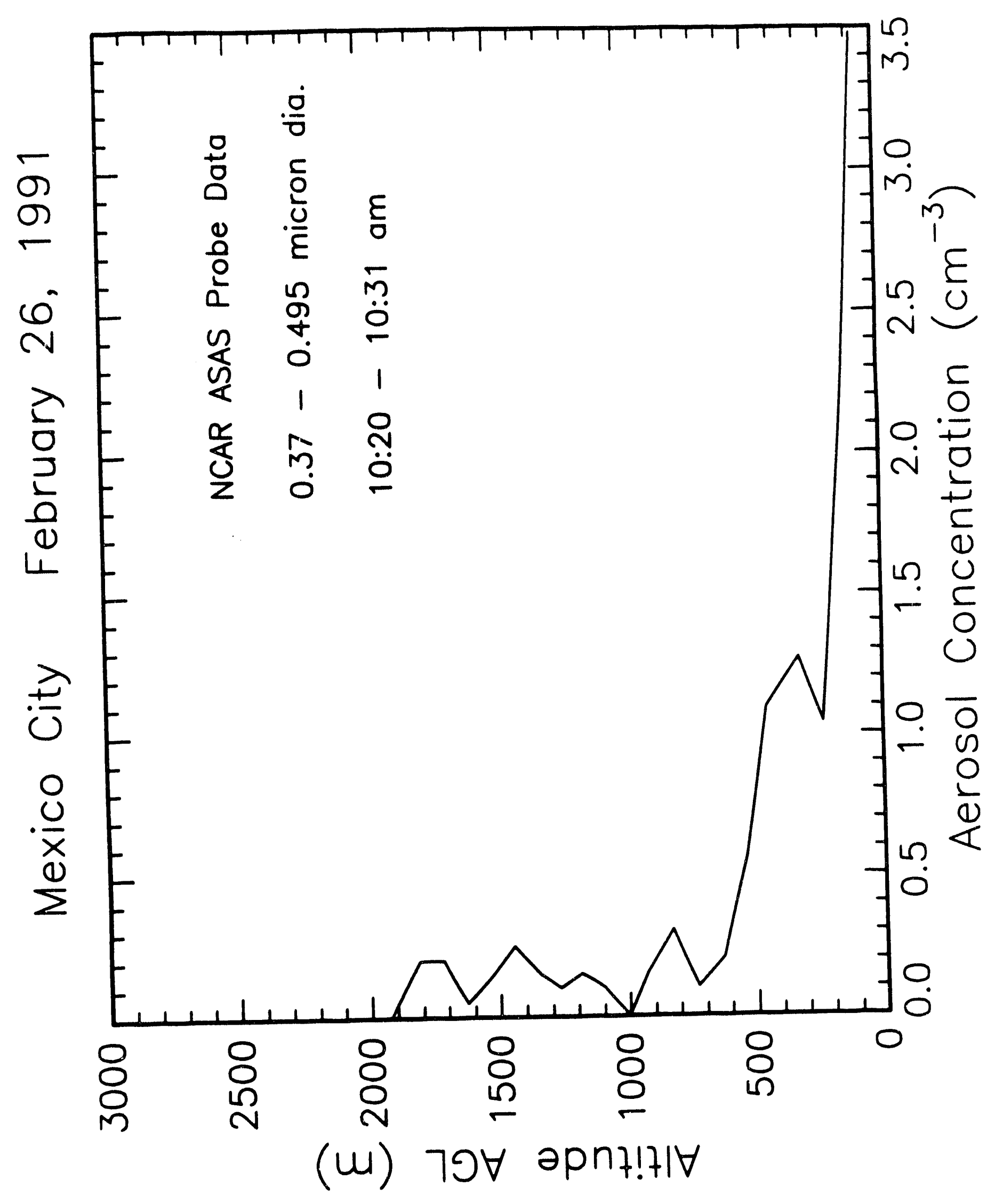




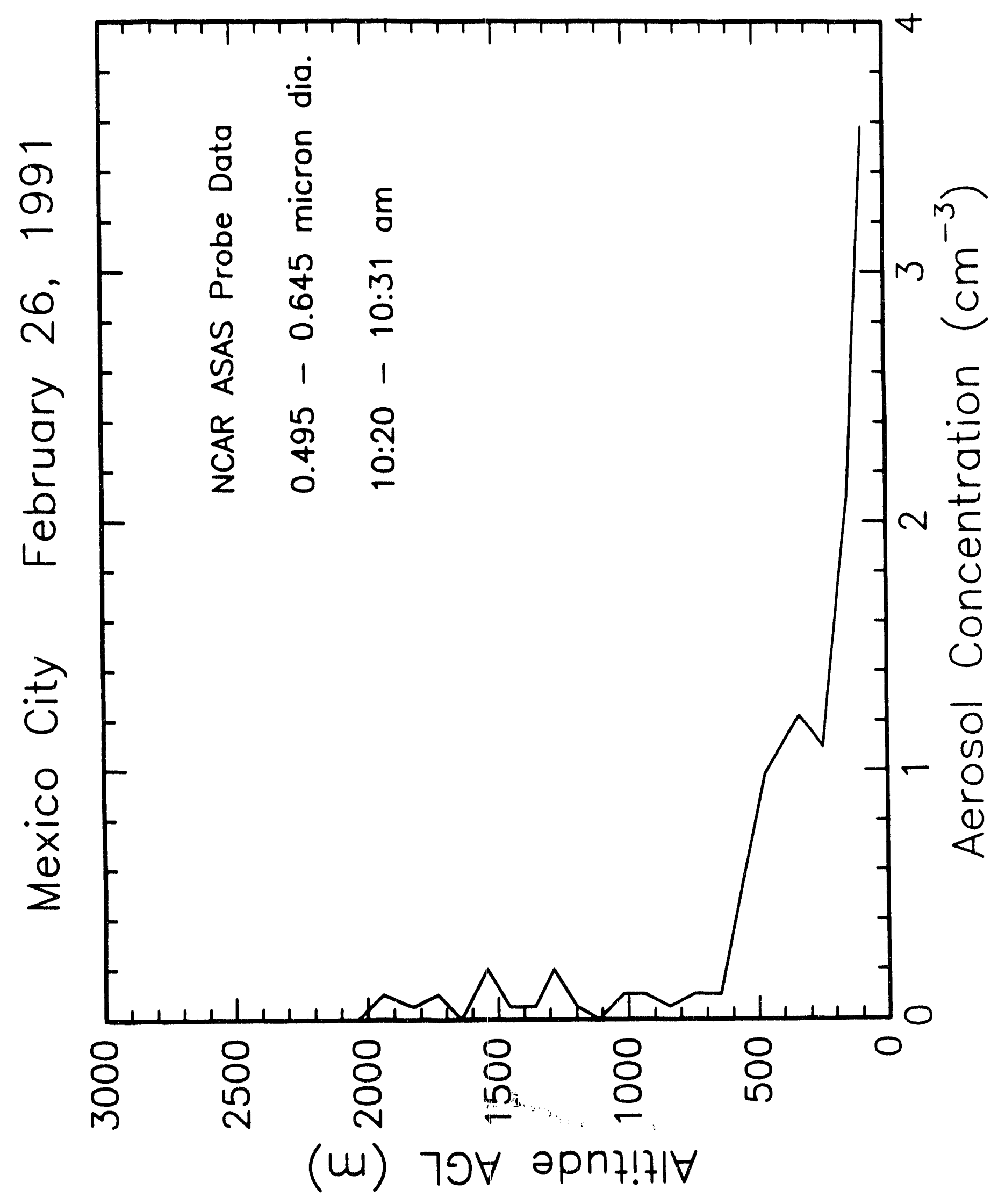




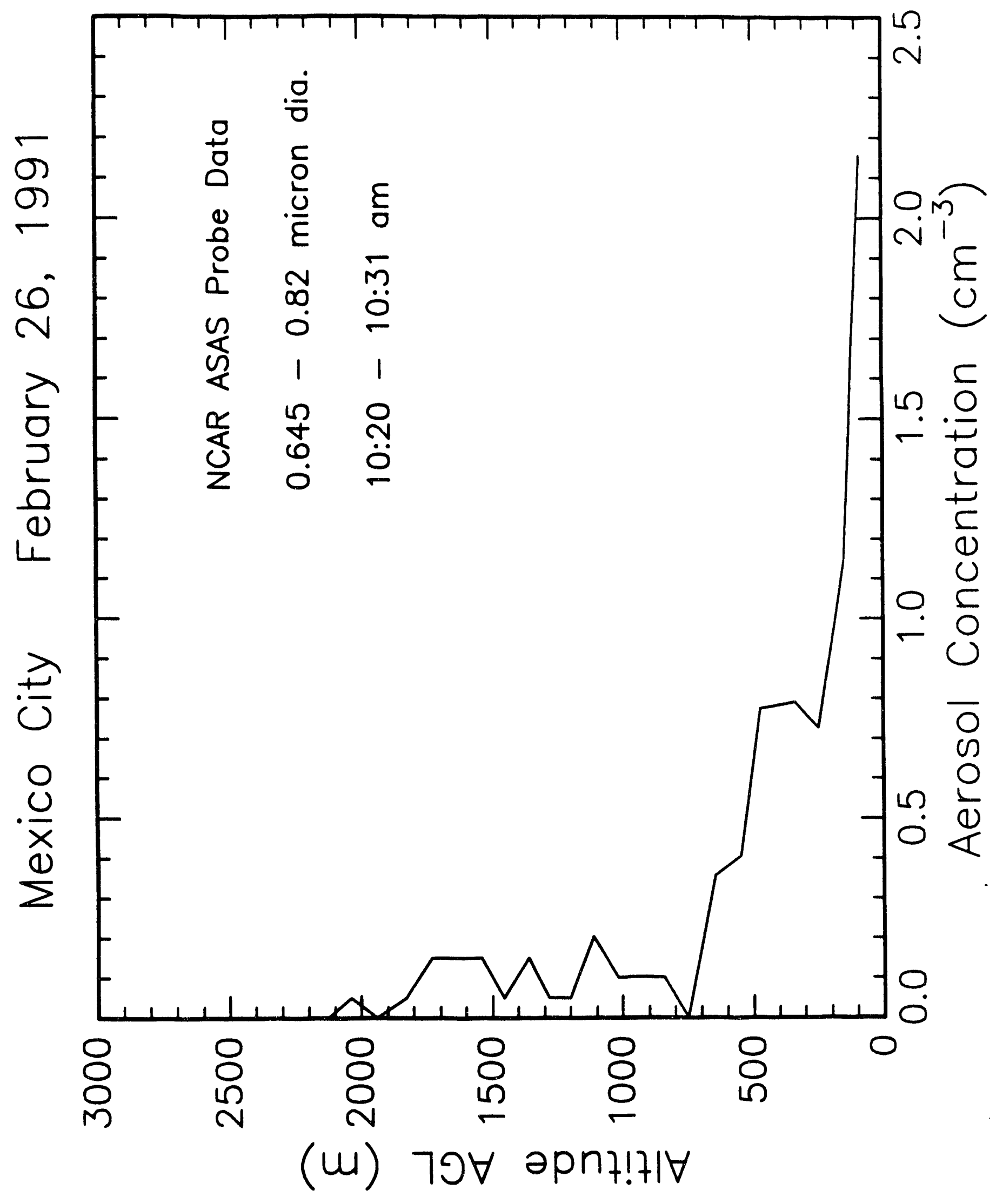




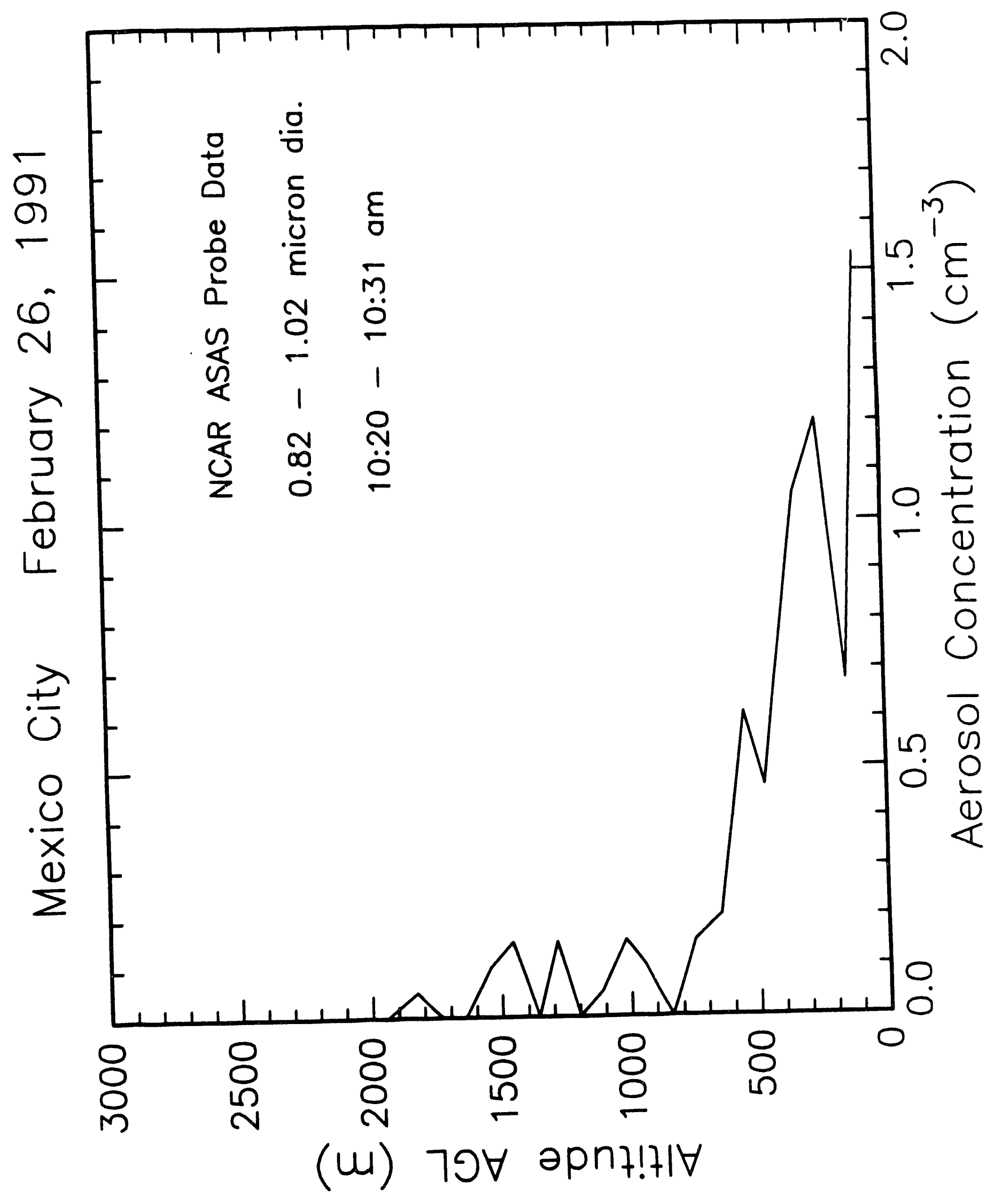




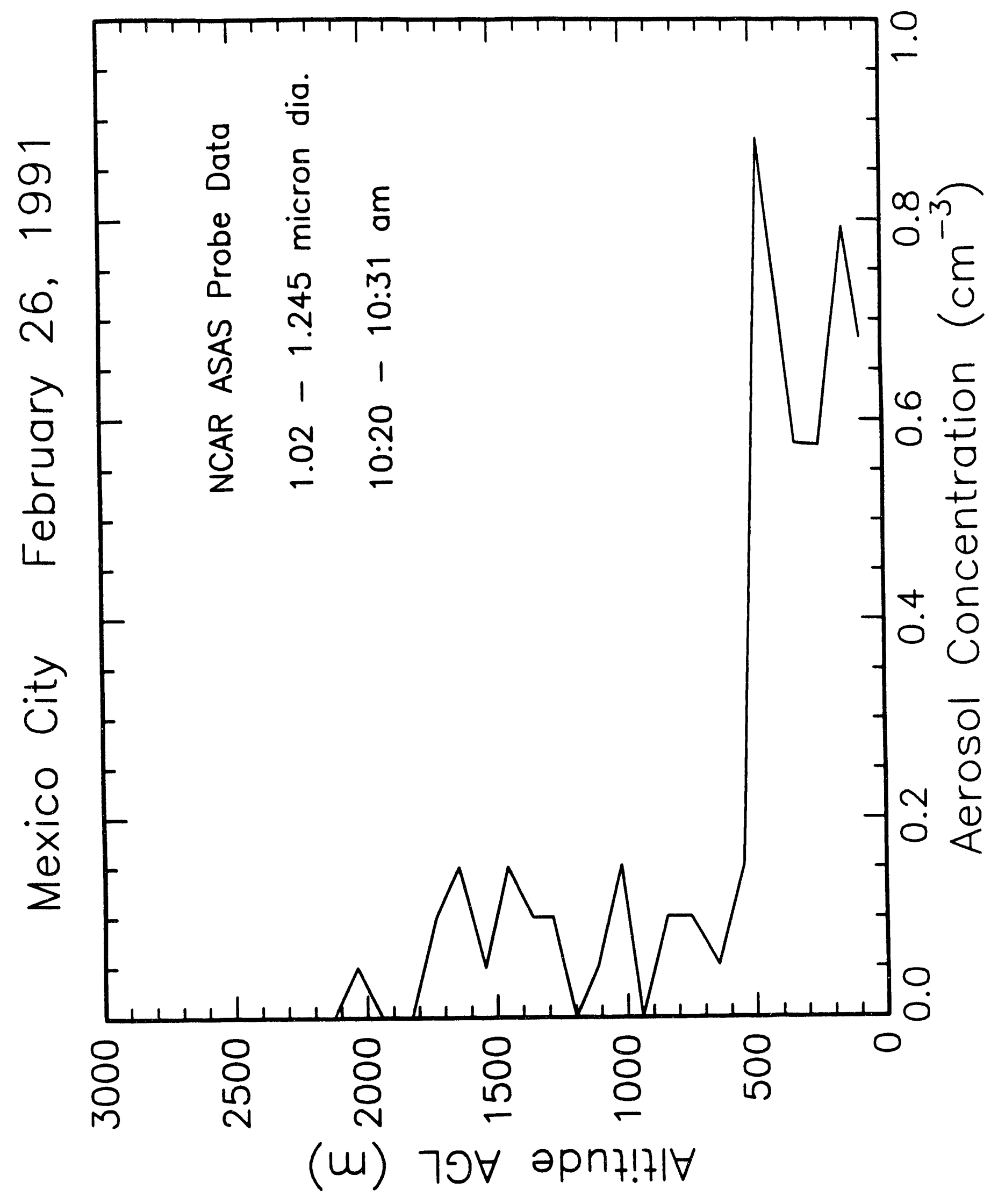




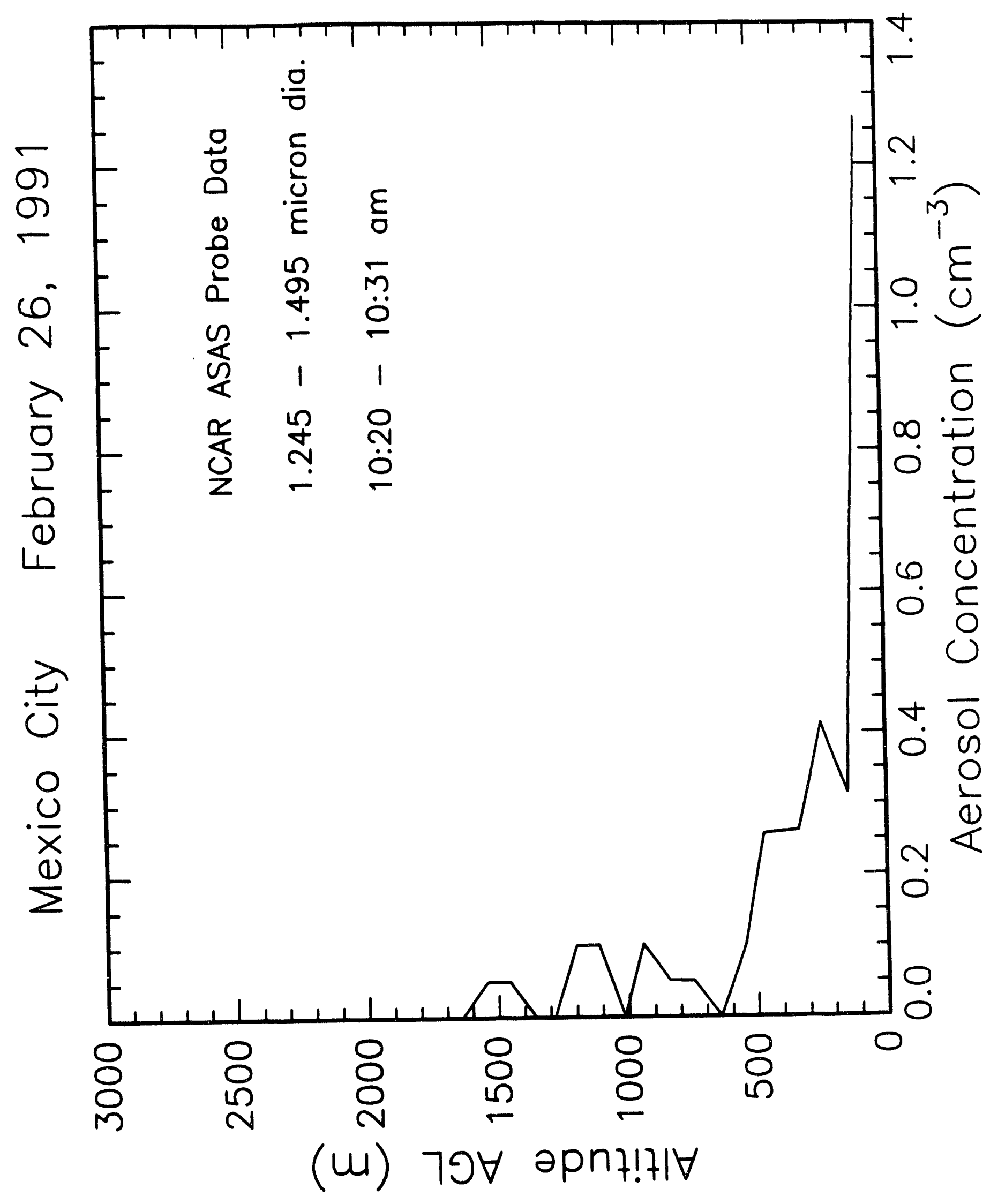




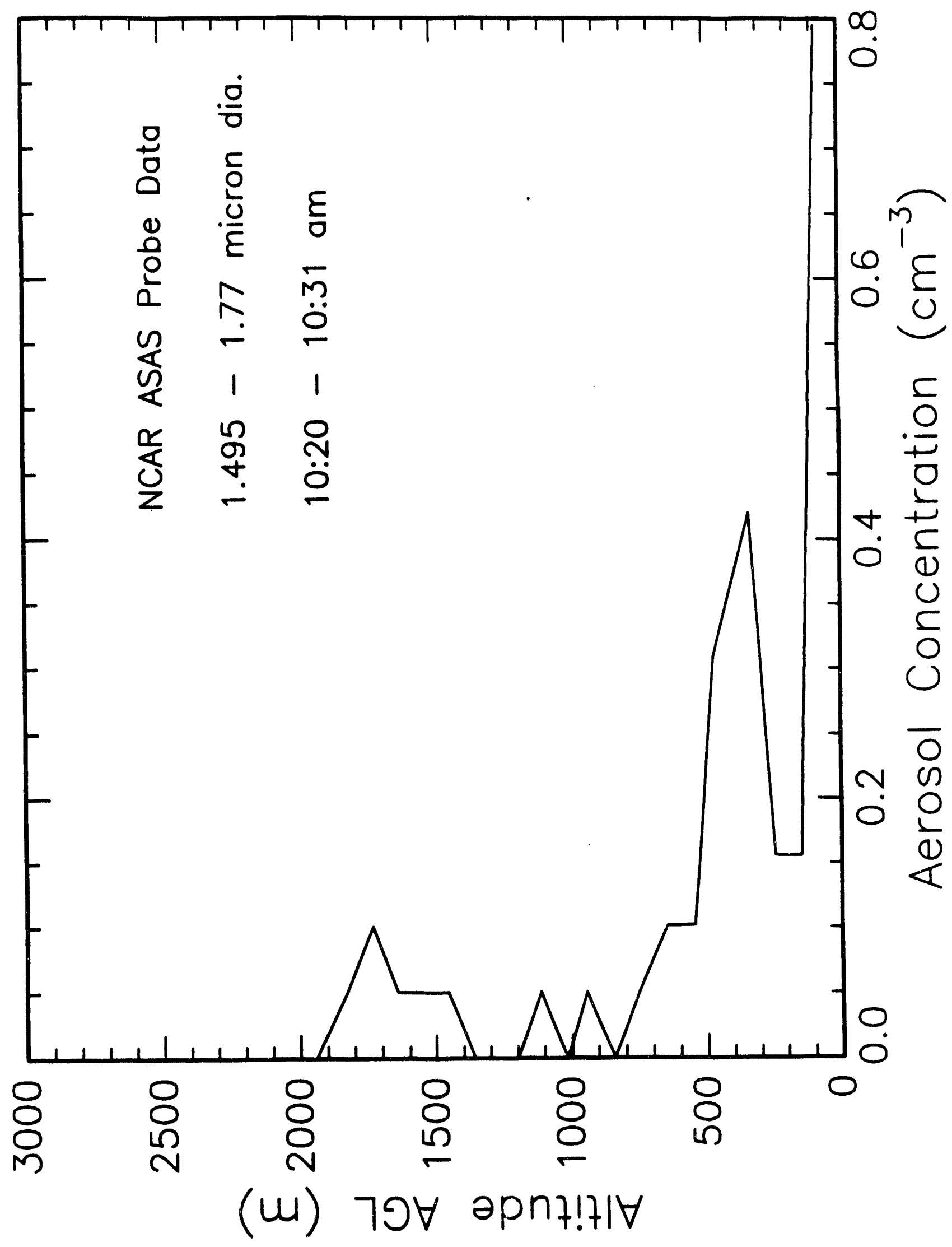




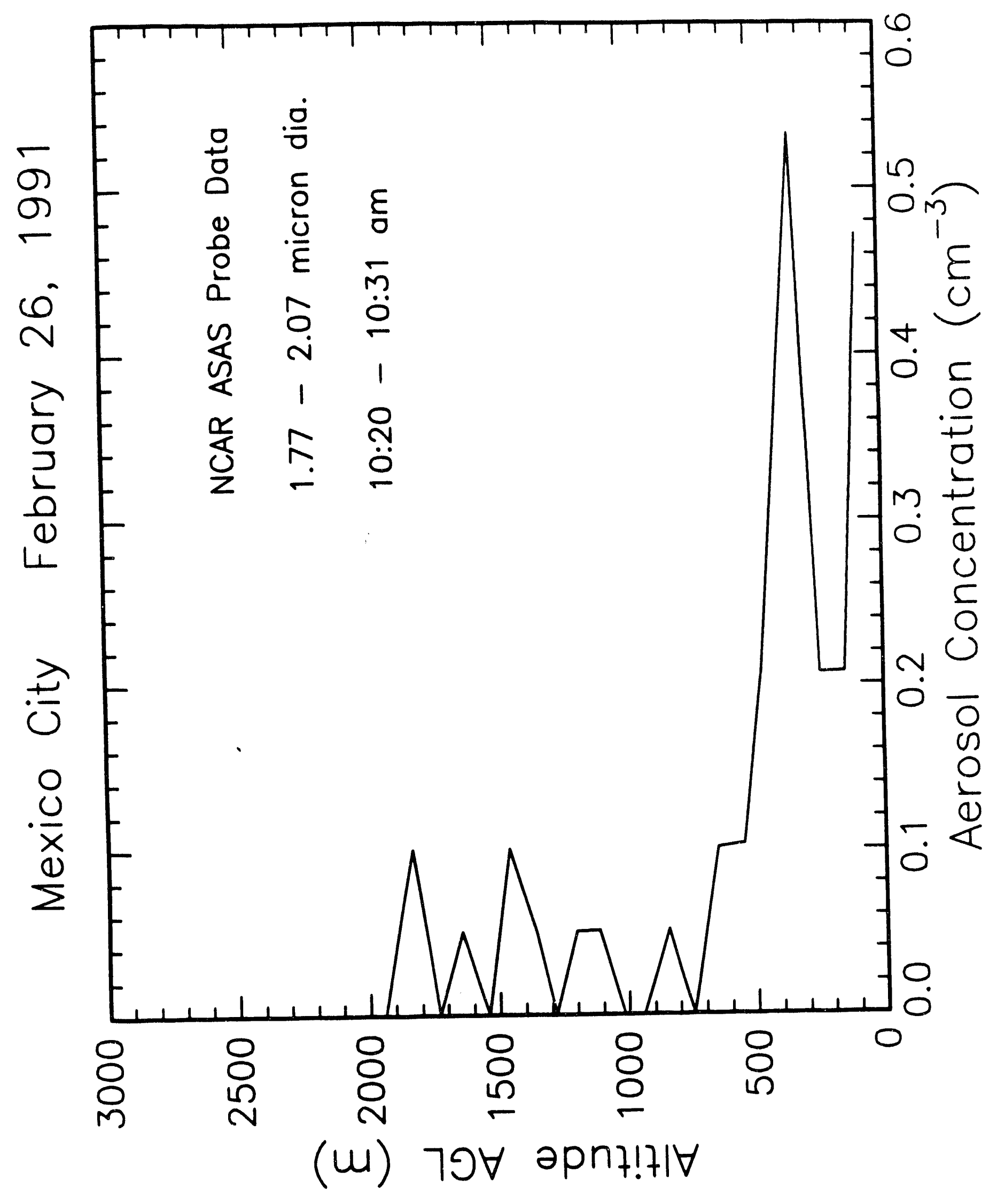




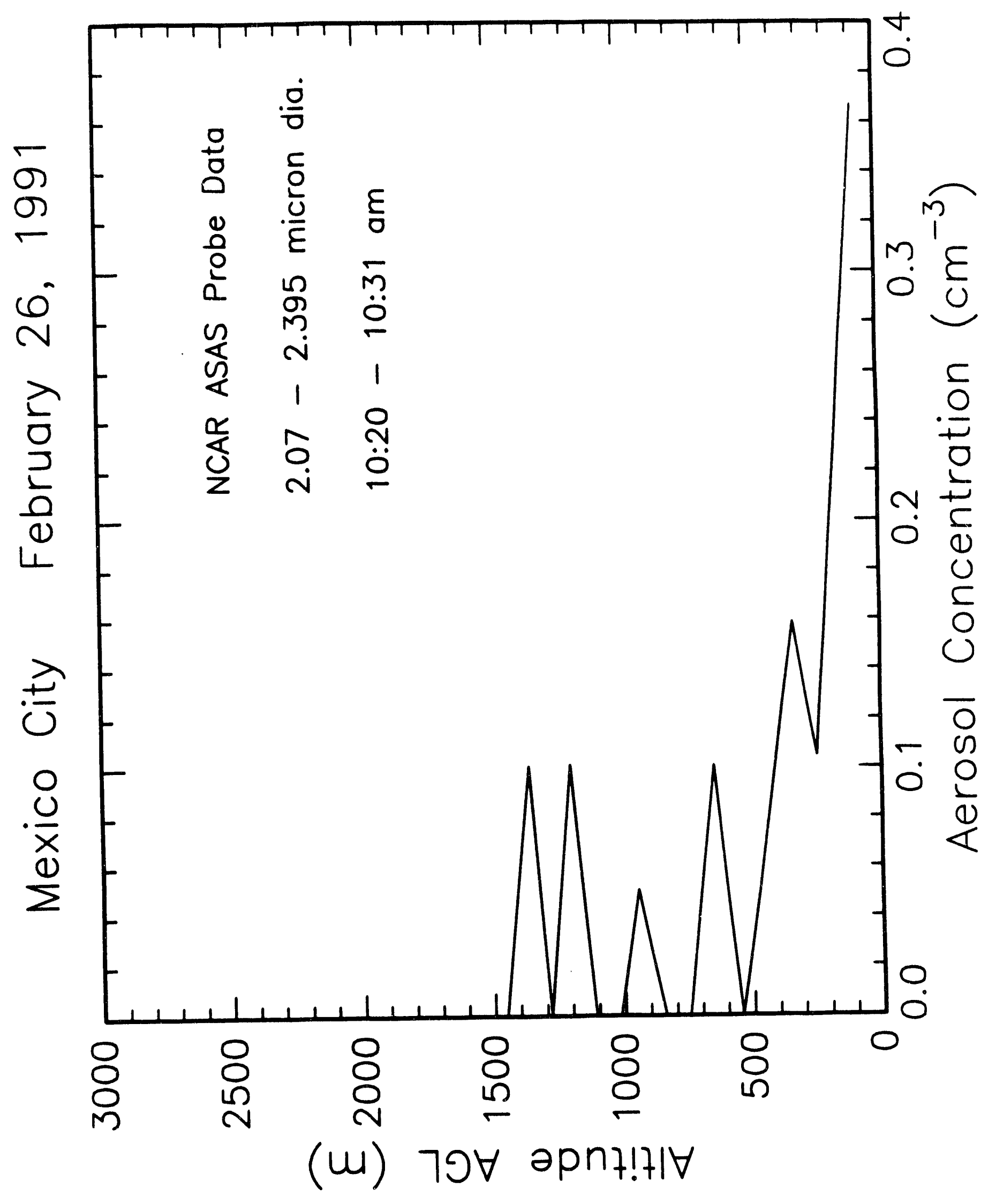




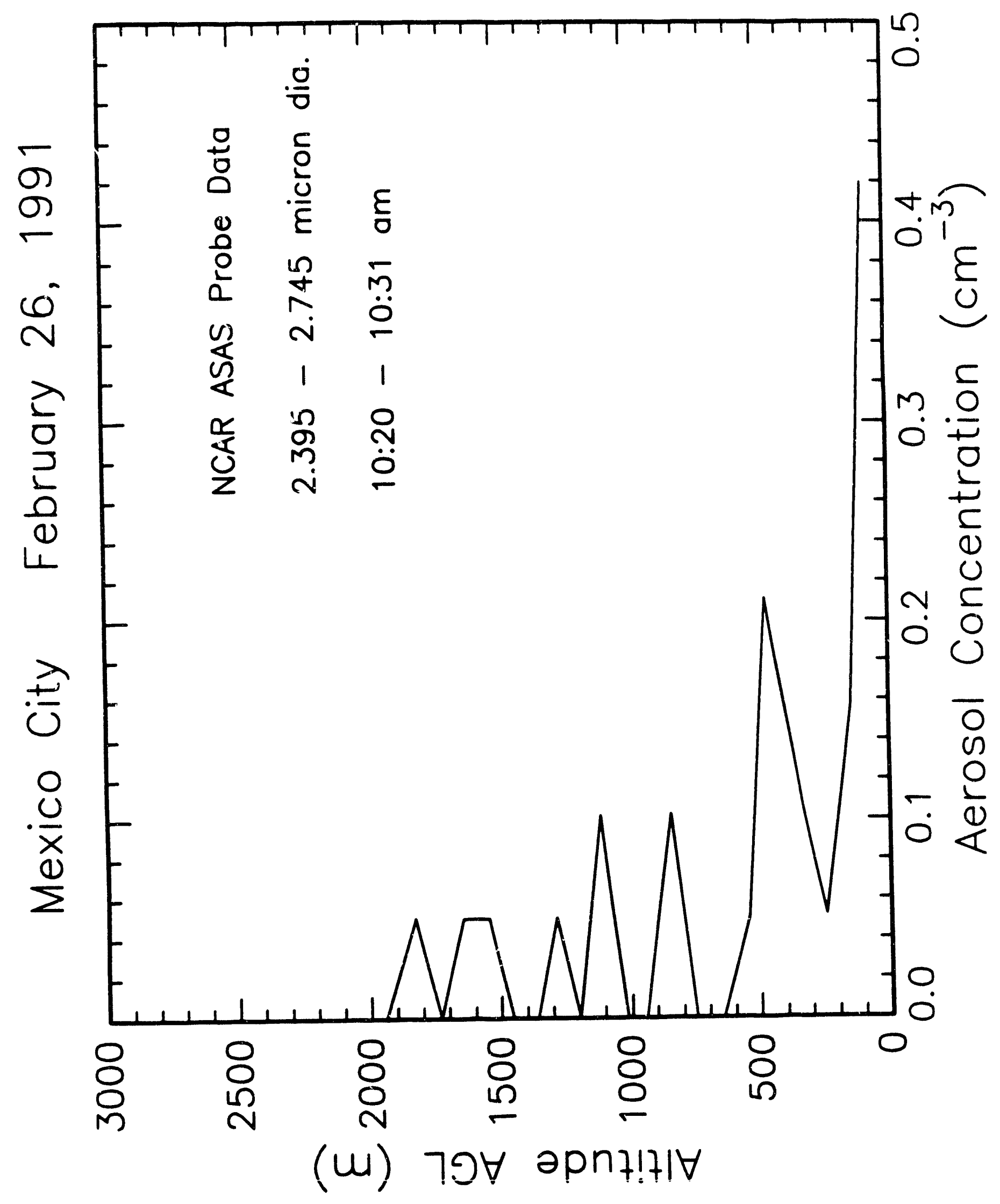




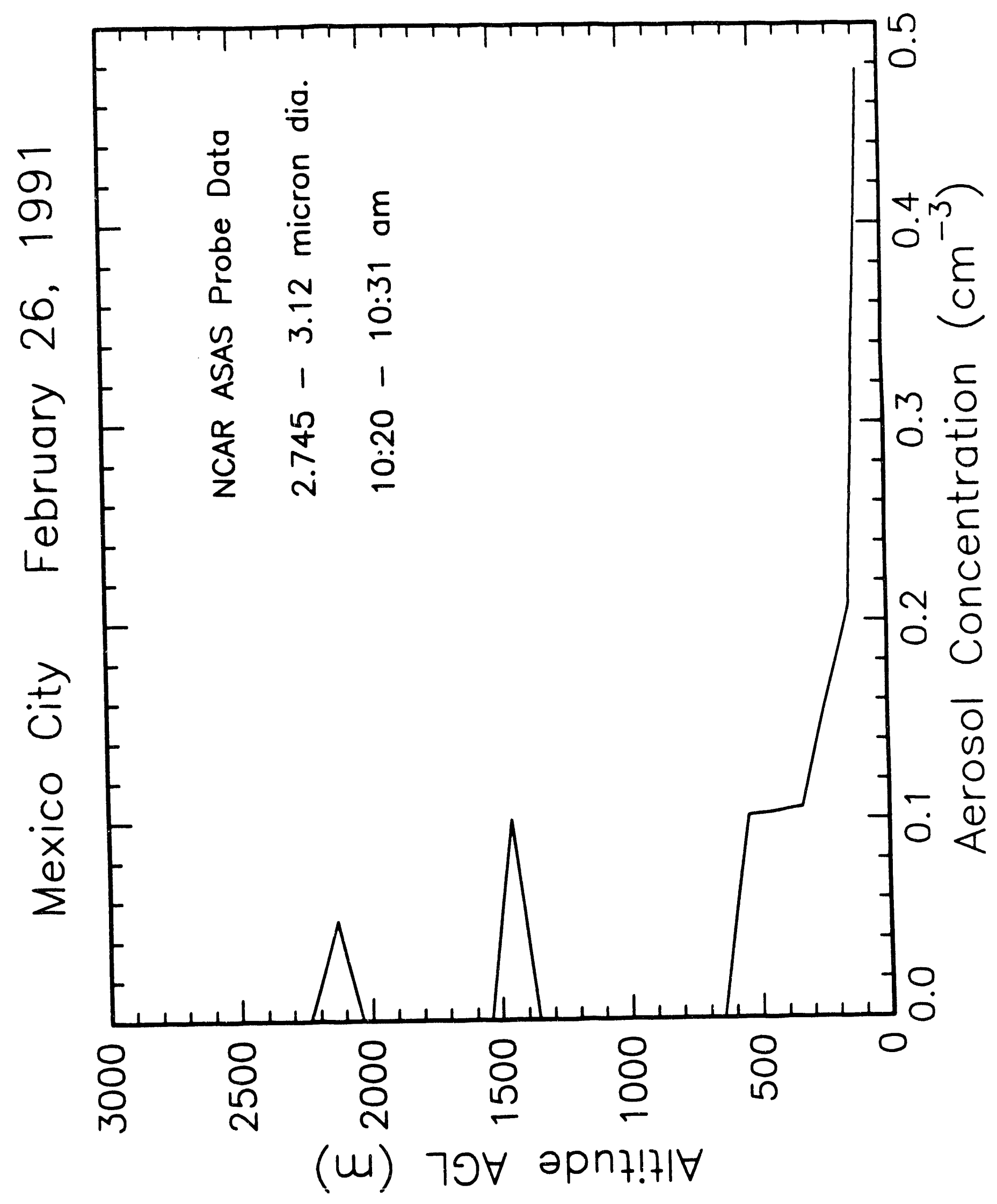




\section{Appendix E}

NCAR Metenrological and Air Pollutant Ascent Data 
NCAR Ascent of February 22, 1991

$10: 13$ - 10:22 am
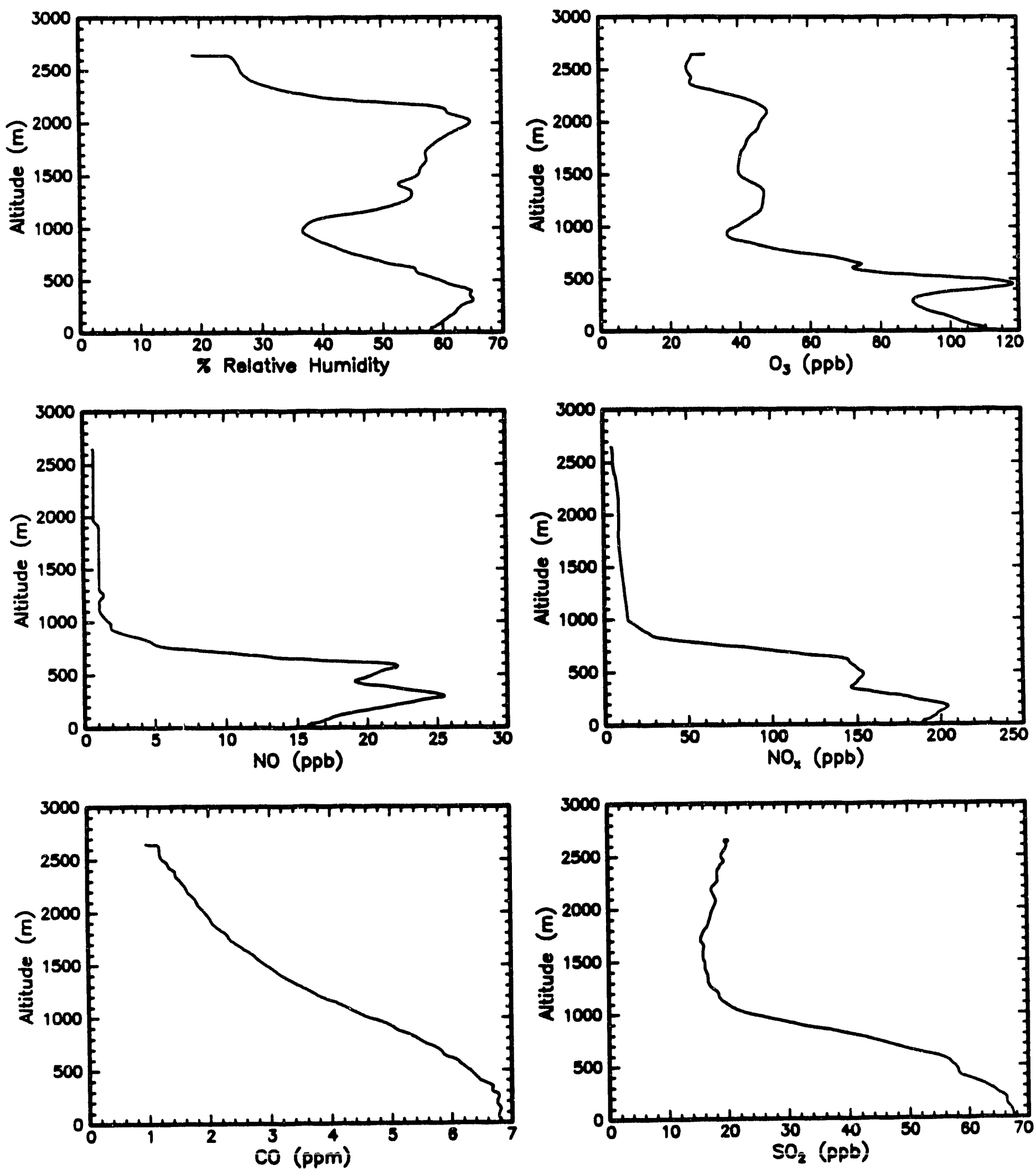
NCAR Ascent of February 22, 1991

$10: 13$ - 10:22 am
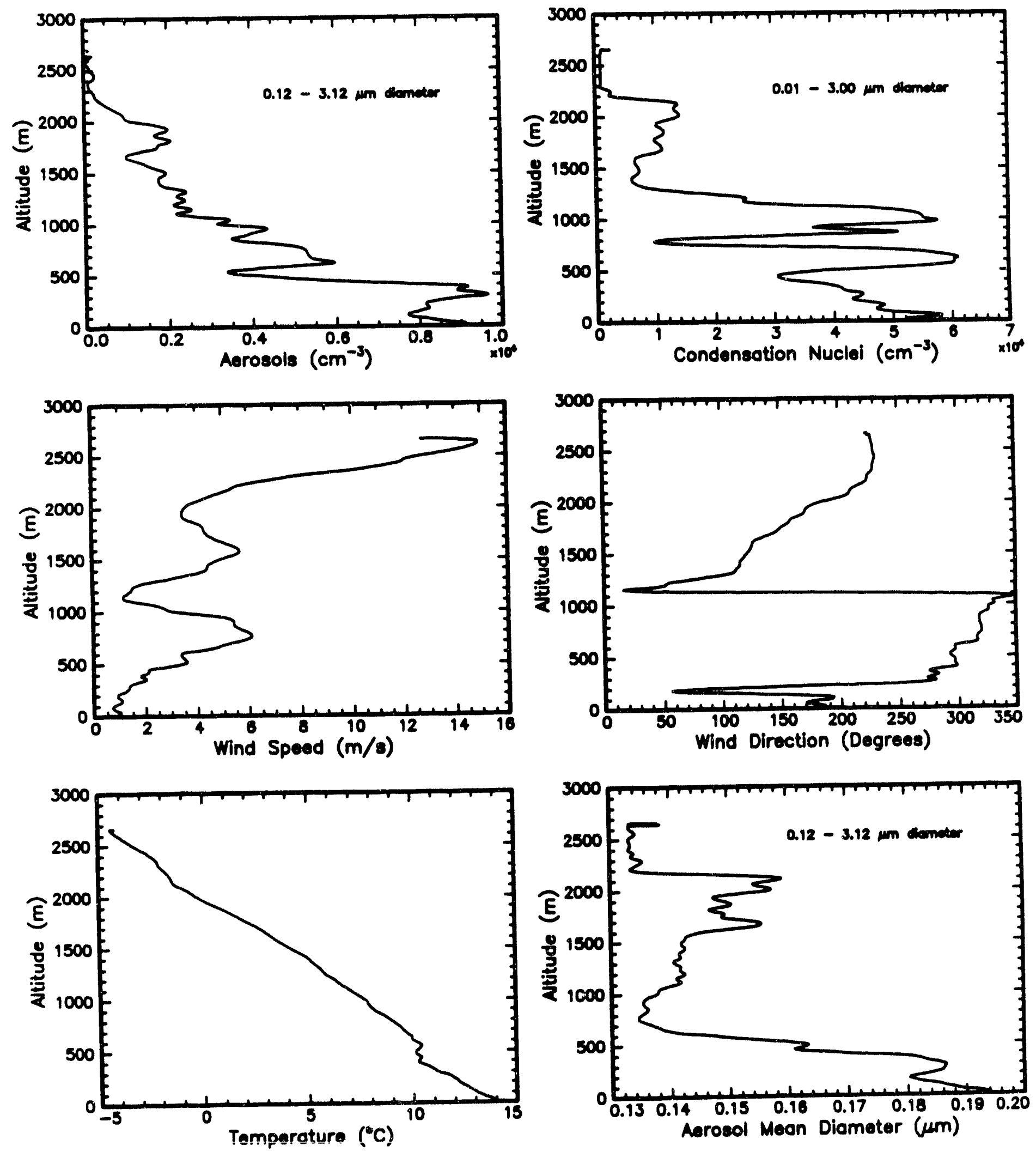


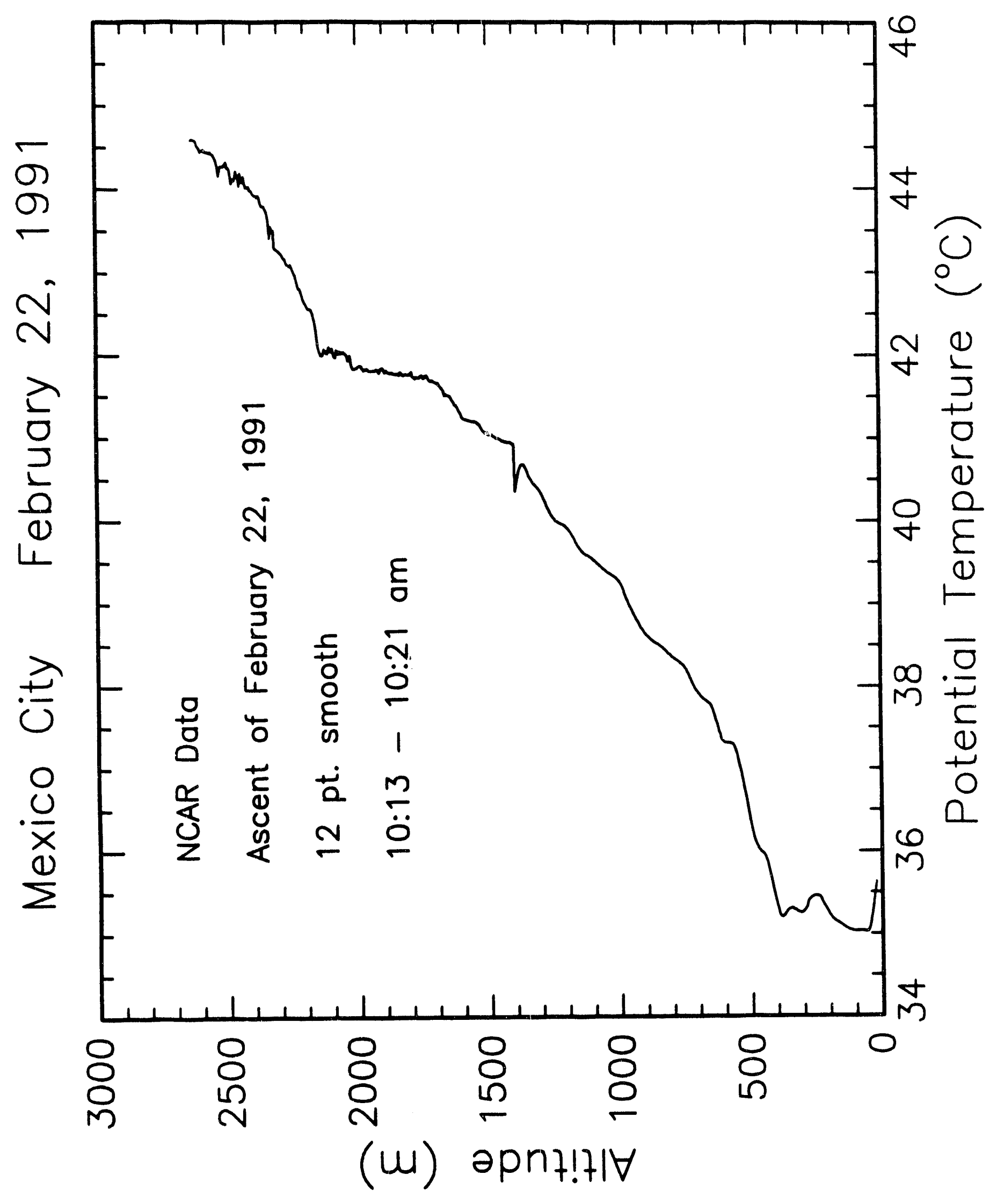




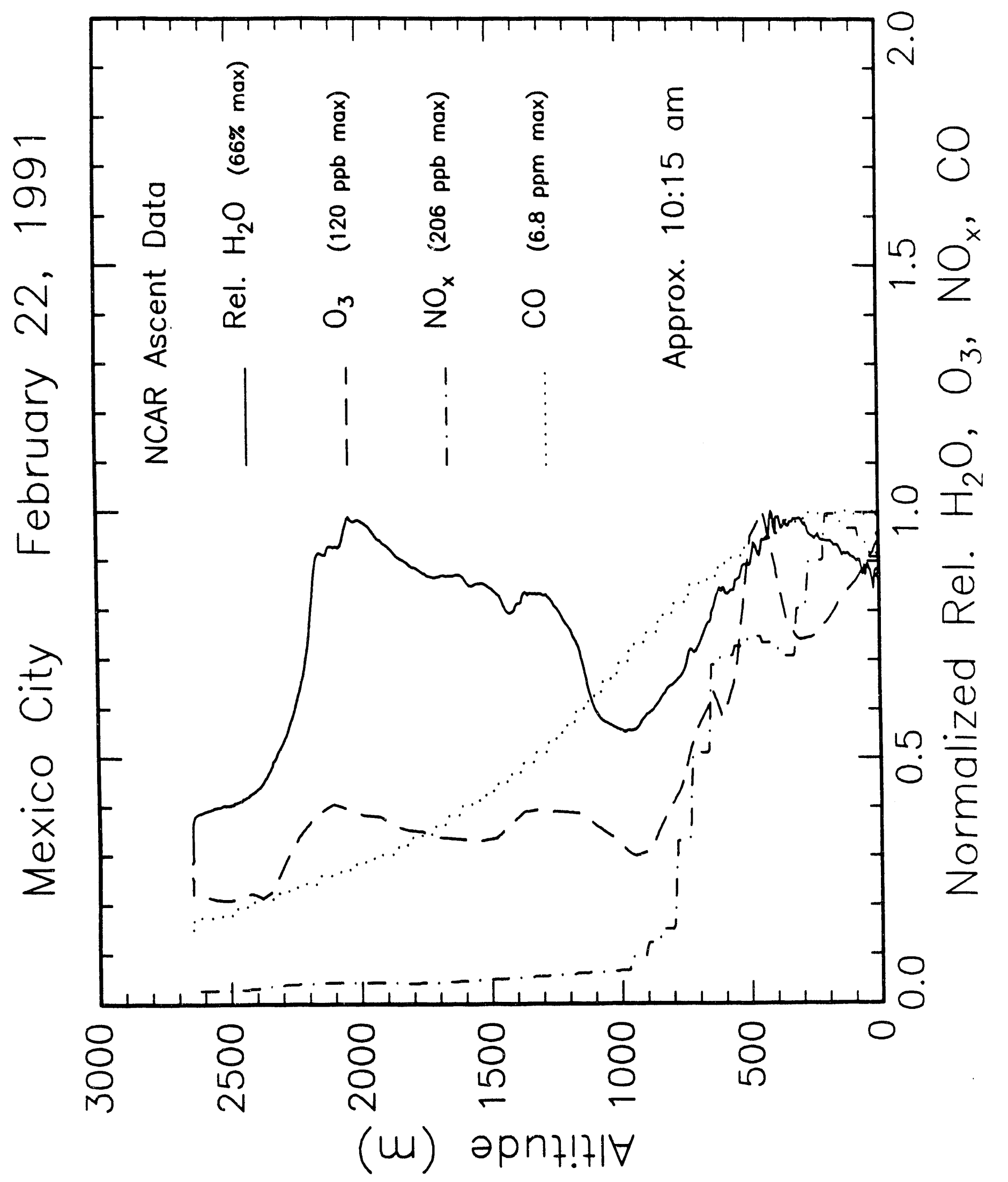


NCAR Ascent of February 26, 1991

10:20 - 10:31 am
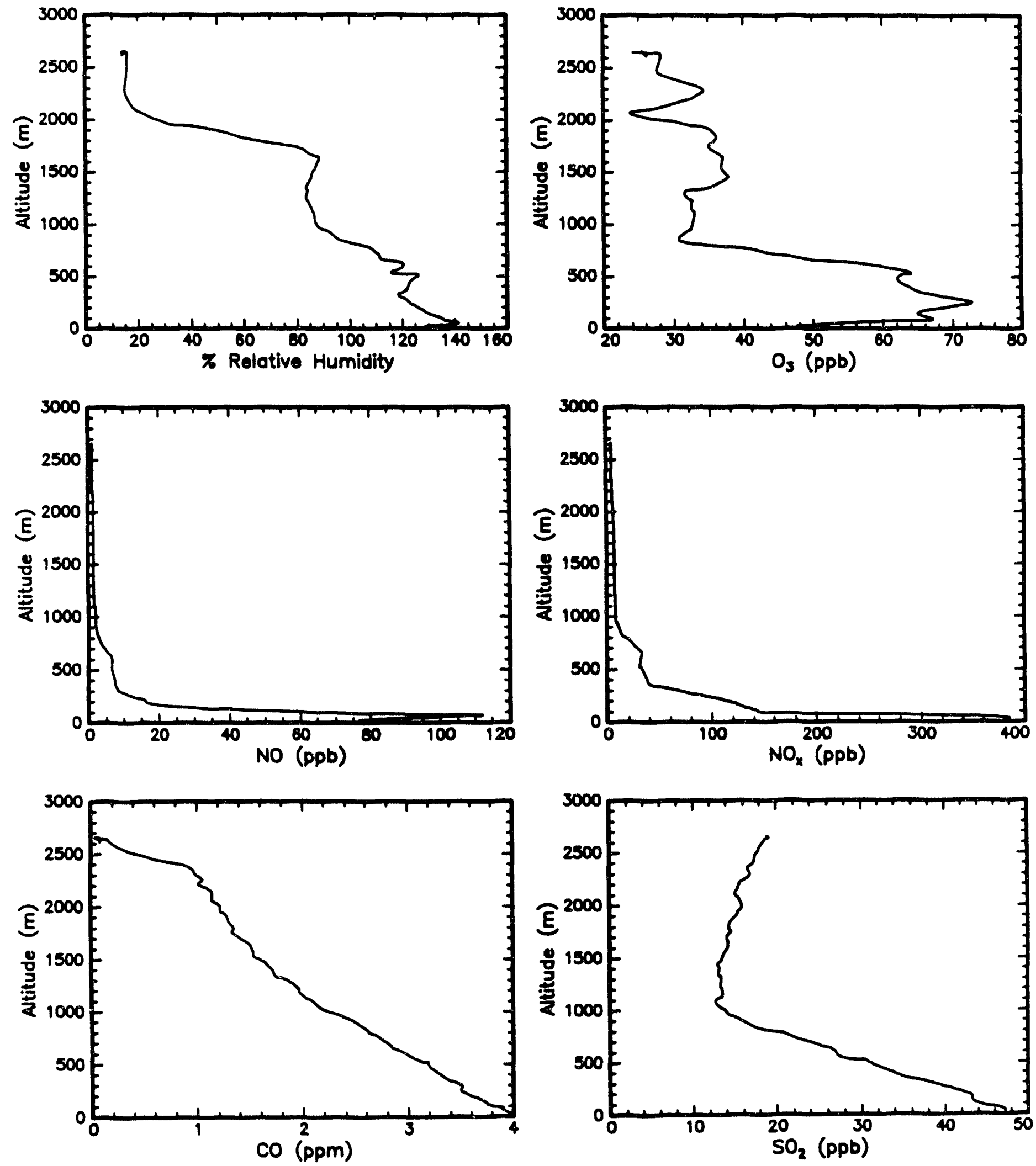


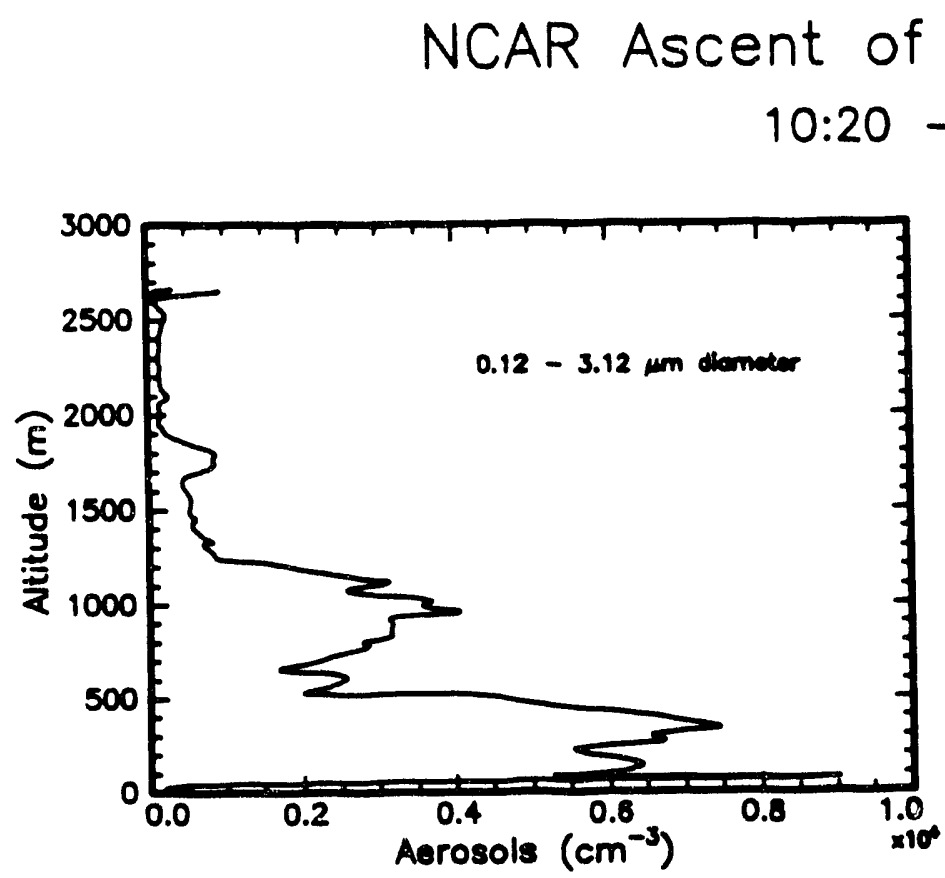

February 26, 1991

- 10:31 am
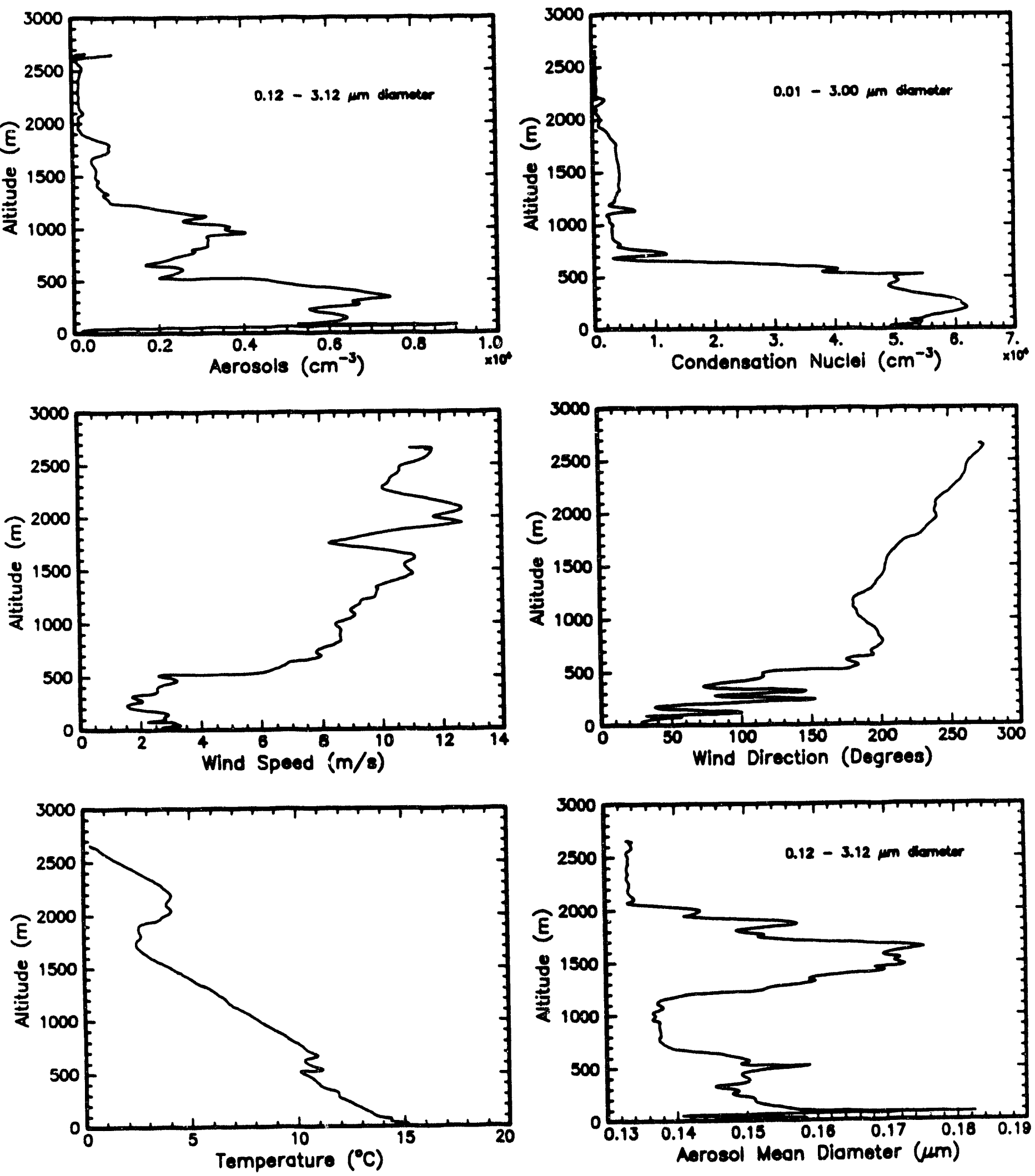


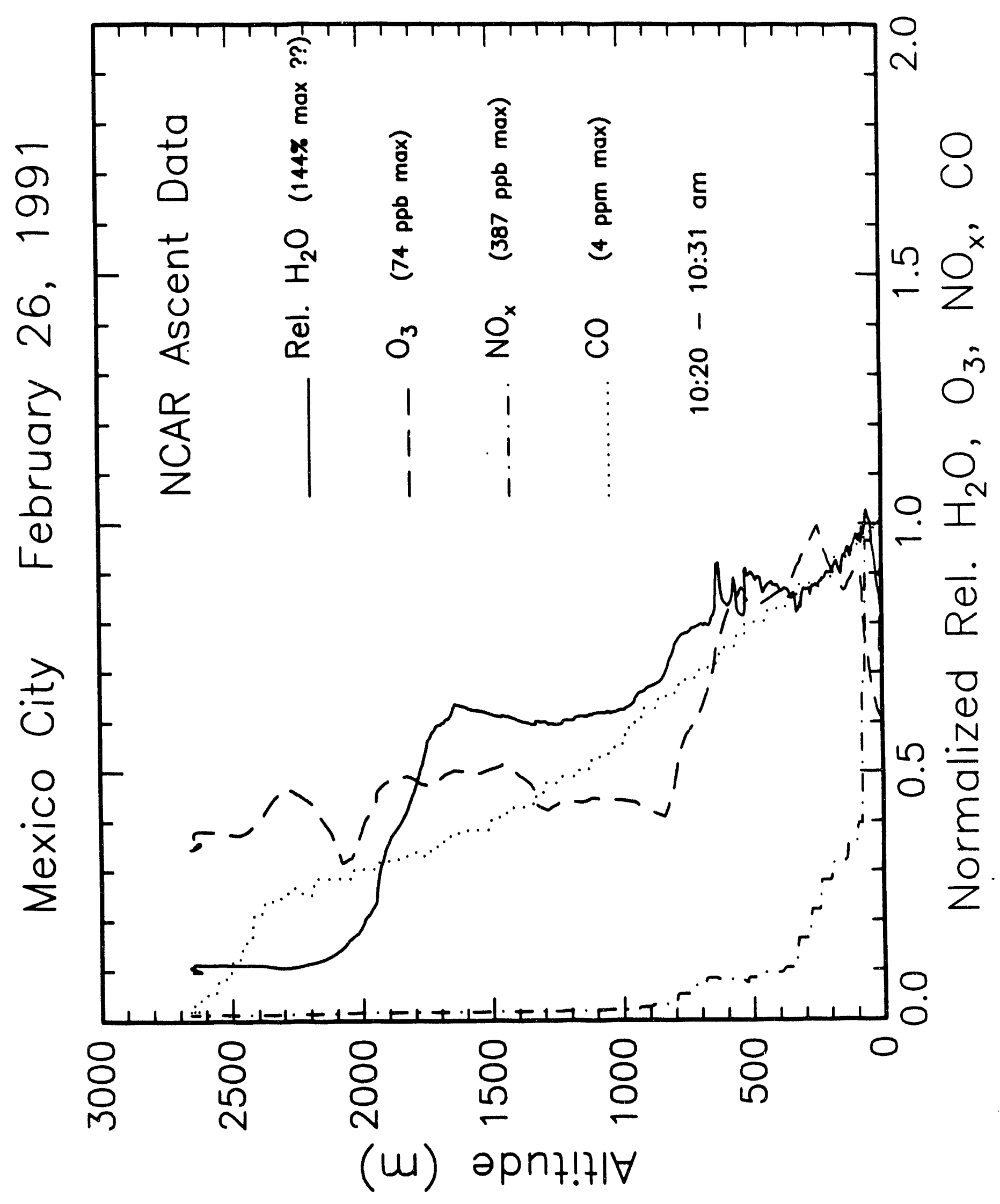




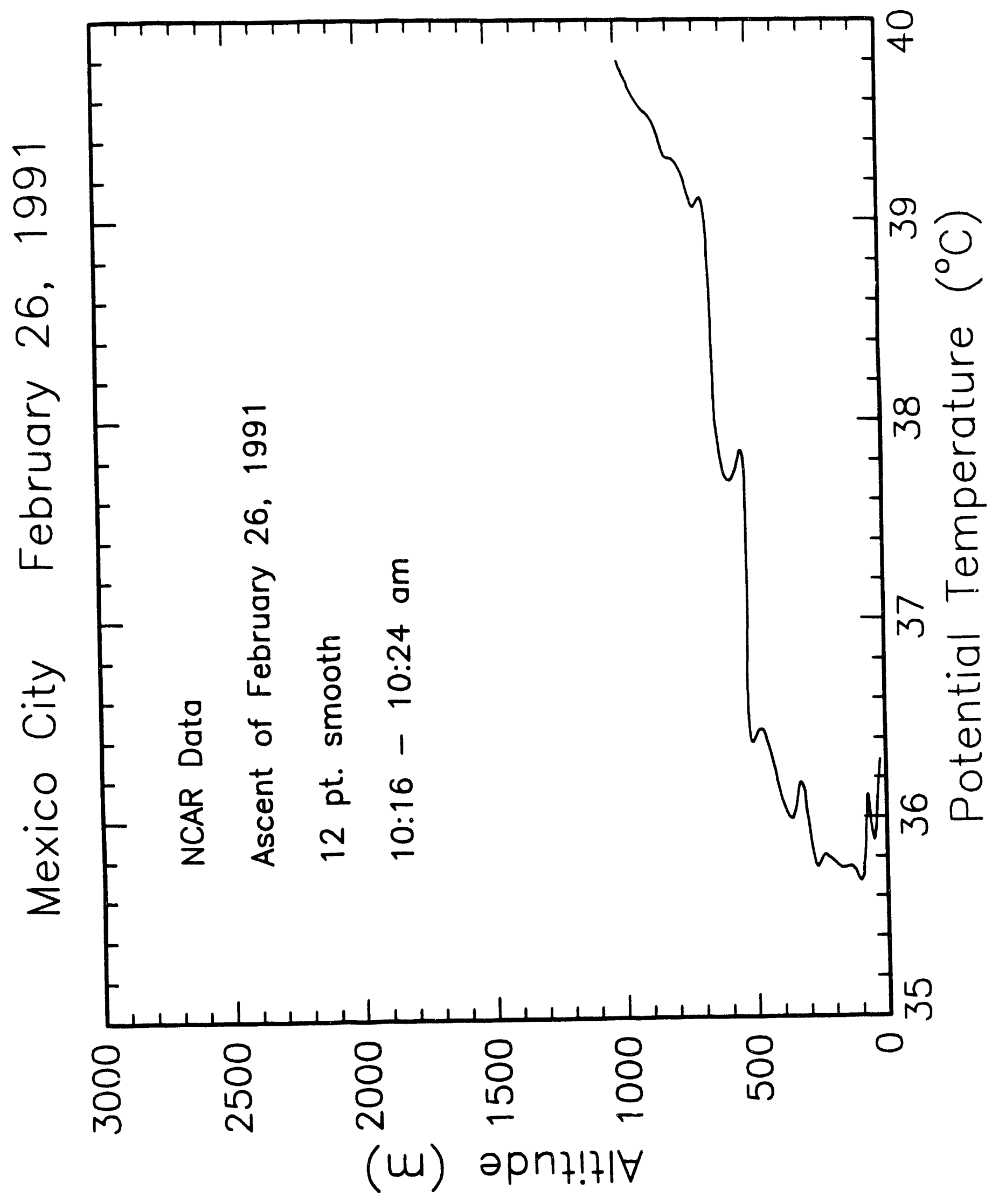




\section{Appendix F}

\section{Mexico City Airport Rawinsonde Data}




\section{Airport Rawinsonde Sounding February 17, 1991}

\section{$11 \mathrm{am}$}
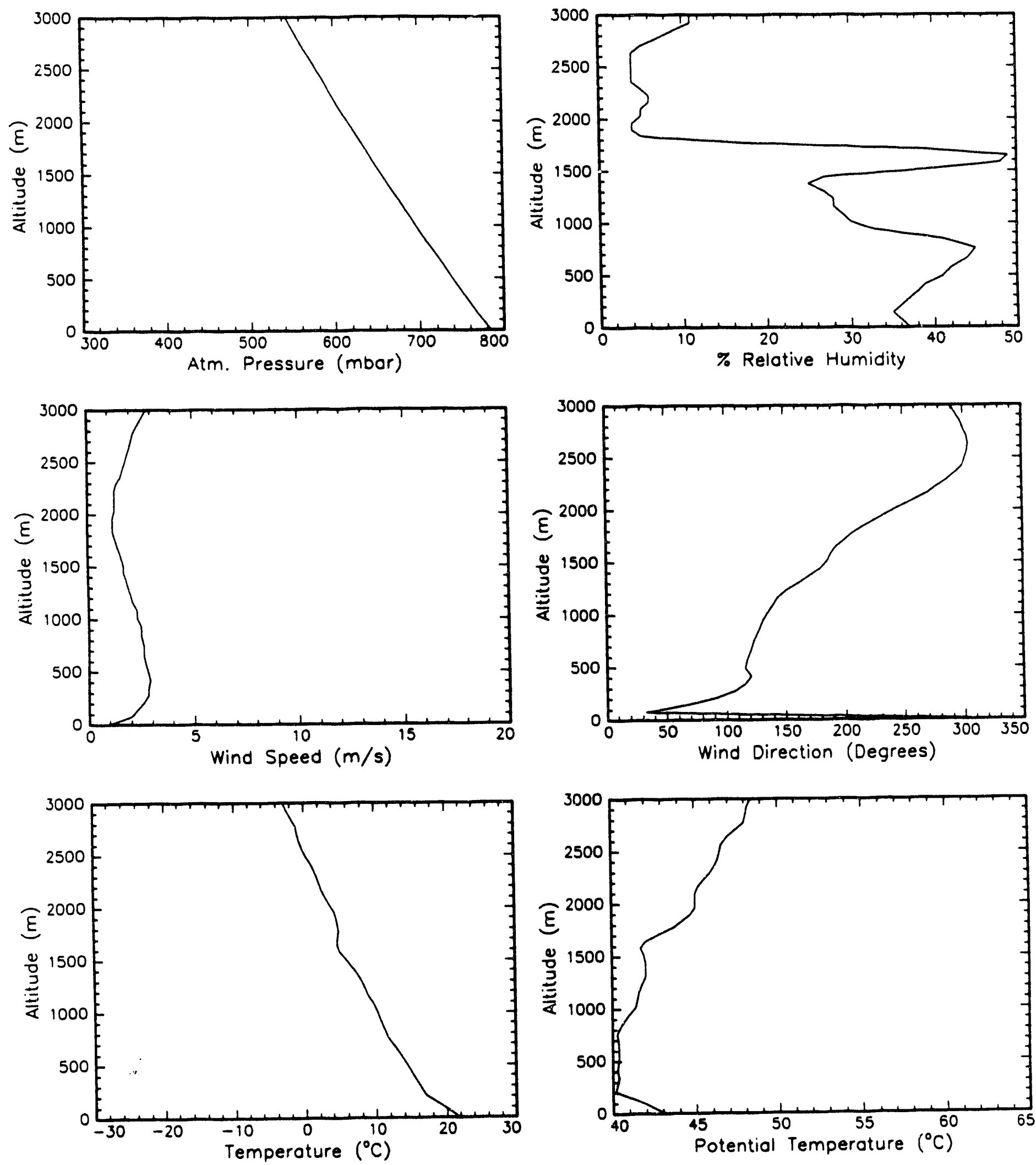
Airport Rawinsonde of February 17, 1991
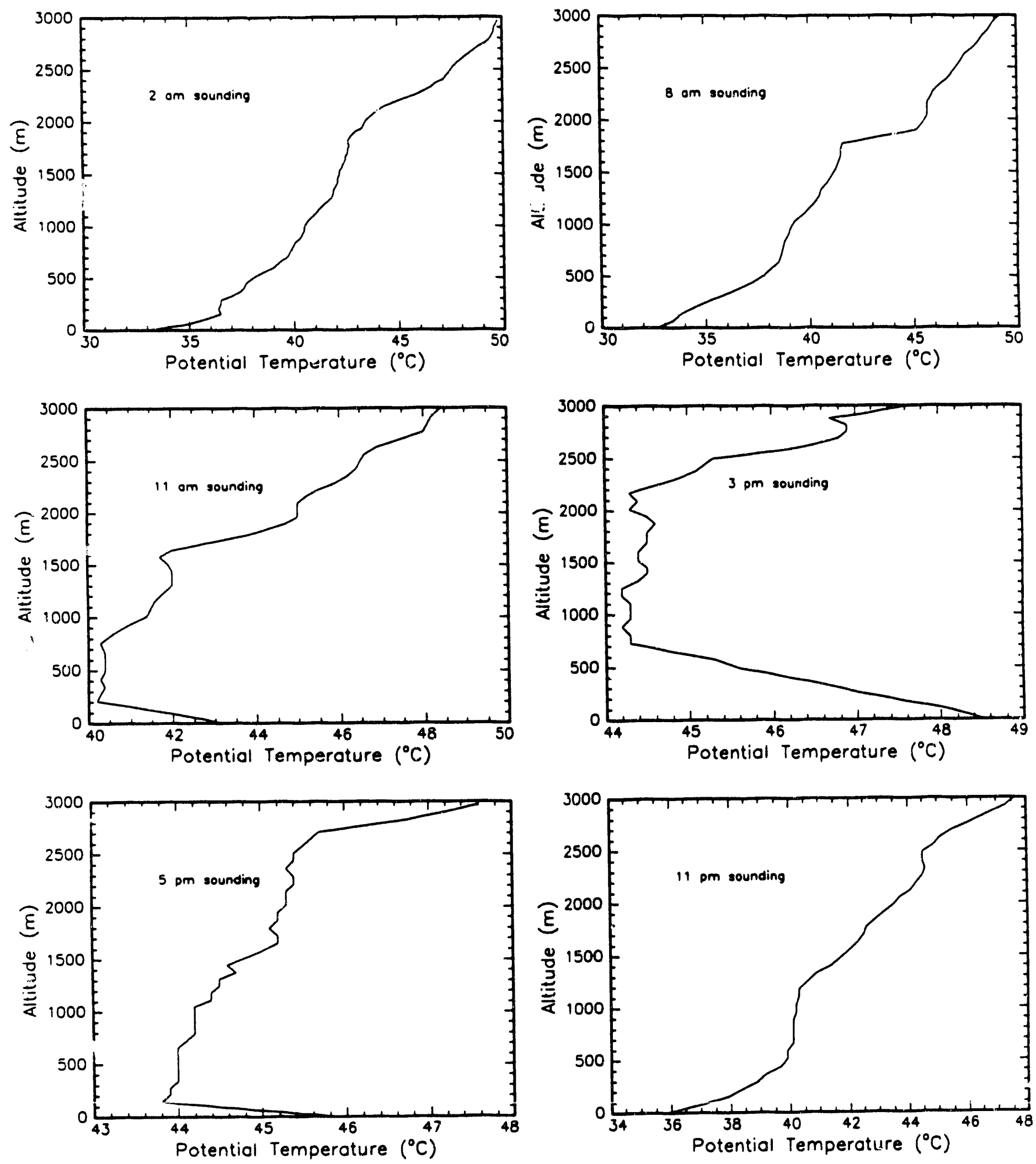
Airport Rawinsonde Sounding February 22, 1991

12 pm
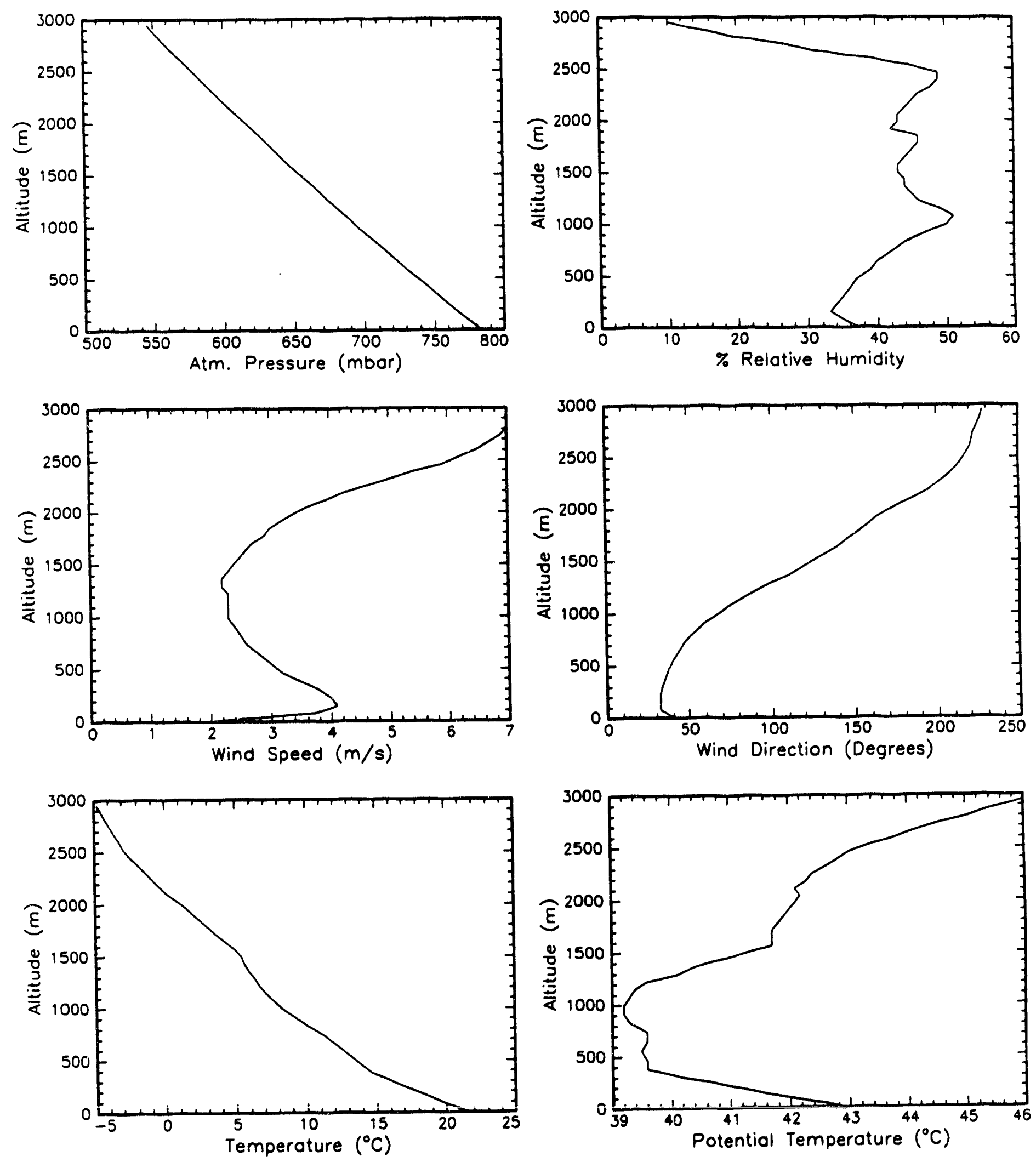
Airport Rawinsonde of February 22, 1991
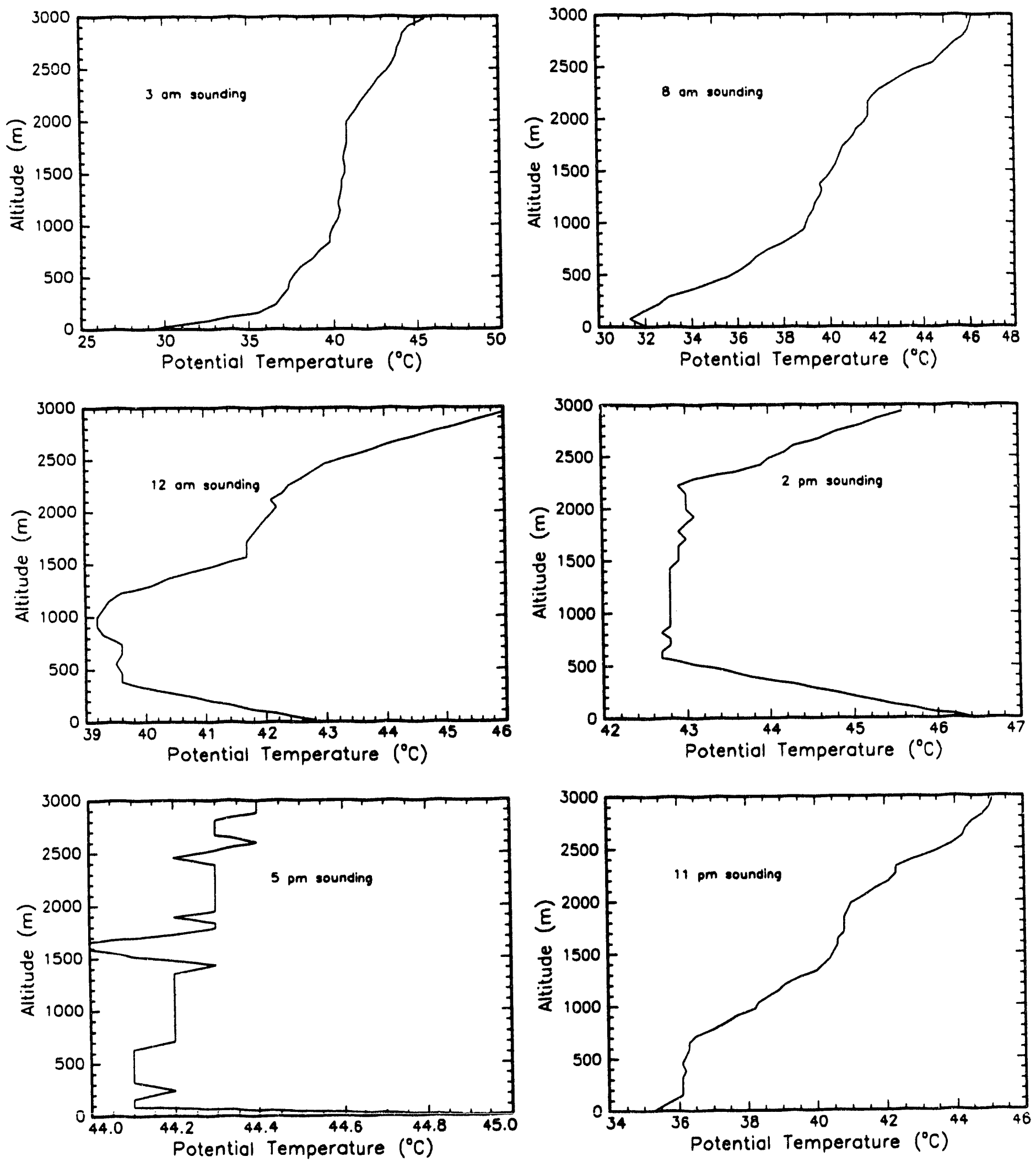


\section{Airport Rawinsonde of February 26, 1991}
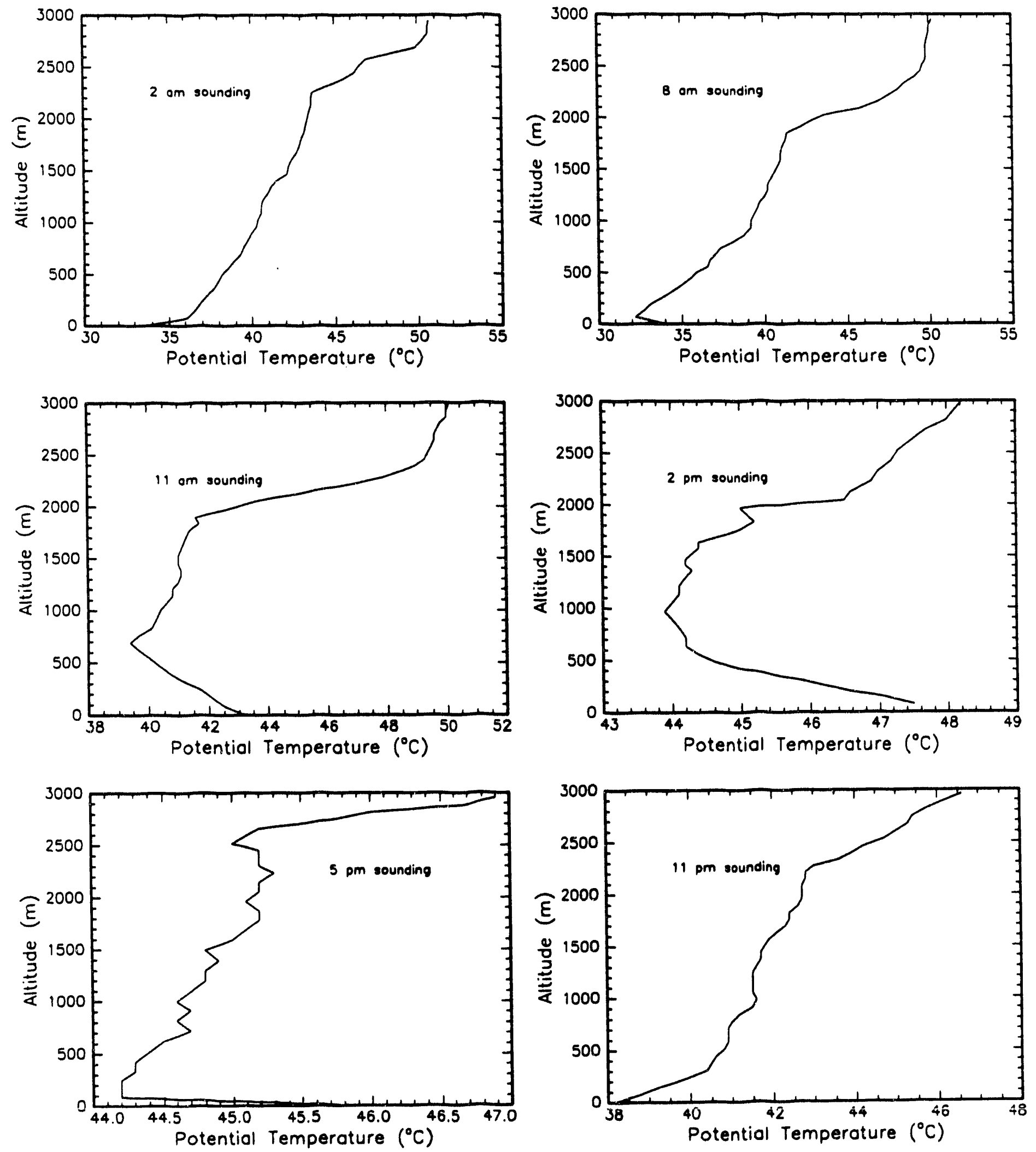
Airport Rawinsonde Sounding February 26, 1991

$11 \mathrm{am}$
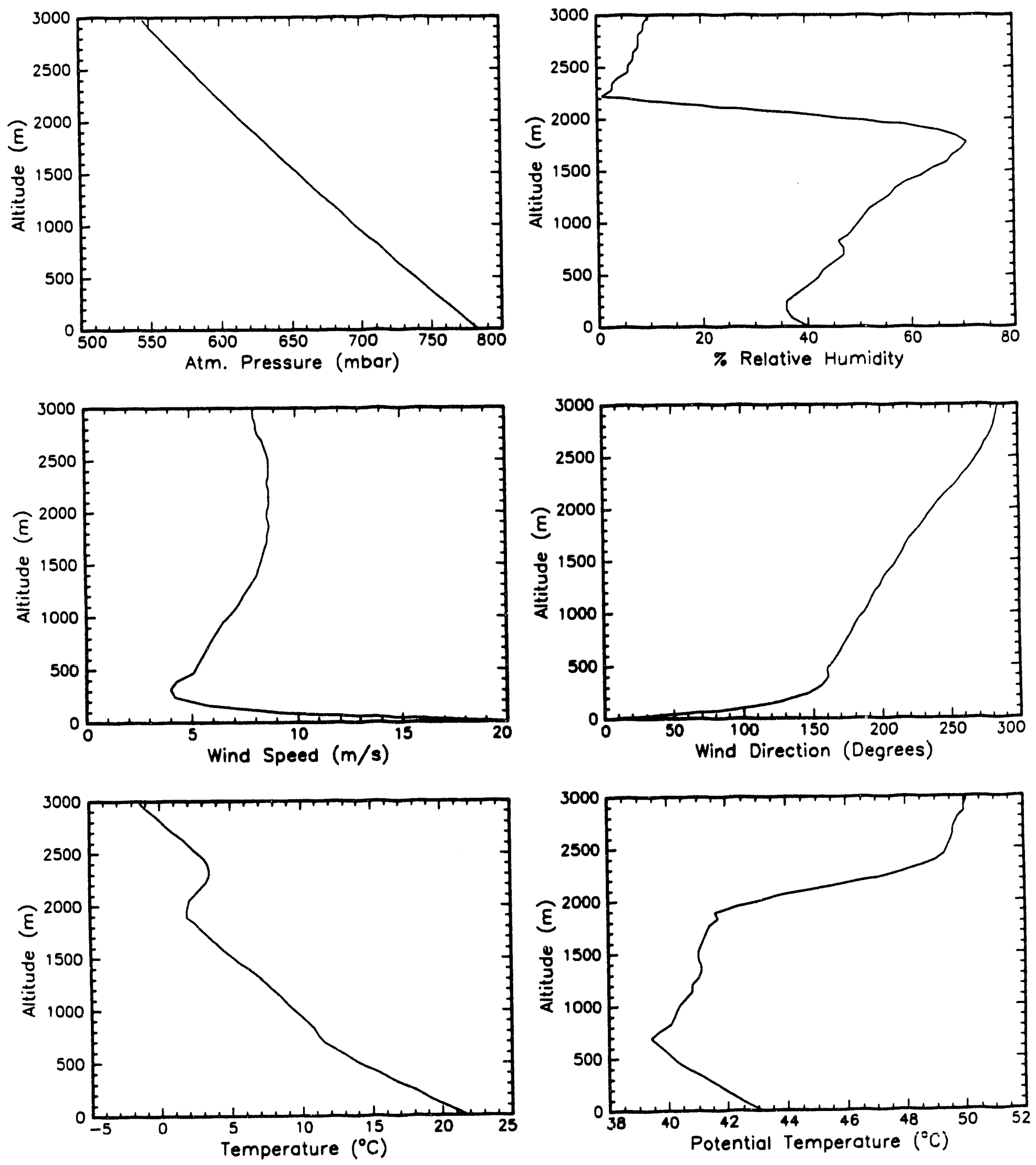
Airport Rawinsonde Sounding February 27, 1991

$11 \mathrm{am}$
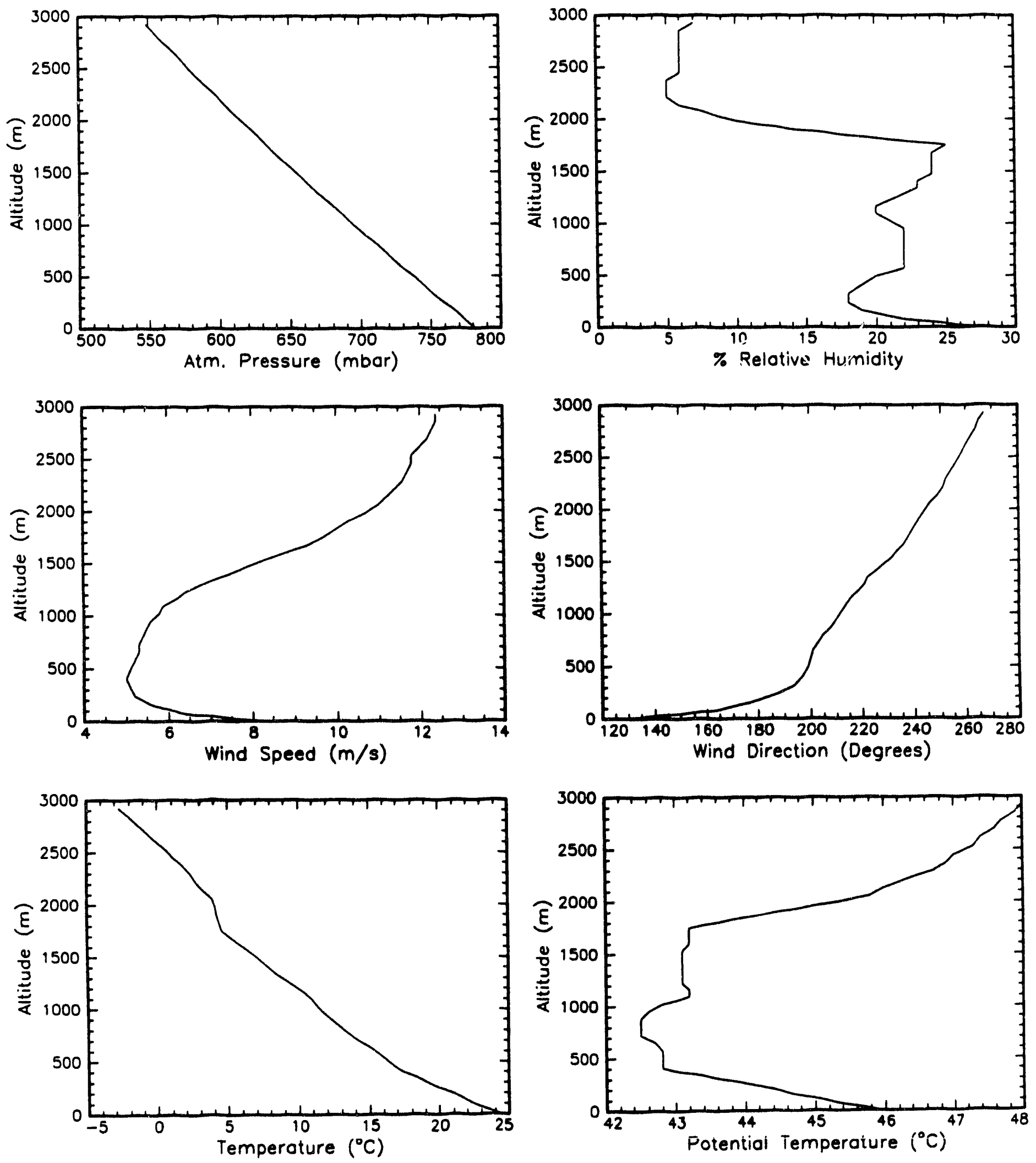
Airport Rawinsonde of February 27, 1991
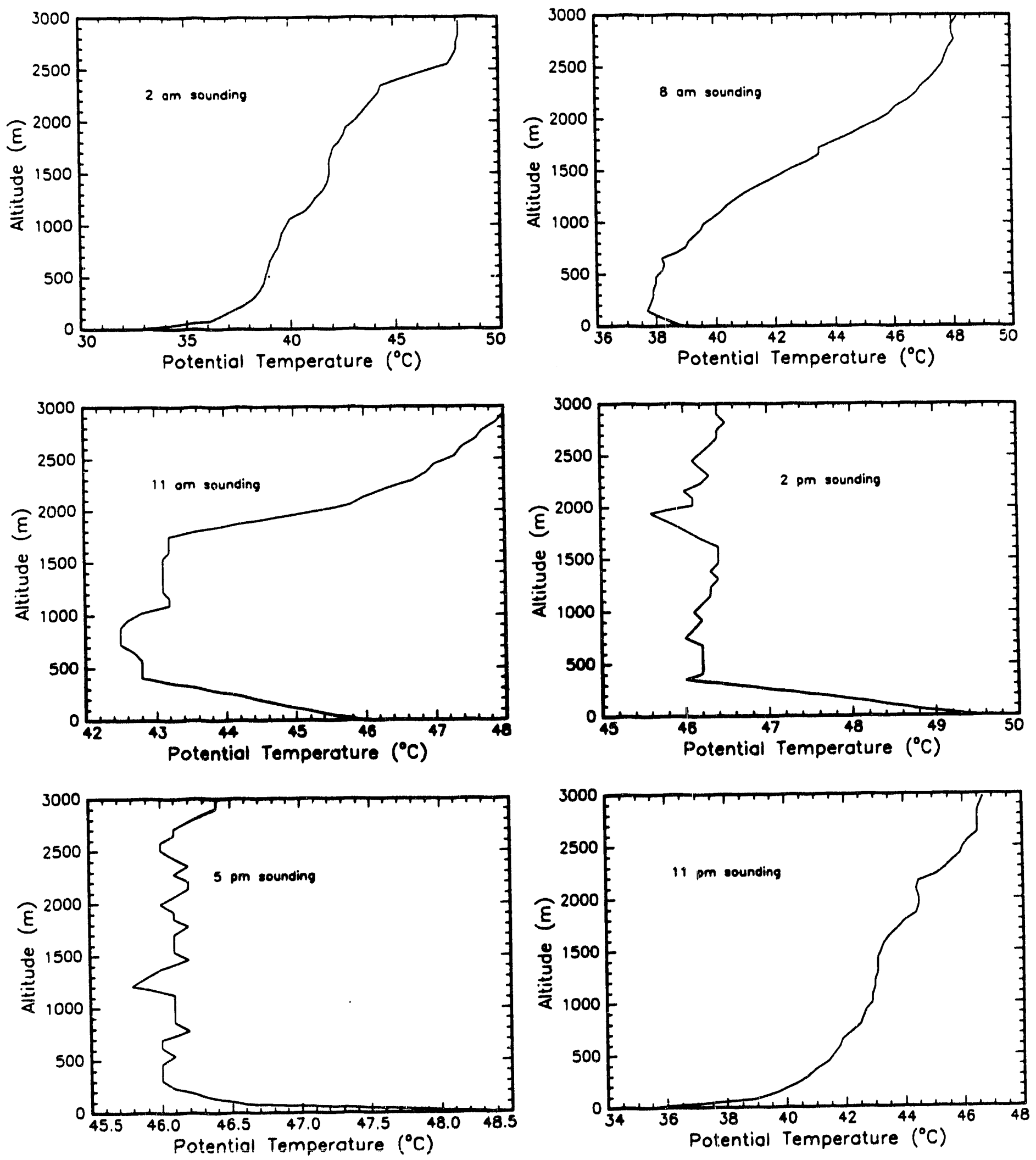


\section{Airport Rawinsonde Sounding February 28, 1991}

$11 \mathrm{am}$
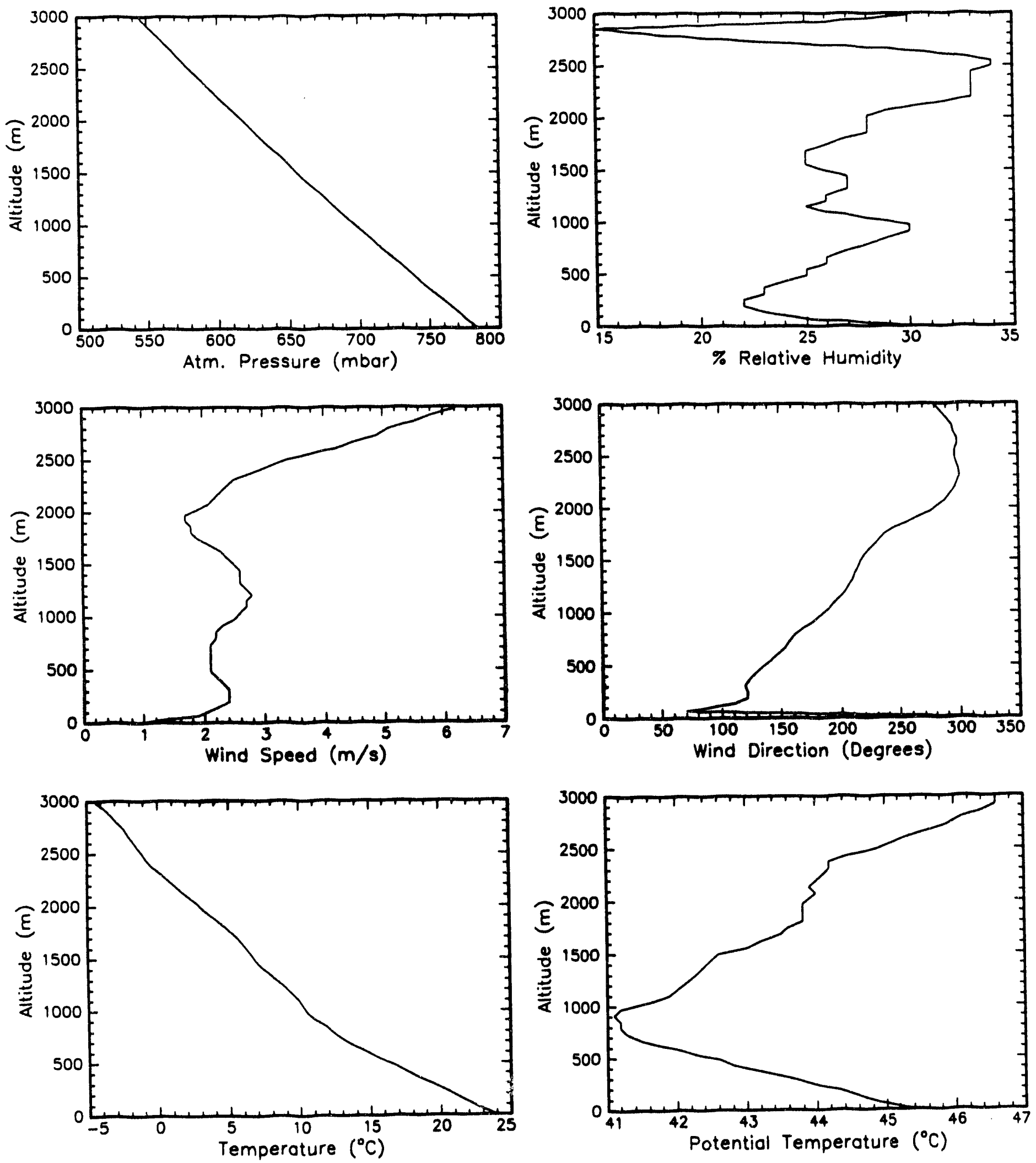
Airport Rawinsonde of February 28, 1991
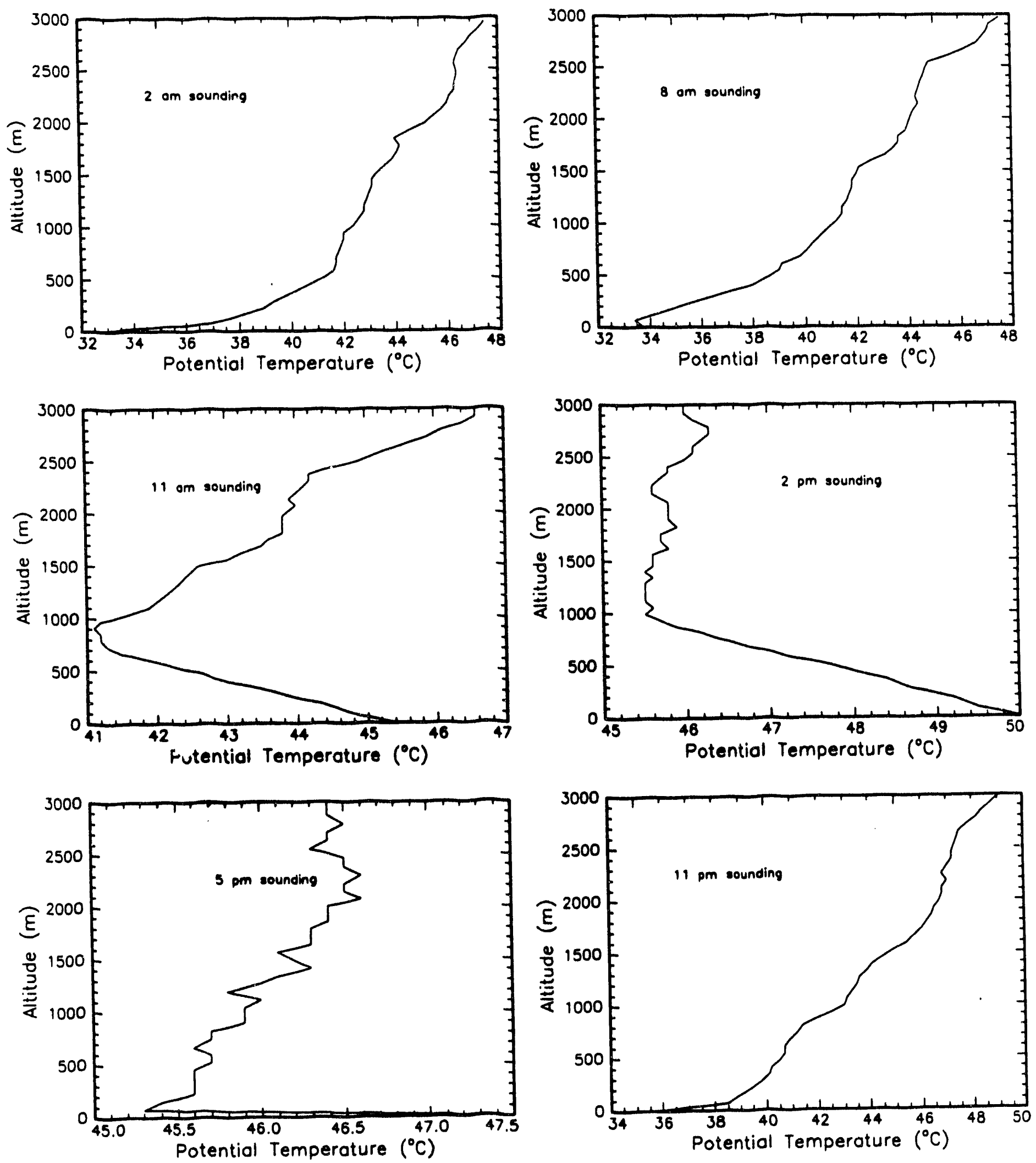

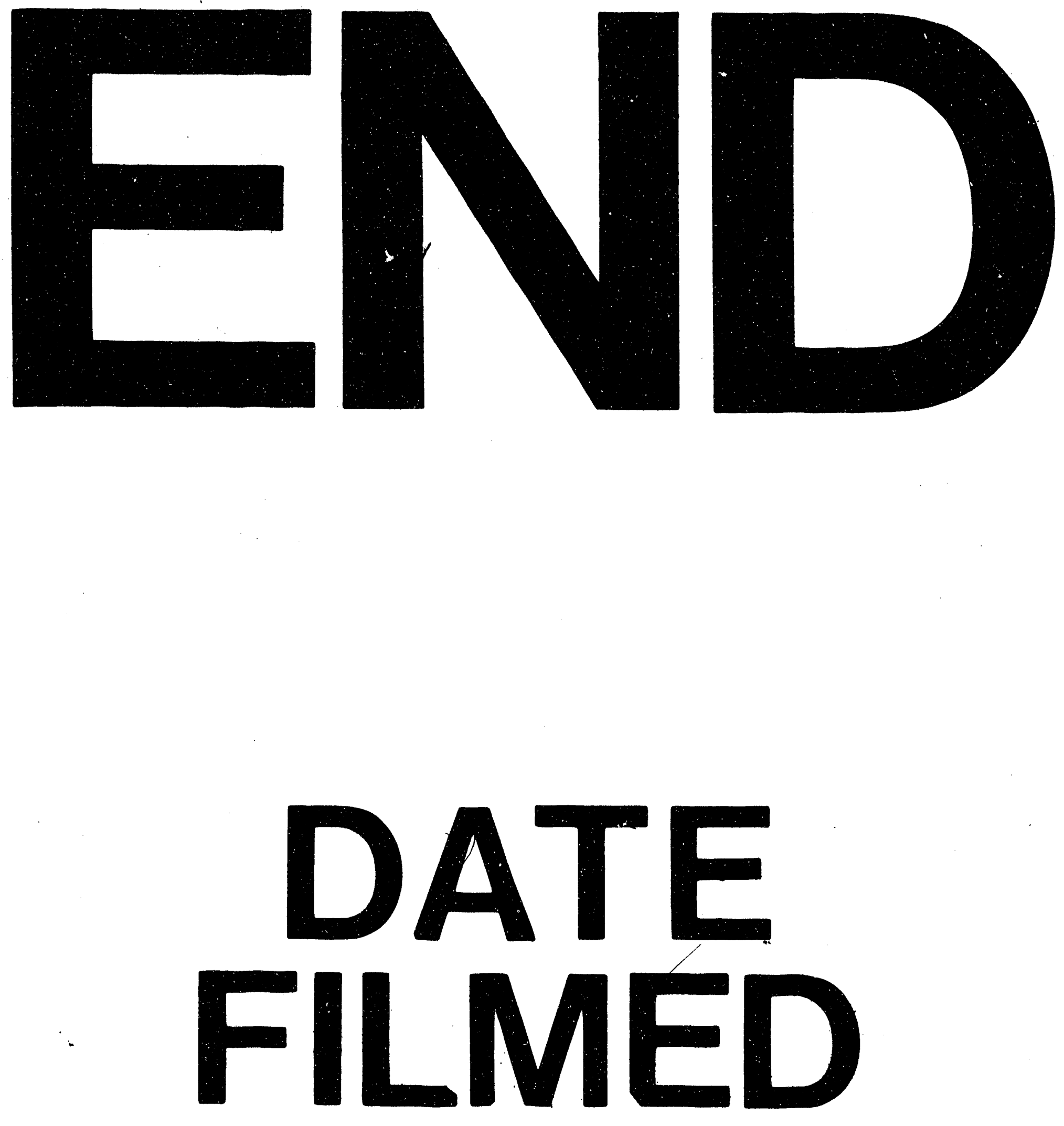

1

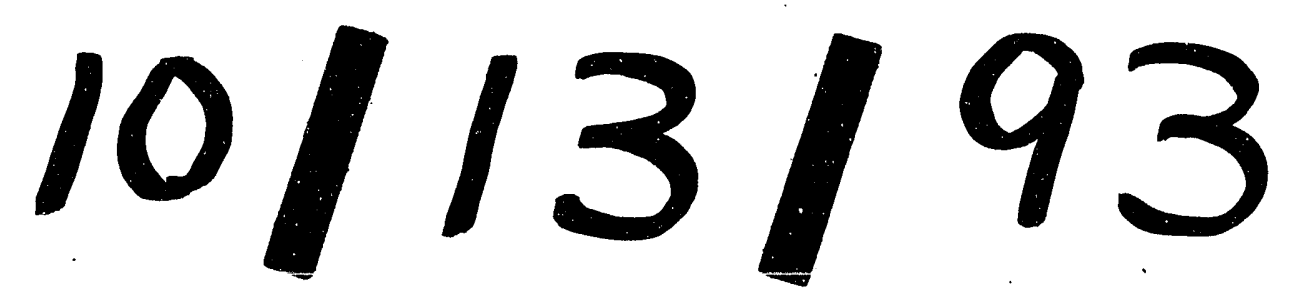


